\title{
Transcending the ethically silent space of New Zealand's social studies curriculum
}

A thesis submitted to Victoria University of Wellington, New Zealand, in fulfilment of the requirements for the degree of Doctor of Philosophy.

\section{Andrea Milligan}

November 2014

Supervisors: Associate Professor Sue Cornforth and Professor Rob Strathdee. 
This is a largely theoretical thesis about social studies education in New Zealand. Its aim is to consider how learners' 'ethical decision-making and action' (to paraphrase the curriculum) could be better supported by proposing a broad theoretical orientation to this curriculum requirement. It argues that although ethics is central to learners' lives and to the purposes of social studies education, this has hitherto been minimally communicated and elucidated through New Zealand curriculum documentation. It takes the view that while providing pedagogical guidance to teachers is urgent and vital, theoretical considerations should be a first priority. The thesis begins by offering a partly stipulative definition for ethics and foregrounds the complexities of ethical decisionmaking and action in our everyday lives and in academic ethics. It then considers the relationship between ethics and the purposes of social studies education, and uses a form of content analysis to describe the curricular meanings that have been implicitly ascribed to ethics over time. It explores how the present New Zealand social studies curriculum is framed theoretically and what could be possible within this framing to better support learners to navigate in their ethical worlds. Three adjustments to the curriculum's framing are proposed: social studies as issues-based education, as counter-socialisation, and as engagement with the philosophy of ethics. These are defended as a matter of social justice, and on the basis of their contribution to a range of social studies outcomes. The thesis then considers the theoretical underpinnings of these proposed adjustments in greater depth. It explores whether an ethically reflexive orientation would better support social studies learners' ethical decision-making and action, through three analytic moves: charting reflexivity's tropes in the social sciences and social theory literature, developing an understanding of ethical reflexivity, and questioning the work this concept could do in social studies education. The thesis argues that an ethically reflexive orientation is a theoretical space in the literature worthy of attention, not least because it maps onto the contemporary ethical space in which learners find themselves. The considerable challenges ahead for such an orientation are readily acknowledged, but the thesis finds within the literature, and from the perspectives of a small group of social studies teachers and learners, some optimism that a reflexive orientation could transcend the ethically silent space of New Zealand social studies education. 
I am indebted to the expert supervision of Dr Jim Neyland (1953 - 2010), Associate Professor Sue Cornforth and Professor Rob Strathdee, whose considerable intellect and insight have sustained me through this project.

With love and gratitude, I acknowledge the steadfast support of my fiancé, Tim, who has not known me without this 'small essay' on my plate. To Jessie, Hana, and Josh, I thank you for welcoming me so warmly into the Rochford Barber whānau, and contributing to this thesis' fruition.

I have a fourth supervisor to thank, my father, and environmental ethicist, John. Thank you for engaging so keenly with this thesis - it's your turn next! To my mother Bev, my brother, Peter, sister-in-law, Julia, and nephew, László, I thank you for your love and continued interest in this project. I am greatly looking forward to being more fully present in your lives.

I am fortunate to have a wonderfully supportive network of colleagues who have accompanied me on this journey. In particular, I'd like recognise Associate Professor Catherine Manathunga, Dr Mark Sheehan, Mike Taylor, Dr Rowena Taylor, and Dr Bronwyn Wood. Thank you, also, to Susan Kaiser for your astute proof-reading. To the Te Papa and the Poststructural and ethical perspectives reading groups, thank you for creating such superbly generative spaces for thinking about education, for your emotional support, and for the fun.

Last, but not least, I wish to thank my friends, especially Jane, who have ever so patiently and un-demandingly waited for this time to come. 


\section{CONTENTS}

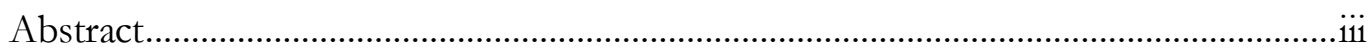

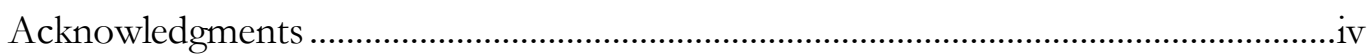

Tables and figures......................................................................................................... vii

Chapter One: Placing the ethical stakes ...............................................................................

Thesis structure and central argument ……………........................................................1

Social studies and citizenship within the New Zealand curriculum.................................7

Exploring assumptions about social studies and ethics education.................................11

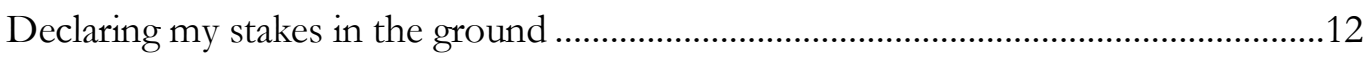

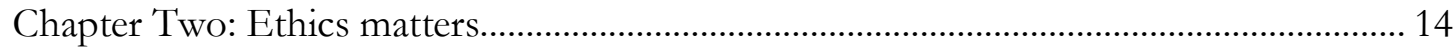

Everyday ethics: the ethicist in all of us ..........................................................................14

Distinguishing 'ethics' from other proximal concepts....................................................20

Ethical perspectives: complex, changeable and contested ..............................................25

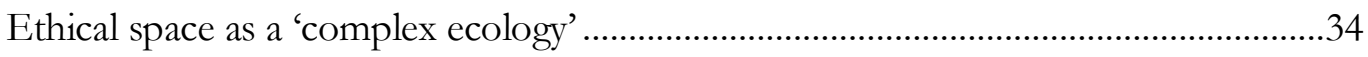

Democracy, education, and the ethical life …………....................................................40

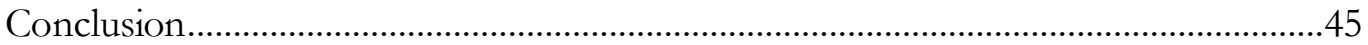

Chapter Three: How central is ethics to social studies? ............................................................ 46

Is social studies a natural home for ethics education? .......................................................46

Locating ethics in New Zealand social studies ...............................................................51

Mapping the conceptual field: ethics in past New Zealand social studies curricula.....51

Summary: the conceptual field of ethics - where are we now? .......................................77

Conclusion: The ethically silent space of social studies...............................................85

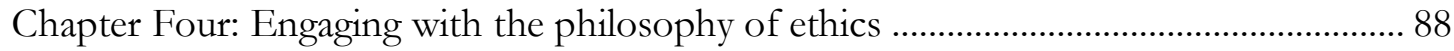

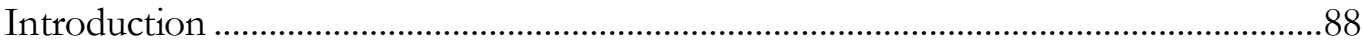

The New Zealand curriculum's theoretical 'foundations' as ways to proceed?............90

Social studies’ framing philosophies ............................................................................93 
Social issues as the focus of ethics education: troubling a public/private divide .99

Social studies as counter-socialisation: the need for ethical pluralism and agonism. 105

Engaging with the philosophy of ethics: the role of perspectives in social studies... 111

Conclusion.

Chapter Five: Social studies learners' reflexive engagement in their ethical worlds.

Introduction 128

Social studies and the philosophy of ethics: the risks of abstraction 130

Critical reflection. 133

Reflexivity's tropes. 135

Ethical reflexivity 144

Conclusion: Ethical reflexivity, counter-socialisation and remaking ethical worlds.. 154

Chapter Six: Prospects and challenges 161

Introduction: doing the 'hard bits' of social studies 161

Signalling the shifts in meaning. 163

Ethics in an era of scientifically managing education ................................................... 169

Knowing what works in evidence-based education.................................................... 172

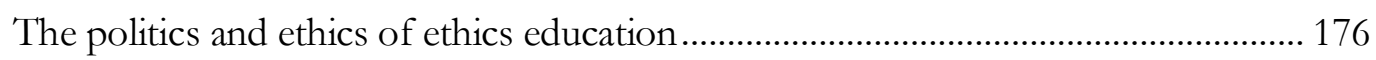

Taking it too far? Social studies teachers' and learners' perceptions of ethics........... 178

Conclusion: what wiggle room for an ethically reflexive orientation? 192

Chapter 7: Transcending the ethically silent space of New Zealand social studies education 195

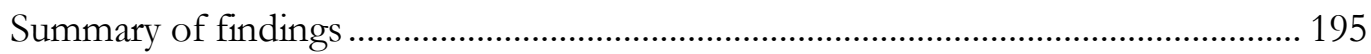

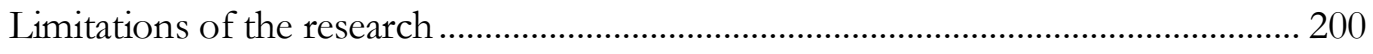

Policy recommendations: a need for agonistic spaces................................................. 201

Implementation recommendations: Pedagogical models as reflexive surfaces ......... 204

Placing stakes in the ground ............................................................................... 210

References. 
Appendix 1: Values in The New Zealand Curriculum .................................................. 240

Appendix 2: Concept frequencies................................................................................. 241

Appendix 3: Ethics in NCEA achievement standards ................................................ 249

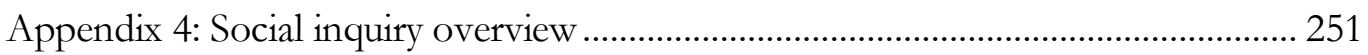

Appendix 5: Student focus group discussion task .................................................... 252

\section{TABLES AND FIGURES}

Table 1: The relationship between student ages and year, curriculum and assessment

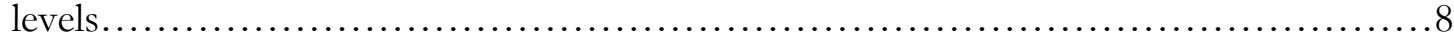

Table 2: Teachers' perceptions of level of students' values skills.....................167

Figure 1: Some Working Definitions.......................................... 8 


\section{CHAPTER ONE: PLACING THE ETHICAL STAKES}

\section{THESIS STRUCTURE AND CENTRAL ARGUMENT}

I begin with a wero - in Māori, a challenge accompanied by a symbolic peace offering of the rautapu, or leaves laid at one's feet. It concerns the story of an 11-year old boy who, unbeknownst to his teacher, orchestrates a campaign amongst his friends to boycott Cadbury in protest at the company's use of palm oil in their chocolate (Television New Zealand, 2009). I am impressed, yet saddened, that his teacher knows nothing of this another social studies conversation lost. At the family dining table I turn to a perennial hobby-horse and decry the lack of critical thinking in social studies classrooms. Very gently his brother challenges me: "yes, but what matters most is where you place your stake in the ground."

I admit with bemused self-reproach that much of my life has been preoccupied with 'examining the stakes'. In relation to social issues and social studies education, I've largely been concerned with matters such as conceptual understanding, critical thinking, and understanding diverse perspectives. The emphasis has been on debate rather than action - considering the stakes, rather than putting them in the ground. In light of this, the thesis is an imaginative act and an attempt to trouble the familiar ground on which I have stood. In a nutshell, it considers the relationship between ethics education and the New Zealand social sciences learning area, in particular social studies as the foundational subject. At heart, it worries about how ethics is to move beyond a curriculum page and gain meaning in learners' real-world concerns, desires, and social participation.

I came to this topic as a result of the revised New Zealand curriculum (Ministry of Education, 2007) ${ }^{1}$, in which the over-arching Values section (see Appendix 1) states that students will "be encouraged to value... acting ethically" and "develop their ability to...make ethical decisions and act on them" (p. 10). As a social studies educator of over 20 years, two things attracted my attention: (a) that this appeared to mark the first occasion where the national curriculum has explicitly linked ethics to social studies

${ }^{1}$ See also: http://nzcurriculum.tki.org.nz/The-New-Zealand-Curriculum 
teaching and learning and, (b) that ethical decision-making and action seemed to lack curricular explication. I wondered about the life that ethical decision-making and action might have in social studies teaching and learning, given that seemingly related features of New Zealand's social studies curriculum have long been considered the 'hard bits' (Keown, 1998; Wood, Taylor, \& Atkins, 2013): values exploration, social decisionmaking, and social action. This is, of course, not a particularly strong research reason, and the next chapters move the justification for this thesis' research focus considerably forward. But my initial observations, it has turned out, picked up on something of a lacuna in social studies education - as in a piece of music, an extended silence.

How should we support learners to consider what is at stake ethically speaking in their own and others' lives, to navigate the complexities of ethical life with a sense of agency, and to place stakes in ever-shifting societal ground? Of course, social studies learners already do so, whether or not they are conscious of curricular expectation. This thesis is therefore guided by the following research question: how could New Zealand social studies education better support learners' ethical decision-making and action? Three subquestions are related to this:

1. What opportunities for ethical decision-making and action are offered through New Zealand social studies curriculum documentation?

2. What theoretical spaces exist for better supporting social studies learners' ethical decision-making and action?

3. What could be possibilities and challenges within these spaces?

I seek here to make two central contributions. The first is to establish what 'is', that is, how ethics gains expression in the New Zealand social studies curriculum. The second and primary aim is to consider the 'ought', that is, to propose a broad theoretical orientation to better supporting social studies learners' ethical decision-making and action. This is, therefore, a largely conceptual piece but also draws on findings from summative content analysis and focus group interviews with social studies teachers and students, and reviews literature throughout.

The argument is built as follows. Chapter Two introduces ethics and addresses a question about its relationship to education. I point out that ethical decision-making is a very ordinary activity and central to the human condition; most of us succeed adequately in daily life without elevating ethics to an academic exercise. Nevertheless, the philosophy of ethics may support us to navigate personal and societal uncertainty. The 
chapter then clarifies a number of key terms used throughout this thesis. First, the sense in which I use ethics is established as an activity - that of coming to an understanding of, and reflecting upon, a range of perspectives about social action. To elucidate the theoretical complexity involved in this activity, I secondly describe a range of ethical theories, terms that are also employed in subsequent chapters. By way of illustration, I draw on discussions with six Year 9 social studies students who considered two ethical issues: whether or not to accept a Facebook friend, and the kinds of images the media should be allowed to use.

Chapter Two then moves to considering the societal backdrop to the proposal advanced in this thesis, a matter that is important because all visions for ethics education are intended to support learners to respond to the societies in which they find themselves. In some respects, this is an elaboration of my Masters' thesis (Milligan, 2006), in which I argued that the social studies curriculum had previously (mis)represented society as predominantly static, ordered and predictable, and called for greater curricular engagement with societal fluidity, uncertainty, and ambiguity. In this thesis, I describe the complex ecology of contemporary ethical space (Poole, 1972; A. Rorty, 2005) and argue that the complexity, plurality and moral ambivalence of contemporary social life necessitates a greater societal focus on matters ethical, and not just in educational settings. Globalisation, technological advances, and environmental degradation, for example, present societies with pressing ethical and political questions as to how we shall live together on this planet, issues we cannot resile from, no matter how intractable they appear. The last part of the chapter considers how ethics is important to education, particularly in democratic settings, and I explore how education could be thought of as a crucible for moral uncertainty and conflict. Not only does democracy accommodate a diversity of visions for the good life, moral education is expected in some way to invite learners to consciously consider the disagreements that stem from such multiplicity. Unsurprisingly, the crucible contains multiple views as to how this ought to be achieved.

Having considered the relevance of ethics to education in general, Chapter Three moves to a focus on social studies education. I ask (a) how central ethics is to New Zealand social studies education, (b) whether social studies might be justifiably considered a 'natural home' for ethics education, and (c) what the subject would amount to if stripped of its ethical content. The relationship between ethics and four traditions of social studies education (H. Barr, Graham, Hunter, Keown, \& McGee, 1997) is considered. As a heuristic, these traditions are referred back to as the thesis progresses - 
although it is important to note that this is not the only way that the theoretical traditions of social studies have been categorised. Chapter Three then addresses the first of my research sub-questions, that is, the opportunities for ethics education afforded through New Zealand's social studies curriculum. I locate ethics in the subject's curricular history, and consider the extent to which teachers and learners are already supported to make sense of the ethical dimensions of the Values statement in The New Zealand curriculum (Ministry of Education, 2007). To do this, I undertake a summative content analysis (Hsieh \& Shannon, 2005) of historical curriculum statements and support documents. By mapping what I have termed ethics' 'conceptual field', that is, the uses of ethics and associated terms over time, one can infer meaning for ethical decision-making and action in the present social studies curriculum. The analysis builds on the contributions of New Zealand academics who have charted the evolution of moral and values education in social studies by focussing specifically on the meanings that might be attached to ethics. This reveals social studies as being, what I have termed, 'an ethically silent space' in that the importance and content of ethics have been minimally communicated through successive curricula.

In the absence of curricular guidance, the work of Chapters Four and Five is to propose a broad theoretical orientation to better supporting learners' ethical decision-making and action through social studies education. These chapters address the second of my research sub-questions about theoretical spaces that are available. They begin from the contention that the curriculum's theoretical framing shapes how the ethical dimensions of the Values statement (Ministry of Education, 2007) might be given expression. This immediately raises a question as to the ends of social studies, and the ethical basis upon which my proposal for a broad theoretical orientation to ethics education in social studies might be defended. Both are addressed recursively over the course of the next two chapters.

Chapter Four opens by highlighting the rather theoretically permissive nature of The New Zealand curriculum (Ministry of Education, 2007) and then moves to considering social studies' implicit educational theory. Two predominant theoretical orientations are identified - social studies taught as social science, and reflective inquiry - and I explore how these frame ethical decision-making and action. I consider how re-focussing social studies in three inter-related ways could open out more opportunities for social studies

2 A term also used in Milligan \& Wood (2010) but, in that context, to mean concepts associated with social studies curriculum achievement objectives. 
learners to explore ethical decision-making and action. In the tradition of social studies taught as reflective inquiry, the first of these proposed adjustments involves a stronger focus on issues-based education and a more flexible conception of issues that collapse a public/private divide. A second draws from the work of Shirley Engle and Anna Ochoa (Engle \& Ochoa, 1988; Ochoa-Becker, 2007) and suggests primarily focussing social studies education on counter-socialisation. I consider how these authors' model of decision-making could be expanded, in particular to (a) include a wide range of ethical perspectives, (b) draw force from theories of robust ethical pluralism (Hinman, 2013) and (c) take an agonistic approach (Mouffe, 2000, 2013). The third proposed adjustment suggests a strengthening of social studies taught as social science. I ask how social studies education might productively engage with the insights of the philosophy of ethics, without collapsing social studies into that discipline. I consider how the philosophy of ethics might be considered an extension of M. Young's (2013) conception of 'powerful knowledge' and how the more explicit inclusion of the discipline in social studies teaching and learning could also be justified in relation to a range of outcomes.

Chapter Five develops this argument into a broad theoretical orientation to better supporting social studies learners' ethical decision-making and action. In doing so, it holds up the seemingly privileged position of academic ethics in the previous chapter to scrutiny, ironically and inescapably using the language of that which I seek to interrupt. I firstly consider the risks of abstraction in employing the philosophy of ethics in social studies education. One cannot, of course, hold the field of philosophy to account for this; the point is how disciplinary insights are used. The chapter explores whether an ethically reflexive orientation could mitigate the risks of abstraction and better support social studies learners' ethical decision-making and action. Having initially been attracted to a concept of reflexivity rather like a magpie attracted to a shiny object, a considerable portion of the chapter is devoted to exploring how reflexivity is (a) to be distinguished from reflective approaches to social studies education, and (b) employed in the social sciences and social theory.

From this literature, I build a definition for ethical reflexivity and consider the work it could do in social studies education. The chapter arrives at a conception of ethical reflexivity that enfolds critical reflection, learners' lived experience and their imaginations. I argue that such an orientation is a vital educational adaptation to the complexity, pluralism and ambivalence of contemporary ethical space. That is, social studies education requires pedagogical approaches that foster learners' reflexivity; their ability to 
assemble possibilities for social action from the resources of critical thought, lived experience and imagination. The last portion of Chapter Five considers how my argument intersects with a tradition of social studies education that currently exists at the curriculum's margins: social studies 'taught as personal, social and ethical development' (H. Barr et al., 1997). My argument for an ethically reflexive orientation moves beyond this tradition in one important respect: it resists a sense of co-ordinated selfhood and certain ground beneath its feet.

Chapter Six begins a consideration of the last of my research sub-questions: what could be possibilities and challenges within the theoretical spaces I have identified? It begins by asking whether teachers could already be taking an ethically reflexive orientation independently of the curriculum. It draws from a range of research evidence about the current curriculum's implementation (for example: Education Review Office, 2010; Notman, 2012; Sinnema, 2011). The findings lend weight to my contention that New Zealand social studies education is an ethically silent space. Having argued that an ethically reflexive orientation warrants consideration as a possibility for better supporting social studies learners' ethical decision-making and action, the prospects and challenges ahead are considered. Given that there is no research literature on this, the chapter represents a somewhat limited test of possibilities and difficulties.

To structure Chapter Six’s discussion, Paul Keown's (1998) insights into why values and social action have traditionally been perceived as the 'hard bits' of New Zealand social studies are synthesised with more recent empirical and theoretical research evidence that is suggestive of an ethically reflexive orientation's prospects. Four themes are considered: signalling the shifts in meaning (Aitken, 2006), ethics in an era of the scientific management of education (Neyland, 2004, 2005, 2010), knowing what works in evidence based education, and the ethics of ethics education. While these themes are only illustrative of what could lie ahead, the prospects appear bleak; an ethically reflexive orientation could be rendered mute under the weight of current educational forces. The chapter's discussion is then supported by a small-scale study of New Zealand social studies teachers' and students' perceptions of issues and needs in relation to developing the abilities of ethical decisionmaking and action. The methodology is outlined: semi-structured focus group interviews with teachers and students in one New Zealand secondary school. These data are analysed in light of my conception of ethical reflexivity. While the findings from this study are clearly limited in their generalisability, it appears that, despite the challenges outlined, a reflexive orientation could transcend the ethically silent space of social studies. 
The concluding chapter summarises the main arguments and findings of this thesis, and explores the limitation to the evidence that is presented. Two sets of recommendations are made: policy and implementation. The latter, in particular, completes the consideration of my third research sub-question in that it considers pedagogical insights from the existing literature that could be assembled, amplified, and applied to an ethically reflexive orientation to social studies education.

\section{SOCIAL STUDIES AND CITIZENSHIP WITHIN THE NEW ZEALAND CURRICULUM}

For the reader unfamiliar with the New Zealand context, this section delimits the scope of the thesis and locates social studies in The New Zealand curriculum (Ministry of Education, 2007) within international approaches to social education, particularly citizenship education. Social studies is the foundational subject of the social sciences learning area in Years 1-10. It is also an optional social sciences specialism in Years 1113, which first became an examinable subject in 2002 with the implementation of the National certificate of educational assessment (NCEA), New Zealand's national secondary school qualification ${ }^{3}$. The social sciences learning area is one of eight learning areas specified in New Zealand's curriculum. Teaching and learning in each learning area is underpinned by the Vision, Principles, V alues, Key competencies and brief learning area statements, in what is colloquially termed the 'front end' of the curriculum. At the back of the document achievement objectives are provided for each learning area in fold-out charts. At Years 11-13, achievement objectives are specified across eight curriculum levels for economics, geography, history and senior social studies. These subjects are supported by teaching and learning guidelines for the senior social sciences (Ministry of Education, 2014c). Schools are also able to provide a much broader range of social sciences options; there are guidelines for accounting, business studies, classical studies, education for sustainability, legal studies, media studies, sociology, philosophy, psychology and religious studies. The relationship between student ages, year levels, curriculum levels, and NCEA assessment levels is mapped out in Table 1 below.

\footnotetext{
${ }^{3}$ See: http://www.nzqa.govt.nz/qualifications-standards/qualifications/ncea/understanding-ncea/how-ncea-works/
} 


\begin{tabular}{|c|c|c|c|}
\hline $\begin{array}{l}\text { Social studies with the } \\
\text { social sciences learning area }\end{array}$ & $\begin{array}{c}\text { Curriculum } \\
\text { level }\end{array}$ & $\begin{array}{l}\text { Year level and } \\
\text { approximate age }\end{array}$ & $\begin{array}{c}\text { National Certificate of } \\
\text { Educational } \\
\text { Achievement }\end{array}$ \\
\hline \multirow{5}{*}{$\begin{array}{l}\text { As a foundational and } \\
\text { integrated subject }\end{array}$} & 1 & Year 1-2; ages 5-6 & \\
\hline & 2 & Year 3-4; ages 7-8 & \\
\hline & 3 & Year 5-6; ages 9-10 & \\
\hline & 4 & Year 7-8; ages 11-12 & \\
\hline & 5 & Year 9-10; ages 13-14 & \\
\hline \multirow[t]{3}{*}{ As an optional specialism } & 6 & Year 11; age 15+ & NCEA level 1 \\
\hline & 7 & Year 12; age $16+$ & NCEA level 2 \\
\hline & 8 & Year 13; age $17+$ & NCEA level 3 \\
\hline
\end{tabular}

Table 1: The relationship between student ages and year, curriculum and assessment levels

New Zealand social studies is a local expression of varying approaches to social education in democratic nations. Because a variety of titles for such approaches exists internationally, Figure 1 below uses Brian Hill's (1994) model to place New Zealand's variant. The social sciences learning area is akin to the social studies, whereas social studies is strongly analogous to the central sphere of this figure. This is because there has been a longstanding commitment to social studies as an integrated field of study, dating back to the Thomas report (Department of Education, 1944) which first recommended social studies as a 'new' subject within the New Zealand post-primary school core curriculum. Today, the continued commitment to integrated study is to be seen in the four interconnected and overarching conceptual strands of social studies: Identity, culture and organisation; Place and environment; Continuity and change; and The economic world (Ministry of Education, 2007). These strands draw on a wide range of social sciences and humanities disciplines and infuse the social studies achievement objectives.

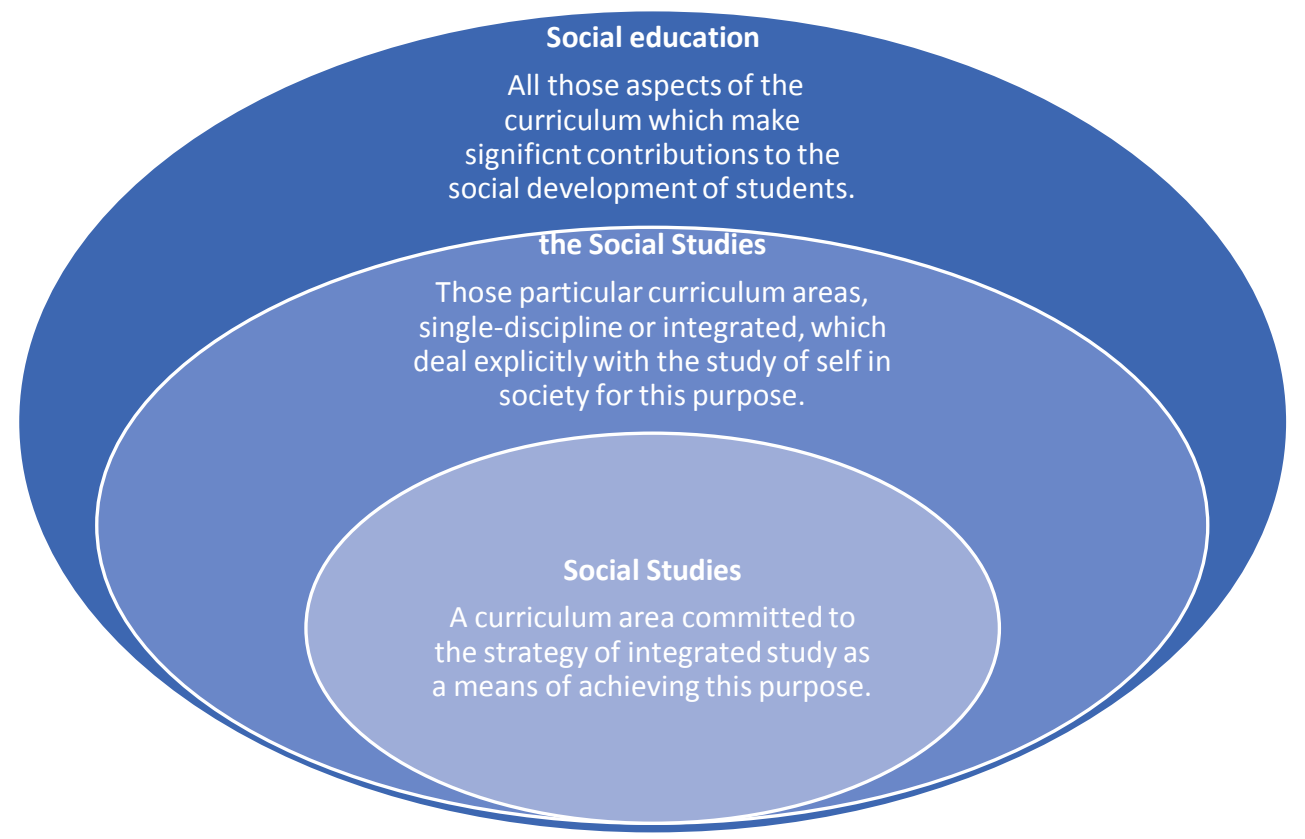

Figure 1: Some Working Definitions (Hill, 1994, p. 3) 
A distinctive, integrating feature of the New Zealand social studies curriculum is its strongly advocated social inquiry methodology. This builds on a lineage of curriculum documents (for example: Department of Education, 1977a; Ministry of Education, $1991,1997,2004)$ that have emphasised the complementary and inseparable nature of ideas/conceptual understandings, inquiry, values exploration, social decision-making and social participation. As currently expressed, the social inquiry methodology enables students to:

- ask questions, gather information and background ideas, and examine relevant current issues

- explore and analyse people's values and perspectives

- consider the ways in which people make decisions and participate in social action

- reflect on and evaluate the understandings they have developed and the responses that may be required. (Ministry of Education, 2007, p. 30)

A series of booklets called Building conceptual understandings in social sciences (see especially: Ministry of Education, 2008a) fleshes out this methodology. These books exemplify how the achievement objectives integrate the conceptual strands and assist in the identification of important social issues, ideas and themes that may be explored through social inquiry. In turn, the social inquiry model generates conceptual understandings (as opposed to the acquisition of facts), including understandings about the significance of these ideas (so what?) and links to social action (now what?).

A strong connection between social studies and citizenship education ${ }^{4}$ in New Zealand is somewhat difficult to communicate diagrammatically. The reader might imagine citizenship education as an ellipse that cuts across each of the aspects of Figure 1. The curriculum indicates that citizenship education is an important cross-curricular expectation; for instance, students are encouraged to explore "what it means to be a citizen and to contribute to the development and well-being of society" (Ministry of Education, 2007, p. 39). Additionally, a wide range of co-curricular learning experiences offer New Zealand students opportunities to participate in, and contribute to, their communities (Schulz, Ainley, Fraillon, Kerr, \& Losito, 2010). The social sciences learning area supports this broader citizenship vision of The New Zealand curriculum (Ministry of Education, 2007), an aim immediately established in the opening whakatauki/proverb and first sentence of the learning area statement:

\footnotetext{
4 Numerous characterisations of citizenship education's landscape exist. See, for example: Arthur and Cremin (2012), Arthur and Davies (2008), Arthur, Davies, and Hahn (2008), Scott and Lawson (2002).
} 
Unuhia te rito o te harakeke kei whea te kōmako e kō? Whakatairangitia - rere ki uta, rere ki tai; Ui mai koe ki ahau he aha te mea nui o te ao, Māku e kī atu he tangata, he tangata, he tangata! ${ }^{5}$... The social sciences learning area is about how societies work and how people can participate as critical, active, informed, and responsible citizens. Contexts are drawn from the past, present, and future and from places within and beyond New Zealand. (p. 30)

Within this learning area, social studies has historically been identified as the principal curricular vehicle for citizenship education. Citizenship has been a longstanding organisational concept for social studies, beginning with the Thomas reports recommendation that social studies have a dual purpose: "(a) to assist in the development of individuals who are able to take their parts as effective citizens in a democracy, and (b) to deepen pupils' understanding of human affairs and to open up wide fields of personal exploration" (Department of Education, 1944, p. 27).

Three points should be made in relation to the citizenship thrust of social studies. First, as in other countries, New Zealand social studies curriculum developers have been "the inheritors of a plurality of competing and contradictory philosophical ideals and political models of citizenship" (Frazer, 2008, p. 282). These have worked their way into a somewhat uneasy amalgamation of differing conceptions of citizenship in successive New Zealand social studies curricula $a^{6}$. Second, it is important to note that New Zealand social studies has tended to accommodate citizenship education rather than being driven by its direction and scope (Aitken, 2005b); it is not possible therefore to wholly equate social studies in this country, or social sciences for that matter, with citizenship education. Third, citizenship education has a low policy priority in New Zealand (Schulz et al., 2010) and social studies has a marginalised status in schools. Few students take social studies as a subject in the senior secondary school, and social studies receives little explicit attention in primary teaching programmes (Education Review Office, 2006). The latter has been, very recently, exacerbated by the narrowing of the primary curriculum through the implementation of national standards in literacy and numeracy (Thrupp \& White, 2013).

\footnotetext{
5 Remove the heart of the flax bush and where will the bellbird sing? Proclaim it to the land, proclaim it to the sea; Ask me, 'What is the greatest thing in the world?' I will reply, 'It is people, people, people!'

${ }^{6}$ For discussion see: (Aitken, 2005a; E. Archer \& Openshaw, 1992; Beals, 2001; J. McGee, 1998; Mutch, 2005a, 2005b, 2011; Openshaw, 2004).
} 


\section{EXPLORING ASSUMPTIONS ABOUT SOCIAL STUDIES AND ETHICS EDUCATION}

This thesis takes as founding propositions many of the 'basic beliefs' about social studies identified in what is known as the Waikato position paper (H. Barr et al., 1997). This was written prior to the publication of Social studies in the New Zealand curriculum (Ministry of Education, 1997) in order to provide the Ministry of Education with contestable advice on the nature and purpose of social studies:

1. The content of social studies is drawn primarily from the social sciences and the humanities subjects and disciplines.

2. Social studies content reflects the changing nature of knowledge in these disciplines and the changing nature of society itself. Therefore, content needs continual review.

3. Social studies is concerned with the study of human beings in the past, present and future.

4. Social studies deals with significant social issues and problems.

5. Social studies is an integrated subject which draws upon a range of disciplinary and philosophical traditions in a systematic manner.

6. Social studies involves social inquiry and the examination and appraisal of values for responsible decision making.

7. Social studies is concerned with empowerment of the social and ethical self which means gaining the knowledge, skills and attitudes necessary for social literacy and making reasoned judgements considering others' views and acting for the benefit of society.

8. Social studies is principally concerned with enabling young people to take their place in today's complex world as informed competent and responsible citizens. $(\mathrm{H}$. Barr et al., 1997, p. 2)

While not the central work of this thesis, it is interesting to note how these assumptions hold up in light of the curricular expectation that social studies education support learners' ethical decision making and action. Some of the basic beliefs are therefore held up to considerable scrutiny in the course of my thesis. For example, at various points I suggest that the anthropocentric view of (3) could be occluding a consideration of environmental concerns. In another example, when read in light of at least the two most recent social studies curricula (Ministry of Education, 1997, 2007) these basic beliefs 
appear to somewhat disembody learners' ethical decision-making and action. Further, Chapter Six presents substantive challenges to basic beliefs (7) and (8) in relation to the conception of the learner at the centre of such beliefs.

Of course, the reason that I question these kinds of assumptions rests on my view of what ethics education in social studies should entail. As a backdrop to the work of this thesis, I have considered Sanger and Osguthorpe's (2005) framework for understanding approaches to moral education:

A. Psychological assumptions regarding what the salient features of our moral psychology are; regarding the nature of those features; and regarding how those features develop and/or how they are likely to respond to various environmental variables

B. Moral assumptions regarding the nature and scope of morality (metaethical assumptions); and regarding what is good/right/virtuous/caring (normative assumptions)

C. Educational assumptions regarding the nature and scope of teaching and education in society; and regarding the aims of education

D. Contingent factors: personal, historical, social, political and institutional. (p. 63)

In building an argument for a particular theoretical approach to better supporting social studies learners' ethical decision-making and action, the chapters in this thesis address each of the categories of the assumptions above (although not in this order). The reader will note that the argument made in Chapter Four for robust ethical pluralism in relation to learners' consideration of ethical perspectives is both a meta-ethical position and contains assumptions about the purposes of social studies education.

\section{DECLARING MY STAKES IN THE GROUND}

Before continuing, I wish to acknowledge that my perceptions of what social studies education could achieve in relation to better supporting learners' ethical decisionmaking and action have been shaped through professional immersion - first as a teacher of social studies, geography, English and health, and then as a social sciences pre-service teacher educator and advisor. More latterly, my academic role has expanded to include lecturing in undergraduate and postgraduate education papers, and research interests in 
curriculum theory, the relationships between philosophy and education, and discourses of diversity, and social and environmental justice. It important to note that I have been involved in the development of a number of Ministry of Education publications referred to in this thesis. I hold these contributions lightly, and it is to my very great delight when students and others engage in critiquing them. It is also notable that the New Zealand social studies education community is small, and many of the authors I refer to in this thesis I count as colleagues, collaborators, and friends. This thesis owes a great debt, in particular, to Dr Paul Keown, not least because he has kept alive the question of values education in this country over many years. My point here is not a roll call but to acknowledge the myriad ways in which the conceptual development of this thesis stands on the shoulders and insights of others. 


\section{CHAPTER TWO: ETHICS MATTERS}

The central work of this chapter is to contextualise the argument built in this thesis. First, it introduces ethics, both an academic and ordinary activity. I argue that while the ethical thinking does not produce certitudes, it is one important means of dealing with the complexity and vicissitudes of life. Second, the chapter clarifies key terms used throughout the thesis, including a range of theoretical perspectives that inflect the ethical challenges and issues that people, communities and society face. To illustrate these perspectives, I draw on a small sample of student data drawn from focus group discussions about ethical dilemmas. This explication is especially important given the variety of senses in which ethics and allied terms are used in academic, educational and everyday settings. Third, the chapter considers the societal context in which ethics (and social studies education) takes place; pluralism, complexity and moral ambivalence are themes that recur throughout this thesis and are central to my proposal for better supporting social studies learners' ethical decision-making and action. The last section of this chapter asks how ethics and education are important to each other. I argue that ethical matters inescapably imbue education, and that the ethical intent of education has been a longstanding matter of debate. Moreover, education has a central, yet contested, role in enlarging learners' ethical thinking in order that they may better navigate in their social worlds.

\section{EVERYDAY ETHICS: THE ETHICIST IN ALL OF US}

What is ethics and how does it matter? In Australia, Ethi-call (St James Ethics Centre, 2014), a counselling phone line, offers members of the public an opportunity to talk through ethical challenges that confront them, especially where there appears to be no easy solution. In Washington DC's interactive museum, Newseum (2014), the Ethics Center invites visitors to explore ethical dilemmas that journalists and editors face in their everyday work. In the United Kingdom, Radio 4 and Radio Ulster produce The moral maze (BBC, 2014a) and Everyday ethics (BBC, 2014b) respectively, dedicated to exploring ethical debates of the day. At New Zealand's Diocesan School for Girls (2014), the Centre for ethics facilitates a series of events focused on ethical issues, delivered by distinguished speakers. Ethical concerns underpin many of the perplexing and keenly felt aspects of our lives, such as our attitudes towards new reproductive technologies, our sense of social and environmental justice, our views about the extent of our right to free speech, or simply deciding whether to lie about being late to work or school. They very often languish as the proverbial elephant in the room, that is, the often unexpressed core of personal, societal and global challenges. Ethical issues are by nature 
complex, very often intractable and persistent, and sometimes baffling. Some of the most heated arguments in public and private arenas, and perhaps social studies classrooms, are fundamentally about ethical issues: for instance, human rights issues to do with the death penalty, torture, or wearing a hijab or burqa. Most heated political debates are inherently ethical disputes. Terry Eagleton (2009), for example, contends that the ethical, "a matter of how we may live with each other most rewardingly", is inseparable from the political: "a question of what institutions will best promote this end" (p. 325). And there are ethical choices in myriad aspects of learners' everyday lives - whether to buy bottled water, give to a gold coin collection, or accept a Facebook friend request, for instance - though they may navigate these subconsciously and without being aware that such decision-making has an ethical content.

Much of this thesis is concerned with the contribution that ethics, as an academic discipline, could make to social studies education by enlarging thinking about social issues and our participation in society. In this sense, I am using ethics to mean an aspect of Western philosophical thought, sometimes termed moral philosophy, which is concerned with the systematic study of what we ought to do (Singer, 1994). The philosophy of ethics is central to the 'examined life', involving the consideration of how we should or could live, what is a worthwhile life, and what we should do in various situations. In essence, the discipline of ethics might be considered philosophies of action. Some may dismiss, or conversely look to, ethics as prescription in life, and ethicists as the 'moral police'. It is true that some branches of ethics are concerned with determining how people should be and what is right and wrong in any given situation (normative ethics). It is also true that many educationalists have particular views about the sort of ethical thinking that ought to be encouraged in learners, Kohlberg (1981) being a notable example. But the field of ethics extends well beyond the prescriptive. Ethics may be concerned, for example, with what people actually do in relation to ethical issues (descriptive ethics) or with what constitutes goodness itself (meta-ethics). Many ethicists will stress that there are no right or wrong answers, merely possibilities for action that depend on the circumstance (situated ethics); in other words, ethical action is always particular, impermanent, and contingent.

Philosophers of ethics advance the field and make a contribution to society through deliberation, judgement, and reasoning (Burgh, Field, \& Freakley, 2006). This requires coming to an understanding of, and reflecting upon, a range of theoretical perspectives - critical thinking that, for example, takes account of counter-arguments. My central 
point here is that ethics may be seen as a verb, more a practice than a set of conclusions. Amélie Rorty (2005) expresses this in these terms: "even when it takes a detour into the terrain of philosophic theories and systems, morality is directed to activity, however internal or spiritual, however self-perfectionist it may be" (p. 8). Furthermore, it is a lively verb. The field of ethics is vast and ever-expanding; responding to the ethical complexities of, for example, scientific and technological breakthroughs and pressing current issues involving issues of justice, power and equity. Many projects involve disciplinary border-crossing or intellectual mobility (Dogan \& Pahre, 1990), that is, taking account of the empirical evidence generated by the sciences and social sciences and creating new theoretical hybridities such as neurophilosophy, environmental ethics, and the ethics of care. Ethics is also a lively verb because numerous ethicists attend to liveliness itself: the multiplicities, messiness, and contradictions of our lived contexts and the need for flexibility, sensitivity and agility in our ethical decision-making and action. One possible counter to this argument is that this activity invariably comes after the fact. In his provocatively titled chapter in a guide to ethical theory, The end of ethics, John Caputo (2000) comments that:

Ethicians appear rather like the crowd that gathers around the scene of an accident to see what has just happened...everyone has something to say about it, up to and including insisting that the proper authorities should have seen this would happen. (p. 111).

Even so, one can imagine the animated discussions that ensue.

This thesis is equally concerned with ethics as a very ordinary activity. Ethical decisionmaking and action arises from the web of interconnectedness that is human existence and our capacity to choose among values (Preston, 2007). Ethics is, firstly, central to the human condition. Moral systems can be found in all societies, albeit with varying cultural configurations of moral codes, and there are some features, such as kinship and reciprocity as sources of obligation, that appear universal to all human moralities. Three points may be made in relation to this. It is, firstly, perhaps plausible to suggest that ethical dilemmas have equally been an enduring feature of the human condition. Second, moral systems are not static, our changed attitudes to slavery being a notable example (and a demonstration that what is right cannot be drawn automatically from universal approval). Third, universal principles of kinship and reciprocity may have little bearing on what we actually choose to do. Certainly, moral choice is an unavoidable feature of modern day-today existence. Like nutritional choices, "we can ignore morality, but we cannot sidestep 
the choices to which morality is relevant, just as we cannot avoid the decisions to which nutrition is pertinent even if we ignore the information that nutritionists provide" (Hinman, 2013, p. 2).

For the most part, ethical matters form the backdrop to all our lives, ethical perspectives being a part of the unseen fabric of our daily thoughts and actions, rather than being what we think about. Ethics can be "relatively tacit, grounded in agreement rather than rule, in practice rather than knowledge or belief, and happening without calling undue attention to itself' (Lambek, 2010, p. 2). 'Ethical know-how' (Varela, 1999) is, therefore, not solely a rational or conscious decision-making exercise. Like driving the car somewhere and then realising that we cannot remember anything that happened en route, we tend to navigate ethical issues with something akin to 'blindsight' (Weiskrantz, 2009). Varela (1999) describes our lived worlds as 'ready-at hand', one of 'immediate coping' in that "we always operate in some kind of immediacy of a given situation" (p. 9). None of us can consciously process our decision-making on a moment-by-moment basis. Getting from home to work, for instance, would be even more exhausting if we were aware of each and every action and reaction along the way. If we notice our ethical decision-making at all, it's very often in retrospect or if something goes awry: a strained friendship, a student complaint about unfair treatment, or our responses to climate change, for example. Similarly, Varela highlights that our most often instinctive and situated ethical know-how is seen with greater acuity in moments where we feel 'stuck', although we may not name this impasse as an ethical dilemma:

It is at the moments of breakdown, that is, when we are not experts of our microworld anymore, that we deliberate and analyze, that we become like beginners seeking to feel at ease with the task at hand. (p.18)

At times, as Varela suggests, consideration of ethical matters will be foisted upon us, perhaps a full-bodied, visceral and emotive experience. At others, we may elect, or be able, to think about ethical dilemmas in slightly more dispassionate terms.

If ethics is such a commonplace activity and for the most part we lead satisfactory lives without consciously examining ethical questions, then why engage, as does this thesis, with the philosophy of ethics? Notably, ethics as an ordinary activity and a discipline are not such distinct spheres. Of course, our sources of ethical guidance and inspiration are many, varied, and commonplace: family, loved-ones, the church, the local community, for example. We learn in part from experience, mostly without direct access to the 
language or wisdom of philosophers, and probably without podcasts about ethical thinking. However, we can and do employ the insights and hone the skills of philosophy in our interactions and relationships with others and the environment. When we reflect on everyday practice, moral dilemmas and conventions, when we seek to understand where others are coming from, we are moving into the practice of ethics. When we consider the consequences of our actions, rights abuses, the content of another's character or how to reduce suffering, we are connecting to the language and conceptual categories of academic ethics. Activities such as these are clearly not exclusively the realm of academics and, most importantly, our conscious participation in them does not relegate us to an ivory tower. Opportunities to think about how we should act are available to the vast majority of us; we are each of us philosophers of action.

In this thesis I argue that the philosophy of ethics could be drawn a little closer to the lives of social studies learners. Arguably, thinking more deeply about ethics is of benefit to us all: a source of personal meaning, explanation, strength, critique and new possibilities for social action (Hinman, 2013). Granted, an examined life does not necessarily assure a life worth living, nor does the study of ethics fully equip us to cope with the vicissitudes of life. "Likewise, understanding ethics is no guarantee that we can live with the doubts often generated by difficult ethical decisions" (Preston, 2007, p. 223). Even where we do reach a decision, none of us is wholly consistent; there may be a marked difference between our professed ethical commitments and our actual behaviour. Further, the hope that ethics might provide us with a guide to ethical reasoning or a once-and-for-all answer to Socrates' question, 'how should one live?', is seriously called into question in Bernard Williams' (2011) book, Ethics and the limits of philosophy. In his view, moral theory is too reductive to cope with the messiness of our social worlds and modern life demands too much of it. Morality, he claims, is a 'peculiar institution', resting on an illusory, almost religious, ideal that 'human existence can be ultimately just" (p. 217). In his view, ethics cannot formulate answers in advance; one must live first, and uncover, in the process, any relationship between truthfulness, reflection, self-understanding, and criticism.

Fundamentally, then, ethical thinking is a matter of uncertainty. Even so, the resources of the philosophy of ethics could help us to think better about dilemmas that confront us. Williams (2011) argues that ethics can play a part in reflective living, as a critique of societal institutions and lived experience: 
It need not seek to join the natural sciences in providing an absolute conception of the world, but we need to have some reflective social knowledge, including history, that can command unprejudiced assent if the better hopes for self-understanding can be realised. (p. 221)

This does not have to be, and is not in this thesis, an argument for the primacy of reason; numerous ethicists have an interest in the relevance of experience, emotion or intuition (see: de Sousa, 2014; Tong \& Williams, 2014). What the philosophy of ethics provides is, for example, a means to identify what lies at the heart of particular social issues, a way to step back from knee-jerk responses and over-reaction and clarify choices, and frameworks for alternative courses of action. It can also provide us with some confidence in re-entering the fray, having had the opportunity to think through what went awry. Importantly, however, it is unlikely that ethics can ever provide a single right answer to personal and social issues, or radically change us. Instead, it is more likely to provide several, perhaps least worst, answers that assist in the ongoing (re)negotiation of our lives. Ethical thinking is one means of dealing with the complexity and vicissitudes of life. It may help us understand even the most seemingly intractable of circumstances further, support greater dialogue and recognition of the 'other', and open up new possibilities for societal participation.

One last point about the nature of ethics before I progress to clarifying key terms used throughout this thesis: doing ethics is alive with danger and contradiction. This is reflected in the language this thesis employs - ethical dilemmas, challenges and issues - which necessarily captures the unsettled and unsettling aspects of our society and experience. On the one hand, as philosophers such as Boethius (d. 524) and latterly Alain de Botton (2007) have argued, consolation for the vicissitudes of life may be found in philosophy. I think there is also room for adjectives not commonly associated with ethical thinking, particularly if one is to read opening passages of academic texts about ethics: wonder, delight, relief and creativity, for example. I am not suggesting that ethical questions lack seriousness; instead, thinking ethics need not be a sombre affair. Aristotle claimed that the philosophy begins in wonder: "philosophy done in this way is pursued for the sheer joy of discovery and exploration” (Hinman, 2008, p. 21). Similarly, Critchley (2002) playfully suggests that the philosopher has a "family resemblance to a comedian ... [both] ask you to view the world from a Martian perspective, to look at things as if you had just landed from another planet" (p. 103). On the other hand, being asked to think about the ethical content of our lives is potentially disquieting. The issues may now appear far more complex, challenging, and dispiriting than they first appeared. Amélie Rorty (2005) 
contends, for example, that morality "sometimes generates the very uncertainties and conflicts it was meant to resolve" (p. 14). Invitations to explore the real, the urgent and the personal are also fraught with peril; what painful, private experiences might be exposed? What harm created? Then again, tears can be joyful, a relief, or washed with hope. So, in doing ethics, we confront contradiction and risk. In this thesis, I do not seek to erase such contradictions. Instead, I take Michel Foucault's (1983) view that we must be alert to the dangers of doing ethics and see what might be made of these:

My point is not that everything is bad, but that everything is dangerous, which is not exactly the same as bad. If everything is dangerous, then we always have something to do. So my position leads not to apathy but to a hyper- and pessimistic activism. (pp. 231-232)

\section{DISTINGUISHING 'ETHICS’ FROM OTHER PROXIMAL CONCEPTS}

The attempt to create a 'barbeque' version of this thesis, a readily understood response to those who have generously enquired into what I have been writing about, has elicited all manner of responses to the term ethics. Perhaps this should be no surprise.

Reflecting the competing ends of ethics, people bring a muddled range of meanings to the concept, and everyday phrases such as 'acting ethically' in fact conceal considerable variation across individuals, communities and contexts. In New Zealand educational contexts, for example, teachers may connect ethical decision-making with their professional code of conduct, with character or virtues education, or with the religious background they have been steeped in, each of which reflects particular ethical traditions. They may also see ethics as something 'out there' that academic philosophers engage in. None of these interpretations is incorrect. However, in this thesis I use the term 'ethics' to mean more than a single moral system, and more than what academic philosophers do. This section elaborates my usage of ethics and in doing so draws a distinction between ethics and other associated terms used throughout the chapters, particularly morals and values.

Ethics can be "applied to any system or theory of moral values or principles" (Singer, 2014, n.p.), that is, refer to particular moralities, to describe what is. However, "in general, ethics is concerned with what is right, fair, just or good; about what we ought to do, not just what is the case or what is the most acceptable or expedient" (Preston, 2007, p. 16). One way of thinking about ethics is to see it as a relationship between moral mores - what people actually do or say - and the contemplation of what we could or should 
do. Ethicists are, however, less concerned with telling people what to do and more with the ongoing consideration of moral claims. Put another way, ethics is an association between 'first order' statements (for example, we should always consider the feelings of others) and 'second order' statements "which would say what is going on when someone makes a first order statement" (Mackie, 1979, p. 9). Though this work may be highly theoretical, ethics is nonetheless rooted in the challenges of ordinary life; even the most abstracted of philosophical arguments are typically propelled through appeal to everyday ethical dilemmas. Ethicists address the intensely practical question "what is to be done?" not from delighted abstraction, but from the need to address real-world and relational concerns. It is also important to note that, as with all academic disciplines, the aim of philosophical ethics is to produce knowledge which may transform individuals and society. As Mackie (1979) urges, the object of this work is "to decide what to do, what to support and what to condemn, what principles of conduct to accept and foster as guiding or controlling our own choices and perhaps those of other people as well" (p. 106), even where there may be no objective values to lead us.

The philosophy of ethics tends to be divided into three main categories that reflect both the types of questions the academic ethicists ask and the way the discipline has evolved. Importantly, as Hugh LaFollette (2000) points out, such categories are more a convenience that denoting sharp boundaries; ancient philosophers would likely have seen them as "a contrivance, carving non-existent joints in the moral universe" (p. 2). Nonetheless, present-day philosophers employ these distinctions as heuristics in order to locate their inquiries. Normative, or prescriptive, ethics is concerned with the theoretical frameworks or perspectives that might be brought to bear on ethical decisions. It "provides theories which aim to guide our conduct, to help us decide what we ought to do and how we ought to live" (Preston, 2007, p. 17) and addresses questions such as "are there general principles, rules, guidelines that we should follow, or virtues that we should inculcate that help us distinguish right from wrong and good from bad?" (LaFollette, 2000, p. 1). Another branch of ethics, meta-ethics (or analytic ethics), attends to the meanings of ethical concepts, and the purposes and processes of ethics. The objectivity of moral claims, the viability of ethics, and the relationship between psychological processes and ethical decision-making are examples of the types of questions that are attended to in this domain (LaFollette, 2000). The work of many modern academic ethicists is exclusively devoted to meta-ethics, "due in part to the increasing difficulty of formulating a system of ethics applicable to all or even most human beings" (Thiroux \& Krasemann, 2009, p. 7). A third category of ethics is applied, 
or practical, ethics which considers what we should do in particular situations, for example in relation to euthanasia, war, or the environment. While applied ethics draws on philosophical ethics, it is also interdisciplinary in nature, extending into fields such as the social sciences and humanities, biological and environmental sciences, and theology. Professional ethics in education is another example of applied ethics and, although not the subject of this thesis, it nonetheless strongly intersects with a consideration of how New Zealand social studies education might better support learners' ethical decisionmaking and action.

Two semantic distinctions are particularly important to the work of this thesis. It is firstly notable that much education literature is replete with 'morals' and its cognate terms (morality, immoral, moral judgement). These are often used interchangeably with ethics and its cognates, for a range of defensible reasons. Readers will note, for instance, that a later section of this chapter refers extensively to moral education and that I use the term morality where other authors have used it. Mirroring the 'is' and 'ought' usages of ethics described above, morality may be defined (a) in a descriptive sense, for example as anthropologists would, to characterise codes of conduct that actually exist among individuals, groups and societies, and (b) in a normative sense (Gert, 2012). I am wary of the latter, not so much the use of morality to make sense of the world, but claims to morality dressed as "sanctimonious self-righteousness, self-centred moral narcissism, [or] misleading justification" (A. Rorty, 2012, p. 1). For example, as Singer (1994) identifies:

'Morality' brings with it a particular, and sometimes inappropriate, resonance today. It suggests a stern set of duties that require us to subordinate our natural desires - and our sexual desires get particular emphasis here - in order to obey the moral law. A failure to fulfil our duty brings with it a heavy sense of guilt. Very often, morality is assumed to have a religious basis. These connotations of 'morality' are features of particular conceptions of ethics, one linked to the Jewish and Christian traditions, rather than an inherent feature of any ethical system. (p. 5)

Thus, to say that someone is immoral (or unethical) refers to a fixed way of doing things and carries with it a strong sense of censure, rather than merely an understanding that a particular, typically un-named, ethical code or framework(s) has not been adhered to. It is perhaps for this reason that though 'morals' is listed as an aspect of values in The New Zealand curriculum (Ministry of Education, 2007), it has not been prevalent in New Zealand social studies curricula (Department of Education, 1977a; Ministry of 
Education, 1961, 1993, 1997, 2007). Whether or not this is the case, my preference for using 'ethics' has two further reasons. First, it reflects a semantic shift in philosophy: 'it is now common to refer to ethical judgments or ethical principles where once it would have been more accurate to speak of moral judgments or moral principles" (Singer, 2014 , n. p.). Secondly, my use of ethics draws attention to how moral values (that is, an individual's or community's position or judgement about what is right/wrong or good/bad) are arrived at, not simply the stances in and of themselves, that is, the analysis of the ethical frameworks from which moral claims emanate. Thus, and importantly for the work of this thesis, ethics is not the same as the inculcation of moral rules, though the latter may be an outcome of ethical processes.

Another important distinction that is needed for the purposes of this thesis is between ethics and values. This matter is especially important given the strong association between social studies and values education in Australasia and elsewhere, as outlined in greater depth in Chapter Three. The concept of values has heavily inflected New Zealand social studies curricula for decades, and most noticeably gained prominence in the Social studies syllabus guidelines: Forms 1-4 as one of four "complementary and inseparable aspects of social studies" (Department of Education, 1977a, p. 5). Ethics is one of a cluster of concepts subsumed under this mantle of 'values' (Gilbert \& Hoepper, 2004; Hill, 1994; Keown, McGee, \& Sands, 1993). The New Zealand curriculum defines values as "a deeply held belief about what is important or valuable" and cites examples of values as being "moral, social, cultural, aesthetic, and economic" (Ministry of Education, 2007, p. 10). The term values is ambiguous however. In a broad sense, values are about preferences and what matters to us, yet:

Having certain values does not guarantee that we will act in accordance with what we cherish as worthwhile. It could be said then that not everything we value has genuine worth. There is room for the improvement of judgment and reappraisal of the things we value. (Burgh et al., 2006, p. 44)

Such reappraisal may lead us also to see differences in the meanings that are brought to particular values. In his book, Cosmopolitanism: Ethics in a world of strangers, Anthony Appiah (2006) points to a landscape of essentially contested concepts ${ }^{7}$. The open textured nature of values means that "even people who share a moral vocabulary have plenty to fight about" (Appiah, 2006, p. 60). In relation to a seemingly incontrovertible

${ }^{7}$ A term he draws from Gallie (1956). 
maxim, do unto others as you would have them do unto you, Appiah notes that the 'Golden Rule' may play out in quite different ways if we take other people's interests seriously into account. He cites the example of Jehovah Witness beliefs about blood transfusions. We may view blood transfusions as a gift of life, just as we would wish our lives to be saved. However, for most Jehovah Witnesses this act violates the word of God and thus not what they would 'do unto others'.

The conceptual complexity of values aside, ethics is sometimes classed as a subset of values, as debatably not all values (such as aesthetic or economic values) have an ethical basis. Therefore, values might be regarded as the more encompassing term. Certainly in philosophy, one use of 'value theory' is as an umbrella term for areas of philosophy that have some evaluative aspect; including, for example, social and political philosophy, aesthetics, and sometimes the philosophy of religion (Schroeder, 2014). However, not all theorists would have it this way, and may prefer to see ethics as distinct in a disciplinary sense. Caplan (1979) found that people who used the language of ethics tended to see it as "firmly rooted in a tradition of systematic theorizing" (p. 248). By contrast, those who used 'values talk', in solicitations sent in response to an announcement about a study of the teaching of ethics in American higher education, took a broader view "associated with a belief in subjectivity, affectivity, and relativity in teaching about normative judgements” (p. 249).

An alternative position, and one that I take, regards ethics as a mechanism for adjudicating between and accommodating conflicting value positions (Caws, 1996), that is, ethics both mediates and provides for the alteration of values. This position has values as both a raw material and as an output of ethical processes. So, I take ethics to mean those ways of thinking that shape our conduct, the values we espouse and the decisions we make as individuals and communities about how we should act. Ethics is a process through which what we take to be desirable, worthwhile, valuable, and important in life is subjected to reformation and refinement. Thus, while both ethics and values are indisputably allied, this thesis draws ethics out from the shadow of values. For the present purposes then, ethics might be described as:

Both the branch of philosophy concerned with the systematic study of what we ought to do, and an activity - that of coming to an understanding of, and reflecting upon, a range of perspectives about social action. 
That is, ethics has to do with a conscious, critical exploration of morality and espoused values. Here, I come back to Burgh et al.'s (2006) view that there is room for the ongoing scrutiny of values. I submit that it is ethical thinking that enables us to conduct such reappraisal, especially in relation to moral values. This is because ethical thinking encourages us to consider the premises on which our moral values are founded, and better understand the forms of action we subsequently take, or do not take. In essence, this distinction between values and ethics would focus social studies learners on the deeper-set machinations of societies and the often unexpressed core of social issues and phenomena, enabling them to "critically analyse values and actions based on them" (Ministry of Education, 2007, p. 10) and modify their own values and actions in light of this. Probing deeper ethical horizons reveals that quite different perspectives may be used in the name of social justice or environmental sustainability, for example. In the next section, I provide examples of such perspectives.

\section{ETHICAL PERSPECTIVES: COMPLEX, CHANGEABLE AND CONTESTED}

This section explores a range of normative ethical perspectives, that is, theories about the ways in which people respond to ethical questions and issues. Aside from introducing these as terms that will be used in this thesis, the purposes of this section are to demonstrate (a) how ethical theories are complex, changeable and contested ${ }^{8}$, and (b) how this is mirrored in young people's ethical decision-making. I seek to demonstrate that there are few easy answers to ethical problems, either in academic or everyday settings, even when one has a preferred ethical standpoint.

Something of the theoretical complexity involved in considering ways to go on can be seen, firstly, in the way that the content of ethics is perennially debated in academic contexts. If one were to pose the question 'what is it to be ethical?' to ethicists, the answers would contain multiple conceptions. The philosophy of ethics encompasses considerable theoretical diversity and encounters a vast array of problems, though individual ethicists may specialise in particular lines of inquiry. Philosophic differences exist over the language, logic and foundations of ethics, even whether there can be foundations to ethical systems (Thiroux \& Krasemann, 2009). About such moral disagreement, Hinman (2013) points out that no field of academic inquiry has reached

8 A heuristic drawn from a paper written with Bronwyn Wood (Milligan \& Wood, 2010). 
its end, nor should we give up on ethics in the absence of complete agreement. The best we can do, he says, is to understand and weigh up the various positions and "come to the best decision we can" (p. 2).

A second point about theoretical complexity is that different ethical stances may be both marshalled and masked under what appears to be the same position. It is notable, for example, that The New Zealand curriculum (Ministry of Education, 2007) uses 'sustainability' in an apparently taken-for-granted and uncontroversial manner. It is claimed, for instance, that "ecological sustainability" is a value that enjoys "widespread support" (p. 10). And yet, upon closer examination of its usages, one can detect at least three ethical perspectives are being drawn upon: an ethic of care, a principle to which we all should hold, and a matter to be judged in terms of consequences. One does not have to delve too deeply into the literature on environmental ethics to see how these perspectives are by no means concordant, nor exhaustive (see, for example, Brennan \& Lo, 2014).

A third point is that different normative ethical theories can both cohere and, conversely, produce quite different answers when applied to the same ethical question. By way of an example, recently in our social studies teacher education classes my colleague Mike Taylor and I asked students to consider an issue that had cropped up in the news: whether or not to buy imported roses for Valentine's Day. Many students argued against the purchase by stating that buying locally should be an important consumer principle. This principles-based decision also cohered with a consequentialist argument: that buying imported roses sustains inequalities because Indian growers receive a negligible return when compared to the final cost to the consumer. Notably, a similar, consequentialist argument was used by some students in favour of buying imported roses: that a widespread consumer boycott would likely damage a critical industry for Indian communities.

To examine these perspectives in a little more depth, what follows is a summary of some key ethical theories. To illustrate, I have drawn on two focus group interviews conducted with six Year 9 social studies students. Further details about the interviews are given in Chapter Six, where I explain how they connected with a study about the place of ethics in social studies education. The students were asked to explore two social issues: whether or not to accept a Facebook friend, and the images that the media should be allowed to use. The following describes the students' responses to these 
issues as being typical of a range of normative theories. Almost immediately, one can see some difficulties with this exercise related to the complex, changeable, and contested nature of ethical perspectives. I firstly caution that the summary of ethical theories is not intended as a synoptic exercise; any number of books survey the philosophy of ethics and there is not the space to do justice to that exercise here. Second, distilling textbook categories of ethical theory can be somewhat misleading. Many synoptic texts concentrate on central figures and paradigmatic positions, presenting differences only when they have reached a sufficient level of adherence to count as sub-categories. The variety of utilitarian positions provides a good example: while adherents of each of these positions strive for coherence within their own approach, attempts to find uniting elements across the variants tend to be somewhat strained. A third risk is that of unhistoricised, free-floating accounts of ethics (MacIntyre, 1996). Social theorising occurs within changing contexts; approaches to virtues ethics now going by that name are neither unified within themselves nor with their historical precursors. The fourth challenge is that the categorisations one finds in textbooks have to do with developed theoretical positions - conceptual schemes that aspire to some kind of internal coherence. That is, of course, not where students are likely to be at, nor is it a discipline to which they may be attracted. Further, while I describe the students' responses as typical of particular ethical perspectives, it is doubtful that one could describe the students as, for example, utilitarians or deontologists; the fluidity of their ethical schema described below is a case in point.

FORMS OF CONSEQUENTIALISM. "Well, like on MSN I can block someone and delete and so on, but they don't know if you're online or not so they just think that you're offline the whole time. It isn't doing anything." (Bob) ${ }^{9}$

Here, Bob reasons that blocking someone as Facebook friend is morally acceptable, because the person cannot tell that they have been blocked and therefore no harm is created. Bob's comment reflects a consequentialist approach which, as the term suggests, primarily calculates the good in terms of consequences. It is a teleological perspective - a theory in which the ends justify the means. One important example of a consequentialist theory is utilitarianism. This is often expressed as the greatest good for the greatest number, where the good may refer to maximising happiness, pleasure, or utility. The long history of utilitarianism is particularly associated with the writings of

$9 \quad$ Student selected pseudonyms. 
nineteenth century progressive social reformers such as Jeremy Bentham and John Stuart Mill. Mill, for example, believed that the good consists in individuals' freedom to calculate, impartially, the happiness that results from an action. There are numerous problems with the basic principles of utilitarianism. Preston (2007) notes, for instance, that the exclusion of learners with behavioural issues from schools and classrooms is often defended along utilitarian lines. Thus, the position "may lead to a spirit of cold pragmatism which often offends our moral sensitivities and ultimately overlooks the cause of justice when that cause requires the defence of the vulnerable or seemingly uneconomic policies” (p. 38). Nevertheless, as Peter and Charlotte Vardy (2012) observe, modern utilitarians such as R. M. Hare and Peter Singer have "explored the difficulties in predicting, measuring and comparing outcomes and the extent to which people can really be expected to weigh consequences in relation to each action" (p. 118), as well as confronting the possibly inhumane consequences of such a position.

Other forms of consequentialism exist. For example, situation ethics, as articulated by James Fletcher, holds as a calculating principle that which maximises unconditional love (agape). While his approach assumes that ethical decisions are always contextual, Fletcher's position avoids absolute relativism; the breaking of a law, for example, is justified only when its effects violate the law of love. By contrast, ethical egoists ${ }^{10}$ hold that we should base our decisions on self-interest, the universal version of this being that everyone should act in a way that considers the consequences to themselves. Another form of consequentialism, John Dewey's pragmatic ethics, differs from these previously described versions on a number of counts: his "insistence on a public evaluation of goods is similar to the utilitarian principle, but it does not result in permanent rules, calculations, or fixed hierarchies of value" (Noddings, 2007, p. 163).

FORMS OF NON-CONSEQUENTIALISM. "I think that rules for the media would be important because most of them are about people's privacy. And that is like real important.” (Michael)

In deontological theories of ethical decision-making, actions are judged generally by standards of duty, obligation, or rights. Michael's point above, about the protections one should expect from the media, positions privacy as an inaliable right. "Non-

consequentialist ethics enjoin us to do the right thing simply because it is the right thing, intrinsically; no extrinsic justification is needed as with consequentialism" (Preston,

10 This is not to be confused with versions such common-sense, psychological and rational egoism, and egoism as a means to the common good (Baier, 1993). 
2007, p. 40). Divine command theory, for example, states that moral action is drawn from the teachings of religious authorities. Another influential deontological tradition is the duty ethics of Immanuel Kant, in which the absolute authority is not a higher power but the universal dictates of human reason. Unlike consequentialist theories, which permit an examination of circumstances, Kant's philosophy relies on moral absolutes. For example, Kant's (1952) categorical imperative states: “act according to a maxim which can be adopted at the same time as a universal law" (p. 392). Good will is a defining aspect of Kant's moral theory, that is, acting out of a sense of duty is more ethically praiseworthy than acting in accordance with duty (Keller, 2010).

The limits to Kant's deontology have been keenly contested. There are those, for example, who strongly doubt that universal principles may be found within historical change, the complexities of societal discourses and differences in cultural traditions (O. O’Neill, 1993). By contrast Onora O’Neill herself argues that Kantian reason “can speak beyond cultural boundaries ... it offers moral philosophers the possibility of speaking meaningfully about issues which affect us all while retaining a grip on the limitations of the human perspective" (P. Vardy \& C. Vardy, 2012, p. 161). Another issue resides in the difficulties associated in resolving conflicts between absolute rules; "some adherents of non-consequentialism may be forced to resort to consequentialist modes of reasoning" (Preston, 2007, p. 42). One attempt to wrestle with such conflicts occurs in the work of William Ross, a follower of Kant's. In response to what he saw as being Kant's inflexible absolutism, Ross posited that we have certain prima facie duties, such as not harming others and honesty, "that we must adhere to unless serious circumstances or reasons tell us to do otherwise" (Thiroux \& Krasemann, 2009, p. 62). He also argued, pace Kant, that we have special duties, for example, to family and friends, which may override moral absolutes. Ethical decision-making becomes, on Ross' account, in part an exercise of acting in accordance with the stronger duty. The selection and prioritisation of, and justification for, prima facie duties is open to scrutiny. However, it is notable that Kant's deontology remains compelling for many contemporary ethicists, and perhaps to us all by engaging with our intuitive, everyday sense of fundamental responsibilities to others. Moreover, "deontological theories, unlike consequentialist ones, have the potential for explaining why certain people have moral standing to complain about and hold to account those who breach moral duties" (L. Alexander \& Moore, 2014, n.p.). 
JUSTICE VS. CARE: “And you shouldn't, like, hang out with the person that's being mean to your friend because you could have known that person for ages and they could actually mean a lot to you." (Michael)

A sometimes polarised debate in contemporary philosophy of ethics is between justice and care perspectives. Broadly speaking, the former begins from the position that societal well-being depends on a shared commitment to the rights of individuals and just resource distribution (Preston, 2007). Preston notes that social justice and rights are often conflated, "as if the granting of rights was the sum total of social justice" (p. 43). I reiterate this here because social justice has less of a focus than rights in the New Zealand social studies achievement objectives (Ministry of Education, 2007). In addition, rights is largely construed in terms of the Universal declaration of human rights. The concept of rights has had, in fact, a much longer, contested history in political philosophy, and has been justified on a number of theoretical grounds (Almond, 1993). On the basis of quite different arguments, John Locke and Thomas Hobbes conceived rights in terms of a social contract designed to protect individuals from harm, whereas theorists such as John Stuart Mill and R. M. Hare have grounded rights in conceptions of utility. More recently, in his book A theory of justice, John Rawls (1999) has spearheaded a duty-based orientation to social contract theory. Through a thought experiment, he argued that people will only choose a social contract "which would not disadvantage them in the event that they turn out to have some liability (such as economic poverty)" (Preston, 2007, p. 45). This led Rawls to argue that social justice is built on two principles: freedom, and equality and social justice. The latter makes the different treatment of members of society possible only when it addresses social disadvantage.

Rawls' theory has attracted criticism from a number of directions; it has been argued, for example, that it overplays the role of rationality and underplays the effects of power. Another line of argument takes a more relational turn, reflected in Michael's feelings about her friendship, above. Feminist care ethics takes issue with Rawls' prescription for social justice (Porter, 1999) and, more generally, calls for a re-evaluation of consequentialist and non-consequentialist theories. In simple terms:

Justice insists on general rules. It has a concept of the self that reduces everyone to a thin moral sameness and that denigrates the importance of particularities and relationships. Caring, in contrast, is context sensitive, has a situated self, and is fundamentally concerned for relationships (Katz, Noddings \& Strike, 1999, p. 22). 
The critiques of theorists such as Carol Gilligan, Virginia Held and Nel Noddings have particular salience to this thesis, in that they attend to (a) different moral voices, especially gendered differences in ethical decision-making, (b) context and moral sensitivity, and (c) the lived, embodied experiences of women's ethical lives, particularly as nurturers. However, feminist care ethics is perhaps problematic as a justificatory normative theory and it is notable that other traditional theories do not necessarily preclude a consideration of care critiques.

VIRTUES/CHARACTER PERSPECTIVES: "I can debate whatever [Michael] said. I can say something. If they were not good people they wouldn't stick to the rules ... because if they were good people they wouldn't need them, they'd just know." (Bob)

Does ethical life require rules? In considering media ethics, Bob suggests that rules are not the only source of ethical guidance. Her position invokes an Aristotelian argument that the cultivation of the good life lies in considering who we should become, or the kind of person we wish to be, rather than what we should do. From an Aristotlean virtues perspective "we are not conducting this inquiry [into the good life] in order to know what virtue is, but in order to become good" (A. Rorty, 2012, p. 13). In the works of Alisdair MacIntyre, Elizabeth Anscombe and Michael Slote, to name but a few, we see a groundswell of attention to virtues theory in contemporary academic ethics. Peter and Charlotte Vardy (2012) comment that though such derivations have important distinctions, almost all contemporary virtues ethicists import three concepts from Aristotelian philosophy: (i) arête - character traits, such as courage, truthfulness and good temper, (ii) phronesis - practical wisdom that should begin from experience and, (iii) eudaimonia, or flourishing. To put these concepts together, human flourishing emanates from the identification and habituation of positive character traits. Happiness stems from leading a virtuous life, that is, engaging in continuous reflection on lived experience rather than reciting moral principles. In other words, "ethical dilemmas must be addressed not fundamentally as intellectual puzzles but by morally-formed persons who bring virtuous qualities to the issues before them" (Preston, 2007, p. 52).

Just as Aristotle's legacy is keenly engaged with in academic circles, and as is discussed later in this chapter, virtues ethics strongly inflects contemporary approaches to moral education. Aristotelian-type virtues find, for example, their expression in The New Zealand curriculum as "values to be encouraged, modelled and explored" (Ministry of 
Education, 2007, p. 10), such as excellence, integrity and curiosity. The curriculum's list of values is not the same as the virtues Aristotle identified but, as he would remind us, what is seen as being important virtues changes with societal context. This points to one of the challenges with virtues ethics - if virtues change over time and place, how do we avoid the descent into relativism? The differences between the virtues emphasised in New Zealand schools (see Keown, Parker \& Tiakiwai, 2005, pp. 90-98) demonstrates the difficulty of arriving at consensus, even within the character education movement, in the present. Other challenges lie in determining what virtuous people are to do in the face of perplexing modern dilemmas, whether virtues theory "can do all the work of ethics" (Pence, 1993, p. 254), and whether there exists an essential connection between virtues.

ETHICS AS DISCOURSES: While the previous selection of ethical perspectives gives something of the flavour of debates in ethics, it by no means captures the complexity of the contemporary academic landscape. The discussion has, further, almost exclusively attended to Western philosophy. The colonising effect of Euro-western philosophies of ethics is a matter picked up in Chapter Four, but it is notable that a vast literature exists on Eastern philosophy and indigenous ethical perspectives in other parts of the world (see, for example, Gyekye, 2014; Singer, 1993). Importantly, in fields such as environmental ethics and research ethics, we see a playing out of attempts to find ways to recognise differentiated moral experiences and speak across difference - applied ethics in a more enriched sense than the application of ethical theories to social and environmental concerns. The discussion, thus far, might also seem distanced from learners. Yet, in the nuanced exchange about friendship and Facebook between the students below, we can discern the traces of previously discussed ethical debates. Destiny communicates her rule in relation to friendships and Bob moves this into a consideration of the consequences of dissing. Isaac is interested in people's ethical motivations as a basis for decision-making, and together with Michael and Destiny, wrestles with deontological approaches in the context of relationships:

Destiny: $\quad$ My friends know not to dis all my other friends because I always like say "that's not cool" or something. So they know not to say things about people in front of me.

Andrea: So if you go on Facebook and they were dissing your mates, that person would be - get rid of them pretty quickly?

Bob: I'd get upset. Cos everybody's done that to me and my friend... 
Andrea: So you think there's actually some very hurtful consequences? Dissing?

Bob: $\quad$ Yes.

Isaac: I'd have a talk to them and ask why they're doing it. And if they say "just cos it's fun" I'd just tell them to back off. Like at Kapa Haka, we got told to look out for each other because we're one big family.

Michael: It's like if you had a new friend and they were saying stuff about your old friend that's not cool. But it's also the same the other way round, like if an old friend is making fun of your new friend ... because like you could seriously trust like that new friend or something, and could be really upset with them.

Destiny: But your friends have also got to learn that you have got other friends, other than them.

How could one think about ethical theories in relation to learners? This thesis does not aim to make a contribution to any one tradition of the philosophy of ethics, or the field in general. Instead, it builds an argument that social studies learners should have access to as much of the insights of the philosophy of ethics as possible. This is not to say that the argument does not draw on ethical perspectives - the reader may detect an Aristotelian thrust to the discussion about lived experience in Chapter Five, for example. Primarily, this thesis conceives ethics as discourses that, for the most part, suffuse our lived experiences. My use of the term discourse draws from a wide body of literature that coalesces around a relationship between post-structural ethics and education, following the works of Michel Foucault, Emmanuel Levinas, Jacques Derrida and others (see, for example, Bagnall, 1998; Hugman, 2003, 2005; Popke, 2003; Slattery \& Rapp, 2003; Todd, 2003). One of the reasons that post-structural thinking presents something of a challenge to traditional ethics is that it calls into question foundational, objective knowledge. "From this perspective, the apparent stability of meaning embedded in any system of thought is potentially destabilized by elided traces of difference, and by the multiple contexts in which knowledge is produced, received and interpreted" (Popke, 2003, p. 300).

In this thesis, I draw on poststructural ethics to assist in the consideration of multiplicity, complexity and contradiction in learners' ethical lives. My justification for adopting discourse theory as an approach to thinking about ethical perspectives in relation to social studies learners is two-fold. First, discursive ethics offers as an understanding of ethical decision-making and action as drawing on socially constructed storylines that are never told in isolation and require affirmation to continue to exist. 
Ethical theories, of the kind outlined in this section, are some of those enfolded storylines in learners' lives - but not all. Second, discursive ethics enables a rethinking of the subject, in this case learners, not as corresponding with ethical theories but as differently positioned by their storylines. In other words, ethical perspectives have constitutive effects (Foucault, 1997) that shape, for example, what is said/not said and who is included/excluded in conversations about ways to go on. Further, "in speaking and acting from a position people are bringing to the particular situation their history as a subjective being, that is the history of one who has been in multiple positions and engaged in different forms of discourse" (Davies \& Harré, 2009, n.p.).

I emphasise that this thesis does not argue for presenting ethical decision-making and action, including the ethical theories that inform such choices, in solely post-structural terms. While I make a case for foregrounding ethical discourses and their effects in the lives of social studies learners, this does not preclude a consideration of foundational ethical theorising, for example. My interest lies, instead, in surfacing the silenced in social studies education - in the context of this thesis, ethical perspectives that languish as a backdrop to New Zealand's social studies curriculum. Most vitally, the argument built in this thesis is that opportunities to explore the complex, contested, and changing nature of ethical perspectives offers learners stories with which to go on.

\section{ETHICAL SPACE AS A 'COMPLEX ECOLOGY’}

In this section I discuss a number of important features of contemporary democracies within which ethics takes place, such as plurality, complexity, uncertainty, and moral ambivalence. These are features that we, including our learners, must inevitably navigate. Without suggesting that ethical issues are any more important or perplexing today than in the past, the discussion draws on two images of occupation to explore the 'complex ecologies' (A. Rorty, 2005) of contemporary ethical space and how societal change has presented new challenges for ethics and ethical decision-making. The argument presented in this section is important because it (a) suggests why a greater focus on matters ethical is both urgent and vital, and (b) establishes the societal context to which this thesis' proposal responds.

Before continuing, two clarifications are necessary. The first is that ethical dilemmas brought about by societal complexity and moral diversity ought not to be seen as 
something peculiar to the twenty-first century. Historically, the writings of ethicists, poets, theologians and politicians alike have responded to the perplexing and troubling societal dilemmas of their time. Consider, for example, Greece: if we examine the society of Plato's upbringing, we see the direct influence of the Peloponnesian Wars on “a period of physical turbulence, social disarray, and changing values" (Barrow, 1978, p. 11). Plato witnessed a diversity of viewpoints and values, drawn variously from poets (chiefly Homer and Hesiod), tragedians, itinerant teachers, and prominent politicians and citizens (Adkins, 1989), formed against a backdrop of war, economic collapse, and tensions within Athenian democracy. Indeed, it was in part this very moral confusion that led Plato to offer an antidote, based in his vision of the Republic, that pursued a more satisfactory polis focussed on the "twin objectives of harmony and security" (Barrow, 1978, p. 11). Since then, we have seen an expansion of the morally considerable in the history of ethics, to include slaves, women and more recently the environment. Well before the twenty-first century, the Lisbon earthquake and the Holocaust ruptured and transformed the philosophy of ethics (Neiman, 2004) and, at least in James Sterba's (2001) view, environmentalism, feminism, and multiculturalism arose as significant and as yet unresolved ethical challenges.

Secondly, one needs to avoid the temptation to discuss ethics in a panicky 'we're all going to hell in a hand-cart' tone, drawing on the type of arguments that proceed "from the claim that contemporary society is rapidly sinking in a rising tide of vandalism, violence and drug abuse to some pet theory of moral formation that might serve to stem this tide" (Carr, 1999, p. 26). Like other educationalists, I think we need to be wary of the language of moral crisis that permeates much of the media representation of contemporary society and, in particular, the continual and perhaps unwitting reprise of Hesiod's despair over the reckless, arrogance and frivolousness of the young. This is not to deny the existence of a sense of moral crisis but to place it, as Carr urges, "in proper historical proportion” (p. 23). Similarly, Amanda Rohloff (Rohloff, 2011; Rohloff \& Wright, 2010) uses the theories of Norbert Elias to argue that we must move beyond conceiving moral panics as inherently fleeting, misguided and therefore dismissible, and instead pay attention to longer-term societal processes and figurations. Rohloff would argue that the recent Roast Busters ${ }^{11}$ scandal, in which a group of young New Zealand men reportedly boasted about having sex with intoxicated young women on Facebook,

${ }^{11}$ For a summary of this issue see: http://en.wikipedia.org/wiki/Roast_Busters_scandal 
should be seen as a short-term episode, where de-civilising trends temporarily dominate over civilising trends. My point here is not necessarily an argument for an Eliasian approach to ethics, but to suggest that ethical issues are as much a matter of continuity as they are of change.

How, then, might one sensibly characterise the ethical landscape of our times? We should acknowledge the ever-increasing array of ethical choices that confront people in Western societies and issues that compete for our attention. Advances in technology and science have presented questions that never existed in modern and pre-modern societies and, in academia, have been responded to through a whole host of new areas of thought such as bioethics, communication ethics, and machine ethics. We should also note the multiplicity of ethical visions in everyday life, something philosophers refer to as the fact of pluralism, or the fact of diversity. Bernstein (1987) notes both the shifting meaning of pluralism and its relationship to an enduring theme of the one and the many, to be found "at the core of Greek philosophy, discernible already in the fragments of the pre-Socratics [and]... replayed in such abstract forms as the relation of the one to the many, the relation of sameness or identity and difference, the universal and the particular"' (p. 520). In philosophy, there is considerable debate about whether pluralism exists at a foundational level, that is, whether there are distinct and perhaps incommensurable values - termed value pluralism - or whether, as monists claim, such values may be reducible to a super value albeit unknown at present (Mason, 2014). Jones (2006) notes an important distinction: "whereas the plurality noticed by value-pluralism is a plurality of different and conflicting goods, the plurality noticed in the fact of pluralism is a plurality of different and conflicting conceptions of the good" (p. 191). About the latter, few philosophers would disagree; ethical complexity, fragmentation and plurality are axiomatic of our everyday experience.

A whole host of concerns arise from the fact of pluralism. Just why ethical diversity is a social fact is one matter of contention. Lynch (2009) suggests that in political philosophy, for example, there are at least two accounts for the reality and persistence of diversity. The first draws on the philosophic conception of value pluralism previously discussed whereas the second, reasonable pluralism, attributes moral and political diversity to the limitations of human reason in achieving consensus. Further debates coalesce around how one should proceed from the fact of ethical pluralism, and whether it ought to be regarded as problematic. It is notable that pluralism both extends from democracy and is enshrined in the concept of democratic rights. I shall return to these issues in subsequent chapters for two reasons. The first is because The New Zealand 
curriculum's (Ministry of Education, 2007) requirement to support learners' ethical decision making and action rests on an unelaborated concept of pluralism. The second is because this thesis argues for an ethically plural approach to better supporting social studies learners' understanding of social issues and responses to moral conflict.

For now, the discussion concentrates on ethical pluralism at the descriptive level - the textures and dimensions of differing conceptions of the good life in what I refer to as 'ethical space' (Poole, 1972). The central point being made here is that as society has become increasingly complex, ethical space is marked by hybridity, interpenetration and intensification. Arguably, this has always been the case; what has shifted is the academic theorising. However, as Gray (2000) argues:

In pre-modern societies, hybrid identity was a marginal phenomenon; today it is common and signifies a vitally important aspect of human well-being. In late modern societies, many people practice variations on the several traditions in which they are situated. The interpenetration of divergent, sometimes rival ethical perspectives is one of the most distinctive features of ethical life today. In few late modern societies is it sensible to count forms of ethical life. (p. 330)

To see how this is so, Roger Poole's (1972) concept of ethical space offers an initial anchor-point. His book, Towards deep subjectivity, opens by describing a photograph of three Russian soldiers being watched by Czech citizens in a public park. The scene is Prague, 1968. The USSR has occupied Czechoslovakia and deposed Dubček, the selfdescribed developer of communism with a human face. Echoing the student uprisings in France, Dubček's movement is supported by many young people challenging the grey conformity of European socialism. Conversely, the USSR is interested in re-imposing itself as the central, organising force of communism. About this scene in the park, Poole writes:

The space spread out before the protagonists of the drama is ethical space itself ... [t]here can be no flaccid action, no action which is not immediately imbued with an ethical ballast, filled in from our point of view in the world of perspectives. The meaning attributed to what goes on in the significant space before our eyes will vary according to our moral presuppositions, the partial vision we receive, the position we occupy in the perspectival world. (p. 6)

Poole uses the concept of 'ethical space' to draw attention to the underflows of this scene: its enfolded, unstated and embodied ethical dimensions. He observes two sorts of intentions, that of the Russians and the Czechs. But widening the frame would reveal, 
perhaps, this ethical space as being a 'complex ecology' (A. Rorty, 2005), marked by multiplicity in morality's demography and sociology, and variations in its tasks and purposes. The photograph does not show the popular, non-violent opposition to the invasion. Of course, not all Czechs saw the events of 1968 as an occupation nor, indeed, did all Russians soldiers view themselves as rescuing Czechoslovakia from the possibility of counter-revolution. Our attention might be, secondly, drawn to the intersections of identity - the Czech woman in the scene as perhaps also an employee, a partner, and a participant in non-violent resistance. As Amélie Rorty puts it, the 'I' and 'we' morality is speaking to has "distinctive needs, rights and obligations, different habits, priorities and virtues... [that] struggle with one another for control of our allegiances and virtues" (p. 9). Third, we could note the historicity of the park's ethical space, the ways in which morality has been drawn from past and distant places; a "palimpsest history of conquest, trade and exile that has formed our practices and evaluation" (p. 11). Fourth, we might see the park scene as an intergenerational ethical space, borne of the incubating 'moral proximity' (Bauman, 1997) of the home: "the pivotal practices of the home [which are] co-constructed by family members in their everyday face-to-face encounters, over time, in a range of possible directions" (Payne, 2010, p. 228). Fifth, as Amélie Rorty (2005) argues, we should be alert to forms of power, the ways in which institutions structure morality, and to inequality: "morality is not always addressed equally to every citizen or intrapsychic persona, each deciding for all” (p. 10). Last, and though Poole uses ethical space to describe a stand-off, it is notable that more recent usages of the concept cognise a space of negotiation, particularly between indigenous and Western ethical worldviews (Ermine, 2007; Ermine, Sinclair, \& Jeffrey, 2004; Longboat, 2010).

We shift ethical space to Occupy Wellington, a local expression of the international protest movement against the global financial system's production of inequality, and the erosion and manipulation of democracy. It is January, 2012, and the site is Civic Square, opposite the New Zealand Stock Exchange. A reporter from TV3's Campbell live ${ }^{12}$ show spends the night in the square after 104 days of occupation. In one respect the scene is a mirror-image of Prague; this time the protestors occupy the public space. Both scenes are of non-violent resistance to systems and concentrations of power. And, in writing about the Occupy movement, Judith Butler (2011) reminds us of the embodied nature of such protests:

12 http://www.3news.co.nz/Occupy-Wellington---behind-the-scenes/tabid/367/articleID/240960/Default.aspx 
When bodies gather as they do to express their indignation and to enact their plural existence in public space, they are also making broader demands. They are demanding to be recognized and to be valued; they are exercising a right to appear and to exercise freedom; they are calling for a liveable life. (p. 12)

There are, however, some important distinctions to be drawn, related to the quickening of globalisation and increased complexities of social systems. We see newer forms of activism, concurrently global and local, borne of technological possibility. Castells (2012) describes the occupiers as a multi-modal, networked movement, using "the autonomous space of flows of Internet networks to seize symbolic spaces of places" (p. 178). In the face of increasingly de-territorialised global financial and corporate systems, Occupy Wellington might be seen as an effort to re-territorialise and re-localise power. Arguably, the movement's goals are diffuse, a matter of some public and journalistic scepticism. However, Butler (2012) argues that the accelerating inequalities resulting from contemporary forms of capitalism have required new ways of objecting that draw attention to the inter-connectedness between issues - a refusal to reduce problems to a set of demands. In one important sense, the process is the message. Behind these concerns lie ethical issues that mark our times: on what basis should we oppose the effects of current global economic structures and power relations? What constitutes responsible and democratic participation in an increasingly globalised world? The Campbell live story also demonstrates how global and local ethical issues are interpenetrated. What form should the rules and relationships with other take in this camp? How should one respond to the array of ethical challenges that co-habit with the wider issues? One protester, there when Occupy Wellington was established, reflects:

You start to realise how hard it is to bring everyone together and when conflict happens what do you do? We're in a public space with people with mental disorders and alcoholism. How do you deal with that when you're trying to also build the cause?

I submit that the fact of pluralism and increased societal complexity produces not only a clattering array of ethical choices, but profound ambivalence. In many instances this ambivalence is hard to resolve; we feel torn between seemingly opposed yet meritworthy positions. What to do, for example, in the face of revelations about SodaStream ${ }^{13}$ : dispose of our fizzy-drink maker (and be wasteful of resources), continue to use it (thereby supporting the Israeli occupation of the West Bank), lobby the

13 http://www.stuff.co.nz/life-style/food-wine/9650582/Fizz-goes-out-of-blood-bubbles 
company directly, or hope that the company relocates its production site? Though some may hope or believe that there exists somewhere in the ethical ether a definitive moral compass, the reality is that moral compasses clash, melt and remould, even as we reach for them. Even the most prescriptive of ethical codes we might ascribe to do not protect us from indeterminacy, ambiguity, and nuance. Bauman (1993), in characterising these times as one of 'postmodern moral crisis', observes that:

With the pluralism of rules (and our times are the times of pluralism) the moral choices (and the moral conscience left in their wake) appear to us intrinsically and irreparably ambivalent. Ours are the times of strongly felt moral ambignity. These times offer us freedom of choice never before enjoyed, but also cast us into a state of uncertainty never before so agonizing ... In the end, we trust no authority, at least, we trust none fully, and none for long: we cannot help being suspicious about any claim to infallibility. (pp. 20-21, emphases in original).

One does not have to accept Bauman's full thesis to recognise these phenomena in our social world. But what now - a wearied cup of tea and a lie down? To acknowledge that we exist in an ethically plural and ambivalent social world is not to suggest that we give up on ethical thinking as a futile pursuit. By contrast, greater consideration of how we might proceed is perhaps no more necessary than in times of strongly felt moral ambiguity. To borrow a metaphor from Somerville (2006), when the 'ethical canary' sings of societal uncertainty and ambivalence, examining the ethical perspectives at the bottom of the mineshaft is both necessary and urgent.

\section{DEMOCRACY, EDUCATION, AND THE ETHICAL LIFE}

What business does education, particularly in democracies, have in the contemporary ethical space as previously described? Amélie Rorty (2005) argues that "philosophic theories of morality without politics and education are empty" (p. 20). How is this so? This section considers two aspects of the relationship between ethics, politics and education: the ethical intent of education and role of ethics education. I note that education is inescapably suffused with ethical intent, even including those who argue against moral education. Furthermore, to be educative, moral education must enlarge learners' ethical thinking; it must do more than simply acculturate and inculcate.

Education must in some way invite learners to debate the good life for themselves. This is particularly important in democracies, which require citizens to notice, consider the importance of, and engage with social issues that confront them and their communities, 
the vast majority of which have an ethical content. How to do so is, of course, a matter of considerable debate.

Carr (2000) notes that "human interest in moral education probably has its source in a general concern with inducting the young into socially acceptable forms of conduct, which is as old as recorded history" (p. 19). A persistent view among the many popular interpretations of the aims of moral education is that it has a necessary role in promoting conformity and ensuring societal wellbeing, that is, a means of social control (Haydon, 2003; Wringe, 2006). This runs to the heart of why many theorists have presented arguments against moral education:

The question as to whether educational institutions have the right or responsibility to present, propose, teach, or impose a moral perspective is a major point of argument throughout the history of education. (Chazan, 1985, p. 101)

Chazan presents two reasons why the diverse views of, what he terms, the 'anti-moral education school' are defensible: (a) the negative experiences of moral education need to be acknowledged, such as manipulation, imposition and loss of self, and (b) whether the world is likely to be better off with more, or different, moral education is a moot point. However, he also argues that the anti-moral education movement may well remain on the margins of educational discourse. This is because the proposed purposes of education, including the dismantling or radical readjusting of the structures of schooling, have thus far proved overly ambiguous or unpalatable. I think Chazan misses one further argument: the fact that each and every alternative presented has an inescapable ethical content. In other words, all debates about the relationship between morality and education inevitably represent varying visions of the good life; education is suffused with ethical intent. Thus, and as Haydon (2003) notes, "there is still room today for the position that all education is moral education in the sense of having an overriding moral end[s]" (p. 320). Of course, these ends are debated just as education is conceptually fluid (Hirst \& Peters, 1970) and its purposes and practices are contested (Egan, 1997; Standish, 2003).

Perhaps the least controversial answer to the question of the purpose of education is that it is to enable students to live a worthwhile life within the societies in which they find themselves. It begins with the contention, attributed to Socrates, as to what a worthwhile life is not: the unexamined life is not worth living. The problem of moral education then becomes: 
Primarily that of how individual human lives might acquire meaning and purpose through the recognition and appreciation of a significant moral dimension to human experience which can serve to enhance personal life and growth. (Carr, 1999, p. 24)

What a meaningful and purposeful life consists of is not attempted here; controversy and complaints of proselytising would no doubt ensue. Rather, I acknowledge that the varying projects of contemporary moral education cognise something more than osmotic inculcation via indirect socio-cultural factors and mechanisms of socialisation (such as the mass media). Morality is undoubtedly 'caught' and emerges, moment-by-moment, in the routine relationships and practices of schooling and everyday life. However, moral education as it is construed today involves teachers' conscious influence on their students' responses to social influences (Haydon, 2003). That is, it involves the intended curriculum (McGeorge, 1992). Concomitantly, the focus of this thesis is on what is 'taught' rather than 'caught', though I stress that intended moral curriculum is not divorced from the classroom climate, school ethos and wider societal discourses. So to approach the least controversial answer suggested above we, as educationalists, must at least attempt to teach ways of reflection, ways in which learners might approach at a personal and societal level, the question of what a good life consists in. Following Colin Wringe, I contend that ethical education's central aim is to enable learners to respond to questions "in a considered and well-informed manner, rather than in terms of simplistic reactions to one's own or other people's choices, actions, attitudes or beliefs" (Wringe, 2006, p. 18). Indeed, this is an expectation of democratic societies because they "not only sustain multiple forms of life but engage in continual contestation about which versions are most consistent with the public good" Jasanoff, 2002, p. 269). While democracies have their necessary forms of socialisation, a founding proposition of this thesis is that, to be democratic, education needs in some way to invite learners to debate the good life. In Glass' (2009) view:

Public schools (as the institution charged with the forming citizens of the state) must build loyalty both for and against the state and the institutions of society. Schools must build the capacity for moral and political conflict into the very nature of citizenship (p. 27, my emphasis)

To take this further, democracy depends on the capacities of critical thought and deliberation because it "can only sustain its truth by keeping alive the question of what democracy is, by way of its necessary voice within" (Standish, 2003, p. 229). And it is 
schools that cultivate those voices within, learners who are able to think for and against democracy.

This is, of course, a politically contentious view, even within democratic nations, and at times the proper relationship between education, politics and ethics is vociferously contested. We have seen in recent years, for instance, considerable debate in New South Wales, Australia, over the introduction and content of a course in ethics ${ }^{14}$, offered as an alternative to primary school religious education (Cook, 2013; Jensen, 2009; Knight, 2010; Longstaff, 2010). In the New Zealand context, Roger Openshaw (2000) comments that "as in the United States and elsewhere, for broadly similar reasons, social studies remains a moral and ideological battleground for the major players involved in curriculum reform" (p. 65). Frazer (2008) reminds us that the political nature of citizenship education has "the power to exclude, or ignore, other moral claims" (p. 289). 'Minimal' and 'maximal' conceptions of citizenship education (McLaughlin, 1992) provide a useful illustration of how this is $\mathrm{so}^{15}$. Minimal views tend to cultivate democratic voices through providing information about civic life and developing students' commitment to a shared democratic culture. One objection to this is that "it may involve merely an unreflective socialisation into the political and social status quo, and is therefore inadequate on educational, as well as other grounds" (n.p.). A more maximalist or 'thick' conception reaches for an understanding of public virtues substantial "enough to satisfy the demands of commonality, but which combines respect for the important role of independence and critical reason for individuals and the demands of justice relating to diversity" (n.p.). This account is equally open to critique on the grounds that a commitment to the examined life through encouraging learners to think against democracy may exceed the principled consensus on which the democracy rests. Each end of the continuum, therefore, represents the assertion of particular moral claims - different conceptions about the proper relationship between democracy, education, and the good life. Because such theoretical tensions are very often glossed over, a number of educators have urged that a political, philosophical, and ethical analysis be brought to bear on citizenship education (see, for example, Frazer, 2008; Openshaw \& White, 2005).

\footnotetext{
14 Now a mandated programme, called Primary Ethics: http://www.primaryethics.com.au/

15 McLaughlin cautions against drawing too simplistic a distinction between these categories. Contemporary descriptions of citizenship education are typically supple; most writers in the field would argue that citizenship theory and education are not reducible to simple binaries.
} 
Such contentions notwithstanding, it is arguable that democracy proliferates the possibilities for moral education. It is notable that moral education's variations are manifold in democratic societies, reaching back into debates in fields such as philosophy, sociology and psychology. In a useful overview of USA and UK approaches, Noddings (2007) notes, for instance: (a) the influence of Aristotelian thinking in virtues and character education, (b) echoes of Kant in Kohlberg's moral reasoning, (c) the utilitarian thrust of courses dedicated to ethics as a philosophic inquiry, and that (d) the more recent 'values clarification' approach is strongly reflective of Dewey's thinking. Haydon (2003) suggests that responses to the question about the content of moral education have had at least two variants, each of which has had its critics. Rationalistic accounts (of which a-c above are examples) focus on developing the skills of independent reason in line with much post-Enlightenment moral philosophy. This "readily cohered with a broader liberal emphasis on individual liberty, including freedom of thought" (p. 322). Yet, such accounts have traditionally said little about the role of feelings, motivation and behaviour, and have downplayed the influence of context and societal expectations. A stronger influence on the philosophy of moral education in the last three decades, and certainly the programmes offered in New Zealand schools (Keown et al., 2005), is that of virtues/character education, which has attempted to capture the multidimensionality of ethical life. On this account, a virtues approach "can enable us to give a better and more comprehensive account of an ethical life in which rationality and other aspects are seen in balance" (Haydon, 2003, p. 325).

However, Haydon (2003) notes that both variants face challenges related to their acceptability within plural and multicultural societies; arguably, this is the case across all visions for moral education. To what extent should learners be able to enact the principles they have developed through reason? Should the virtues nurtured in special character schools be considered a model for all? To what extent should a public education enable the cultural and moral continuity of diverse communities? Susan Verducci (2009) reminds us that the nexus of democracy, education, and moral life is as much a space of contradiction as it is accommodation of diverse visions for the good life. She argues that moral citizenship in democracies "requires a stance that recognizes complexities and oppositional forces at play. It requires a stance that allows one to see clearly and to recognize the haze in the same instant" (p. 7). To answer the question posed at the beginning of this section, this is precisely the sort of business that education has in contemporary ethical space. 


\section{CONCLUSION}

This chapter has provided the context for the work of the thesis in a number of ways. I have established the sense in which ethics and a number of other related terms are used throughout the thesis. In particular, I have sketched a contemporary ethical landscape in our everyday lives, in society, and in theory - that is by nature plural, complex, and changing. This landscape inevitably works its way into education which is then expected to, in some way, support learners to navigate the uncertainties and ambivalence of ethical life. This discussion is an important backdrop to the work of the thesis because it establishes the difficulties of providing a blueprint for ethics education - just as there are no simple answers to ethical questions, there are no easy educational responses. However, such is the centrality of ethics to learners' lives and the challenges they face that some kind of educational response is commanded. The chapters that follow defend a broad theoretical orientation to ethics education, appropriate to the purposes of social studies as I see them. While some pedagogical ways forward are offered, the reader will note that there is not an attempt here to produce a 'ready-to-run' package. The spirit of this thesis is very much in line with the themes that have been introduced in this chapter - an attempt to reveal, explore, and open up dialogue about a challenging aspect of social studies education, acknowledging that my proposal rests in particular moral claims. 


\section{CHAPTER THREE: HOW CENTRAL IS ETHICS TO SOCIAL STUDIES?}

Chapter Two established that education has a central role in enlarging learners' ethical thinking so that they may better navigate the complexities and vicissitudes of their social worlds. This chapter connects this thesis' key foci: ethics and social studies. In order to establish a rationale for the central research question, the chapter begins by asking how central ethics is to New Zealand social studies education. Additionally, and given that supporting learners' ethical decision-making and action is a cross-curricular expectation of The New Zealand Curriculum (Ministry of Education, 2007), the discussion considers whether social studies might be justifiably considered a 'natural home' for ethics education. The chapter then introduces the first of my research sub-questions: what opportunities for ethical decision-making and action are offered through New Zealand social studies curriculum documentation? Having noted the lack of curricular explication for ethical decision-making and action in the introduction to the thesis, the substantive part of this chapter uses a form of concept analysis to map a conceptual field of meanings that have been built up in New Zealand social studies curricula over time, into which ethics, its cognates and proximal terms have been inserted. The chapter closes with a discussion of what ethical decisionmaking and action is most likely to mean in the context of the New Zealand social studies curricula, and conceptual moves that are yet to be made.

\section{IS SOCIAL STUDIES A NATURAL HOME FOR ETHICS EDUCATION?}

Why consider ethics in relation to social studies education? One reason is because the Values section of The New Zealand curriculum, which outlines values that are "to be encouraged, modelled and explored” (Ministry of Education, 2007, p. 10) requires teachers of all learning areas to do so. Among other values, "students are to be encouraged to value integrity, which involves being honest, responsible, and accountable and acting ethically" and that "through their learning experiences, students will develop their ability to make ethical decisions and act on them" (p. 10). The V alues statement is part of what is colloquially termed the 'front end' of New Zealand's curriculum, containing the vision, principles, values, and key competencies that span all learning areas. The social sciences learning area and social studies within it are therefore but one of eight charged with giving expression to the Values statement and its ethical content. New Zealand is not alone in seeing ethical decision-making and action as an important cross-curricular expectation. The Australian curriculum (Australian Curriculum 
Assessment and Reporting Authority, 2014), for example, positions ethical understanding as a cross-curricular capability, with the following rationale:

Ethical understanding involves students in building a strong personal and socially oriented ethical outlook that helps them to manage context, conflict and uncertainty, and to develop an awareness of the influence that their values and behaviour have on others. (n.p.)

Another reason to consider ethics in relation to social studies is that numerous educators have already identified a connection, albeit with varying degrees of emphasis. One can discern a sheaf of connections to ethics across a host of pedagogical approaches that have been advocated for social studies. For example, Kohlberg's moral reasoning approach, character education, and values clarification have all inflected New Zealand social studies education over time. We have also seen the influence of the Philosophy for children community of inquiry approach (Burgh et al., 2006; Lipman, 2003; Pritchard, 2014; Splitter \& Sharp, 1995), a dimension of which is ethical inquiry. In Australasia, this approach has been strongly advocated for social studies (see, for example: Collins \& Knight, 2006; Golding, 2005; Knight \& Collins, 2010a). Other authors have noted that the types of issues, arguments and evidence attended to in social studies classrooms may be ethical in nature (see, for example: Hess, 2009; Lockwood \& Harris, 1985). Still others have considered the relationship between ethics and the aims of social studies, particularly reflective and affective outcomes (H. Barr et al., 1997; Burgh, 2004; Hill, 1994; Zevin, 2007). Indeed, a profoundly ethical orientation is detectable in the questions that numerous social studies educationalists argue the subject should be directed towards:

[Social studies] enables one to ask such important questions as, What is the good society? What is the good person? What obligations do I have to the ideals and people of the past, present, and future? What is the proper relationship between the individual and the state? How and to what extent should I be involved with people and institutions on this globe? To what extent is our civilization likely to endure? What values do we wish to preserve? What heritage should we leave for future generations? (Hartoonian \& Laughlin, 1989, p. 389)

Those social studies educators who have not expressly articulated the connection between social studies and ethics would no doubt see it as axiomatic. One can understand why: I submit that all visions for social studies education are imbued with an ethical content. That is, each and every theoretical orientation advanced rests on particular ethical perspectives. To illustrate, I draw on the influential work of R. D. Barr, 
Barth, and Shermis (1978) who identified three traditions that have shaped social studies' aims and content over time: social studies taught as citizenship transmission, reflective inquiry, and social science. This work has significance for the New Zealand context because it was taken up by the Waikato position paper's authors (H. Barr et al., 1997) as an organising framework for understanding the likely influences on social studies curriculum development in this country. These authors added one further tradition: social studies taught for the development and empowerment of the personal and ethical self. While orientations to social studies education have, of course, been expressed in other ways ${ }^{16}$, I employ the Waikato position paper's 'four traditions' heuristic throughout this thesis.

What might be the ethical content of each of these four traditions? The first, social studies taught as citizenship transmission, is overtly directed towards the inculcation of ethical norms such as a commitment to democratic rights and responsibilities, faith in societal institutions, and pride in national heritage and traditions. By contrast, social studies taught as reflective inquiry appears ethically neutral in that it tends to emphasise the development of critical thinking and reasoning skills that allow normative propositions and values to be placed under review. However, teaching in this tradition is no less devoid of ethical content than citizenship transmission because ethics, although not explicitly included, remains inexplicitly within the ambit of reflection. The third tradition, social studies taught as a social science, might at first glance seem similarly silent on ethical matters because of an emphasis on objective knowledge framed as laws, principles, and generalisations (H. Barr et al., 1997). Yet, the universal truth approaches in this tradition bear the imprint of Enlightenment thinking, the moral content of which emphasises social change through human rationality (Noddings, 2007). Further, ethical perspectives are a feature of all cultures and societies, an object of study in the social sciences, manifesting as differences in values, social mores, and cultural preferences. The fourth tradition, social studies taught for the development and empowerment of the personal and ethical self, has strong commitment to open reflective inquiry. Yet, at the end of the day, it is directed towards particular moral ends:

The goal of Social Studies is the empowerment of the social and ethical self, resulting in a person critically loyal to democratic society, and therefore committed, not just to private or sectional goods, but to the common good ... students acquire the capacity to interrogate their own cultural conditioning, and be encouraged to embrace beliefs and

16 See, for example: Aitken, 2004; Evans, 2004; Gibson, 2009; Gilbert \& Hoepper, 2004; Hill, 1994; Reynolds, 2009; Zevin, 2007. 
values which they have examined and judged reasonable ... schools and teachers should teach and exemplify a view of citizenship which is based on critical affiliation with their communities, while working towards the goal of a just, caring, participatory, multicultural and environmentally responsible democracy. (Hill, 1994, pp. 109-110)

I contend that an examination of any heuristic in relation to the nature and purposes of social studies education would reveal not simply matters of pedagogical preference but of differing conceptions of the proper relationship between learning and society. As R. W. Evans (2010) points out, the perennial debates over social studies' purposes are intrinsically ethical controversies, representing "competing visions of the good society" (p. 32). Ethics is a central, integrative feature of the subject; it persists no matter which tradition or combination thereof predominates. In other words, ethics has an inescapable presence in social studies precisely because we may argue about the proper purposes of the subject. Furthermore, descriptive and prescriptive approaches are inevitably implicated in each tradition of social studies education. Even the most openended and descriptive orientations cannot be separated from decisions about what should constitute the good society - a particularly pertinent matter given the current endorsement of conceptual, reflective and critical social inquiry in New Zealand social studies education. Conversely, "normative theory itself must be based on some descriptive theory of how the world works; and, of course, normative theories influence the formation of policy and the construction of institutions" (Frazer, 2008, p. 282). The point being made here is that social studies can only be ethically null if it sets out explicitly to be so, in which case the subject would cease to do what the words imply.

Just because such unavoidable connections can be identified does not answer the question as to whether social studies is a natural home for ethics. Hill (1994) argues that "the discipline of Ethics... is at least as basic to the social studies as Sociology" (p. 5). Rather more strongly, I submit that social studies has an ethical core so fundamental that to imagine the field in the absence of ethics would be to render it mute. This is because, if it were at all possible to remove the ethical content of the subject, there would be little to say about social issues or people's participation in society, two key aspects of social studies in The New Zealand curriculum (Ministry of Education, 2007). Students could not "engage critically with societal issues" (p. 30) without recourse to ethical debates and questions at some level. And they would be severely constrained in their use of the strongly advocated social inquiry methodology, in which they are to 
"explore and analyse people's values and perspectives" and "consider the ways in which people make decisions and participate in social action" (p. 30).

The temptation here might be to argue that social studies is somehow the curricular crucible for ethical thinking. Social studies does not, however, constitute the sole domain of experience, educational or otherwise, through which learners might consider ethical decisions and actions. It has been argued, for example, that the 'ethical dimension' is one of six big historical thinking concepts (Seixas, Morton, Colyer, \& Fornazzari, 2013) and, further, that disciplinary approaches are insufficient without ethics and social action being at the core of history education (den Heyer, 2012). Similarly, Peter Jackson and Doreen Massey (2005) have urged that learners' geographical thinking should be expanded by including an emphasis on geographical challenges to our ethics. A considerable body of work has emerged since the 1980s on the relationship between geography and ethics (see, for example: Popke, 2010; D. M. Smith, 2001) and, in light of some of the claims, Paul Standish (2009) has questioned the risks an 'ethical turn' poses for geographical thinking. Other subjects in New Zealand's curriculum can equally lay claim to ethics, and do. The place of ethical thinking in socioscientific issues is an aspect of the New Zealand science education literature (see, for example: B. Ryan \& Buntting, 2012; Saunders \& Rennie, 2013).

Further, a number of NCEA achievement and unit standards include ethics as an explicit focus of assessment. Appendix 3 lists the subjects that do so, and provides examples of selected standards to illustrate varying usages of ethics. Ethics may refer, for example, to procedural concerns, understanding social issues or, in the case of technology, to the discipline as a whole. In relation to this, it is perhaps important to note that there are no achievement standards for philosophy; teaching and learning in this subject in the senior school draws from a variety of standards in other subjects, including senior social studies.

Because social studies in the New Zealand curriculum is, broadly speaking, charged with enabling students to understand more clearly and participate in their social worlds $(\mathrm{H}$. Barr, 1998), it might be regarded as a natural home for addressing questions about what constitutes a worthwhile life or how we might live together. A strong overlap between social studies and ethics exists because, in response to the fact of pluralism, both are concerned with social issues and social action, or 'how should we go on?' So, just as societal controversies necessarily have an ethical content, ethics is inescapably central to 
the subject that examines such issues and responses to them. Moreover, social studies in The New Zealand curriculum (Ministry of Education, 2007) explicitly offers space to critically examine the diverse values and perspectives that contribute to societal debates. If this critical stance is to be taken at all seriously, then ethical perspectives should be available for learners' consideration, a matter that I will say more about in Chapter Four.

\section{LOCATING ETHICS IN NEW ZEALAND SOCIAL STUDIES}

This chapter has thus far established that ethics and the nature and purposes of social studies are inextricably linked. The fact that The New Zealand curriculum (Ministry of Education, 2007) has signalled that, through the cross-curricular intent of the Values statement, ethical decision-making and action is part of the proper content of social studies education adds weight to this contention. Given the sheaf of connections identified in this chapter thus far, one might safely assume that New Zealand social studies teachers have plenty to guide them in relation to the expectation that they support their students' ethical decision-making and action. The bulk of what follows tests that assumption through exploring how ethics has been expressed in the history of New Zealand social studies curricula and mandated support documents. This is important to the work of this thesis because it establishes whether the central research question is warranted; social studies teachers may be already well supported in interpreting what ethical decision-making and action is to mean. It also begins a consideration of the first of my research sub-questions: what opportunities for ethical decision-making and action are offered through New Zealand social studies curriculum documentation?

\section{MAPPING THE CONCEPTUAL FIELD: ETHICS IN PAST NEW ZEALAND SOCIAL STUDIES CURRICULA}

The analysis presented in the following sections reflects C.E. Beeby's ${ }^{17}$ (Alcorn, 1999) and Roger Openshaw's (2004) insistence that understanding a curriculum's antecedents is pivotal to making sense of its present content. Yet, I am careful not to infer a seamless, linear or cumulative history of curricular re/presentations of ethics. This point

17 An influential New Zealand educationalist: http://en.wikipedia.org/wiki/C._E._Beeby 
is underscored by Colin McGeorge (1992), who notes that the experience of moral education in New Zealand has been as much that of continuity as it has transformation: when one consults past curricula, school practices and educational resources "there is much that is immediately familiar to the historian and much that is familiar on reflection" (p. 52). Virtues ethics, for example, has had a longstanding role in New Zealand social studies education. I therefore take Davis' (2004) point that concepts need to be understood within a changeable, web-like crossing and re-crossing of sensibilities: Concepts do not emerge through successive generations. Critical moments in the evolution of an idea can occur at any time as branches flourish, atrophy or fuse. Hence, the emergence of a cluster of ideas, such as contemporary conceptions of teaching, cannot usefully be interpreted or represented in terms of any sort of chronology. (p. 3)

Acknowledging such fluidity and complexity, what can sensibly be achieved through an analysis of past social studies curriculum statements? After all, what is contained in curriculum documents is unlikely to map directly onto the usage within the social studies community. Whether or not concepts such as ethics, values, and morals have been present in past curricula, for example, will not have fully determined social studies educators' lexicon. And there is no guarantee that particular terms have been used advisedly; it may well be that a content analysis imputes far more meaning than was ever considered by curriculum writers. I think we can at least gain some insight into curriculum intentions, that is, how curriculum writers have historically cognised the relationship between ethics and social studies. One can establish semantic dis/continuities through analysing the traces, interconnections, divergences and spaces for meaning in previous curricula. My argument here is that over time a conceptual field of meanings has been built up in New Zealand social studies education into which a phrase such as ethical decision-making and action has been inserted. This conceptual field contains numerous proximal terms and phrases, such as morality or social decision-making, themselves shifting in meaning. A consideration of the relationships within the conceptual field helps to discern a definition of sorts for ethical decision-making and action in the present context of social studies education. 
Davis' (2004) point presented in the previous section notwithstanding, the texts selected for analysis are presented chronologically. I begin with the Syllabus of instruction for primary schools, 1928 (Department of Education, 1928) ${ }^{18}$ which was still in usage in the 1940s and therefore provides a backdrop to the inception of social studies. This, of course, does not mark the beginning of an ethical content in New Zealand education; indeed much of the 1928 syllabus had its origins in nineteenth century thought (J. McGee, 1998). Five key clusters of documents that represent critical moments in the history of social studies are subsequently analysed, grouped around the report that first recommended social studies as a subject and four subsequent curriculum statements (Department of Education, 1977a; Ministry of Education, 1961, 1997, 2007). Mandated support documents are included in the analysis where they provide elaboration of ethics, its cognates or proximal terms in relation to the social studies curriculum.

\begin{tabular}{|c|c|c|c|}
\hline Cluster & Documents and notes & $\begin{array}{c}\text { Pages } \\
\text { analysed }\end{array}$ & $\begin{array}{l}\text { Estimated } \\
\text { word count }\end{array}$ \\
\hline 1 & $\begin{array}{l}\text { The post-primary school curriculum: Report of the } \\
\text { committee appointed by the Minister of Education in } \\
\text { November, } 1942 \text { (the Thomas Report, Department } \\
\text { of Education, 1944) which first recommended } \\
\text { social studies as part of the common core in the } \\
\text { post-primary school curriculum. } \\
\text { - The primary school curriculum revised syllabuses: Social } \\
\text { studies in history and geography (Department of } \\
\text { Education, 1948). This predates the inception of } \\
\text { an integrated approach to social studies } \\
\text { education. }\end{array}$ & $\begin{array}{l}\text { pp. 1-9, 14-15, } \\
22-29,48-50\end{array}$ & $\begin{array}{l}19,900 \\
\text { words }\end{array}$ \\
\hline 2 & $\begin{array}{l}\text { - Syllabuses for schools: Social studies in the primary school } \\
\text { (Ministry of Education, 1961); the first full social } \\
\text { studies syllabus. } \\
\text { - Suggestions for teaching social studies in the primary } \\
\text { school, a series of four handbooks published in } \\
1962 \text { and subsequently assembled as one edition } \\
\text { (Department of Education, 1971) with minimal } \\
\text { alterations. }\end{array}$ & $\begin{array}{l}\text { All } \\
\text { pp. } 7-33 \\
\text { NB: } \\
\text { pagination } \\
\text { refers to the } \\
1971 \text { edition }\end{array}$ & $\begin{array}{l}11,800 \\
\text { words }\end{array}$ \\
\hline 3 & $\begin{array}{l}\text { - Form } 14 \text { social studies syllabus guidelines } \\
\text { (Department of Education, } 1977 \text { a). The } \\
\text { guidelines for Forms } 1 \text { and } 2 \text { replaced those } \\
\text { provided in the } 1961 \text { syllabus. } \\
\text { - Faces 4, } 5 \text { and } 6 \text { (Department of Education, } \\
\text { 1978, 1981, 1983), three of a series of booklets } \\
\text { designed to help primary teachers re-interpret } \\
\text { the } 1961 \text { syllabus in light of the } 1977 \text { statement. } \\
\text { - Social studies forms } 3 \text { and } 4: \text { A handbook for teachers } \\
\text { (Ministry of Education, } 1991 \text { ) which offered a }\end{array}$ & $\begin{array}{l}\text { 4: pp. } 2-10 \\
\text { 5: pp. } 2-13 \\
\text { 6: pp. } 2-15 \\
\text { pp. } 1-51\end{array}$ & $\begin{array}{l}3,000 \text { words } \\
3,900 \text { words } \\
5,500 \text { words } \\
\text { 21,200 } \\
\text { words }\end{array}$ \\
\hline
\end{tabular}

${ }^{18}$ pp. 5-7, 31-41, 63-65, 147-164. Approximate word count: 19,400 words. 


\begin{tabular}{|c|c|c|c|}
\hline Cluster & Documents and notes & $\begin{array}{c}\text { Pages } \\
\text { analysed }\end{array}$ & $\begin{array}{c}\text { Estimated } \\
\text { word count }\end{array}$ \\
\hline & $\begin{array}{l}\text { "tighter definition of the areas for study and of } \\
\text { the desired outcomes in terms of knowledge and } \\
\text { skills" (p. 1) than its } 1977 \text { precursor. }\end{array}$ & & \\
\hline 4 & $\begin{array}{l}\text { - The New Zealand curriculum framework (Ministry of } \\
\text { Education, 1993) } \\
\text { - Social studies in the New Zealand curriculum (Ministry } \\
\text { of Education, 1997) }\end{array}$ & $\begin{array}{l}\text { pp. } 1-9,14, \\
17-28 \\
\text { pp. } 5-58\end{array}$ & $\begin{array}{l}8,700 \text { words } \\
14,700 \\
\text { words }\end{array}$ \\
\hline 5 & $\begin{array}{l}\text { - The New Zealand curriculum (Ministry of } \\
\text { Education, 2007). } \\
\text { - Building conceptual understandings in the social sciences: } \\
\text { Approaches to social inquiry (Ministry of Education, } \\
\text { 2008a). }\end{array}$ & $\begin{array}{l}\text { pp. } 4-17,30, \\
34-44, \text { fold } \\
\text { out charts for } \\
\text { social sciences } \\
\text { pp. } 2-17\end{array}$ & $\begin{array}{l}10,200 \\
\text { words } \\
\text { 5,200 words }\end{array}$ \\
\hline
\end{tabular}

Two further points may be made about this text selection. First, and given all curriculum statements are informed by their context, to the extent that is possible I position the texts selected here within local and trans-local discourses that have shaped the development of New Zealand social studies education. There is not the space to include a detailed account of the periods between publications of the curriculum statements listed above but I have attempted to draw on numerous histories of social studies education, and moral and values education in the wider curriculum, which have charted the troubled waters of curriculum development and intercession. Second, and bearing in mind that ethics education, however expressed, may be specified in cross-curricular terms, I have analysed general introductions to the curriculum statements and/or overarching curriculum statements where they apply to social studies education. 
The approach used here is a form of content analysis, classical variants of which involve identifying, through a process of coding, concepts, themes or variables in text $(G$. W. Ryan \& Bernard, 2000). The researcher may code for the existence or frequency of explicit and/or implicit instances of these categories. Given that methodological approaches to content analysis vary widely (see, for example: Hsieh \& Shannon, 2005; Stemler, 2001; M. D. White \& Marsh, 2006) and may be employed within both quantitative and qualitative research paradigms, it behoves the analyst to "make public the basis for the sampling and analytic choices... [and ensure that the] culminating interpretations are tied to these revealed procedures" (Thomas, 1994, p. 694). Further, it is vital that the assumptions (philosophical and otherwise) underpinning the strategy are made explicit (Duncan, Cloutier, \& Bailey, 2007; Paley, 1996; Risjord, 2009). Duncan et al. (2007) contend that this is particularly important if nurse professionals are to be supported to "critically examine a concept prior to its adoption into praxis" (p. 294). This contention may equally be applied to social studies teacher professional development in relation to ethical decision-making and action.

While the ontological and epistemological status of concepts and therefore conceptual analysis is a matter of considerable debate in philosophy (Margolis \& Laurence, 2014), the position I take is that concept analyses ought not to be directed towards uncovering complete or fixed meanings; I am particularly sensitive to the defensible critiques of content analysis that point to reductionism and foundationalism (Thomas, 1994). By contrast, respectable lines of argument exist in philosophical literature defending the idea that concepts are theory-dependent or discursive in nature, and thus might be understood as contextual, changeable and contestable (Milligan \& Wood, 2010). This section does not therefore offer the kinds of content analyses aimed at concept correction or advancement, or statistical reliability or validity. What is undertaken is simply aimed at identifying and understanding a conceptual field - how ethics is elaborated and related to a range of allied concepts in successive social studies curriculum statements. I seek to establish the kinds of trends, relevancies and contradictions that may be observed within and across these documents and, moreover, the silences or kinds of movements that do not appear.

The approach adopted here is analogous with 'summative content analysis' (Hsieh \& Shannon, 2005) which begins by identifying occurrences of, in this case, ethics and its 
cognates and then extends to include concept frequencies for allied terms. To map the conceptual field associated with ethics the following were coded for:

a) explicit mention of ethics and its cognates;

b) mention of ethics as a contributing discipline to social studies; and

c) the existence and frequencies of proximal terms that stand in place of ethics, such as morals, values, social decision-making and social action ${ }^{19}$. These are plainly used in an ethical sense and, from their context, bear an ethical weight. This includes examples of particular virtues, either said to be or plainly implied.

Summative content analyses usually report concept frequencies in relation to other variables (such as the roles or ages of interviewees). The frequencies for (a)-(c) above are reported against the publication date of each document. A move into latent content analysis is made in three ways. First, snippets of text, or illustrative examples, convey the sense in which ethics or proximal terms were used and how they articulate with each other, that is, the conceptual company that they keep. Second, the analysis is, as much as space allows, set within historical events and curriculum debates. Third, and in order to strengthen this contextual analysis, I additionally coded for concepts that:

d) convey societal controversy, complexity and diversity;

e) imply an ideal society, such as citizenship and democracy (these concepts are in part process);

f) have a bearing on the degree of critical and creative thinking expected from students; and

g) convey affect and/or appreciation of affect in others, including spirituality and beliefs.

The concept frequencies are presented in Appendix 2. The second and third columns of this table present the concept frequencies for (a)-(c) and (d)-(g) respectively. For reasons of space, examples of virtues, part of coding category (c) are included in a fourth column. Three further points may be made in relation to (c). First, bearing in mind the integral nature of ethics in social studies and education as a whole, my choice of proximal terms was limited to those that most closely align with ethics; I acknowledge that this selection involves assessments of relevance. Second, and given that the texts vary considerably in purpose, length, and structure, the use of frequency coding must be regarded with some scepticism. Such a crude approach does little to convey semantic

\footnotetext{
${ }^{19}$ Not including: title pages, tables of content, headings or referents.
} 
nuances or identify terms used in the pejorative, for example. It does, however, in some small way serve to highlight those concepts that are given greatest emphasis within each curriculum statement. Third, to the best of my knowledge the only other research using a similar method has been undertaken by Paul Keown (Keown, 2001, 2003), who analysed the values content of seven curriculum documents that stemmed from The New Zealand curriculum framework (Ministry of Education, 1993). This study analysed the existence of values terms (values, attitudes, feelings, viewpoints, beliefs, ethics, and perspectives) in the aims and objectives of each curriculum. Ethics appears only seven times in these documents: technology (3), science (3) and health and physical education (1). The analysis undertaken in this chapter differs in three respects: it considers only social studies curriculum documents and over a longer time period, the documents are largely examined in their entirety and, most importantly, the purpose is to establish the meanings that might be brought to ethical decision-making and action in the context of the present social studies curriculum.

\section{SYLLABUS OF INSTRUCTION FOR PUBLIC SCHOOLS}

This syllabus provides solely for history and geography and thus predates the inception of social studies, but I begin here because teachers were to some extent still grappling with the 1928 syllabus even as the Thomas Committee was meeting. While ethics is not explicitly mentioned, ethics education is primarily couched in terms of character training and principles-based approach to moral instruction. The former receives by far the greater emphasis, reflected in the fact that concepts associated with virtues ethics (character $n=16$, virtues and moral habits $n=5$, examples of virtues $n=65$ ) far outweigh those associated with right conduct and deontological conceptions of morality ( $n=9$ ). Virtues and conduct are, however, intertwined; duties and responsibilities $(n=6)$, for example, are positioned as both a disposition and an ideal. Moreover, pupils are to develop "a sense of responsibility" (Department of Education, 1928, p. 65) through undertaking school duties. Nevertheless, the weight ascribed to virtues ethics is immediately made clear in the opening pages, in which it is stated that "the whole of school life should centre on character-training...implanting such moral habits as honesty, modesty, perseverance" (p. 6). The virtues identified are most notably those of physical and behavioural restraint, including self-reliance, self-control, and self-sacrifice - traits and strength of character which "make alike for personal happiness and racial uplift" (p. 64). Of particular note is that the history syllabus recommendations advocate the sedulous cultivation of "a strong faith in a more peaceful, harmonious, and 
prosperous world" (p. 145) and explicitly reject patriotism presented as narrow, nationalistic and fervent nationalistic allegiance.

This syllabus reflected what Judy McGee (1998) describes as a major shift in curricular emphasis leading up to the 1940s: from a perception of schools as formal organisations to microcosms of the society in which children were to be "trained for the wider service of humanity" (Department of Education, 1928, p. 64). The considerable optimism that lay behind the idea that the school, as a miniature society, could cultivate desirable characters reflected a "faith in the improvability of mankind and the inevitability of their ultimate conversion" (E. Archer \& Openshaw, 1992, p. 22). It is, however, notable the syllabus' ethical space is located primarily within the school grounds. Despite the intent that service $(n=5)$ would be enacted in ever-widening social spheres, the domains of family, public places, workplace, State and international relationships receive far less in the way of attention. Yet, within these narrow confines "nothing was left to chance" (J. McGee, 2001, p. 9). The ethos and routines of daily school life were to be deliberately and conscientiously arranged to instil a sense of duty and responsibility to their fellow man. In essence therefore, this syllabus is characterised by a strong moral transmission orientation, connoted by the notion of character-training. It is notable for example, where questioning is encouraged at all, it is "about the rightness or wrongness of a certain course of action" (p. 144), that is, with a correct moral response in mind.

In the main, however, the approach to instilling virtues was not to be direct moral inculcation; it was suggested, for example, that a desire to promote peace could be developed through participation in annual commemorations of war. The syllabus writers distanced themselves from moral lessons $(n=2)$, arguing that "set moral lessons tend to be uninteresting and tedious to children" (Department of Education, 1928, p. 6) and that much more was to be gained from example and experience. The influence of child psychology and developmental education (J. McGee, 1998) is notable in this syllabus. The character-training sections explicitly reject the notion of tabula rasa and instead speak strongly to the teacher's role in providing experiences that draw out a pupil's innate goodness, develop desirable traits and promote "growth towards higher moral ideals" (Department of Education, 1928, p. 65). The teacher is expected to model virtues, as the success of character-training "depends neither on carefully prepared lessons nor on the most vigorously applied injunctions, but on the nature of the teachers' own example and influence” (p. 64). As with the 1904 syllabus, teachers were thought of as "journeyman moralists and expected to exemplify all the conventional 
virtues rather than express a distinctive moral vision" (McGeorge, 1992, p. 44).

Vigorous injunctions are applied to the teacher, in that providing a kindly atmosphere in which the qualities of the pupil may be nurtured and emerge are positioned as an act of obligation to the State. Thus, and in contrast to the considerable focus on the pupil's character, much more is made of the teacher's duties.

One last point might be made about the way in which the history syllabus less explicitly carries the exhortations of the character-training sections. Some dimensions of history education, such as romantic stories of great men and women, are intended to exemplify "such virtues as kindness and consideration for others, courage, industry, and respect for the law" (Department of Education, 1928, p. 31). However, the concept of citizenship $(n=8)$ is used much more extensively than character and its cognates, and is named as a dimension of history education. Used in this way, citizenship is closer to what we might call civics today, that is, predominantly confined to content knowledge about social control: club and school rules, the postman and policeman, parliament and so on. The geography syllabus, heavily content focussed, uses none of the proximal terms for ethics.

\section{DOCUMENT CLUSTER 1: THE THOMAS REPORT AND THE INCEPTION OF} SOCIAL STUDIES

The Thomas report's publication was a significant historical marker for New Zealand social studies, as one of its key recommendations was the addition of the subject as part of the common core of the post-primary school curriculum. The social studies course was to be integrated, "organized around the central theme of man in society" (Department of Education, 1944, p. 24) and draw on history, geography, civics, psychology, anthropology and descriptive economics. A number of social and political forces shaped both the necessity for the Thomas report, and the committee's findings: the interwar years had seen rapidly rising school rolls, the School Certificate examination was to be given more clout as a leaving certificate in order to cater for the majority of students who were non-academic, and the Labour Government of the day desired a well-balanced education open to all (Openshaw, 1995; Shuker, 1992). Secondary education, previously oriented towards preparation for university, was now expected to "be preparatory to everyday life rather than schooling" (Department of Education, 1944, p. 8). In part, growing liberal-progressivism, lent greater impetus by World War Two, forms the backdrop to these shifts in educational ideals. This partly plays out in 
greater attention to adolescents' full development, including their emotional and spiritual worlds. The child of this report, for example, has less bodily restraint: "entitled to the full enjoyment of the high spirits of youth" (p. 7). A glint of the affective dimensions of ethical life is detectable, though never explicitly explored.

At least four important semantic shifts are discernible when one compares the 1928 curriculum with the Thomas report. It is firstly notable that the term ethics is used in this document, though only in relation to a discussion of "the sexual ethic" as an aspect of "general ethics" in the committee's physical education recommendations (Department of Education, 1944, p. 47). Second, morality and its cognates all but disappear $(n=1)$, though the report certainly conveys judgement about what is right/wrong or good/bad. We thirdly see values $(n=5)$ introduced as a concept, used in relation to democracy and spirituality. The third linguistic move is away from the language of character training. 'Character' is mentioned only once in the general aims, in which the authors suggest that education should foster such qualities as responsibility and generosity in social life, the ability to give and take, willingness to serve "and to lose themselves in social purposes greater than themselves" (Department of Education, 1944, p. 4). Yet, this is minimally elaborated in the introduction, general aims and recommendations for social studies. Notable also is the marked reduction in examples of virtuous qualities $(n=18)$. This is despite a statement (again in the physical education section) that the whole report implies that "the school should give to the development of character, and particularly to the quality of self-discipline, the central place it is always granted in theory" (p. 47).

But if one semantic shift is to both sum up the report's spirit and provide a conceptual nexus for social studies, it is an over-riding focus on democratic citizenship ( $n=18)$. It is remarkable that the 'basic', 'human' and 'essential' values of democracy are unelaborated. Nevertheless, the whole of school life was expected to run along these lines and social studies was to take a lead role. The dual purposes of the new subject were "(a) to assist the development of individuals who are able to take their parts as effective citizens of a democracy...(b) to deepen pupils understanding of human affairs and to open up wide fields for personal exploration" (Department of Education, 1944, p. 23). To be an effective citizen, the committee meant "one who has a lively sense of responsibility towards civilised values, who can make firm social judgements, and who acts intelligently and in the common interest" (p. 23). This usage of citizenship, in which adolescents are expected to exercise judgement, is therefore somewhat distinguishable from the civics thrust of 'citizenship' in the 1928 syllabus. A critical orientation was lent 
somewhat greater weight in the Social studies in history and geography syllabus (Department of Education, 1948) for primary schools. An ability to weigh evidence and think independently, for example, is linked to the expectation that they analyse the achievements and shortcomings of their district and New Zealand. Like the Thomas report (Department of Education, 1944), however, such critical thinking is not unfettered, making their communities still better to live in is as much a matter "of unselfishness and a readiness to accept responsibility" (Department of Education, 1948, p. 79). The questionable extent of this shift and the inherent ethical tensions are noted by Archer and Openshaw (1992):

Being committed to 'civilised values' and being taught to act 'in the common interest' do not appear to be self-evidently 'democratic', yet these imperatives were, presumably, to override the necessity of 'forming social judgements' should the goals conflict in any way. The citizenship transmission leopard, even in its liberal-progressive guise, still displayed its procedural spots. (p. 24)

The rationale that social reconstruction was dependent on democratic citizenship underpinned the committee's view that all School Certificate courses should offer social studies. The Thomas report (Department of Education, 1944) emphasised that recent troubling events $(n=0)$ had stimulated the need for a better-balanced education that enabled students to exercise "unceasing vigilance" (p. 5), and assist in building, defending, and extending the influence of democracy. The spirit of international brotherhood, detectable in the 1928 primary school syllabus, unsurprisingly sustained its place in the Thomas report. One can discern a concomitant widening of the ethical realm in the underpinning ethos of the report. Quoting an English White paper on post-war education, the authors suggested that the social studies ought to "arouse and quicken in pupils a livelier interest in the meaning and responsibilities of citizenship of this country, the Empire, and of the world abroad" (p. 23). Though the Social studies in history and geography syllabus (Department of Education, 1948) for primary schools did not reflect the Thomas report's vision for integrated social studies, it did carry much of the report's ethos. Notably, co-operation $(n=5)$ and the interdependence of human beings $(n=7)$ were lent even greater weight in 1948. In particular, history and geography were assigned a special place in developing world-minded attitudes and the appreciation of human connectedness, and numerous co-curricular activities are cited as opportunities for practising social living and developing co-operation. 
The Thomas report's key messages did not reach a wide audience until the early 1960s, partly because the report went rapidly out of circulation and was not reprinted until 1959. Its minimal uptake has also been variously ascribed to the attitudes and expertise of teachers, social and economic pressure for examination success, and a lack of support from the Department of Education (Openshaw, 1995; Shuker, 1992). A turning point came, however, with the publication of Social studies in the primary school (Ministry of Education, 1961) and a set of handbooks Suggestions for teaching social studies in the primary school published in 1962, later reprinted with minor alterations as one book (Department of Education, 1971). The Thomas Committee's vision for an integrated subject directed towards developing effective citizens in a democracy began to gain expression, influenced in part by an American emphasis on teaching democratic values (E. Archer \& Openshaw, 1992).

The 1961 syllabus opens with the statement that "social studies is the study of people" (p. 1), with three-fold aims: clear thinking about social problems, intelligent and responsible behaviour, and a sympathetic interest in the lives of others around the world. This direction was not without its critics and in particular a number of commentators (see, for example: Gorrie, 1963; Lockstone, 1963; Openshaw \& Archer, 1992; Stone, 1963) lamented the neglect of disciplinary approaches which, they argued, would enable students to think more systematically. Stone (1963) felt that the syllabus overstated ethical and social, as opposed to intellectual, ends. Articulating a perennial debate in moral education, he furthermore questioned the extent to which schools should be involved in character training or developing social competence. This risked, he argued, ethical imperialism. Another area of concern, at least for R.H. Lockstone (1963), was the poorly explicated nature of democratic aims, values, virtues and teaching methods. "The word democracy", he bemoaned, "is so bandied about in the social studies books that it assumes all the force of an incantation - or a charm to call fools into a circle" (p. 52). Interestingly, as Lockstone notes, the Suggestions handbooks most heavily promoted democratic means and ends $(n=14)$, whereas notions of democratic citizenry appear somewhat as a back-drop to the syllabus $(n=4)$ and only clearly stated in a brief section on social studies in the post-primary school at the back of the document.

The syllabus and suggestions handbooks contain no explicit reference to ethics, but it is notable that both refer to 'the good life'. Further, at least two dimensions of these 
documents offer some scope for students to think about ethical matters, as opposed to being inculcated with particular moral perspectives. First, a striking emphasis on social problems (1961, $n=32 ; 1971, n=16)$ undoubtedly has an ethical content, to the extent that students are permitted to explore the contested nature of their social worlds. Students are, for example, expected to evaluate differing ideas, appreciate viewpoints other than their own $(1961, n=3)$ and discover others' beliefs about the good life (1971, $n=1)$. Thus, we see in this document the inception of a trend towards values analysis in descriptions of the purposes of social studies education ${ }^{20}$ (Aitken, 2005b). In one report of exemplary teaching practice - a teacher's discussion lesson about what constitutes a good man - the students concluded that "there might be varying standards of goodness, for different peoples, and at different periods" (Department of Education, 1971, p. 242). The sense that students might explore differing perceptions of what constitutes the good life is strengthened by the fact that the syllabus and handbooks place greater weight on critical, clear, and open-minded thinking $(1961, n=7 ; 1971, n=10)$ than in the past. One must be a little cautious however about how synonymous these terms are. Moreover, little is said about how students are to address social problems other than the expectation that students will act intelligently $(1971, n=7)$ and responsibly $(1971, n=9)$.

The second opportunity for exploring ethical dimensions of people's lives comes through a very evident emphasis on social studies taught for the development and empowerment of the personal and ethical self (H. Barr et al., 1997). The syllabus states that the subject's aims "sum up a number of aspects of personal development to which all other subjects, and indeed the whole of school life contribute" (Ministry of Education, 1961, p. 3). Reprising the expanding universe model advocated in previous documents, personal development was to be achieved through programmes that enlarge and deepen children's experience and understanding beyond their own lives. And, in an important shift from the Thomas report's (Department of Education, 1944) focus on the feelings of the students themselves, references to affect $(1961, n=25)$ included understanding affect in other people - their beliefs, aspirations and pleasures. Children were to "enter sympathetically" into the feelings of peoples of other countries and "appreciate their ideas and problems" (Ministry of Education, 1961, p. 3). Compared to the Thomas report, one can detect here rather more than a glimmer of potential connection between affect and ethical decision-making, if only understood in relation to the lives of others.

20 Expressed in four New Zealand curriculum documents (Department of Education, 1944, 1977a; Ministry of Education, 1961, 1997). 
Like its predecessors, the syllabus avoids direct moral instruction. Openshaw and Archer (1992) suggest that, post war, the impact of "social meliorist-developmental links may explain why many early social studies reformers, their social concerns notwithstanding, rejected direct inculcation of values" (p. 59). However, a strong orientation towards ethical transmission and social reproduction suffuses these documents, eclipsing any latent opportunities for enlarging students' ethical thinking. The suggestions handbooks, for example, open with the statement that:

The school is an instrument of society. Its aims must always be those that society requires it to achieve. Our society requires its schools to produce responsible and competent citizens who will support its values...The competent citizen of a democratic society is one who is aware of democratic values and is both ready and able to do what is necessary to uphold those values. (Department of Education, 1971, p. 7)

One can also see an emphasis on desirable character traits, such as "generous attitudes to peoples and opinions, a determined loyalty to the truth, and strong feelings of humanity and kindness" (Ministry of Education, 1961, p. 2). Rather more strongly than the Thomas report, the suggestions handbooks clarify that personal development is to result in suitable characters because democracy is "wrapped up with the development of people, but...its very existence depends on having the right kind of people" (Department of Education, 1971, p. 8), seemingly said without irony. Additionally, lurking behind this emphasis on character is the proposition that there are standards of behaviour, such as loyalty to humanity and respect for the views of others, that students should adhere to. Indeed, the very concept of a competent citizen $(1971, n=4)$ implies some set of standards. Furthermore, when one looks at how the term 'values' is used in these documents, once again social norms are implicated: the handbooks, for example, equate the term with societal values, democratic values, or behavioural standards.

The syllabus and handbooks are, in sum, beset with ethical tensions contained in such statements as "the syllabus aims at clear thinking and good behaviour" (Department of Education, 1971, p. 18). In the same breath, students should begin to develop "their own ideals of behaviour" and feelings of loyalty to New Zealand "which will make them neither blind to its faults nor boastful of its merits" (Ministry of Education, 1961, p. 2). Stone (1963) was to particularly take issue with these contradictions, arguing that responsible and competent democratic citizenship does not amount to someone who uncritically upholds New Zealand's values. This kind of citizen, he argued, "is in fact, a faceless committee man, plucking all his ideas from the common stock" (p. 53). 
E. Archer and Openshaw (1992) note that such comments were "little heeded at the time or, for that matter, subsequently. Liberal-progressives had assumed the mantle of the traditional conservatives they had displaced" (p. 25).

\section{DOCUMENT CLUSTER 3: SOCIAL STUDIES IN THE MIDDLE YEARS}

The 1970s was marked by considerable interest in values and moral education, influenced by the values clarification approach and Lawrence Kohlberg's research on moral reasoning in the USA and, in the UK, moral education theory developed by the Farmington Trust and the Lifeline curriculum (Keown, 2001; McGeorge, 1992, 2000). In New Zealand, The Ross report and the Johnson report (Department of Education, 1973, 1977b) both reflected and stimulated considerable educational and public debate about moral and sex education. Against this backdrop, and a period of economic downturn, rapid social change and increased socio-political tensions, the Social studies syllabus guidelines: Forms 1-4 (Department of Education, 1977a) underwent a 10-year process of development. The syllabus defines social studies as being about how people "think, feel and act" (p. 4) and is structured around four "complementary and inseparable aspects": knowledge, abilities, values, and social action (p. 4). In relation to a theme for each year ${ }^{21}$, the selection of content and learning experiences is guided by itemised 'important ideas about human behaviour' $(n=11)$ which students are to develop through comparative and inquiry approaches.

The foreword to the new syllabus (Department of Education, 1977a) contends that much of the spirit of the 1961 document is retained. However, the document in fact heralded some noteworthy shifts in relation to this thesis' focus. In line with the growth of values education internationally, the language of values $(n=33)$ liberally populates the document: values and its cognates appear in nearly half the 'specific objectives' and close to a third of the 'important ideas'. Five further curricular expectations hint at the existence of ethical theories and perspectives which may inform values. The syllabus:

1. States that "social studies draws on the knowledge, ideas and methods of inquiry of social sciences and humanities disciplines" (p. 4). Thus, but while not

21 Cultural difference (Form 1), Interaction (Form 2), Social control (Form 3) and Social change (Form 4). 
expressly stipulated, this statement offers the possibility that the philosophy of ethics might be considered an underpinning discipline.

2. Makes much of the changeable and context-specific nature of values, unlike the 1960s' statements which implied fixedness in societal and personal values.

Students are expected "to accept that values conflicts exist" (p. 7$)^{22}$.

3. Gives greater weight to values awareness and analysis (Mutch, 2000). Students are to have opportunities to: consider diverse values and beliefs, develop the ability to form and clarify their own values, and attempt to resolve values conflicts through reason.

4. Advocates a consequentialist approach $(n=2)$ to adjudicating between rival values, an approach evident in subsequent documents, although an ultimate recourse to principles is also apparent (a matter I pick up on later in this section).

5. Hints at something deeper-set than values in a number of phrases. They are, for example, to understand that differences in values arising in part from different ways of seeing the world and that "all societies rank individuals on some scale of values" (p. 12).

The preponderance of values terminology was a trend that continued across Faces 5 $(n=29)$, Faces $6(n=9)$ and the Forms 3 and 4 bandbook $(n=79)$. In particular, Faces 5 (Department of Education, 1981) stands out as being dedicated to illuminating values education, and the first official document to explicitly introduce values clarification methodologies based on the work of Raths, Harmin, and Simon (1978). It was also notable for emphasising Kohlbergian moral reasoning $(n=21)$, although teachers were encouraged to critique this approach. Faces 6 (Department of Education, 1983) reiterates that students should "reason about moral dilemmas (related to their own experience) and ... consider the consequences of moral decisions" (p. 8). But by the publication of the Forms 3 and 4 bandbook (Ministry of Education, 1991) this emphasis had dropped away, leaving values as the term most closely allied to ethics.

Decision-making, problem-solving $(n=6)$ and social action $(n=13)$ emerged as three further important proximal terms for ethics in the Social studies syllabus guidelines: Forms 1-4

22 Similarly, an earlier and influential teachers' handbook (Taba, Durkin, Fraenkel, \& McNaughton, 1971) emphasised developing in students "the capability not only to expect but to evaluate change, and then to adjust to new ways and events" and "a tolerance for uncertainty and ambiguity with minimal anxiety" (p. 13). Notably, this handbook introduces ethical concern as a major criterion for measuring students' responses to exercises on attitudes, feelings and values. 
(Department of Education, 1977a). The identification of social action as being one of the four key and inseparable elements of social studies conveyed another noteworthy shift from the 1960s' documents: from clear thinking about social problems to bow such problems might be addressed and students' participation in society, consistent with the increasing view that social studies should support children "to interpret and respond to social situations rather than merely describe them" (Department of Education, 1983, p. 3). The Forms 3 and 4 bandbook (Ministry of Education, 1991) expresses an even greater sense of mindful, active contribution; decision-making $(n=7)$, social participation, and action $(n=32)$ are a strong thrust of this document. Social studies is described as partly being about how "people initiate or respond to change" (p. 5) and students are to "investigate appropriate forms of social and cultural participation in a changing society" (p. 6). The handbook also positions 'considering social action' as an integral part of an inquiry approach focussed on contemporary, controversial issues.

Another move drew together the inseparable aspects of social studies identified in the 1977 syllabus and, significantly, was to lay the groundwork for subsequent curricula. This was the delineation of valuing and social participation as skills (Department of Education, 1983; Ministry of Education, 1991). The term values exploration emerges $(n=3)$ in the Forms 3 and 4 handbook (Ministry of Education, 1991) which includes the skills of, for example, identifying and explaining values, recognising the consequences of these values, and explaining and resolving conflict that arises from differences in values. It is also notable that valuing $(n=14)$ and social participation skills $(n=10)$ are tagged to stages of inquiry. Students are to develop, for example, the valuing skill of "remain[ing] open-minded and prepared to change position on the basis of new evidence” (p. 34). This new spirit of open-ended inquiry was, perhaps unsurprisingly, tempered by prescriptive curricular stances. The Form 3 theme of social control, for instance, makes it clear that membership of a group "demands some conformity and acceptance of responsibility" (p. 16). Further, the development of 'citizenship virtues' is very clearly expected in all of the documents examined in this cluster (E. Archer \& Openshaw, 1992). Social studies is, for example, to "develop those feelings of empathy and humanity which will help them grow towards responsible participation in society" (Department of Education, 1978, p. 2; 1981, p. 4) and:

By its approach and content, aims to commit students and teachers to respect human dignity, to show concern for others, to respect and accept the idea of difference and to uphold justice. (Department of Education, 1977a, p. 5; Ministry of Education, 1991, p. 6) 
For all that these documents hint at learners' consideration of ethical decision-making and action, the enacted, emotional, embodied dimensions of ethical life are occluded by a prevailing ethos of reason, distance, and objectivity. Two points may be made in relation to this. First, E. Archer and Openshaw (1992) suggest that a Brunerian approach to the 1977 syllabus design arguably worked against students' actual participation in addressing social problems. This is because the syllabus established a pattern of strongly linking decision-making, problem-solving, and social action with critical thinking and rationality, a pattern evident right through to the 1997 curriculum. Furthermore, opportunities for social participation and taking action were very much confined to the classroom. The 1991 handbook, for example, couches the assessment of social action in terms of constructive group contribution $(n=8)$ and states that "social studies can lead students to realise that they contribute to the life of their community" (Ministry of Education, 1991, p. 6). There is not, therefore, the sense that students are to be actually involved in resolving the conflicts or solving the social problems identified in their social studies learning.

Second, the affective dimensions of ethical life flourish and wither in the curriculum documents of this period, this despite the oft-repeated mantra that social studies' overarching focus is about how people 'think, feel, and act'. The Faces documents (Department of Education, 1978, 1981, 1983) are notable for strongly foregrounding the affective domain; the term feelings appeared more frequently in Faces $4(n=12)$, Faces $5(n=44)$ and Faces $6(n=18)$ than values and its cognates. In addition, the Faces 5 opening paragraph states: "the viewpoint taken here is that thinking, feeling and valuing are closely related, and in most social studies situations children will be using all three processes" (Department of Education, 1981, p. 2). However, by 1991 this emphasis had waned considerably, a trend that was to continue in subsequent social studies curricula.

\section{DOCUMENT CLUSTER 4: SOCIAL STUDIES ACROSS YEARS 1 TO 13}

The late 1980s and early 1990s saw a quiescence of moral and values education debates, arguably as administrative reform and curriculum development took precedence (Clark, 2000). Colin McGeorge (2000) argues that conservative backlash was mitigated by Tomorrow's schools (Minister of Education, 1988) which offered school and parent communities the capacity to act at the local level. Added to this, he notes that the "disestablishment of the old Department of Education and its Curriculum Development Division also squelched any remaining official interest in, for example, Kohlberg's 
research or the Farmington Trust's theorising" (p. 62). The politically and ideologically divided nature of the 1990s has been extensively documented elsewhere (see, for example: A. O'Neill, Clark, \& Openshaw, 2004; Openshaw, Adams, \& Hamer, 2005), including the vociferous debates that centred on the development of the social studies curriculum (see, for example: Hunter \& Keown, 2001; Mutch, 1998; Openshaw, 1998; Sullivan, 2002). Hard on the heels of Tomorrow's Schools, and in contrast to the evolutionary progress that characterised previous curriculum development, The New Zealand curriculum framework (Ministry of Education, 1993) ushered in a period of rapid change in which the foundations of the current New Zealand curriculum were laid. The framework established a single overarching and outcomes-led structure for all core subjects, across all levels of the curriculum. Curriculum documents were subsequently published for individual learning areas, among them Social studies in the New Zealand curriculum (Ministry of Education, 1997). A key support document, Getting started (Ministry of Education, 1998) is briefly mentioned in this section; its content has not been closely analysed as it largely reiterates Social studies in the New Zealand curriculum through the provision of examples.

The New Zealand curriculum framework. (Ministry of Education, 1993) stresses the integral nature of attitudes $(n=13)$ and values ${ }^{23}(n=21)$ across the whole curriculum, and devotes a section to this. Interestingly, two learning area descriptors make explicit reference to ethics. In science, students are to examine ethical questions and values underlying decisions about the use of resources. With quite a different end in mind, the Health and Physical well-being descriptor encourages students to "develop personal responsibility and judgment in matters of values and ethical standards" (p. 16) ${ }^{24}$. These usages imply a degree of critical thinking but the framework most strongly emphasises the reinforcement of commonly held values $(n=15)$ and valued attributes $(n=27)$, that is, virtues. Valuing skills, for example, receives no more than a passing mention in the Essential skills section

(p. 17). By contrast, the Attitudes and values section contends that "values are mostly learned through students' experience of the total environment, rather than through direct instruction" (p. 21). It is notable that the Social sciences descriptor only lightly

23 'Attitudes' is defined in affective and dispositional terms, whereas values are described as "internalised sets of beliefs or principles of behaviour held by individuals or groups" (p. 21).

24 Across this cluster of documents, Keown (2001) identifies three types of values goals, these being that students: (a) develop valuing skills such as the ability to "make judgements using criteria and/or ethics" (p. 50), (b) are encouraged to adopt particular values, and (c) gain knowledge about values. 
incorporates the framework's attitudes and values dimension, and that the emphasis is once again on the inculcation of particular values such as "concern for social justice and the welfare of others, acceptance of cultural diversity, and respect for the environment...along with commonly valued attributes such as initiative, effort and responsibility" (p. 14). This perhaps prefigured McGeorge's (2000) observation that 1990s' values programmes were "not the resumption of the unfinished liberal business of the 1970s" but rather "their lists of values and virtues are much more reminiscent of the 1904 and 1928 primary school syllabuses” (p. 63). The vast majority of values programmes still operating in New Zealand schools appear to carry this flavour, for example: The Living Values Project, The Cornerstone Values Project, The Virtues Project and The New Churches Education Commission Programme (Keown et al,, 2005).

Ethics is once again unmentioned in Social studies in the New Zealand curriculum but, interestingly, does appear in its revised draft (Ministry of Education, 1996) in which it is stated that students will examine "ethical principles as they apply to specific decisions and events in the past and present, developing generalisations about ethical behaviour” (p. 23). Quite what is meant by ethical principles is unclear, and the expectation's ambiguous nature may well have led to it being dropped out in the final version. However, and in stark contrast to The New Zealand curriculum framework (Ministry of Education, 1993), one move affirmed and considerably amplified the valuing, decision-making and social participation aspects of the Forms 3 and 4 handbook (Ministry of Education, 1991). This was the crystallisation of social studies skills into three inter-related processes - inquiry, values exploration, and social decision-making became leading features of social studies curriculum design. Values $(1997, n=12)$, values exploration $(n=10)$, social decision-making $(n=44)$ and social participation $(n=60)$ now received considerable emphasis, albeit with a noticeable softening from 'social action' to the rather less critical, controversial and active terms such as social decision-making (Wood et al., 2013).

Nevertheless, the coalescence of at least five features of Social studies in the New Zealand curriculum (Ministry of Education, 1997) offered more potential for learners to consider ethical decision-making. When read together, these features engender a greater sense of contentiousness and criticality. Moreover, the potential for ethics to occupy a more explicit space in social studies education is moved considerably further forward than previous curriculum statements: 
1. Picking up social studies' longstanding focus on social problems, we see the burgeoning use of issues $(n=44)$, around which inquiry, values exploration and social decision-making processes are built.

2. There is a much stronger sense of evaluation $(n=14)$ and judgement, both throughout the curriculum and built into the values exploration process. The definition for values includes "judgements about what is valuable or important in life" (p. 58, my emphasis); students should now be "challenged to think about the nature of social justice” (p. 17) rather than accept concern for social justice as a commonly held value; and Getting started provides a direct injunction that the values exploration process "is not a context for the formal teaching of a set of values" (Ministry of Education, 1998, p. 15).

3. The values exploration process indicators give an even stronger inkling than the 1977 syllabus that something lies deeper than values. Students are, for example, to: "use criteria to evaluate a range of solutions" (Ministry of Education, 1997, p. 53); "establish criteria to evaluate values positions" (p. 54); and "explain how people prioritise values positions in order to come to a decision about action" (p. 55).

4. In a move that was to take on more significance over time, perspectives $(n=24)$ is introduced as a new term, although undefined and arguably represented more as categories than clearly delineated positions (for example, multi-cultural perspectives and perspectives on current issues) ${ }^{25}$.

5. The curriculum contains the most promising indication that the philosophy of ethics might be among social studies' contributing disciplines. Like the previous syllabus, the subject is described as "the systematic study of an integrated body of content drawn from the social sciences and the humanities" (p. 7) but here the glossary specifically lists philosophies as being part of the humanities (p. 57).

Despite these moves, the inescapable and unconscious socialisation into ethical life, common to all the documents examined here, is once again evident in Social studies in the New Zealand curriculum (Ministry of Education, 1997). An example of this is contained in the highly contentious nature of this curriculum's development, characterised by Hunter and Keown (2001) as being between two dominant discourses: one "calling for an open,

\footnotetext{
${ }^{25}$ Neither Getting started nor The New Zealand exemplars: Social studies (Ministry of Education, 2004) were to shed much light on this; however, the latter did clarify that 'bicultural perspectives' included a range of stories, commentaries and contemporary voices of tāngata whenua, thereby underscoring the multiplicity of Māori perspectives.
} 
inclusive, negotiated, and liberal-democratic kind of social studies curriculum [and the other] favouring more sectarian (neo-liberal), closed (Eurocentric), and educational conservative social studies" (p. 56). One can see in The New Zealand curriculum framework (Ministry of Education, 1993) an inkling of the furore that was to surround social studies. The framework makes much of the international labour market and trade relationships, reflective of a widely documented and debated backdrop of neo-liberal reforms. The ideal student of this framework is not just a responsible democratic citizen, but one who can participate effectively and productively in a competitive world economy. Almost in the same breath, the framework makes an express commitment to inclusive education, with a strong rights orientation. It is stipulated that "all programmes will be gender-inclusive, non-racist, and non-discriminatory" (p. 7). The critical point here is that both discourses make students' ethical commitments for them, a priori. For this reason, Keown (2001) argues that the framework placed too great an emphasis on encouraging particular values, "without linking this to the need to think critically about the wide range of values and perspectives in society" (p. 51). Of course, and as has been stated previously in this chapter, Social studies in the New Zealand curriculum's (Ministry of Education, 1997) subsequent commitment to critical thinking about values and social decisions may equally be regarded as just an unquestioned good.

Both discourses identified by Hunter and Keown (2001) were to inflect Social studies in the New Zealand curriculum (Ministry of Education, 1997), which the authors describe as being ultimately a compromise position. However, this can by no means be seen as a resolution of the ethical tensions contained within the curriculum. While the curriculum makes little mention of the social studies learners' characters, there is a notable emphasis on rights-based ethics $(n=37)$, consequentialism $(n=35)$, and principles-based ethics encapsulated in terms such as principles $(n=2)$, standards $(n=2)$ and responsibilities $(n=22)$. It is unclear therefore which ethical perspectives learners are to bring to bear on the social issues under consideration in their social studies lessons ${ }^{26}$. This point is very clearly underscored in the Education Forum's ${ }^{27}$ (1996) submission on the curriculum's revised draft (Ministry of Education, 1996), much of which is arguably pertinent to the final version. Though the Forum's submission was given limited credence by many social studies educators, perhaps for ideological reasons, it does at least point to the contestable nature of values, debates about the limits of freedom in plural societies, and

26 Social studies in The New Zealand curriculum (Ministry of Education, 2007) again emphasises rights ( $n=8$ ), responsibilities $(n=7)$ and consequences $(n=8)$. This may have rather a reductive effect on social studies learners' ethical thinking.

27 An arm of the New Zealand Business Roundtable. 
the priority we may give to ethical principles when making judgements. The author, Geoffrey Partington (see also, Partington, 1998), argues, for instance, that if we are to support the right to hold different values, then we must have higher regard for societies that provide the freedom to do so. Although this position is debatable and there is much to be said against the Forum's advocacy of 'contingent moral relativism', the submission is significant in its acknowledgement of ethics' relevance to curricula.

DOCUMENT CLUSTER 5: SOCIAL STUDIES IN THE PRESENT NEW ZEALAND CURRICULUM

The last mandated document published in relation to Social studies in the New Zealand curriculum was The New Zealand curriculum exemplars: Social studies (Ministry of Education, 2004). This supported teachers to identify learning, achievement and quality in relation to levels 1 to 5 of the curriculum. The exemplars firstly clarified the essence of social studies and the conceptual focus of the achievement objectives so that teachers could be clear about what to look for. Second, the exemplars repositioned the process skills as complex, often reiterative pathways rather than the broadly levelled sets of steps identified in Social studies in the New Zealand curriculum (Ministry of Education, 1997). Third, they reinforced the inter-related nature of inquiry, values exploration, and social decision-making, as being directed towards:

- developing ideas about human society;

- participating in society as an individual or part of a group in relation to these ideas; and

- developing an understanding of the personal and social significance of these ideas. (Ministry of Education, 2004, p. 1)

The publication of the exemplars occurred amidst a period of substantial analysis of the post-1993 curriculum reforms; they were aimed at reframing, refocusing and revitalising the current curriculum. For social studies in The New Zealand Curriculum (Ministry of Education, 2007) the revisions resulted in: (a) one single 'social inquiry' methodology (described in the introduction to this thesis), (b) a reduced number of achievement objectives, and (c) the provision of achievement objectives for economics, history and geography at curriculum levels 6 to 8 (Years 11 to 13). While much of the current social sciences/social studies curriculum can be read in light of its 1997 predecessor, two key changes to the wider curriculum have a particular bearing on the representation on ethics in the current curriculum: the Values and Key competencies statements. These are 
considered in turn, followed by a section that briefly outlines the place of ethics in the senior social studies achievement standards.

THE VALUES STATEMENT: A first key change to the wider curriculum is the centrality of values $(n=51)^{28}$ as a cross-curricular concept, the subject of extensive consultation and consideration (Ministry of Education, 2005b). The resultant V alues statement (Ministry of Education, 2007, p. 10) assumes greater precedence at the 'front end' of the curriculum than the 1993 framework. Three types of value goals, identified by Keown (2001) as being evident in the 1990s' curriculum documents, are much more explicit in the body of this statement (see Appendix 1). In the left-hand column students are (a) “encouraged to value", for example, excellence, diversity and ecological sustainability values, it is maintained, that "enjoy widespread support" (Ministry of Education, 2007, p. 10). This carries much of the flavour of the 1993 framework's value attributes. In the right-hand column students are to (b) learn about different values, among which moral values are noted but the connection to ethics is not made clear. Again, in the right-hand column students are to (c) "develop the ability to" express, explore and analyse values.

Significantly, two usages of ethics exist within the Values statement, both of which appear to mean something different to values. The phrase 'acting ethically' appears in the left-hand column, in a statement that "students will be encouraged to value...integrity, which involves being honest, responsible, and accountable and acting ethically" (Ministry of Education, 2007, p. 10). To return to the terminological explication undertaken in the previous chapter, the phrase acting ethically could infer a particular moral stance or unnamed ethical code - this has rather less to do with ethics in the sense that I use the term. The second usage, "make ethical decisions and act on them" (p. 10), is to be found in the right-hand column and among a list of abilities students are to develop. The phrase appears somewhat more congruent with ethics as it is employed in this thesis. One may infer contestability from the wording and, from the phrase's position in the text, that the expectation is more strongly aligned with critical thinking than the inculcation of normative values, that is, it is akin to the terms 'valuing skills' and 'values exploration' used in previous social studies curricula. Furthermore, the sense that ethics is deeper-set than values was signalled in a key report that fed into the development of the Values statement. The authors note that "core values frequently conflict with each other in real world situations. This creates complex ethical dilemmas

28 The definition of values, "deeply held beliefs about what is important or desirable" (p. 10), is consistent with the 1993 framework. 
that are difficult to resolve with a simple core values lists [sic] and inculcation approaches" (Keown et al., 2005, p. 170).

Nevertheless, precisely what teachers are to understand by ethical decision-making and action and how, if at all, ethics is to be distinguished from values are open questions. This is because phrases 'acting ethically' and 'make ethical decisions and act on them' appear only once in The New Zealand curriculum, within the Values statement (Ministry of Education, 2007, p. 10), and are not explicated. Equally unelaborated are concepts such as participation for the common good; its contested nature obscured by the debatable assertion that it is "associated with values and notions such as peace, citizenship and manaakitanga" (p. 10). One further matter adds to the semantic confusion. The statement goes some way to acknowledge that the values to be encouraged may be situated: "the list is neither exhaustive nor exclusive...the specific ways in which these values find expression in an individual school will be guided by dialogue between the school and the community" (p. 10). However, the statement simultaneously obfuscates the ways that ethical/moral codes play out at a contextual level in the dubious contention that "it is by holding these values and acting on them that we are able to live together and thrive" (p. 10). One wonders, then, about the scope for ethical decisionmaking and action in such a murky context.

Critically, and despite the Values statement having cross-curricular intent, ethical decision-making and action are not explicitly carried through to the social sciences learning area. This reflects a wider issue of poor articulation across curricular elements (Hunter, 2007). Instead, proximal phrases are used such as "explore and analyse people's values and perspectives" and "consider the ways in which people make decisions and participate in social actions" (Ministry of Education, 2007, p. 30). Once again, the semantic connections and distinctions between these proximal phrases and ethics are not made clear, an important example being the lack of connection between ethical decision-making and action, used in the Values statement, and the term perspectives, used in the social sciences learning area statement. A subsequent clarification made in the Building conceptual understandings in the social sciences: Approaches to social inquiry booklet (Ministry of Education, 2008a) does, however, offer some hope that this connection might be established in future. This booklet places considerably more weight on perspectives $(n=19)$ than the curriculum, and defines perspective as being "a world view or ideology" (p. 9). This definition is fleshed out in inter-related support 
documentation in senior social studies and geography (Ministry of Education, 2014e, 2014f), for example:

- People's points of view may be expressed in their words or actions.

- Understanding people's values involves being able to explain why people hold a particular point of view.

- Points of view and values are shaped by a complex and intersecting landscape of perspectives. Other words for this are worldviews, ways of looking at the world, lenses, paradigms, ideologies, and theoretical frameworks. (Ministry of Education, 2014e, n.p.)

Thus, perspectives are now strongly aligned to theoretical frameworks, ideologies and worldviews, that is, something deeper than values. To the perspectives already identified in this support document (such as libertarian and post-colonial perspectives), one might add ethical perspectives such as virtues ethics, consequentialism or utilitarianism.

THE KEY COMPETENCIES STATEMENT: The second curricular shift that has bearing on ethical decision-making and action is a move from 'essential skills' identified in the New Zealand curriculum framework (Ministry of Education, 1993) to "key competencies: capabilities for living and lifelong learning" (Ministry of Education, 2007, p. 12). Though the competencies are interlinked, three are arguably most strongly aligned to the curriculum's ethical content: thinking, relating to others, and participating and contributing. The thinking key competency strongly endorses critical, creative and reflective thinking; students are, for example, to reflect on their own learning, draw on personal knowledge and intuitions, and "challenge the basis of assumptions and perceptions" (p. 12). 'Relating to others' and 'participating and contributing' focus on students' capacities to negotiate difference and be actively involved in their communities. Albeit that these come with caveats, it is significant that a focus on social participation $(n=64)$ and citizenship $(n=7)$ is carried right throughout the curriculum. Reading ethical decision-making and action in light of these key competencies would appear to strengthen the critical, relational and participatory dimensions of the phrase. However, as this chapter's summary outlines, these opportunities appear restricted by other features of the curriculum. For example, subsequent clarifications in support materials notwithstanding, perspectives $(n=4)$ receives much less emphasis in The New Zealand curriculum (Ministry of Education, 2007) than in the previous curriculum - a matter that arguably works against the critical orientation of the Key competencies. In relation to the present curriculum, Philippa Hunter (2007) contends that this "diminished status of perspectives learning about New Zealand suggests that any critical engagement with social contexts and issues may be nominal” (p. 49). 
THE SENIOR SOCIAL STUDIES ACHIEVEMENT STANDARDS: While ethics is not a term employed in the social sciences learning area statement, it is notable that the NCEA achievement standards for senior social studies do: students consider (a) the ethical implications of their plans for social action and, (b) the ethical issues related to undertaking a social inquiry (see Appendix 3). Both occur prior to undertaking the action or inquiry. Presumably, these could offer rich opportunities for exploring ethical decision-making and action. However, it is most likely that ethical content of these standards is meant as a procedural concern - a matter of adherence to rules. The students' retrospective reflection on their personal involvement in social action is, for example, couched largely in terms of evaluating the effectiveness of their involvement rather than considering the ongoing ethical issues that came to light.

\section{SUMMARY: THE CONCEPTUAL FIELD OF ETHICS - WHERE ARE WE NOW?}

This section brings together the historical analysis of New Zealand social studies curriculum statements by considering how the conceptual field of ethics might be mapped in the present. In other words, what kinds of meaning might be brought to phrase ethical decision-making and action? In exploring this question, I come back to Davis' (2004) contention that concept development is non-linear; as the previous sections have revealed, particular conceptions and re/presentations of ethics and its cognates have involved the flourished, fused or atrophied over time. Not only are the alliances, vestiges and absences identified in this section pivotal in discerning curricular meaning; they offer potential lines of pursuit in considering how learners' ethical decision-making and action might be better supported in social studies, both theoretically and pedagogically.

The first point to be made about ethical decision-making and action's conceptual field is that, as surmised, the concept of ethics is indeed a newcomer to the lexicon of social studies. What is striking about this is the way in which small words, that is, ethics and its cognates, appear to have significant meaning yet are left as small words. Perhaps one should not be surprised. New Zealand social studies curricula have a history of minimally elucidating pivotal concepts, for example, citizenship (Aitken, 2005a; Milligan, Taylor, \& Wood, 2011), community, society (Hunter, 2007; Milligan, 2006), and New Zealand identity (Bailey, 2005; Beals, 2001; Siteine, 2013). The reader will note that terms such as democracy, sustainability and social justice have been left similarly hanging. Crucially, and in over three decades, very little New Zealand social studies 
literature sheds light on what might be meant by ethical decision-making and action. The Waikato position paper (H. Barr et al., 1997), for example, includes ethical analysis and inquiry in the process of values inquiry but this is unelaborated beyond reference to an Australian social studies educator, Brian Hill (1994). Additionally, although the Waikato position paper puts forward 'personal development: the empowerment of the ethical self' as a key tradition of social studies education, the section that outlines this does not explicate the notion of the 'ethical self. One might have hoped for greater illumination in the Ministry of Education's commissioned literature review on values education (Keown et al., 2005) which informed the Values statement in The New Zealand curriculum. But again, ethics appears infrequently - only 21 minor mentions in a 217 page document - and without definition.

Crucially, it appears that very few New Zealand educators have elucidated, to a limited extent, ethics or ethical decision-making in the context of social studies (Francis, 2007, 2009a, 2009b, 2009c; Keown, 1998, 2001; Keown et al., 1993). Keown et al. (1993) position ethics thus:

The study of values includes aesthetics, viz. the study and justification of what people enjoy, and ethics which are the study and justification of how people behave (including the reflective consideration of what is right and wrong). (p. 2)

Keown's later work positions ethics in a similar vein; he recommends, for example, the Institute for global ethics' (2014) model of ethical thinking as a useful strategy for social studies, in which students consider ethical dilemmas through a range of named philosophic frameworks (Keown, 1998). By contrast, the series of resources developed by Gwen Francis primarily adopt a deontological approach by encouraging social studies learners to appeal to four ethical principles (wisdom, justice, truth, and love) in their critical social inquiries.

Although I am sceptical about taxonomies of concepts, one might conclude that ethics is akin to a 'partially mature' concept (Hupcey, Penrod, Morse, \& Mitcham, 2001). Using these authors' parameters for evaluating concept maturity, ethics is certainly pragmatically mature in the sense that it fits within phenomena common to New Zealand social studies education. Indeed, ethics is potentially very useful to the subject, particularly the values exploration, social decision-making and social action aspects of social inquiry. Ethics is, furthermore, and as previously argued, central to the nature and purposes of social studies. However, on three remaining parameters ethics (as it appears 
in New Zealand's curriculum) may be considered epistemologically, linguistically and logically immature. This is because they are ill-defined and unclearly differentiated from other concepts such as values. Further, and though one cannot say that ethics is used inappropriately in the Values statement (Ministry of Education, 2007, p. 10), the fact that students are both encouraged to value acting ethically and develop the critical valuing skill of making ethical decisions is potentially confusing to the reader. Moreover, when one looks at the potential synergies between the Values statement and the social sciences learning area statement, there lacks coherence and systemisation in the way in which values is related to proximal terms such as 'analysing people's values and perspectives'. Lastly, and critically, in instances where ethics has been used in New Zealand's curriculum documents the field of ethics has been unjustifiably narrowed. For example, the use of ethics in the statement that students are to examine "ethical principles as they apply to specific decisions and events in the past and present, developing generalisations about ethical behaviour" (Ministry of Education, 1996, p. 23) appears to restrict their examination to deontological perspectives.

A second point about the present conceptual field of ethics within the present curriculum is that, like its predecessors, social studies in The New Zealand curriculum (Ministry of Education, 2007) has inherited a range of ethical perspectives. Though character-training appeared central to the 1928 syllabus for history and geography (Department of Education, 1928), we see its embers continually rekindled through the kinds of citizen each social studies document seeks to create. For example, the ideal pupil to be fashioned through the 1961 syllabus was "to see themselves as people striving to be tolerant, kindly, honest, courageous, just, generous and independent" (Ministry of Education, 1961, p. 2). Part of the vision for today's young people is that they be "confident: positive in their own identity, motivated and reliable, resourceful, enterprising and entrepreneurial, and resilient” (Ministry of Education, 2007, p. 8). Similarly, the responsible citizens social studies is to turn out today is not that far removed from the deontological responsibilities and duties of the Thomas Report (Department of Education, 1944); while the content of citizenship may have changed, the ethical stance has not. Likewise, the flourishing of rights-based ethics in social studies curricula since 1961 undoubtedly relates to the growth of the Civil Rights movement and legislative change in New Zealand. But rights-based ethics in fact has a long history and it is no surprise therefore that the concept was used in the 1928 syllabus for history and geography. That these ethical perspectives have washed up in the current curriculum, and in tension with one another, may be considered inevitable; 
simply a reflection of the plural nature of society. But if social studies teachers and students are to explore the range of ethical perspectives that inhabit society and have found their way into the curriculum, they are limited in doing so. This is because by and large the reader is left to infer the ethical perspectives each curriculum statement draws upon, as they are not named as such. The one exception to this is the 1928 syllabus for primary schools which, in an explicit critique of (rule) utilitarianism, established a curricular pattern of resistance to direct moral instruction:

The teacher should be a man or woman of high ideals and inspiring personality - one who does consider that the dictum "Honesty is the best policy" is a sufficiently firm foundation on which to found any system of morality. The utilitarian aspect of conduct is probably too frequently presented to children. (Department of Education, 1928, p. 63)

What then, is to be said of the meanings that might be brought to ethical decisionmaking and action? Clearly, it is considered an aspect of values education, as indicated by the appearance of the phrases acting ethically and make ethical decisions and act on them in the current $V$ alues statement (Ministry of Education, 2007, p. 10). Ethics appears, therefore, to have slipped into New Zealand's curriculum, and consequently social studies, through this already open door. But ethics' usage in social studies is arguably more strongly affiliated with the right-hand column of the Values statement, that is, the phrase 'make ethical decisions and act on them'. It is highly significant that the previous process indicators for values exploration (Ministry of Education, 1997) and the more recent elaboration of 'exploring values and perspectives' in the Building conceptual understandings in the social sciences: Approaches to social inquiry booklet (Ministry of Education, 2008a) map almost directly onto the right-hand column of the Values statement (Ministry of Education, 2007, p. 10), that is, knowledge about values and the development of critical thinking. Furthermore, and because arguably Values statement's aspects are interconnected, the other usage of ethics on the page - the encouragement to act ethically - cannot be read in purely prescriptive terms. Thus social studies education holds the contestable nature of 'acting ethically' up for scrutiny; the righthand wants to know why the left-hand acts as it does.

We could equally align ethical decision-making and action, as the term suggests, to the 'social decision-making' (Ministry of Education, 1997) and 'considering responses and actions' (Ministry of Education, 2008a) aspects of social inquiry, which have gained increasing emphasis in recent years. As Keown (2001) points out, social decision-making 
necessarily turns on value judgements and, one might add, ethical perspectives. As has been identified in this chapter, social studies has a history of a critical orientation to values and decision-making, dating back at least to the 1977 syllabus. In this regard, the subject places considerable weight on counter-socialisation (Engle \& Ochoa, 1988), "a learning process designed to foster the independent thought and social criticism that is crucial to political freedom" (p. 31). One sees this, for example, in how the social sciences descriptor tempers the prevailing neo-liberal thrust of the New Zealand curriculum framework (Ministry of Education, 1993) by stating that students are to "develop the knowledge and sense of perspective needed to understand and appraise New Zealand's changing society and economy" (p. 14, my emphasis). Again today, and if one compares how the terms sustainability and citizenship are used in the Future-focused issues section of the curriculum (Ministry of Education, 2007, p. 39) with the social sciences learning area statement, we see that the latter is about critical citizenship and enables students to "evaluate the sustainability of alternative social, economic, political, and environmental practices” (p. 30, my emphasis).

At some level therefore, social studies students are expected to critically consider the plurality, complexity, uncertainty, and moral ambivalence described in the previous chapter. We see the messy and contestable nature of the ethical realm increasingly being conveyed through New Zealand social studies curricula, the use of 'issues' having reached a peak in Social studies in the New Zealand curriculum (Ministry of Education, 1997), and the values exploration and decision-making aspects of social inquiry conveying some sense of ethical complexity today. It is clear that students may consider such societal controversy at different depths, as a recent clarification of viewpoints, values and perspectives indicates (Ministry of Education, 2014b). A future iteration of the social studies curriculum may 'connect the dots' between perspectives and ethical decision-making and action, but for the meantime a strong inference may be made that ethical decision-making and action is intended to draw attention to something deeper than values. Arguably, the phrase closely aligns to the definition for ethics established in Chapter Two: involving the branch of philosophy concerned with the systematic study of what we ought to do, and meaning an activity - that of coming to an understanding of, and reflecting upon, a range of theoretical perspectives about social action.

So far, the conceptual field's centre has been examined, that is, ethical decision-making and action's most proximal terms. What lies further afield? It is firstly noteworthy that students' personal and cultural identities are somewhat peripheral. The current 
curriculum makes much of diversity $(n=15)$ and identities $(n=10)$, and expects students to "learn about their own values" (Ministry of Education, 2007, p. 10) and "clarify their own identities" (p. 30). However, it overwhelmingly positions students on the outside of ethical life, looking in. In part, this has to do with social studies' shifting gaze, that is, a change in aims. The reader will recall that in the 1970s the subject was described as the study of people. It was stressed that social studies should "help children to find their own identities by developing a growing awareness of society and of their sense of belonging to it" (Department of Education, 1978, p. 2). As an example, Faces 6 (Department of Education, 1983) made much of supporting students to make sense of personal moral dilemmas. However, social studies is now positioned as the study of societies, in which students clarify their own identities as a consequence of studying how others see themselves, and the values perspectives, and decisions of others. The learning area statement only minimally communicates that students' personal and cultural contexts might be important funds of knowledge. Though the Building conceptual understandings in the social sciences (Ministry of Education, 2008a, 2008b, 2009a, 2009b, 2012) booklets clarify that linking the personal and the societal is pivotal to effective social studies education, and that social inquiry might stem from students' concerns and interests, the current social studies learning area statement does not make this clear. Such de-centring, that is, disconnection from the complexities of learners' actual lives and real concerns, risks shutting out ethical questions that might matter to them.

It is secondly significant that the affective dimension of social studies, so apparent in the 1970s' and 80s' documents, has become nascent. The Social studies syllabus guidelines: Forms 1-4 (Department of Education, 1977a) focus on how people think, feel and act and Faces 6 s bundling together of thinking, feeling and valuing have, in later iterations, become dis-affected, that is, drained of any emotional content. Paul Keown (2001) comments that the 1997 social studies document made no mention of examining how people meet their emotional and spiritual needs, an explicit feature of the social sciences descriptor in the over-arching curriculum framework. The current curriculum has not addressed this affective absence. Values are now described as being "expressed through the ways that people think and act" (Ministry of Education, 2007, p. 10), and although students are to "explore, with empathy, the values of others" (p. 10) no mention is made of feelings in the social sciences learning area statement, save for only oblique references to beliefs $(n=4)$ and well-being elsewhere in the body of the document. In particular, care-based and relational ethical perspectives are stripped out of the V alues statement, along with 
ethical sensitivity, this despite 'relating to others' being among the key competencies and a Vision for connected learners "who are able to relate well to others" (p. 8).

The teaching guidelines and assessment for senior social studies have a similarly disembodying effect. Though the recently revised NCEA achievement standards are arguably laudable for encouraging social action, learners are not required to discuss their feelings about social action they undertake, what meaning it had in the context of their own lives, or what they have drawn from that experience into their everyday lives ${ }^{29}$. Similarly, the Teaching and learning guidelines for senior social studies (Ministry of Education, 2014d) encourage learners to consider the social significance of understandings drawn from the achievement objectives, not the personal significance ${ }^{30}$. In contrast, the affective dimensions of citizenship are acknowledged in the Building conceptual understandings in the social sciences: Belonging and participating in society (Ministry of Education, 2008b) booklet, in which it is stated that "the ability to participate in a society or community is essentially linked to a feeling of belonging to that group" (p. 5). Furthermore, the "ability to explore and analyse their own and others' values, and...a commitment to such values as social justice and equity" are positioned as aspects of affective outcomes in the Best evidence synthesis for the social sciences (Aitken \& Sinnema, 2008). But if we are to accept these views, they are not what The New Zealand curriculum (Ministry of Education, 2007) seems to say.

It is thirdly critical that the important connection between the ethical and the political are not made clear to the reader. Three points may be made in relation to this. First, social sciences learners are to "evaluate the sustainability of alternative social, economic, political, and environmental practices" (Ministry of Education, 2007, p. 30). What that statement is to mean with reference to the political is unclear, although ethical perspectives could conceivably provide one means of evaluation. Second, citizenship, and in particular democratic citizenship, lies dormant in The New Zealand curriculum. One could be forgiven for overlooking the centrality of citizenship to social studies education, given its minimal appearance in successive curricula. Similarly, scant mention of democracy in post-Thomas Report social studies curriculum documents has relegated it to an axiomatic backdrop. Gregory and Howard Lee (2007) point out that "a diverse, democratic society" disappeared from the draft values statement (Ministry of Education,

29 Interestingly, this is not the case in English achievement standards where students are asked to form personal responses to texts.

30 This despite the 'personal and social significance of ideas' being identified as one of three key aspects of social studies learning in the New Zealand curriculum exemplars: Social studies (Ministry of Education, 2004). 
1994, p. 10) and its absence in the entirety of the current curriculum is notable. The $V$ alues statement does align 'participation for the common good' with citizenship and the Building conceptual understandings in the social sciences: Belonging and participating in society (Ministry of Education, 2008b) booklet outlines four major views of citizenship ${ }^{31}$. However, the content of, and relationships between, citizenship, political practices, democracy and participation for the common good are not spelled out. More particularly in relation to the work of this thesis, the differences in ethical visions that lie behind these concepts are not elucidated, nor are learners strongly encouraged to consider the political dimensions of ethical decision-making and action.

Fourthly, and while there has undoubtedly been a flourishing of social participation in the most recent social studies curriculum, the extent to which learners' active engagement in their social worlds is genuinely encouraged is debatable. On the one hand it has been argued that The New Zealand curriculum suggests greater focus on participatory citizenship (Wood et al., 2013) in phrases such as "take action" and "engage critically with social issues" (Ministry of Education, 2007, pp. 17, 30). On the other, Jane Abbiss (2011) argues that it depends how statements such as "consider the ways in which people make decisions and participate in social action" (Ministry of Education, 2007, p. 30) are read; both cognitive and participatory interpretations can be construed. One might also question the kinds of social action that are encouraged. Wood et al. (2013) argue that successive social studies curricula have been oriented towards personally responsible and participatory citizenship, rather than fostering a more critical orientation to addressing society's structural inequalities and encouraging political action. Moreover, Philippa Hunter (2007) argues there is a reduced sense of conflict and a neutral approach to human agency in the present curriculum, and I am inclined to this view. There is a noticeable decline in terms that convey societal issues and controversy $(n=10)$ from the 1997 curriculum, and the phrase "engage critically with social issues" is notably some way down the text of the current learning area statement (Ministry of Education, 2007, p. 30). Graeme Aitken (Aitken, 2006b) notes the risk that "without further elaboration...this issues-centred shift could be interpreted as an example of social science study, rather than the focus" (p. 19). Perhaps this has been heeded to some extent, as social issues ( $n=19)$ are a greater feature of the more recent Building conceptual understandings in social sciences:

Approaches to social inquiry booklet (Ministry of Education, 2008a).

31 Drawing on Gilbert (1996), these are listed as being: (a) status implying formal rights and duties, (b) an identity and a set of moral and social virtues based on the democratic ideal, (c) a public practice conducted through legal and political processes and, (d) participation in decision making in all aspects of life. 
This curriculum has also been criticised for its timidity, that is, a refusal to confront the big issues of the day such as global power relationships, conflict and climate change (Hunter, 2007; Snook, 2007). Given the pressing nature of the latter, it seems extraordinary that environmental values is not listed among the types of values that students are expected to explore (Ministry of Education, 2007, p. 10). Moreover, the minimisation of contemporary issues arguably truncates an important avenue through which students could consider ethical decision-making and action. I would also add that the curriculum also overlooks learners' everyday ethical issues and participation. Yet, arguably, the day-to-day issues of ordinary life are the big issues writ small. It is interesting to note that drafts of the social sciences learning area statement positioned social studies as having "significance for their everyday participation" (Ministry of Education, 2006a) and "everyday interactions as citizens and members of communities" (Ministry of Education, 2006b, p. 22). But such references were omitted in the present statement. Furthermore, and though creative thought is part of the cross-curricular thinking key competency, it is not a feature of the social sciences learning area statement's description or rationale - subordinated, instead, in only one of the four conceptual strands (continuity and change) in which students "imagine possible futures" (Ministry of Education, 2007, p. 30). Against this static, distanced, and de-contextualised curricular backdrop, one could be forgiven for wondering what real and potential opportunities for ethical decision-making and action are open to social studies learners.

\section{CONCLUSION: THE ETHICALLY SILENT SPACE OF SOCIAL STUDIES}

What might be said, then, of the opportunities for ethical decision-making and action that are offered through the New Zealand social studies curriculum? This chapter has identified that ethics has a longstanding and central place in the varying traditions that have likely inflected the subject, no matter how social studies' purposes are construed. This point is especially important in light of one of the more persistent criticisms of social studies: that it lacks a unifying focus, "about everything - and therefore about nothing" (Lockstone, 1996, p. 15). That the purposes of social studies are wholly suffused by ethical perspectives presents at least one counter-argument to this view. Nevertheless, the content analysis undertaken in this chapter reveals that explicit usage of ethics is only a more recent curricular feature, and one that is minimally communicated. There is not, therefore, a longstanding corpus of curriculum content that clarifies what might be meant by ethical decision-making and action - although there is much within successive social studies curriculum statements that is directed 
towards particular ethical positions. Whilst fixed, universal definitions may not be possible or desirable, the lack of elucidation - even as to the variations in meaning that may be attached to concepts such as values and ethics - risks confusion among social studies teachers and, ultimately, risks restricting learners' critical engagement in society.

Sadly, and despite the strength of connection between the fields of ethics and social studies at a theoretical level, the New Zealand social studies curriculum is an ethically silent space. This silence is exacerbated through the ways in which social studies in The New Zealand curriculum (Ministry of Education, 2007) decentres, disembodies and decontextualises learners. This chapter has illustrated how the subject is drained of emotional content, positions learners as spectators on ethical life, and renders their personal and cultural identities as peripheral to learning. It is a curriculum that has some way to go in terms of representing the complexity of learners' lives, and despite an increased curricular emphasis on learners' social participation, that concept lacks vigour. In sum, the social studies curriculum could go much further in enabling learners to explore the complex ecology of contemporary ethical space - the plural, uncertain, complex, and morally ambivalent substance of ethical decision-making and action. Most likely, instead, learners currently make ethical decisions despite the social studies curriculum.

This issue appears to be not only a function of curriculum content. Chapter Six reveals that current teaching practices are also likely to preclude learners from spaces to expand their understanding of ethical decision-making and action in relation to their present and future social worlds. What, then, should social studies teachers be making of the crosscurricular expectations that students are to be supported to value "acting ethically" and “make ethical decisions and act on them" (Ministry of Education, 2007, p. 10)? This chapter's content analysis suggests that particularly the second phrase should be understood as (a) a dimension of, but deeper set than, values, (b) cognising societal complexity and plurality and, (c) involving criticality. The chapter has established that it is unlikely to have been the curriculum writers' intent that social studies education could be solely directed towards pre-determined expectations of 'correct' ethical decisionmaking and action, that is, take a prescriptive orientation. Moreover, when read in the context of New Zealand social studies curriculum history, 'ethical decision-making and action' is likely to be strongly connected to the values exploration and social decisionmaking aspects of social inquiry, that is, more readily coheres with a critically reflective rather than citizenship transmission tradition of social studies education. 
Should ethics be elaborated in future iterations of New Zealand's social studies curriculum, it is conceivable that it might align more strongly to the definition offered in Chapter One, meaning both the branch of philosophy concerned with the systematic study of what we ought to do, and an activity - that of coming to an understanding of, and reflecting upon, a range of perspectives about social action. Yet, such semantic clarification would not support social studies teachers to consider the theoretical underpinnings, and in turn, the broad pedagogical orientation that could be taken to better supporting their learners' ethical decision-making and action. This matter is the focus of Chapter Four. 


\section{CHAPTER FOUR: ENGAGING WITH THE PHILOSOPHY OF ETHICS}

This chapter addresses the second of my research questions: what theoretical spaces exist for better supporting social studies learners' ethical decision-making and action? To begin to answer this question, I explore how the New Zealand social studies curriculum's predominant theoretical orientations frame ethical decision-making and action. I then consider what could be re-focussed and amplified within this extant framing in order to meet the curricular requirement to make ethics a visible part of social studies learners' lives. Three spaces for theoretical development are identified: social studies tanght as social issues, as counter-socialisation, and as engaging with the philosophy of ethics. The importance of each of these spaces for better supporting learners' ethical decision-making is discussed in relation to the purposes of social studies as I see them, and the proposed adjustments are justified. Of course, a theoretical orientation to better supporting learners' ethical decision-making and action is not necessarily a matter of working with the curricular status quo. With this in mind, Chapter Five looks to theoretical spaces that appear to lie beyond the purview of the current social studies curriculum.

\section{INTRODUCTION}

Chapter Three described the place of ethics in New Zealand social studies and considered the opportunities that the curriculum affords students in terms of exploring ethical decision-making and action. While values exploration has been a strong feature of New Zealand's social studies curriculum since the 1970s, ethics and its cognates have not. The New Zealand curriculum's expectation that learners" "ethical decision-making and action" (Ministry of Education, 2007, p. 10) be supported is therefore a new expectation for social studies teaching and learning. Critically, however, this expectation is unelaborated; for example, while the $V$ alues statement infers that ethics is to be distinguished from values, this difference is not elucidated. The problematic nature of what I termed the 'ethical silence' of New Zealand social studies education is two-fold: (a) a central aspect of our lives and of social studies education is only minimally acknowledged and (b) what the phrase ethical decision-making and action is to mean is likely opaque to social studies teachers and learners, or interpreted in different ways. The next two chapters consequently consider the direction that could be given to social studies teachers wishing to better support their learners' ethical decision-making and action. Together, their contribution lies in initiating a discussion about the kind of 
theoretical underpinnings and broad orientation that would be appropriate for ethics education in social studies, that is, they question the possible theoretical spaces for better supporting learners' ethical decision-making and action.

The plan of this chapter is as follows. The opening section looks to the wider New Zealand curriculum for guidance about the educational theory that should shape the approach to supporting learners' ethical decision-making and action in social studies. I find within the curriculum a philosophic mélange. While not particularly helpful in clearly determining a way forward, this does at least offer considerable scope in terms of supporting learners' ethical decision-making and action. The second section reveals that, by contrast, the current social studies curriculum's implicit educational theory provides a little less latitude. Two theoretical orientations predominate in the social studies curriculum: the traditions of social studies taught as reflective inquiry and as social science. If one were to adhere to these framing philosophies, learners' ethical decisionmaking and action would primarily be shaped by the melded traditions. Of course, the thesis is not required to be an exercise in curriculum compliance, and to this end the purposes of social studies as I see them is a matter explored recursively throughout the chapters. In general terms, I adopt Hugh Barr's (1998) view that social studies may be understood as having two broad goals: understanding society, and one's effective participation within it as citizens.

It is notable that nothing in this chapter is a wild departure from the traditions of social studies taught as social science and reflective inquiry. These framing philosophies do, however, require re-focussing in order to satisfactorily accommodate the cross-curricular expectation that learners' ethical decision-making and action be supported. The bulk of this chapter considers the nature of, and justification for, this refocusing. I propose three inter-related adjustments to social studies' already extant framing philosophies: (a) and (b), below, draw primarily from social studies taught as reflective inquiry, whereas (c) suggests an expansion of social studies taught as social science.

(a) Social studies as issues-based education: Issues education has long been a feature of the reflective inquiry tradition of social studies but, as the previous chapter revealed, has only recently received greater emphasis in the New Zealand social studies curriculum. Because the phrase ethical decision-making and action presupposes dilemmas and controversies of some kind, I argue that ethics education in social studies requires a stronger focus on social issues. Further, and in contrast to the 
existing issues-based social studies education literature, I argue for greater attention to the everyday and the 'private' in conceptions of social issues and their ethical content.

(b) Social studies as counter-socialisation: Within the reflective and issues-based tradition, Shirley Engle and Anna Ochoa-Becker (Engle \& Ochoa, 1988; Ochoa-Becker, 2007) have argued that over time social studies should involve students in societal critique, or 'counter-socialisation'. I am cautious, however, that their model of reflective decision-making underplays the need for counter-socialisation to be supported by, and broadly inclusive of, differing worldviews, among them ethical perspectives. An argument is made, therefore, for an ethically plural (Hinman, 2013) and agonistic (Mouffe, 2000, 2013) approach to understanding social issues and responding to moral conflict.

(c) Social studies as engaging with the philosophy of ethics: Social studies taught as social science has long focussed on disciplines such as history and geography. I urge that aspects of the philosophy of ethics should take a more prominent place in social studies' inter-disciplinary stable. I consider how ethical perspectives, drawn from philosophy, might better support learners' critical exploration of social issues, ethical decision-making, and social action. I explain that this amounts to more than applied ethics. The justification for bringing the philosophy of ethics more closely into view in social studies education is made along two lines, firstly, that this inclusion is a matter of social justice and, secondly, that the discipline potentially contributes to a range of social studies outcomes related to learners' counter-socialisation.

Of course, as the conclusion to this chapter underscores, the extent to which the philosophy of ethics might support these outcomes is a matter of how it is taught. This concern is the focus of Chapter Five.

THE NEW ZEALAND CURRICULUM'S THEORETICAL 'FOUNDATIONS' AS WAYS TO PROCEED?

Because educational theory has an inexorable role in considering how to better support learners' ethical decision-making and action, this section enquires as to the guidance offered through the New Zealand curriculum. It is firstly notable that, over the last 20 years, relatively few academics have elucidated the New Zealand curriculum's philosophic underpinnings, though many have attended to the political and ideological orientations of curriculum change (for example: Codd, Clark, O'Neill, \& O'Neill, 
1996/7; C. McGee, 1995; A. O'Neill et al., 2004). Still fewer philosophic critiques pertain to the current curriculum. What can be gleaned from the literature signals persistent and unresolved theoretical tensions, partly stemming from a lack of sustained examination of curriculum philosophy on the part of the Ministry of Education.

According to G. Lee and Hill (1996), the New Zealand curriculum framework's philosophic justification was never established beyond the Ministry's assertion that "the curriculum as a whole has not undergone substantial overhaul since the 1940s' Thomas Reforms" (Ministry of Education, 1993, p. 1).

Even more critically, as John Clark (2004a) argues, the curriculum statements failed to convey the theories of knowledge upon which they were based. Instead, the curriculum development process admitted a variety of incommensurable and inexplicitly articulated philosophic positions, among them: instrumental rationalism, post-positivism, constructivism, progressivism, and postmodernism. In Clark's view, the entire framework lacked "an articulated philosophy of the curriculum which would give any semblance of unity or cohesion to the foundation and pedagogy of each of the learning areas" (p. 127). The authors of Understanding the social sciences as a learning area: A position paper (Mutch, Hunter, Milligan, Openshaw \& Siteine, 2009) ${ }^{32}$ observe that much of the controversy surrounding the development of Social studies in the New Zealand curriculum (Ministry of Education, 1997) centred on two poles of thought: those that supported or resisted postmodern discourses. The lack of resolution to this debate is evident in the existence of both modernist and postmodern orientations in the final statement, though the extent to which each prevailed is debatable (Beals, 2001; Hunter \& Keown, 2001; Irwin, 1999; Milligan \& Beals, 2004). However, such philosophic eclecticism was not necessarily viewed negatively. The authors of the Waikato position paper (H. Barr et al., 1997) contended, for example, that "most social studies educators would agree...that social studies is an integrated field of learning drawing on a range of disciplinary and philosophic traditions" (p. 39).

There is little to suggest that The New Zealand curriculum's (Ministry of Education, 2007) advent has added coherence or clarity. The review process leading to its publication was always intended as curriculum revision rather than wholesale change and, as I have argued elsewhere (Milligan, 2006), revisiting curriculum philosophy was never within the scope. Were it not for The New Zealand curriculum's 'front end', one might be forgiven for

32 A position paper written in relation to The New Zealand curriculum (Ministry of Education, 2007). 
assuming that the social sciences statement carries a 'business as usual' message for social studies, as much of its content appears a heavily pruned version of its predecessor (Ministry of Education, 1997). This has gone some way to addressing the structural inadequacies identified by commentators (Aitken, 2005a; Ferguson, 2007; Le Métais, 2002), yet the inherent theoretical contradictions remain (Abbiss, 2011). Clark (2004b) argues that the 1990s' curriculum stock-take failed to investigate the philosophic issues identified by leading academics, and that conceptual confusion and debatable assertions are contained in the report to the Minister. In his view, the Ministry of Education's "refusal to confront philosophical challenges is an intellectual disgrace" (p. 77). Not all agreed. Clive McGee (2004), for example, countered that wholesale change was not within the ambit of the review process and that "capitalising on what is right about the current curriculum" (p. 82) was beneficial. Furthermore, the general tenor of Ministry of Education commentary was that broad, sector-wide consultation would create a more robust curriculum (Chamberlain, 2004; Cubitt, 2005, 2006; Ministry of Education, 2005a). Critically, however, and as Gregory and Howard Lee (2007) note, the arguably laudable attempt to include various perspectives in the curriculum development process has had the effect of ossifying philosophic and ideological tensions. One consequence of this almost determined theoretical obscurantism is that considerable - near impossible decoding is required to discern the theoretical assumptions that underpin the curricular requirement to support learners' ethical decision-making and action. Such efforts would likely bring empty reward in terms of a definitive way to proceed, offering instead the vestiges of numerous philosophic positions. Alternatively, it could be argued that this curriculum is theoretically permissive, offering considerable latitude in the midst of incoherence.

But is the theoretical coherence, unity and foundationalism that Clark (2004a) seeks achievable, or even desirable? Given the competing purposes perennially alive in education, outlined in this thesis' introductory chapter, attainability seems a distant horizon. Myriad philosophies of education exist and, in a shifting field, Burbules (2000) argues that "one lasting change may be that the question, "What is the philosophy of education?' will never again be asked in the expectation that a single, unified definition is either possible or desirable" (p. 16). Many would add that deliberate eclecticism ought not to be seen in the pejorative. Amélie Rorty (2005), for example, contends that "postmodern attempts at eclectic philosophical systems multiply the number of viable theories” (p. 16). I take the view of Pinar, Reynolds, Slattery, and Taubman (1995) that theoretical commensurability is not only unattainable, though we may find instances of 
confluence and consilience, but that we must be wary of the exclusionary effects of any attempts at a totalising curriculum philosophy. Curriculum, they argue, is more a matter of understanding than theoretical development - a realm of possibility rather than a firm foundation, process not product.

The purpose of the next two chapters is, therefore, not to resolve the New Zealand curriculum's philosophic contradictions, or even to settle on a definitive purpose for social studies. It is to suggest, instead, a way to proceed - to situate ethics education in social studies within a realm of theoretical opportunity. This positioning does require coherence, but I do not for a moment suggest that what these chapters proffer is an incontestable, water-tight blueprint for ethics education in social studies.

Egan (1997) demonstrates that varying imperatives of education, while not mutually exclusive, present a challenge to each other; as outlined in the previous chapter, these are tensions that are inevitably mirrored in the social studies traditions ( $\mathrm{H}$. Barr et al., 1997; R. D. Barr et al., 1978). For instance, social studies 'taught as citizenship transmission' effectively inculcates social norms, whereas social studies 'taught as personal development and the empowerment of the ethical self may involve values that conflict with these. Similarly, the traditions of social studies taught as social science (akin to Plato's notion of academic excellence in the pursuit of knowledge for its own sake) and personal development (reaching back into Rousseauian thought) are at philosophic odds. Egan (1997) notes that "for Plato education is a time related, epistemological process; for Rousseau it is an age-related, psychological process ... both the Platonic and Rousseauian ideas are necessary for education, but the more we try to implement one, the more we undermine the other" (p. 20). Of course, these are not the only philosophic tensions evident in the social studies curriculum.

\section{SOCIAL STUDIES' FRAMING PHILOSOPHIES}

The previously described philosophic mélange of the New Zealand curriculum appears to permit all manner of proposals for ethics education. Happily for me, perhaps, this chapter's proposal might easily be defended on the basis that nothing in the wider curriculum precludes it. But does such a contention hold for the social studies curriculum's implicit educational theory? The theoretical muddle of successive New Zealand social studies curricula notwithstanding, this section notes that two broad 
theoretical orientations frame the current curriculum: social studies taught as reflective inquiry and as social science. The reader will recall that these are two of the social studies 'traditions' introduced in Chapter Three. That I spend some time illuminating these framing philosophies is not because I feel the need to adhere to the New Zealand curriculum. Instead, I bring to the reader's attention that my proposal for better supporting social studies learners' ethical decision-making and action in many respects draws from these framing philosophies, albeit with some important adjustments. Further, I ultimately wish to explain to social studies curriculum developers and teachers that the proposal built over the next two chapters is a matter of continuity and change, rather than radical departure.

I have stated that a strong thrust towards social studies taught as (i) reflective inquiry and (ii) social science is discernible in The New Zealand curriculum (Ministry of Education, 2007). What is the evidence for this? The former, social studies taught as reflective inquiry, gains expression in the strongly advocated social inquiry approach (Ministry of Education, 2007), outlined in the introduction to this thesis, and the genesis of which dates back to at least the 1977 syllabus guidelines (Department of Education, 1977a). This approach was expressed in the 1997 social studies curriculum as the processes of inquiry, values exploration, and social decision-making. The latter, social studies taught as social science, is partly belied by the name of the learning area, within which the subject of social studies rests. Hill (1994) suggests that this orientation has predominated in New Zealand social studies education ${ }^{33}$ over time. The dual emphases of social studies taught as reflective inquiry and social science are also detectable in the section of the learning area statement entitled: How is the learning area structured? (Ministry of Education, 2007). Approximately a third of the word count is devoted to the learning area's (i) conceptual focus, (ii) inquiry orientation, and (iii) relationship between the contributing disciplines, respectively. Further, the title of a key support document, Building conceptual understandings in the social sciences: Approaches to social inquiry (Ministry of Education, 2008a), conveys an important intersection between the reflective inquiry and social science orientations - a link also captured in the recurring use of the phrase 'conceptual, reflective and critical social inquiry' in the series. As I explore further in this section, the social inquiry methodology is intended to enable students to develop conceptual understandings drawn from the contributing disciplines.

33 Before 1961, and though primary school syllabi used 'social studies', it was expressed as being through history and geography; "thus the application of the concepts and methods of social sciences was not encouraged in social studies” (H. Barr et al., 1997, p. 23). 
How have the traditions of reflective inquiry and social science come to predominate in the current social studies curriculum? Through a significant influence on curriculum organisation in North America since the 1960s (Ross, 1985), developments in the reflective inquiry tradition have strongly shaped New Zealand's social inquiry model. This tradition owes much to John Dewey's theory of reflective thinking, articulated in works such as How we think (Dewey, 1910) and Logic: The theory of inquiry (Dewey, 1939). For Dewey, inquiry is central to learners' growth and is the means by which they adapt to their environments. The teacher's role is to help learners identify their 'felt difficulties' (Dewey, 1910), something that is truly problematic in the context of their own lives. Dewey's process of inquiry enables students to transform their puzzlement into a more harmonious, coherent and meaningful understanding, "where that puzzlement is removed and where the 'solution' re-establishes the essential unity of the situation" (Pring, 2007, p. 66). In Dewey's (1939) words, "that which satisfactorily terminates inquiry is, by definition, knowledge" (pp. 104-105). This process is what might be described as scientific, involving the formulation and refinement of hypotheses, and controlled experimental testing and observation. It also reflects the philosophic tradition of American pragmatism, in which Dewey was a key figure, where all thinking and reflective considerations are to be referred "to consequences for final meaning and test" (Dewey, 1916, p. 330). Importantly, the result of inquiry is not immutable facts but warranted assertions that are amenable to further scrutiny; inquiry is therefore re-iterative.

Dewey's work is perhaps the least acknowledged influence on New Zealand's model of social inquiry (Lee \& Lee, 2007), though his impact on liberal and progressive educational thought in this country has been profound (Dowden, 2011). It is hard to know for sure what he would have made of this methodology and of social studies in The New Zealand curriculum (Ministry of Education, 2007), especially given that when writing in the 1930s he expressed guarded optimism about the social studies' potential in the USA (Carpenter, 2006). Nevertheless, Dewey's conviction that education should assist students to meet the challenges of democracy through open-minded inquiry has been clearly imprinted on numerous models for reflective inquiry developed by social studies scholars in North America (R. D. Barr et al., 1978; Ross, 1985). Three features of New Zealand's social inquiry approach reflect Deweyan thought: the presence of 'social studies taught as citizenship' is tempered by ongoing reflection, method is emphasised over abstract thinking, and the approach is re-iterative yet orderly. These aspects are most clearly conveyed through the visual model of social inquiry provided in the Building conceptual understandings in the social sciences series (see Appendix 4). At its heart, 
the social inquiry model reflects Dewey's position that effective democracy requires inquirers who do not hold slavishly to ideas, but see them as provisional. There are shades of Dewey's pragmatism in these support documents too: it is explained that 'considering responses and actions' should involve "examining the implications and consequences of people's actions and decision making" (Ministry of Education, 2008a, p. 9).

Social studies in New Zealand has been historically influenced by the disciplines of social sciences and humanities (Abbiss, 2011; Hunter, 2006). Graeme Aitken (2004) argues the strong orientation towards social studies taught as social science in part stems from the subject having been historically viewed by many New Zealand secondary school teachers as a chief vehicle for history and/or geography. Advocates of this tradition want "young people to perceive the world through the eyes of a social scientist, to ask the kinds of questions that a social scientist asks, and to use the analytical tools and concepts of the social scientists" (R. D. Barr et al., 1978, p. 71). Coherent bodies of thought are seen as avenues to understanding society, yet not through rote learning and memorising facts. Importantly, such an enterprise incorporates relies upon, and arguably enhances, critical thinking (Siegel, 2003). Its philosophic roots of the new social studies date back to the Platonic idea of education: knowledge understood as a rational view of reality, a quest for universal truth, and important for its own sake. In modern day terms, it is intended to connect "children with the great cultural conversation that very definitely is there and that transcends politics, special milieus, local experiences, and conventional sets of norms and experiences" (Egan, 1997, p. 14).

One particularly important strain of thought in this tradition was 'the new social studies', a series of projects associated with post-Sputnik educational reform in North America and the pre-eminence of cognitive and developmental psychology. "A very strong emphasis in this period was the focus on the inquiry learning process and the development of concepts and methods drawn from a range of social sciences disciplines, particularly sociology and anthropology" (H. Barr et al., 1997, p. 20). One can trace the emergence of the new social studies movement through (i) the Woods Hole, Massachusetts conference of 1959 that drew together leaders in science and mathematics reform, (ii) Jerome Bruner's (1960) summary of the conference themes in his book, The process of education, and (iii) a series of meetings in Endicott House, Massachusetts that considered broadening these curriculum reforms into other curriculum areas, including English and social studies (R. W. Evans, 2004, 2010). A 
central intuition of these reforms was that 'the structure of the disciplines', as Bruner (1960) called it, would enable learners to develop disciplinary epistemology which may be transferred to novel situations. He argued that "it is possible to present the fundamental structure of a discipline in such a way as to preserve some of the exciting sequences that lead a student to discover for himself' (p. 20). Hill (1994) comments that, at the height of this era:

Little was said about the skills associated with the ethical (and not just social) analysis of values and belief systems in their own right. Nor was this model sufficiently alert to the part played in the social sciences (and other areas of life) by 'paradigms', or value-laden models of thought. (p. 149)

While the new social studies movement of the 1960s "was headed mostly in one direction, asserting the individual disciplines and abandoning the possibility of integrated social studies" (R. W. Evans, 2004, p. 131), there were a number of voices suggesting a different path. One cluster of voices coalesced around issues-centred developments that grew from the new social studies, among them Shirley Engle, Byron G. Massialis and Lawrence E. Metcalf. In varying projects, they proposed applying Bruner's structure of the disciplines to an integrated social studies curriculum that incorporated both a reflective inquiry orientation and the social sciences and humanities. Significantly, we see in these educators' work an increasing emphasis on values exploration and social decision-making as a critical component of social sciences and reflective inquiry. Here, students employ critical thinking to inform their decisionmaking about pressing problems related to the immediate needs of students and/or wider society. Thus, emphasis is placed on "the synthesizing skills of the decisionmaker, not the analytical skills of the social scientist" (Ross, 1985, p. 9), though the importance of the latter is not eschewed.

It was to be this grafting together of a Deweyan tradition of reflective inquiry, the new social studies, and a growing emphasis on values education, which significantly shaped New Zealand's approach to social studies education. Notably, the 1960s and 1970s was a period of fertile intellectual exchange between the North American and New Zealand social studies communities. A key catalyst for New Zealand social studies curriculum review during this time drew from the work of Hilda Taba (Mutch et al., 2009), a student of Dewey's, whose influential thinking about social studies curriculum organisation was synchronous with the new social studies (Stern, 2010). It is notable that Anthony McNaughton (University of Auckland) worked with Taba on what became 
known as the 'Taba project', at San Francisco State University and co-authored the significant $A$ teachers' handbook to elementary social studies: An inductive approach (Taba et al., 1971). In this book we see the genesis of New Zealand social studies framed as both reflective inquiry and social science. It emphasised organising learning experiences around concepts and ideas drawn from the social sciences and humanities, and inquiring and thinking using the methods of these disciplines. Critically, it also stressed the importance of values analysis, and in this way made an important connection to the issues-centred developments of the time.

Though Taba died in 1967, and the projects associated with the new social studies were being wound back in the USA by the late 1970s, the depth of thought generated in this milieu significantly shaped the Syllabus for Forms 1-4 (Department of Education, 1977a) and associated documents. It produced a curriculum pattern that emphasised ideas-led ${ }^{34}$ (as opposed to facts-driven) learning through processes of self-critical, reflective inquiry and revisiting important ideas, a pattern that underpins the structure of the social studies curriculum today. Variants of the North American reformers' watchwords are easily detectable in the New Zealand social sciences learning area statement and support documents: "concepts, generalizations, the structure of the disciplines, inquiry operations, social issues, values clarification, and attitudes and value development" (Fenton, 1991, p. 1). The contemporary presence and evolution of these organising features in the New Zealand social studies curriculum, particularly as 'conceptual, critical and reflective social inquiry', owes much to the important contributions of Australian and New Zealand social studies academics such as Brian Hill, Paul Keown, Graeme Aitken and Bronwyn Wood (Ministry of Education, 2008a).

Where does this discussion leave us in terms of how to better support learners' ethical decision-making and action, theoretically speaking? It suggests several potentially productive and inter-connected lines of consideration. It would firstly appear that ethical decision-making and action is to be considered within a tradition of 'social studies taught as reflective inquiry' and that issues-based approaches would be consistent with this tradition. Second, and given that 'social studies taught as social science' (Hill, 1994) is also emphasised in New Zealand's social studies curriculum, it is

34 For example, the term 'concept' was first introduced in Faces 4, and elaborated in Faces 5 (Department of Education, 1978, 1981). 
not too much of a stretch to imagine that philosophy, and ethics within this, might count within the social studies' interdisciplinary stable.

I turn now to considering ethical decision-making and action in light of these interrelated framing philosophies. The next two sections primarily pertain to 'social studies taught as reflective inquiry' and build a case for an issues approach aimed at countersocialisation. The third section draws strongly from 'social studies taught as social sciences' and urges that the philosophy of ethics be afforded a much stronger curricular and pedagogical presence. Notably, both framing philosophies emphasise the importance of critical thinking. This strongly aligns with the way that the phrase 'ethical decisionmaking and action' is conveyed through the text of the V alues statement (Ministry of Education, 2007, p. 10), that is, as having a critical dimension.

\section{SOCIAL ISSUES AS THE FOCUS OF ETHICS EDUCATION: TROUBLING A PUBLIC/PRIVATE DIVIDE}

This section explores the first of the previously identified philosophies that currently frame the New Zealand social studies curriculum: reflective inquiry. In particular, I consider how ethical decision-making and action could be located within issues education, an orientation long advocated elsewhere but a comparatively more recent and less explicated feature of New Zealand social studies curricula. I argue that issues education requires refocusing in order to better accommodate ethical decision-making and action because ethics troubles conventional definitions of issues as being matters of public concern. Better supporting learners' ethical decision-making and action must instead cognise issues that have both public and private implications.

As this thesis' introductory chapter alluded, stormy debate has surrounded questions as to the exact rationale for and aim of social studies. In this discordant context, the position I take is that discord itself is the very stuff of contemporary social studies - and certainly at the heart of ethical decision-making and action. There is undoubtedly a legitimate role for social studies in attending to societal stability, that is, "how society works" (Ministry of Education, 2007, p. 30, my emphasis) or the "positive traditions and institutions' that characterise society (Patrick, Vontz, \& Nixon, 2002) such as how local or national decision-making processes operate. However, greater attention to societal controversy, contradiction and complexity is needed, lifting up phrases such as "engage critically with social issues" (Ministry of Education, 2007, p. 30) that are somewhat 
submerged in the current learning area statement. As Nelson (1996) argues, "pervasive human issues remain at the center of the human condition and at the core of knowledge. The legitimate study of society, human knowledge, and competing views, therefore requires a focus on issues" (p. 14).

What I am essentially proposing is that supporting learners' ethical decision-making and action, as the phrase suggests, necessitates considering social issues and their ethical content. In other words, dealing with uncertainty should be the core business of social studies education. This is hardly a novel suggestion. Issues education has had a long, albeit variable place in social studies and citizenship education internationally. Furthermore, its relationship to ethics has been noted in this literature, although mostly without substantial analysis. In the USA, and with the associated tradition of social studies taught as reflective inquiry, issues education reaches back into the work of Dewey, the social welfare and humanitarian movements of the early nineteenth century, and arguably to the teachings of Socrates (R. W. Evans \& Saxe, 1996; Patrick et al., 2002; Saxe, 1992). Often referred to as the 'problems of democracy', two prominent experiments with this approach were The Harvard social studies project and The crucial issues in government series of the 1960s and 70s. Zevin (2007) notes both produced small pamphlets for students that included data and a range of ethical positions about problems such as racism, community participation and foreign aid. Shaver (1992) observes that such public issues are of interest to social studies education and are inherently ethical because they "involve questions of proper aims and actions for society or for individuals and subgroups in society" (p. 97). Academic interest in teaching controversial issues in the UK stems from the Humanities Curriculum Project in the late 1960s led by Lawrence Stenhouse $(1968,1971)$ and developments in the 1970s and 80s (see, for example: Carrington \& Troyna, 1988; Dearden, 1981; Stradling, 1984; Wellington, 1986). This body of work has seen controversial issues occupying a central place in citizenship education in the UK until 2013 (see, for example: Claire \& Holden, 2007; Department for Education, 2014; Oulton, Day, Dillon, \& Grace, 2004; Qualifications and Curriculum Authority, 1998). Most notably within this literature, Hilary Claire $(2001,2003)$ has provided examples of how controversial issues can result from conflicting interpretations of ethical concepts and differences in theoretical positions.

The argument that social studies should focus on issues is not new to Australasia either (see, for example: Gilbert \& Hoepper, 2004; Reynolds, 2009) and, in particular, Brian 
Hill (1994) has emphasised the ethical content of social issues. In the New Zealand context, Graeme Aitken (2005a) has argued that topical issues should be a strong feature of a social studies curriculum structure based on citizenship education. His suggested process for approaching topical issues has considerably influenced the current curriculum's model of social inquiry. Aitken chiefly acknowledges Hill (1994), but also the influence of teaching for intercultural understanding, issues-based learning (Zevin, 2000), and Oliver and Shaver's (1986) jurisprudential inquiry model. Notably, the latter explicitly rests on the exploration of ethical dilemmas. Aitken (2005a) describes topical, controversial issues as having the following characteristics:

- they involve a specific problem about which different groups in a community urge conflicting courses of action

- they are of such significance that each means of resolution is objectionable to some groups of citizens and arouses protest

- they are concerned with value judgements and therefore cannot be settled on facts and evidence alone

- they involve participants in a decision-making process. (p. 102)

Aitken continues:

They also need to have relevance and meaning to young people, to connect to the civic realities of everyday life and to "help them understand their reality and give them a stake in the future that rightly belongs to them.” (citing Kennedy, 1997, p. 3)

Such is the weight behind issues education, that the vast majority of contemporary social studies and citizenship academics "would agree that social studies involves practising problem solving and decision making for developing citizenship skills on crucial social issues” (H. Barr et al., 1997, p. 39). It is, however, notable that, internationally, varying definitions and characteristics have been ascribed to 'issues', different rationales have been advanced for this focus in education (see, for example: R. W. Evans \& Saxe, 1996; Hess, 2008; Levinson, 2006; Shaver, 1992), and opinion is divided over how central an organising concept 'issues' should be (Patrick et al., 2002). Some, for example, "would advocate the study of only perennial issues while other [sic] emphasize current or personal issues, such as moral dilemmas and values clarification" (Ross, 2006, pp. 22-23).

Beyond the axiomatic observation of societal pluralism, issues education has been variously defended on the basis that (i) it enables learners to adapt to society and cope 
with the complex demands of participating in their social worlds, (ii) it has a transformative dimension, allowing students to define the 'good life' for themselves and their communities, and (iii) controversy is essential to democratic life and that democratic well-being depends on a knowledgeable, articulate and politically engaged citizenry (see, for example: Hess, 2004, 2009; Ochoa-Becker, 2007; Shaver, 1992). While I would defend an issues focus on each of these counts, such variable rationales and definitions reflect an unsettled terrain into which ethical decision-making and action might be inserted.

One predominant assumption across differing definitions of issues - that they are publically observable - requires some revision if ethical decision-making and action is to receive greater attention in New Zealand social studies education. Even though the difficulty of discerning where the change takes place between public and private is well understood ('public' issues arise from 'private' decisions and matters of public policy affect the individual, for example), the issues education literature is overwhelmingly directed towards public issues. Diana Hess (2002), for example, provides a stipulative definition that controversial issues are "unresolved questions of public policy that spark significant disagreement" (p. 11). Here she is not disregarding the private; instead she argues that a sole focus on private issues "could lead students to believe that whatever they decide to do is what everybody should do" (p. 42). Yet, in the context of this thesis, I think more needs to be said. Though Aitken (2005a) suggests that controversial issues 'arouse protest', it may be possible to imagine situations where differences are not open and visible, and protest (indeed any form of disagreement) may not be an available means of response (Claire, 2003; Levinson, 2006).

But it is the focus on community and societal issues that is the most limiting factor in thinking about ethical decision-making and action, and even a stipulative distinction between the private (personal) and public (societal) appears insufficient. How so? Ethical decision-making and action interrupts a public/private dichotomy because there do not appear to be some ethical issues that stop at our front gate and others that take over in a 'public' domain. Instead, I submit that ethical issues are scalable - as opposed to scale-dependent - to the extent that if the private issue in question cannot be expanded to the societal level and vice versa, it is unlikely to be an issue within social studies. Consider a 'public' example: "Should the federal government grant amnesty to people in the USA without legal documents?" (Hess, 2009, p. 5). While this is certainly a matter of policy debate, its ethical content speaks fundamentally to one's relationships with, and 
responsibilities to, the other; thus it does not solely pertain to publicly observable. Conversely, the answer to Socrates' question "how should one live?" may begin with an everyday question such as 'what shall I do?' but in ethics arrives at a question about 'a manner of life' (Williams, 2011), and thus expands to include the societal/public sphere.

Recent theorising about intractable 'wicked problems' and their implications for public policy recognise the complex interdependencies between issues; consumer choices are, for example, linked to issues of poverty, global politics, and environmental degradation. Just as the roots of such issues are tangled (Camillus, 2008), so too is their public and private nature. Among the challenges of global climate change, for example, is that those who seek to end the problem are also causing it. Further, "decision makers within public authorities do not control all the choices required to alleviate pressures on the climate" (Levin, Cashore, Bernstein, \& Auld, 2012, p. 127). Ethical responses to climate change, therefore, are not easily demarcated along the lines of public policy/private action. Allied objections have been raised about citizenship being conceived as having clear demarcation points: a matter of public rather than private concern, and/or tethered to concentric 'layers' such as local, national, regional and global. Some research has, therefore, sought more flexible, nuanced and enmeshed conceptions of citizenship (see, for example: Abowitz \& Harmish, 2006; Lister, 2003, 2007; Mitchell \& Parker, 2008).

Furthermore, a growing body of work questions what we miss as a result of too great a preoccupation with the 'public': young people's everyday and ordinary citizenry may be valuable sources of insight into, for example, their political worlds. For some (such as Kallio \& Häkli, 2011; Skelton, 2010; Wood, 2012), this takes seriously the idea that children's life-worlds are not simply a site of induction, or preparation for future public political life, but worthy of consideration in their own right. Thus, a second problem with a distinction between public/private ethical issues is that this overly simplistic dichotomy risks the 'private' being dismissed as trivial, domestic and/or the associated with particular groups, such as women ${ }^{35}$ or children. As in traditional moral theory, the concerns and domains of these groups may be perceived as a less suitable object of moral investigation (Hinman, 2013) ${ }^{36}$. It is ironic that the vestiges of this position are still to be found in the issues education literature. For example, Anna Ochoa-Becker's

35 For a discussion of the public/private distinction from feminist perspectives see Gavison (1992).

36 For example, while the nature and ethics of friendship has been debated since Aristotle, more recent friendship critiques have forced "moral theories to take personal relationships seriously and consequently to refine and complicate their accounts in the process" (Helm, 2014, n.p.). 
(2007) work conveys a sense that students' personal issues are something to be left behind in pursuit of understanding more serious civic issues:

Trivial issues should not consume class time. However, in order to motivate young citizens, we may start with the immediate issues of personal interest and then expand the study to broader issues that are more complex and effect [sic] wider populations. (p. 44)

Of course, contemporary social studies and citizenship education does not expressly exclude private, domestic or seemingly mundane issues. Gilbert (1996, cited in Ministry of Education, 2008a), for example, notes that one major view of citizenship and citizenship education is as "participation in decision making in all aspects of life" (p. 5). However, the argument being made here is that learners' everyday experiences, such as the ethical challenges they face in family and peer group relationships, requires greater status in issues education if they are to explore ethical decision-making and action in any real depth. The central point of clarification thus far, distinctive from much of the international literature on issues education, is that the ethical content of public issues is necessarily interwoven with the personal and vice versa. This means that social studies' gaze need not rest - indeed cannot - on either learners' immediate ethical worlds or some kind of civic ethics existing 'out there' in society. By contrast, exploring ethical decision-making and action in social studies enables learners to see the personal and social significance of ethical issues that are at once private and public in content.

And so, to the sense in which I use 'issues' in this thesis. Notably a range of cognates are used for issues in the literature, including controversial, current, topical and social issues. I am conscious that controversial or topical issues might readily bring to mind public policy debates and occlude the private dimension of ethical issues. So, henceforth I therefore adopt social issues, the term currently employed in the New Zealand social studies curriculum, in order to capture the multiplicity of students' ethical lives and the fullness of their participation in society. Four points may be made in relation to this usage. First, it is different from the idea that learners' social inquiries "provide links to wider societal issues" (Ministry of Education, 2008a, p. 5, my emphasis) or, alternatively, students' consideration of the personal implications of a public policy debate. Second, and acknowledging the interpenetration of problems that confront society, the term social issues is to be understood as including environmental issues. I thirdly stress that while this thesis concentrates on the ethical content of social issues, this is not to deny the interplay with other dimensions such as political, historical or sociological questions and 
debates. Last, and drawing on Hess' (2009) work, I view three attributes as inherent in my use of social issues; that they are:

- open and unresolved questions - really matters of debate.

- authentic - affecting real people in real contexts.

- contemporary - issues confronting people, communities and societies today, though the content of such issues are very often matters of longstanding ethical debate.

SOCIAL STUDIES AS COUNTER-SOCIALISATION: THE NEED FOR ETHICAL PLURALISM AND AGONISM

The history of thought and culture is, as Hegel showed with great brilliance, a changing pattern of great liberating ideas which inevitably turn into suffocating straightjackets, and so stimulate their own destruction by new emancipatory, and at the same time, enslaving conceptions. (Berlin, 1999, p. 159)

Still within a tradition of reflective inquiry, this section considers the deeper intent of exploring social issues, their ethical content, and the decision-making and action that arise from this. I highlight here, the influential work of Shirley Engle and Anna OchoaBecker (Engle \& Ochoa, 1988; Ochoa-Becker, 2007) because their reflective decisionmaking model appears to align well with ethical decision-making and action. I suggest, however, a broadening out of the worldviews and methodologies which students might engage with in their consideration of social issues. I argue, in essence, for a plural approach to better supporting learners' ethical decision-making and action.

Citizenship transmission, or socialisation, is an ever-present aspect of social studies education. The subject is inevitably, and desirably, a domesticating and conserving force that "inducts young children into its customs, values and behaviours as a way of continuing existing traditions and practices" (Engle \& Ochoa, 1988, p. 30). Further, I think there is an important place for a civics approach to ethics in social studies; understanding New Zealand's decision-making processes is a notable example in the context of this thesis. Similarly, the Values statement in The New Zealand curriculum (Ministry of Education, 2007) states that students should learn about different kinds of values, the values of others, and those that underpin New Zealand's cultural and institutional traditions. I have no quarrel with this and of course accept that, in any society, values are inculcated - or, in the words of the curriculum, "to be encouraged" (p. 10). 
However, I contend that social studies education in a democracy equally requires countersocialisation (Engle \& Ochoa, 1988; Ochoa-Becker, 2007). This by no means eradicates the forces and products of socialisation, nor the need for social cohesion. Countersocialisation is, instead, responsible social criticism and action borne of ongoing, independent, and thoughtful assessment of social norms - an ethic of critique (Starratt, 1994) or 'thinking against' socialisation. Perhaps, therefore, one could more properly characterise counter-socialisation as a differing kind of socialisation, focussed on interrupting and interrogating the status quo. For Engle and Ochoa-Becker, the intellectual dimensions of this include the ability to appraise the validity of truth claims, and make decisions in relation to public issues, the latter involving problem clarification, and identifying values assumptions, suggesting alternatives, predicting consequences, reaching and justifying decisions. To return to a theme explored in Chapter Two, these educators stress the tentative nature of ideas: "democracy assumes an open society in the sense that change and improvement are taken for granted. Democracy is never completed. There are no final solutions, no unquestioned answers" (Engle \& Ochoa, 1988, p. 10).

Like Engle and Ochoa, I contend that counter-socialisation can and should become the dominant goal of social studies as learners progress through their schooling, and that socially critical understanding is entirely possible for young learners. I do, however, depart from their position over three key matters. To return to the argument made in the previous section, I firstly stress that counter-socialisation is directed towards public and private transformation. Social criticism, therefore, includes critical reflection on, and action in, one's own ethical life. A second departure is discussed more extensively in Chapter Five: the need for a greater focus on social action, in other words, imbuing the 'counter' with a sense of agency and the enacted. This understanding of countersocialisation places social transformation at the heart of social studies learning rather than social criticism, although the latter is a vital dimension. Might this conception of counter-socialisation more properly be described as an argument for orienting social studies education towards 'educating citizens for cultural transformation' (Gibson, 2009; Gibson \& McKay, 2005)? To the extent that a strong relationship between critically informed and engaged citizenry is emphasised, my answer to this question is yes. However, cultural transformation, at least in the sense used by Susan Gibson and Roberta McKay, strongly links social action to a critical pedagogy approach. This carries forward a conception of ethics and society which sees social justice in particular terms. 
This brings me to my third reservation about Engle and Ochoa's (1998) conception of counter-socialisation and, likewise, social studies directed towards cultural transformation (Gibson, 2009; Gibson \& McKay, 2005). I contend that counter-socialisation should draw its force from multiple paradigms, that is, social studies' purposes should enable students to critically explore their social worlds, issues and participation, through as wide a range of ethical perspectives as possible. By contrast, Engle and Ochoa's (1998) work sits squarely within the American pragmatic tradition of philosophy, this despite the authors' distancing from what they see as Dewey's scientism. I do not wish learners to be confined to this tradition or their model of reflective decision-making, partly because pragmatism takes a, broadly speaking, consequentialist approach to ethics. As Chapter Two introduced, there is rather more to be said about ethical decision-making and action than this. Moreover, one can arrive at a similar notion of counter-socialisation from a whole host of alternative theoretical underpinnings. Avner Segall (2004), for example, identifies a wide variety of proposals for social studies education that share a critical goal, albeit with differing ontological and methodological dispositions. This thesis is not, therefore, an argument for paradigmatic privileging or dethroning, nor, as I go on to point out, is it an attempt to smoothly synthesise perspectives or dissolve theoretical tensions. I do, however, have an interest in drawing in theoretical terrains that have existed at the margins of social studies education, such as postmodernism and poststructuralism (Segall, 2013; Segall, Heilman, \& Cherryholmes, 2006), in order to offer learners a broader range of tools for societal critique and action. So my primary interest lies in introducing learners to a wider realm of possibility than might have otherwise been the case if, at heart, the purposes of social studies were anchored in a narrow set of commitments.

Familiar and defensible objections to an encompassing position of this kind draw on critiques of relativism. Examples of relativism include the claim that truth is relative to particular conceptual frameworks and that reality is a social construction (Swoyer, 2014). There is not the space here to canvas all species of, and arguments for and against, relativism. So, I focus instead on relativism as a meta-ethical standpoint, given its particular salience to this thesis. In its most extreme form, ethical relativism "claims that what is right or good is always relative to the particular circumstances of cultures, groups or even individuals. It denies that there are objective ethical standards" (Preston, 2007, p. 30). Hinman (2013) notes the immediate attractiveness of this as a doctrine because, for instance, it offers the promise of tolerance and understanding, reflects the fact of moral diversity, and addresses a lack of a plausible alternative. But there are numerous limits to these stances. Tolerance, for example, and at least at this extreme 
end of the relativist spectrum, presents particular philosophic problems. At its most selfrefuting level, ethical relativism commits one to being tolerant of intolerance. In addition, the reality of experience is that, sooner or later, the ethical relativist who desires tolerance finds unpalatable exceptions and thus reaches for an ethical standard. Such tolerance may also offer little in the way of compulsion to change, or even to take a position. By taking seriously multiple ethical perspectives, it is argued that "for the full-fledged moral relativist, there is no vantage point from which to exert moral pressure, for each person is considered right relative to his or her culture" (Hinman, 2013, p. 43). Presenting learners with such limited means for adjudication has a potentially numbing effect, producing inertia in the very subject that encourages taking ethical action. I should point out here that a criticism often levelled at poststructuralism is that of extreme relativism. However, in post-structural arguments about the need to attend to power relations and open up spaces for considering marginalisation, the relative positions are necessarily critiqued; this is not the same as 'anything goes'.

The previous objections considered, this thesis locates counter-socialisation within Hinman's (2013) conception of robust ethical pluralism, which posits that "disagreement and difference are standard features of the moral landscape and can be sources of moral strength" (p. 45). I note Swoyer's (2014) point that "relativistic themes are frequently defended under alternative banners like 'pluralism' or 'constructivism' (with a particular author's line between relativism and pluralism typically marking off those views he likes from those he doesn't)" (n.p.). The content of robust ethical pluralism is indeed relativistic but, pace Swoyer, the argument in its defence necessarily requires some kind of 'marking off'. For Hinman, robust ethical pluralism may be distinguished from weaker versions that suggest ethical theories offer different answers to different types of questions, and therefore offer different angles on moral life. The lack of recognition this gives to contradiction is central to Hinman's thesis. Robust ethical pluralism is therefore more alert to inconsistency and while it "does not give up the hope of compatibility [it] does not make compatibility a necessary requirement" (Hinman, 2013, p. 49). But this is not an 'anything goes' position; Hinman argues that four principles, though not incontrovertible, ought to guide our responses to moral conflict:

- Understanding - avoiding judgemental un-thought and seeking instead to understand people's moral practices with their wider cultural contexts;

- Tolerance - providing space for the pursuit of diverse moral visions, to the extent that this is possible; 
- Standing/speaking up against evil - "at least in the cases of egregious moral wrongdoing" particularly because this is often directed at the powerless; and,

- Fallibility - recognising with humility that moral ideas may be mistaken or incomplete and committing to continual process of scrutinising such ideas. (pp. 50-51)

My expectation is that these principles would be made explicit to students and they are, of course, open to scrutiny. The productive intersection between 'social studies as counter-socialisation' and robust ethical pluralism is at least two-fold. Robust ethical pluralism firstly cognises the diversity and complexity of our ethical worlds, including that: (i) our moral codes are contingent, historically constituted and culture-soaked, (ii) there is not (yet) a moral system that both claims to be absolute and is universally accepted as such, and (iii) there exist multiple and not necessarily consistent ethical frameworks. These recognitions offer considerable scope in terms of learners' critical consideration of ethical decision-making and action, particularly if they are made explicit. Attentive, unsettling or disturbing pedagogical practices would therefore expose ethical diversity and contradiction and support learners to locate social issues, and their own and others' ethical decision-making and action within a landscape of theoretical tension. Importantly, this is not to dismiss varieties of, and defences for, moral absolutism. To do so would be to undermine legitimate stances within the purview of social studies education, such as adherence to the Universal Declaration of Human Rights, students' own religious-ethical views, and arguments for cosmopolitan citizenship (Osler \& Starkey, 2005). As a description of the social world, robust ethical pluralism counts universalist approaches as being among a range of considerations that exist in the world and that might be brought to bear on ethical issues.

A second reason why robust ethical pluralism is cogent for 'social studies as countersocialisation' is that it engages with ethical inconsistency and disagreement - the stuff of contemporary social issues. From this standpoint, social decision-making may be strengthened because ethical perspectives are positioned as productive counter-points in considering ways to go on. In another context, Patti Lather (2006) points out that philosophic tensions borne of paradigm proliferation are 'good things to think with' because they "keep us moving in order to produce and learn from ruptures, failures, breaks, refusals" (p. 45). What Hinman's (2013) notion of robust ethical pluralism conveys, I think, is a sense of agonism, as opposed to antagonism, between ethical perspectives. In taking up this concept to argue against merging the inclinations of continental and analytic philosophy, Robrecht Vanderbeeken (2011) explains that: 
Agonism implies the opportunity to express disagreements. It does not assume that conflicts are harmful by definition and that every conflict can be eliminated given sufficient time for deliberation and rational agreement. In other words, it does assume that conflicts can have a non-rational or emotional component which should not be neglected and that they can have a productive contribution in the long run. (p. 21)

Similarly, Chantal Mouffe $(2000,2013)$ draws attention to the ways in which deliberative democracy's search for consensus is overly rational and ends up excluding some voices. Her work sits in feminist political philosophy which:

...comes out of poststructural continental feminist and philosophical traditions. It takes from Marxism the hope for a more radically egalitarian society. It takes from contemporary continental philosophy notions of subjectivity and solidarity as malleable and constructed. Along with postmodern thought, it repudiates any notion of preexisting moral or political truths or foundations (McAfee, 2014, n.p.)

For Mouffe, the aim of democratic politics "is to transform antagonism into agonism. This requires providing channels through which collective passions will be given ways to express themselves over issues" (Mouffe, 2000, p. 16) and in which political ideas are seen as interlocutors. In an analogous context, Malcolm MacDonald and John O'Regan (2013) theorise through Levinas and Derrida to argue that the ethical grounds for intercultural praxis should lie in keeping the conversation going; in their words keeping "a reflexive eye on the many" (p. 1016). In their view, it is through responsibility for the other "that the discursive terrain remains open and that a non-normative ethics becomes possible" (p. 1015). Retaining this openness enables constant alertness to the silencing of alternatives and the potential for turning away from the other. Significantly, this position rejects closure brought about through tolerance - where tolerance is understood as retaining one's power in the process of suffering the other - a position similar to Hinman's (2013) even though he uses the term tolerance.

Critically, given the extensive social studies education literature that is dedicated to democratic values, virtues, ideals (and so on), robust ethical pluralism and agonistic approaches enable learners' counter-socialisation to extend to a critique of the ethical content of democracy. Following Mouffe (2009), democracies are a matter of historical and spatial specificity; one cannot speak of democracy as being immutable. This point has been sheeted home in a recent comparative study (Fischer, 2012) which indicates that the democratic values evident in the USA may well be distinct from New Zealand. Moreover, I concur with Mouffe's (2009) argument that while liberal democracy is: 
Constitutive of our form of life and it is certainly worthy of our allegiance... there is no reason to present it as the only legitimate way of organising human existence and to try to impose it on the rest of the world. (p. 557)

To summarise the argument thus far, ethical decision-making and action understood within a reflective, issues-based tradition does not promote "critical thinking for the sake of debate, argument or logical reasoning, but for constructive change, for the transformation of society" (Alquist, 1990, cited in R. W. Evans, Newmann, \& Saxe, 1996). Critical ethical decision-making and action has a personal dimension also, attending to the transformation of learners' everyday experiences. Understood in this more expansive sense, social issues are pedagogical sites of counter-socialisation in which students agonise with ethical perspectives in order to consider social action, or ways to go on. But to support the critical function of reflective inquiry in any meaningful sense, social studies needs to open the windows wide to ethical perspectives. It is to this end that I suggest that social studies may profitably engage with the philosophy of ethics - a matter to which the next section now turns.

\section{ENGAGING WITH THE PHILOSOPHY OF ETHICS: THE ROLE OF PERSPECTIVES IN SOCIAL STUDIES}

Until you can see the truth in at least three sides of an issue, you probably don't understand it. And until you can convincingly argue all three perspectives, you probably can't work with a diverse group of people to find a mutually satisfactory solution (Schutt, 2001, p.108)

Up until this point, the discussion about ethical decision-making and action's theoretical framing has taken place within the context of social studies taught as reflective inquiry. This section considers the intersection with social studies taught as social science and, in many respects, reflects the way in which these two traditions have been brought together in the New Zealand social studies curriculum. My argument builds on that of the previous two sections by exploring how the philosophy of ethics could better support learners' capacity to critically and reflectively engage with social issues and their ethical content. I contemplate the role that the formal study of this discipline should play in social studies learners' exploration of ethical decision-making and action.

Chapter Three revealed that successive New Zealand curricula have barely noted the potential contribution of philosophy to social studies' interdisciplinary approach. I take it that this is a matter of oversight rather than deliberate exclusion but, either way, I urge 
that the philosophy of ethics should have a greater voice. What might this look like, and on what basis might one argue for its more overt inclusion? This section rests on a fairly simple proposition, and advances an aspect of Preston's (2007) recommendations for whole-school approaches to understanding ethics: that if social studies education is to permit an open exploration of ethical decision-making and action, learners require access to the language or discourse of philosophical ethics, as well as an understanding of the ethical systems 'in play'. Preston argues that though we mostly learn to navigate our ethical lives experientially - through interactions with significant others and from significant events - the study of ethics potentially complements the educative experiences of life. In his view, this provides a vital "bridge between the micro-moral world of home and the macro-impersonal ethical systems of society" (p. 217). He further contends that students:

Can be educated to recognise when they are encountering ethical issues, and to be aware of the principles or normative considerations at stake, and then to be able to relate this to decision-making in their own lives. This approach goes well beyond the clarification of values to a conversation about the justification of ethical decisions within a caring environment. (p. 217)

In other words, the discipline of ethics offers a means with which to conduct and extend discussion about ethical decision-making and action in educational settings, and in a way that stands outside programmes for the inculcation of 'morals'. This potential contribution is here explored in two parts: (a) its nature and extent, and (b) a justification for inserting ethics' disciplinary modes of thinking and theoretical perspectives into social studies.

\section{A. THE NATURE AND EXTENT OF ETHICS' DISCIPLINARY CONTRIBUTION TO}

\section{SOCIAL STUDIES}

If the language and discourse of ethics were to be employed in social studies, what would this include? Preston's (2007) use of 'discourse' can be understood in two senses. The first has to do with doing ethics, and pertains particularly to the analytic traditions of philosophy that, broadly speaking, focus on the clarity and cogency of argument. These modes of thinking and discussion involve both rational procedures and analytical concepts, such as logic. A second sense in which Preston's use of discourse can be understood is as a field of substantive concepts that categorise (i) what is thought about in ethics, such as fairness or responsibility, and (ii) types of inquiries, arguments and positions in ethical theory. The latter arrives at a term introduced in Chapter Two and 
that has recently become a feature of New Zealand senior social studies and geography curriculum and assessment support materials (see Chapter Three): ethical perspectives. As previously discussed, within the field of ethics we can identify categories, or perspectives, that classify particular inquiries, arguments and positions: virtues, deontological, or consequentialist ethics, for example. Ethicists use these categories to provide comprehensibility to a diverse range of philosophic positions. It is possible to trace genealogies of these perspectives, to identify debates within and between them, and even to recognise the limits of such systems of classification.

One could see this characterisation as advocating something along an axis between 'social studies as normative ethics' and 'social studies as applied ethics' - relegating meta-ethics, for example, to the periphery. In many ways, applied ethics does come very close to what I am proposing, if understood as reflection on social issues and action through a range of ethical perspectives. The field's themes and issues - such as war, capital punishment, and poverty - are certainly rich resources for social studies teaching and learning. Furthermore, the interdisciplinary nature of applied ethics is analogous to that of social studies education. However, I think one needs to be cautious about conflating social studies' interest in ethics with applied ethics, not least because the latter's nature and status is a matter of debate (Beauchamp, 1984, 2003; Cortina, GarcíaMarzá, \& Conill, 2008). At least one line of critique suggests that the field, which has grown in academic interest since the 1970s, does what philosophers of ethics have always done: attend to practical social problems. If we accept Adela Cortina's (2008) contention that "applied ethics limits its sphere of prescription to the exigencies of a civic ethics and does not get involved in the personal projects of a good life" (p. 15), an assertion that seems descriptively false, then we are once again caught in the dichotomous bind outlined in the previous section. But perhaps a greater concern is that a sole focus on normative or applied ethics belies the extent to which the many fields of philosophy and ethics intersect.

To locate social studies learners' exploration of ethical decision-making and action purely in normative or applied ethics is to neglect at least two dimensions of philosophical ethics education: (i) an area of content, that is, "a body of historical and theoretical knowledge and of perennially contestable questions" and (ii) meta-ethics, "in which contending theories are studied conceptually and logically, but then the move is made to epistemology and/or critical theory in order to determine how these theories can be evaluated" (Gregory, 2009, p. 105). How might this affect social studies 
teaching and learning? It could, firstly, minimise an important contextual dimension: learners' ability to locate the present ethical issue in question within a history of (Western) ideas, and to see that the ethical content of many current issues are matters of longstanding debate. In the language of the New Zealand social studies curriculum's social inquiry approach, they would be limited in their capacity to "ask questions, gather information and background ideas, and examine relevant current issues" (Ministry of Education, 2007, p. 30). Secondly, learners could be restricted in their ability to consider the meanings and nature of moral judgements or how the adjudication between rival ethical perspectives might be defended. And yet meta-ethical theories may throw 'exploring values and perspectives' - another aspect of social inquiry - into sharp relief. For example, surfacing a distinction between moral universalism and moral relativism is both simple to explain and would offer learners a conceptual framework with which to explore debates about the extent to which rules or human rights ${ }^{37}$ ought to apply. This distinction may also support them to consider ethical issues close to their experience, such as disjunctions between espoused school rules and instances of differential treatment.

\section{B. JUSTIFICATIONS FOR BRINGING IN THE PHILOSOPHY OF ETHICS}

The previous section argued that social studies' engagement with the philosophy of ethics should incorporate the latter's conceptual, analytic/modes of thinking and contextual/history of ideas dimensions. I have also suggested that, while applied ethics aligns strongly with a focus on social issues in social studies, other branches of ethics have a potentially important role to play in learners' counter-socialisation. I have begun to suggest how such a disciplinary insertion is concordant with the New Zealand social studies curriculum, particularly its social inquiry methodology. There is, however, a rather more substantive argument to be made as to why the philosophy of ethics should occupy a more overt space in social studies' interdisciplinary stable. The following subsections develop this argument. I firstly argue that the philosophy of ethics is among the powerful knowledges that learners should have access to as a matter of social justice. I secondly argue that, in principle at least, the philosophy of ethics contributes to a range of social studies outcomes that support counter-socialisation.

${ }^{37}$ Concepts central to Level 3 and Level $5 / 6$ of the New Zealand social studies curriculum, respectively. 
The main contention laid out in this section is that social studies learners' access to the language and discourse of ethics rests on a principle of social justice. Here, I draw on the work of sociologists such as Michael Young and Johan Muller (M. Young, 2008, 2013; M. Young \& Muller, 2010, 2013) who fear that the worst excesses of progressive education - a system that 'over-socialises' knowledge, or emphasises process to the detriment of content - risks excluding already socially disadvantaged learners. This, they argue, is because they are precluded access to the 'powerful knowledge' to which all are entitled: specialised disciplinary knowledge that, although fallible, has considerable capacity for generalisation. This concern has resonated with many academics similarly concerned with "constructivist variants that make little reference to existing bodies of knowledge” (Dyke, 2013, p. 1).

Notably, Michael Young (2013) cites ethics as an example of powerful knowledge, and in particular Kant's Formula of the End in Itself as being as "near to being a generalizable (or universal) principle for how human beings should treat others as we can get” ( $p$. 108). As Chapter Two outlined, other normative theories may be similarly defended as having generalising capacities. Rather more generously, one could assume that he would want to count the insights generated from virtues ethics, consequentialism or an ethic of care as 'powerful knowledge'. Understanding diverse ethical perspectives, therefore, might indeed have some explanatory power in terms of ethical controversies in plural societies. Second, Young wants to use ethics as an example of powerful knowledge that is not restricted to $\mathrm{STEM}^{38}$ subjects, and which has two important characteristics: it is (a) specialised (with generalising capacities) and (b) differentiated from that knowledge that learners bring to school. The argument built thus far in this thesis casts some doubt over where exactly the line might be drawn between 'academic' and 'everyday' ethics. Furthermore, when one links explanatory power, as Young does, to meritocracy and social mobility his argument appears to founder. In an important sense the philosophy of ethics is not powerful knowledge - one can conduct life without such academic insight and it does not appear necessary for social mobility.

I do, however, contend that bringing the knowledge foundations into the curriculum mitigates the risks of unfettered constructivism and share Young's view about the power of disciplinary knowledge, that epistemic access is crucial in addressing educational

38 Science, technology, engineering and mathematics. 
inequality. Because I am cautious about where the concept of powerful knowledge takes us, I wish to explore these reservations before suggesting how Young's argument could be re-worked in order to more satisfactorily defend the role of ethics in social studies education. Thus, what follows could be considered an extension of his thinking. Young wants to suggest, for example, that learners' everyday knowledge is to be reworked in light of more sophisticated, powerful knowledge. As Simon Catling and Fran Martin (2011) note, “inherent in this perspective is that children's experience, knowledge and understanding are poorly formed and of limited everyday use and value" (p. 317). The discipline of ethics is thus valorised over one's 'ordinary' experience of successfully navigating in a complex ethical world, for example. I'm not convinced, therefore, that learners fetch up to school with sloppy ethical thought. But even if this were the case, and as has been argued earlier in this chapter, better supporting learners' ethical decision-making and action most particularly requires an 'articulation' (Catling \& Martin, 2011) between their everyday ethical learning and that to which they might be exposed at school. This is what Parker Palmer (1998) describes as bonouring both "the 'little' stories of the individual and the big stories of the discipline and tradition" (p. 76). Arguably, social studies can explore the productive multiplicities across these spheres, without subordinating one to the other. Martin Dyke (2013) questions whether: In trying to reassert the value of knowledge (scientific or otherwise) over more experiential approaches to learning, Young has missed the importance of practice and the relationship between knowing and doing. Perhaps what really counts is the relationship between our knowledge and our practice: how we engage, critique and test ideas and theories and practice, and upon what basis we make our judgements. (p. 8)

As someone with an interest in poststructural theorising, I contend that powerful knowledge is both contextual and discursive in nature, as does Michael Young (2013). But I do not assume "that 'access to subject knowledge' can be discarded as a priority" (p. 114) for those included in New Zealand's 'long tail' of underachievement. Ethics' more explicit insertion in social studies is, as I have argued, a critical and urgent move. However, a key tenet of this thesis is that ethics' contribution to social studies is just that, the input of one discourse among many ways of seeing. I wonder, therefore, whether cultural discourses are to count among the 'specialised' sites, institutions and forms of transmission that Young contends produce powerful knowledge. I think that there are some important reasons they should. Māori and Pacific cultural discourses, for example, have their own epistemic forms and discipline, legitimate certain practices and forms of authority, and 'fiction' certain truths (Foucault, in Rabinow, 1984). Māori 
ethical perspectives are, furthermore, diverse and tied to local contexts (Keown et al., 2005, p. 17). For young Māori connected to their marae, such knowledges offer different powerful positions in their communities and, increasingly, in a wider society coming to terms with decolonisation - in iwi corporations and businesses, tourism and hospitality, the creative arts, and public service, for example. While the powerful knowledges Michael Young (2013) speaks of may predominantly determine access to these employment sectors, a degree of comfort and ease in tikanga and te reo Māori is increasingly advantageous. Granted, we are by no means witnessing an end to a consistent and deplorable pattern of Māori social and educational disadvantage in this country. However, education's role in realising cultural potential, that is, offering young Māori opportunities to enlarge what may exist as tacit cultural knowledge, is pivotal to reducing disparities - a view strongly endorsed through the Ministry of Education's $\mathrm{Ka}$ bikitia 2013-2017 strategy (Ministry of Education, 2014a). Furthermore, New Zealand's education system has a critical role to play in prising open the "particular forms of ethics" (Munshi, Broadfoot, \& Smith, 2011, p. 128) that have shaped Māori-Pākehā communication since colonisation. This is perhaps no more acute than in social studies education, which has a concerning history of silencing Māori (and Pacific) worldviews (Harrison, 1998; Luke, 2005; May, 1992; Samu, 2009; J. Simon, 1992).

My point here is that all learners require access to the powerful knowledges produced in multiple epistemes and discourses if they are to successfully navigate in New Zealand's bicultural, plural and complex society. In particular, addressing historical injustice and concomitant educational disparity cannot be achieved by marginalising cultural epistemologies - any more than it can by precluding access to the powerful knowledges Michael Young (2013) cognises. Young's question of social justice stretches, therefore, into the interdependent issues of content and representation that have confronted the philosophy of education at least since the 1970s and 80s: which philosophical issues are discussed/never discussed, how those conversation take place, and who is included/excluded from the discussions (Burbules, 2000). An allied debate is the extent to which Western philosophy may be extended to non-Western thought. Philip Catton (2012) asks: if we are at all serious about cross-cultural dialogue, and about those who are present, at what point might philosophy hurt?

We aim to consider philosophy in relation to traditional Māori intellection; to learn philosophically from Māori; to engage in bicultural dialogue...Is philosophising universal to all cultures? Does the question 'is philosophising universal to all cultures' in net terms help or harm cross-cultural dialogue and understanding? (p. 1) 
Thus, while I defend the philosophy of ethics' role in better supporting learners' ethical decision-making and action as a matter of social justice, I am sensitive to the limits of Western philosophising. Also, as previously discussed, I do not think the field offers a complete account of, and response to ethical life, a matter I explore in greater depth in the next chapter. To see ethics as a matter for philosophical abstraction is also to lose something of the inter-woven texture of academic thought and overlook the need for interdisciplinary responses to the complex issues that face societies - again, powerful knowledges produced in multiple epistemes and discourses.

\section{SUPPORTING COUNTER-SOCIALISATION: ETHICS' CONTRIBUTION TO SOCIAL STUDIES OUTCOMES}

How could the philosophy of ethics be powerful knowledge in social studies learners' lives? This section canvasses the potential disciplinary contribution to a range of interrelated outcomes in social studies education: (i) affective/dispositional, (ii) skills, (iii) knowledge/conceptual understanding, (iv) cultural identities, and (v) participatory (Aitken \& Sinnema, 2008). I explore how the philosophy of ethics might contribute to each of these in turn, particularly when social studies has a focus on social issues and counter-socialisation.

AFFECTIVE: One of the principal reasons for bringing the philosophy of ethics into social studies is its role in consciousness raising and encouraging learners to care about social issues. Because the discipline is fundamentally about what kind of life is worth living, it directly supports learners' consideration of what matters most in their own lives and in the lives of others. It enables them to explore what they care about and offers opportunities for discussion and debate in relation to contextual issues. The New Zealand Philosophy Teachers' Association argues, further, that the subject "is in a unique position to nurture and strengthen the (innate) desire to find meaning in the world" (Tweedie, 2013, n.p.). Tempting though it may be to describe learners as apathetic about social issues, at least in relation to climate change, a number of psychological barriers may limit their engagement with the issue. Gifford (2011) describes these as dragons of inaction, manifested as, for example: numbness, optimism bias, denial and unwillingness to confront the effects of one's worldviews. To add to Gifford's suggestions as to how these barriers could be overcome, environmental ethics could assist students, for example, to formulate their own ethical vision for the environment or to cope with uncertain environmental knowledge (Warner \& De Cosse, 2014). Undertaking these kinds of exploration need not undermine learners' spirituality 
or religious views. In an example explored further in Chapter Seven, the Dialogue Australasian network $k^{39}$, which has shaped numerous religious education programmes, includes theoretical and applied ethics as one of its five key strands.

Another strongly dispositional reason for mobilising the field of ethics in social studies pertains to appreciating difference. I draw here on Robert Hanvey's (2004) and others' (for example: Banks et al., 2005; Case, 1993; Pike \& Selby, 1988) conception of perspective consciousness. These authors argue that learners' capacity to make effective judgements in a plural, globally interconnected world is dependent on developing their perceptivity and receptivity: "the recognition of the existence, the malleability, and the diversity of perspective" (Hanvey, 2004, p. 5). In their view, the benefits of developing learners' perspective consciousness are two-fold. First, it may add to learners 'synoptic view' of the world, their ability to "see the 'whole picture' whether focussing on a local or international matter" (Case, 1993, p. 318). Importantly, seeing the whole picture does not mean a crisp, permanent global view; the authors emphasise the dynamic and complex nature of social and environmental issues. They secondly argue that perspective consciousness may prompt an inclination to "probe the deep layers" (Hanvey, 2004, p. 7) of claims, that is, to move past too ready an assessment of individual stances and instead more closely consider the assumptions that give rise to those positions. Although their use of 'perspective' is somewhat different to mine, I should think it likely that they would wish learners to be conscious of ethical perspectives and would see some role for the formal study of ethics in this. Hanvey mentions, for example, that "some (but not all) values clarification exercises can heighten awareness of otherwise unrevealed aspects of perspective” (p. 7).

Another reason for drawing the philosophy of ethics into social studies is that the discipline's modes of thinking encourage the disposition of tolerance, a capacity required for agonising with differing ethical perspectives. The New Zealand philosophy teaching and learning guidelines (Ministry of Education, 2014b) suggest that it is the reasoned exchange of ideas in the classroom that fosters tolerance of, and respect for others, a matter expanded upon in Teaching philosophy in Asia and the Pacific (UNESCO, 2009):

Learning how to reflect is important for the construction of the personality of children and adolescents. It is an opportunity for them to experience that they are thinking

39 http://www.dialogueaustralasia.org/ 
beings, which strengthens their self-esteem and helps them grow in humanity by experiencing disagreement in discussion in peaceful coexistence. This, in turn, raises the threshold of tolerance with respect to others and prevents violence. (p. 18)

SKILLS: Critically, the kind of perspective consciousness that Hanvey et al., and no doubt many social studies teachers, seek cannot be arrived at without the tools fit for the task. There is a vast body of international philosophy education literature that suggests the discipline has much to offer in this regard. Clinton Golding (2005) argues that philosophy should be added to the social sciences curriculum because "the discipline is specifically designed for answering complex conceptual questions and resolving controversial ethical issues" (p. 115) that are central to the learning area. As a methodology, Golding (2002) argues that philosophical inquiry's benefits for social studies learners are three-fold: it (i) aids meaning-making and conceptual understanding, (ii) enables learners to examine the 'substructure' of social studies and make connections to their own experiences because philosophy is foundational to education and life, and (iii) promotes 'good thinking' - both the conditions for, and improvements in, rational thought, critique and discussion. Similarly, The New Zealand philosophy teaching and learning guidelines (Ministry of Education, 2014b) argue that philosophy has a vital role in developing students' ability to question, to form rational, plausible arguments, and to explore the limits of their understanding. These are precisely the sort of intellectual skills that Engle, Ochoa and others have argued are necessary for counter-socialisation. Arguably, and as explored further in Chapter Six, the philosophy of ethics' modes of thought are able to be encompassed with social inquiry, the methodology strongly advocated for the social sciences (Ministry of Education, 2007).

KNOWLEDGE/CONCEPTUAL UNDERSTANDING: A further justification for bringing the language and discourse of ethics into social studies relates to the development of conceptual understanding. I submit that just as history and geography has its specialist languages, social studies education might conceivably mobilise ethical concepts in order to assist learners to make connections across the vast array of ethical issues that confront themselves and others. This contention rests on wide-ranging research on the role of concepts in enlarging understanding in social studies (e.g., Ministry of Education, 2009a; Taba et al., 1971), geographic and historical thinking (e.g. Brooks, 2013; Centre for the Study of Historical Consciousness, 2014; Counsell, 2011; Lambert \& Morgan, 2010), discipline mastery (e.g., Meyer \& Land, 2003, 2005, 2006), and conceptual change in science education (e.g., Vosniadou, 2010). Although this literature encompasses 
considerable debate, some agreement might be found in The New Zealand Curriculum's (2007) statement on learning areas and language:

Each learning area has its own language or languages. As students discover how to use them, they find they are able to think in different ways, access new areas of knowledge, and see their world from new perspectives. (p. 16)

Many concepts central to the social studies curriculum are also central to ethical inquiry: rights, racism, justice, rules, responsibilities and so on (Collins, 2004; Knight \& Collins, 2010a). Clinton Golding (2005) points out that these concepts are contestable, and that "there is a tangle of related questions and issues that need to be addressed before we can really understand" them (p. 118). For example, "would we be irresponsible in certain circumstances (Nazi Germany perhaps) if we followed the rules?" or "do we have a duty to uphold a Treaty signed by our forefathers?" (p. 119). The formal study of ethics supports students to ask questions about these concepts and debate the essential questions that underlie their citizenry. It is of course entirely possible for ethical inquiry to possess the critical thinking and reflective capacities previously noted, without recourse to what might seem like the heavy 'jargon' of ethical theories, as the Philosophy for Children literature demonstrates (see: Burgh et al., 2006). But harnessing the language of ethical perspectives is, I submit, a particularly important aspect of learners' conceptual growth in relation to their ethical decision-making and action. A statement on perspectives for geography (Crown, 2001) argues that:

We do not often get the opportunity to sit back and think about the mind-sets or theoretical perspectives that inform these disciplines or to think about the key philosophers whose ideas shaped these perspectives in compelling ways...[but]...different theoretical perspectives give us the capacity to critique and challenge these taken-for-granted ways of understanding the world. New perspectives give us the opportunity: to ask hard questions about the information we are dealing with in geography, to wonder whether or not there are other ways to represent information and ideas, to encourage school students to think very differently about the world that they are part of. (pp. 2-3)

Ethical perspectives are, therefore, a key aspect of content knowledge, or information that social studies learners might bring to discussing ethical issues. Learners' facility with ethical perspectives is, moreover, central to meeting The New Zealand Curriculum's (Ministry of Education, 2007) expectation that they will develop their ability to "critically analyse values and actions based on them" (p. 10). This is because ethical perspectives offer a language to explain why, for example, the curriculum's espoused values, such as social justice and sustainability, are contested. Learners may come to see 
that such values may be considered and translated into action from quite different ethical worldviews. Further, ethical perspectives provide a language to describe and explore similarities, differences, and contradictions across ethical issues, decisionmaking processes and proposed courses of action. Learners may notice, for example, that consequentialist arguments cut across people's views about giving to charity, public spending, and international aid. They may come to understand that, as discussed in the previous chapter, the social studies curriculum they learn from draws on some ethical perspectives, but not others. In short, ethical perspectives have descriptive and genetic dimensions: the first because of a focus on normative stances found within society as to how we should act, and the latter because it seeks to locate those stances within the wider frameworks of which they are part.

CULTURAL IDENTITIES: Another reason for affording the philosophy of ethics a more prominent role in social studies is that it potentially supports learners' understanding of their own and others' cultural identities. This could include becoming more aware of the ethical underpinnings of New Zealand's religious, cultural and institutional traditions, such as the trade union, women's suffrage or Ratana movement. The philosophy of ethics could prompt students to think about the relationship between culture, ethics and social issues - to ask, for instance, who decides whether a matter is an issue or problematic in the first place, whether morality is culturally relative, or the extent to which Western philosophy provides a sufficient account of ethical decision-making and action in their own cultural communities. Critically, to suggest the philosophy of ethics contributes to cultural identity outcomes is not to say that it should determine learners' cultural identities. Instead, and particularly in New Zealand's bicultural and Pacific context, greater attention to the philosophy of ethics would enable students to explore consonance and contradiction in non-Western and Western cultural traditions. I am thinking, for instance, of John Patterson's $(1992,1994)$ consideration of Māori worldviews in light of virtues ethics, and Tula Brannelly, Amohia Boulton and Allie te Hiini’s (2013) more recent paper on the relationship between care-based ethics and Māori mental health provision. I am also thinking of Paul Janman's (2012) documentary, The Tongan Ark. This portrait of Futa Helu and the Atenisi ${ }^{40}$ Institute he founded highlights the challenges of bridging Tongan and Western intellectual traditions. In different ways, each of these texts contemplates how we should live together in

40 The Tongan word for Athens. 
postcolonial contexts, a question that is as pressing for learners who have their feet in two cultural traditions as it is for Pākehā learners.

PARTICIPATORY: Access to ethics' analytic modes of thought, concepts and theoretical perspectives is also arguably central to participatory outcomes, particularly that of democratic citizenship. In one sense, the formal study of ethics ideally establishes a habit of democracy through relying "on a communal ethic that requires a co-operative approach to resolve complex or controversial human problems in practical situations" (Tweedie, 2013 , n.p.). In another, philosophy's role in democratic education can be viewed as encouraging freedom of thought and judgment in future citizens, "protecting them from ideological indoctrination and persuasive advertising" (UNESCO, 2009, n.p.). Further, having an understanding of the range of ethical perspectives and considerations involved in societal controversy, decision-making and participation is a key aspect of being an ethically-informed citizen. Precluding learners' access to such perspectives has, I argue, a narrowing effect: it removes significant pieces from the puzzles of moral life and limits the options for democratic participation within learners' purview. Here, I am reminded of John Annette's (2006) reflections on community involvement:

Digging a pensioner's garden is itself an act of doing good rather than an act of good Citizenship. The Citizenship learning begins when the student gardener begins to question why the pensioner is in the position that they are: in short, they may learn a thing or two about gardening, but the greater lessons are less about the pansies and more about the politics. (p. 263)

The greater lessons are also, I add, about ethics. It is notable, for example, that the Level 2 NCEA Education for Sustainability achievement standard ${ }^{41}$ that requires learners to undertake social action does not ask them to reflect on the ethics of their personal involvement. As discussed in the previous chapter, a similar standard in social studies ${ }^{42}$ somewhat obliquely requires students to describe the perspectives that justify their position but greater ethical evaluation could be encouraged. Similarly, a variety of school-wide efforts are aimed at raising awareness of the nature of other lives and of promoting the virtue of empathy, such as fund-raising for disaster relief or the 40 hour famine. These could be enlarged to include contemplation of the ethical basis for such action and alternatives, without dismissing learners' very real desire to make a difference

41 AS90810: Plan, implement and evaluate a personal action that will contribute towards a sustainable future. http://www.nzqa.govt.nz/qualifications-standards/qualifications/ncea/subjects/education-forsustainability/levels/

42 AS91282: Describe personal involvement in a social action related to rights and responsibilities. http://www.nzqa.govt.nz/qualifications-standards/qualifications/ncea/subjects/social-studies/levels/ 
in the lives of others. This would resist social and cultural transformation amounting to a-critical volunteerism and service learning.

SUMMARY: What might the philosophy of ethics add to learners' everyday and educative experiences of social issues and their ethical content? How is this powerful knowledge? This section has articulated a range of disciplinary contributions to social studies outcomes and counter-socialisation. Two of the most significant are directly related to the social studies curriculum's framing philosophies: social studies as reflective inquiry and as social science. As a social science, philosophy offers thinking tools for making sense of social issues and decisions about social action, that is, for socially critical reflective inquiry. The conceptual language and categories of ethics also enable social studies learners to understand what they are agonising with and make connections in their consideration of ethical decision-making and action. If I had to select the single most important contribution the discipline could make to social studies, this would be it. This is because ethical perspectives tug at the heart of the social studies; they have a uniquely powerful role to play in digging deeply beneath social issues, supporting learners' values exploration, critically assessing social participation and considering alternative actions. Moreover, the use of ethical concepts and perspectives in social studies is what makes ethics an explicit rather than a hidden dimension of their lives, the social studies curriculum, and their educative experiences. Not only do the analytic language and discourses of ethics open out the possibilities for genuine dialogue and inquiry about curricular concepts such as responsibility, human rights, and sustainability, but the substantive content of discipline holds a great deal of as yet unrealised potential to enrich this dialogue. The substantive content of ethics is perhaps akin to 'threshold concepts' (Meyer \& Land, 2003). These concepts are characterised as:

- Transformative, in that, once understood, its potential effect on student learning and behaviour is to occasion a significant shift in the perception of a subject, or part thereof;

- Probably irreversible, in that the change of perspective occasioned by acquisition of a threshold concept is unlikely to be forgotten, or will be unlearned only by considerable effort;

- Integrative; that is, it exposed the previously hidden inter-relatedness of something;

- Possibly often (though not necessarily always) bounded in that any conceptual space will have terminal frontiers, bordering with thresholds into new conceptual areas; and

- Potentially (and possibly inherently) troublesome. (pp. 4-5) 
I have also argued that providing an entrée to the discipline's language and discourses potentially supports more than purely cognitive aims. As I see it, the 'end game' of the discipline's involvement in social studies education is not to develop young philosophers of ethics or to hone rational thought, though these ends are most certainly positive. Without suggesting that social studies become the philosophy of ethics by another name, I have argued that the field plays a vital role in consciousness-raising about, and the critical examination of, social issues. The philosophy of ethics could also better support affective, cultural identity and participatory outcomes in social studies. The discipline offers learners opportunities to consider what lies at the heart of social issues, what matters most, and the cohering elements and contradictions of their own and others ethical decision-making and action. An understanding of ethical perspectives also supports learners' critical reflection about the cultural identities they have inherited and those they might select. Further, the discipline brings to light the ethical dimensions of participatory citizenship by enabling students to evaluate justifications for social action and ask, ultimately, whether we might do or be otherwise.

\section{CONCLUSION}

This chapter set out to consider theoretical spaces that could better support learners' ethical decision-making and action. I explored the extant framing philosophies of the wider New Zealand curriculum, and social studies within this. I have identified that the current social studies curriculum embeds ethical-decision-making and action in two theoretical traditions: social studies taught as reflective inquiry and as social science, both of which emphasise critical thinking. It is important to note that the alliance between social studies' framing philosophies is by no means unproblematic. Critical thinking, for example, has traditionally had quite different roles in social studies taught as reflective inquiry and social science. There exist also potentially uneasy philosophic tensions between, for example, approaches to reflective inquiry that draw on forms of constructivism, and critical realist positions in the social sciences. Further, Mullen (2004) notes a longstanding debate between disciplinary and issues-based approaches, the former seeing the social sciences as generating knowledge and the latter positioning social studies as the application of that knowledge to social problems. While such tensions are not entirely resolved here, this chapter has suggested that the distance between disciplinary and issues-based approaches may not be as great as others have suggested. We can see within the philosophy of ethics, for example, a strong focus on bridging that gap. 
Much of this chapter has been devoted to considering what would need adjusting within social studies' 'framing philosophies' to accommodate ethics. I have made a case that, in order to better support learners' ethical decision-making and action, (a) social studies requires a stronger focus on social issues and that learners' everyday experiences of ethical dilemmas and challenges should be more visible, (b) social studies should serve a largely critical function and, in order to do so, should be as encompassing of ethical perspectives as possible, and (c) learners require access to the language and discourses of the philosophy of ethics if they are to give full consideration to the ethical content of social issues and be able to speak into power. The justification for bringing in philosophy was two-fold: it provides access to powerful knowledge and contributes to a range of social studies outcomes. I have argued that, in particular, the formal study of ethics provides social studies learners with (a) the tools with which to engage critically with social issues, and (b) categories of thought to make connections in their learning. The latter, the substantive content of the discipline, is what I mean by a 'range of perspectives' in understanding ethics as:

...meaning both the branch of philosophy concerned with the systematic study of what we ought to do, and an activity - that of coming to an understanding of, and reflecting upon, a range of perspectives about social action.

My next chapter troubles the happy coincidence between the proposal put forward in this chapter and the already implicit theoretical orientations in the current social studies curriculum. Thus far, the proposal appears to rest squarely within the reflective, issuesbased and social sciences traditions of the subject. While an approach focused on social issues, counter-socialisation and the philosophy of ethics is both urgent and vital, these foci may not be sufficient, particularly if they are to be framed purely by the traditions of reflective inquiry and social sciences. Chapter Five, therefore, looks to the theoretical spaces that lie beyond social studies' existing framing philosophies. We have started to see in the discussion up to this point, for example, some important links to social studies taught 'personal, social and ethical development' (H. Barr et al., 1997) - a tradition focussed on the development of the whole person and much less emphasised in the current social studies curriculum. Chapter Five also shifts to a consideration of how the philosophy of ethics could be brought into social studies. I argue that whether the discipline meaningfully assists in learners' counter-socialisation is a matter of approach rather than content; one can, for example, teach the philosophy of ethics and social studies in an arid manner. My proposal for better supporting learners' ethical decision-making and action builds to what I term an 'ethically reflexive' approach to 
social studies education, one that resists construing learners' exploration of social issues, their counter-socialisation and engagement with the philosophy of ethics understood as just having to do with abstracted thinking. 


\section{CHAPTER FIVE: SOCIAL STUDIES LEARNERS' REFLEXIVE ENGAGEMENT IN THEIR ETHICAL WORLDS}

This chapter continues a consideration of the second of my research sub-questions, regarding the theoretical spaces that could be better support learners' ethical decision-making and action. Whereas Chapter Four urged a more overt insertion of the philosophy of ethics into social studies education, this chapter considers how ethics could be mobilised in social studies. I ask: could 'ethically reflexive' approaches better support social studies learners' ethical decision-making and action? Ethical reflexivity is a concept that has not as yet been employed in relation to social studies education. In building a definition for this concept, I explore its theoretical wellsprings in social theory and social sciences research. My point here is not to produce a settled term from unsettled academic terrain, but to consider what these diverse conceptions of reflexivity might coalesce around and, in turn, to consider its usefulness in better supporting social studies learners' ethical decision-making and action. The chapter arrives at a sense of 'ethical reflexivity' that emphasises critical reflection, lived experience and imagination - approaches to social studies education that draw on the insights of the philosophy of ethics as learners encounter, explore and shape their ethical world. An argument is made that etbical decision-making and action must amount to more than critical analysis if learners' counter-socialisation is to be supported. The chapter concludes with a consideration of the relationship between ethically reflexive approaches and the traditions of social studies.

\section{INTRODUCTION}

In considering the theoretical spaces for better supporting social studies learners' ethical decision-making and action, Chapter Four stressed a productive intersection between a focus on social issues, the subject taught as counter-socialisation, and the philosophy of ethics. Philosophy's modes of inquiry, ethics especially, enable students to ask questions about concepts central to their understanding of their ethical world and participation within it. In the previous chapter, I re-worked Michael Young's (2013) notion of powerful knowledge to draw attention to the explanatory power of multiple ethical perspectives. I argued that a facility with diverse theoretical perspectives would enable learners to better understand moral conflict and navigate in plurality; such a facility would support learners to situate themselves within a realm of ethical tensions and provides important intellectual tools with which to agonise. While there is no established empirical link between ethics education and social mobility, I argued that 
access to the powerful knowledges of ethics ought not to be limited to the already educationally privileged or confined to higher education. Further, to be both democratic and educative, social studies must not exclude learners from a cultural conversation that has spanned many centuries and informs many of the issues that face communities today. Nor should learners be sheltered from the uncertainty that coming to see a diversity of ethical perspectives may provoke. Ethics is more likely to bring clarity to the messiness of life that they already intuit.

Chapter Four also urged against viewing the philosophy of ethics as a narrow form of intellection - that is, simply knowledge and skills employed in the abstract. Instead, ethics contributes to a range of social studies outcomes that support learners' countersocialisation. I suggested, for example, that the field has much to offer social studies learners in terms of consciousness-raising, considering what matters most in their social worlds, the search for personal meaning in their lives, and exploring how they will live together within a postcolonial context. Bringing ethics more overtly into social studies currently framed as reflective inquiry and social science - encourages critical thought, but this is not critical thinking for its own sake. This is because, to return to a theme introduced in Chapter Three, both ethics and social studies are innately concerned with participation in society. The language and discourse of ethics is one of participatory possibility, offering social studies learners mechanisms with which to re/consider social action and potential moves in responding to ethical issues in front of them. Ethics, in the sense that I use the term here, is not simply a mode of societal critique, but a means with which to go on.

Whether the philosophy of ethics fulfils its potential in social studies education depends, of course, on how it is taught. This chapter begins by considering what might be lost if social studies education looked to academic philosophy in order to reflect on ethical life, rather than in ethical life. That is, I point out the risks of mobilising ethics in social studies in ways that are overly abstracted and distance theory from learners' lives. Most centrally, this chapter continues to address my second research sub-question, an exploration of theoretical possibility. I ask: could 'ethically reflexive' approaches better support social studies learners' ethical decision-making and action? Given that the reflexivity may be used interchangeably with reflectivity and critical reflection (D'Cruz, Gillingham, \& Melendez, 2007; Dyke, 2009), I begin by providing a description of reflective approaches. The semantic shift from reflective to reflexive is particularly important to tease out because social studies teachers are most likely familiar with 
'reflective' social inquiry. Then, aware of the protean nature of 'reflexivity', I explore how the term is employed across the social sciences. From this literature, I highlight the ways in which ethical reflexivity may be thought of as incorporating a critically reflective dimension - in the sense of re-casting our understanding of ethical decision-making and action. My use of ethical reflexivity, however, moves on from critical reflection by emphasising learners' lived experiences and ethical imaginations. The last section of the chapter considers how this conception of ethical reflexivity might pay in social studies education when it is directed towards counter-socialisation.

\section{SOCIAL STUDIES AND THE PHILOSOPHY OF ETHICS: THE RISKS OF ABSTRACTION}

No doubt we can all imagine situations where the philosophy of ethics, and indeed social studies, might be taught as if learners are in an art gallery and expected to observe the retrospective of someone else's creativity, from behind a white floor-marked line that divides the expert from the observer. Perhaps we might say that this has something to do with philosophy itself. In vastly different projects and contexts, for example, John Dewey and Martin Heidegger have questioned the roles and goals of philosophy $(\mathrm{R}$. Rorty, 1976). Dewey wanted to turn away from philosophy as a distinctive activity altogether and argued, instead, for a logic of inquiry "as a model for all forms of disciplined reflection" (Blattner, 2008, p. 58) that would both engage with learners' experience and more readily address society's problems. Heidegger essentially felt that philosophy, trapped in its own language of analytic reasoning, had moved further and further from a consideration of a way of being in the world. He argued that we access the world not through the abstractedness of philosophy but through being immersed in activities, projects, and practices.

There is much that divides these philosophers; Heidegger, for example, avowedly rejected epistemology whereas Dewey did not. But there is something in the flavour of their work that wrestles with a distinction between philosophy as an academic enterprise and 'real life'. Each perceives the discipline as having distanced itself from lived experience. I mention these authors here because their work inflects this chapter's discussion, but they are not the only theorists to have raised such meta-philosophical problems (Joll, 2010), nor are they issues that social studies may resolve. The salient insight for this thesis is, instead, the danger of importing the philosophy of ethics into social studies in ways that make the subject seem distanced from learners' emotions, 
experience, and real-world concerns. The problem is not that the philosophy of ethics' potential contribution to social studies is conceptual, academic, or rigorous - it is how it is used. I point out, therefore, the risks of abstraction.

The sense in which I use notions of distancing and abstractedness is akin to Donald Schön's $(1983,1987)$ conception of 'reflection-on-action' in teachers' professional work. By this he means that the real work of learning to be a teacher is mistakenly perceived as coming after the fact when one has the opportunity to step back and reflect on the lessons learned. The analogy here would be to think of ethics education as existing solely in classrooms rather than in the everyday experiences of life, or as an exercise that is perennially in retrospect. Schön argues that the reflection-on-action model is exacerbated by a climate of 'technical rationality', positioning teacher educators as the deliverers of pre-packaged knowledge and where teachers "often collude in seeing the truth as lying wholly outside themselves, regarding as 'higher' the knowledge that appears more general, abstract and theoretical” (Schön, 1992, p. 121). Again by analogy, the risk is that the social studies learner comes to see the ways that they already navigate in the swampy, indeterminate nature (to use Schön's metaphor) of their ethical life as something lesser than the seemingly assured higher ground of a classroom lesson in ethics.

Schön's contribution to education lies in drawing attention to the previously, and arguably still, marginalised aspects of professional practice and learning. Critically, he is not rejecting 'expert' knowledge. Instead, and in a genealogy that owes much to Dewey, Schön argued for much greater research attention to reflection within action - the artistry of practitioners' decision-making. Within this, he saw a variety of complex components. Knowing-in-action, for example, is the "knowing built into and revealed by our performance of everyday routines of action" (Schön, 1992, p. 124) such as riding a bike, and is akin to the notion of blindsight introduced in Chapter One. This type of reflection is to be distinguished from Dewey's notion of a felt difficulty because the situation does not feel problematic. By contrast, reflection-in-action is our ability to take note of surprise and respond to it in a fleeting moment. Conversation with the (uncertain) situation is, for Schön, much more like Deweyan inquiry: "mediated by conscious reflection and, at the same time, on one's way of thinking and acting on it" (p. 126). There is much that is open to question in Schön's work. The difficulty in finding examples that match ethical experience makes me somewhat uncomfortable about this typology. Moreover, and as others have pointed out (Munby, 1989), Schön relies on 
dualistic thinking to make his argument for greater attention to 'the swamp' as opposed to the 'higher ground' of academic thought, and to distinguish between reflection-onaction and reflection within action. Alan Bleakley (1999) argues Schön's thesis "paradoxically smacks of the kind of technical mapping that Schön opposes in principle" (p. 322) when he equates developing teachers' artistry and capacity to improvise with good coaching and modelling.

Schön is not, of course, directly commenting on ethics education in social studies. But, despite the previously expressed reservations, and in extending his work into the purposes of this thesis, I contend that, like teaching practice, learners' everyday experience may be conceived as sites for "generating, not only applying, usable knowledge" (Schön, 1992, p. 134). The role of the philosophy of ethics in social studies may therefore be contrasted against 'banking education', in the Freirean sense (see Freire, 1986), where the teacher issues ethical communiqués and deposits the insights of philosophy. Perhaps today this distinction seems rather crude. Surely no educator sees their practice in these terms? As I explore in subsequent chapters, much of the philosophy education literature strenuously resists a banking model. But abstraction and distancing are, anecdotally, challenges already faced in New Zealand social studies education. It is not too much of a stretch to imagine, for example, that the history of ethical ideas might be left in the past or that a glossary of ethical terms would be relegated to the back pages of learners' notebooks. Furthermore, there is some risk of the definition I have provided for ethics, exacerbating the distance between ethics and learners' lives (see below). This is because the definition infers that the role of the student is to consider accepted wisdom - to assimilate or accommodate that information, or perhaps even to reject it - but not to generate wisdom. It positions learners as being in a dialogic relationship with ethical perspectives, but there appears to be nothing outside of theory. It is as if learners are locked in a reflective bubble, divorced from their existence. In voicing a similar concern in the context of higher education, and in arguing for an 'ontological turn', Dall'Alba and Barnacle (2007) argue that knowing is not merely intellectual; it is inhabited, enacted and transformative. Drawing on Heidegger, they urge a much closer coupling between "formal and propositional knowledge, and the informal kind of knowing that arises out of being in the world" (p. 683). 
...meaning both the branch of philosophy concerned with the systematic study of what we ought to do, and an activity - that of coming to an understanding of, and reflecting upon, a range of perspectives about social action.

To use Schön's metaphor, this chapter attempts to re-balance the scales of the definition (above) for ethics in the direction of learners' swamps. This is because there is something more that I wish to capture in relation to bringing the philosophy of ethics into social studies learning - about learners as ethical beings, dealing with the everyday, emotive, indeterminate, and emergent nature of ethical decision-making and action. As an index ${ }^{43}$ to this, I was initially attracted to the idea of reflexivity, rather like a magpie attracted to the shiny quality of a newly found item. As the reader will see, others have similarly been drawn to reflexivity, but for all manner of reasons. The work undertaken in the next sections of this chapter is three-fold. I firstly consider the term critical reflection in order to set this apart from my use of reflexivity. The following section surveys the ways in which reflexivity has been employed in social theory and the social sciences. I then consider whether this concept has any force in social studies education, and what precisely reflexivity is an index to in the context of better supporting learners' ethical decision-making and action.

\section{CRITICAL REFLECTION}

The argument built thus far has been that greater opportunities for social studies learners to consider ethical decision-making and action are afforded through a more explicit insertion of the philosophy of ethics. The previous chapter stressed that such an insertion ought not to be seen as a narrow form of intellection; affective, participatory and identity are strongly associative outcomes. There can be no doubt, however, that the predominant framings of the current New Zealand social studies curriculum (taught as reflective inquiry and social science) draw heavily on critical thinking skills and dispositions, as does each aspect of my proposed adjustments to this framing. The argument so far might therefore be seen as speaking directly into that which has been called the 'critical thinking movement' (Ennis, 2011; Paul, 2014).

43 Indexicality is, notably, a central concept in ethnomethodology: "a phenomenon which Husserl has addressed under another name - implies that a meaning bearing unit (a word, a behaviour, a happening) may have more than one sense" (Alvesson \& Sköldberg, 2009, p. 39). 
Notably, a definition for critical thinking is by no means settled, and whether its skills are generalisable or domain-specific is an open debate (T. Moore, 2011; Mulnix, 2012). Furthermore, the extent to which varying models of critical thinking enable learners to challenge the theoretical landscape on which they stand is also a matter of critique. For example, moral reasoning approaches may limit the extent to which learners are invited to consider the ethical ends that are privileged, and some have questioned whether such approaches amount to a philosophical exploration of morality (Pring, 2008). This issue notwithstanding, critical thinking, with reason at its core, has become a leading feature of contemporary education (Goldberg, 2011). Because critical thinking and critical reflection are cognate terms familiar to social studies, and my use of reflexivity may appear synonymous, I offer here stipulative definitions.

The sense in which I use critical thinking and reflection has at least two dimensions. The first is the rational capacity to think otherwise, developed, for example, in the skills of logic and argument analysis. I have contended in the preceding chapter that these critical orientations, particularly as expressed in the philosophy of ethics, play a vital role in learners deciding for themselves what the good life consists in. Interestingly, one of the most prodigious writers on critical thinking, Richard Paul (2012), makes the converse link. He argues that multi-dimensional ethical issues are a vital site for teaching critical thinking in the strong sense - that which avoids atomistic approaches that treat critical thinking as a "battery of technical skills" (p. 467) to be mastered. He argues that by introducing ethical issues into "the analysis and evaluation of reasoning, we help them [students] more clearly see the relationship between world views, forms of life, human engagements and interests, what is at stake (versus what is at issue)..." and so on (p. 468).

The second dimension refers more particularly to the term critical reflection, the way that thinking may arc back on theory and concepts, that is, draw on inherited understandings and existing bodies of thought. The philosophy of ethics is an example of such knowledge that has been laid down over time. If this discipline were to be brought more overtly into social studies, students would employ its conceptual categories of thought and modes of intellection to critically reflect upon, for example, the understandings about social decision-making generated through the process of social inquiry or the ethics of the process itself. Importantly for the stipulative definition I am building here, critical reflection carries with it a strong sense of re-examining and reframing of a social world that was - things having inexorably moved on since the time 
of the occurrences or the thoughts being reflected upon. Notably, this interpretation predominates in what is called the conceptual, reflective and critical (Ministry of Education, 2008a) social inquiry methodology. It is explained that critical thinking skills "involve thinking outside the square, asking effective questions, and stepping back to reflect on the answers and findings" (p. 5) and that reflecting and evaluating "should focus on: the knowledge and understandings developed through the social inquiry process; the actual learning process itself; the depth of critical thinking about the understandings gained" (p. 9). Notwithstanding critical reflection being described as an ongoing dimension of social inquiry (that is, occurring throughout the process, not just as the end), the stance is largely one of "revisiting aspects of learning" (p. 4).

I return to a consideration of critical reflection later in this chapter. The reader will note there that my argument for an approach to better supporting learners' ethical decisionmaking and action does not dismiss critical reflection. Instead, my contention is that critical reflection is a necessary, but not sufficient, condition of reflexive approaches to expanding learners' ethical explorations. Two further points may be made in relation to this. First, while I argue that an emphasis on critical reflection is limiting, I do not suggest that this is a problem with the centrality of reason to that concept. Following Mulnix (2012), I take the view that critical reflection "is an inherently reason-based process, and as such, it cannot escape the central focus it places on reason" (p. 468). It is, secondly, important to stress that I am in no way suggesting there is something awry with retrospective analyses, or that somehow we are condemned to the past. Critical reflection means that we can never go back, because one is transformed in the process of thinking otherwise. As I go on to argue, there is also an important connection between reflection and imagination because we find the seeds of the latter in our own past and in the changing perceptions of the world within which it is formed.

\section{REFLEXIVITY'S TROPES}

I turn now to the prospects for an ethically reflexive approach in social studies. This section attends to the ways in which the concept of reflexivity has been taken up in social theory and in the social sciences, with a view to considering whether reflexivity might have a function in better supporting social studies learners' ethical decisionmaking. In general terms, the concept of 'reflexivity' connotes something bending back on or taking account of itself: "conceptions of reflexivity range from self-reference to self-awareness to the constitutive circularity of accounts or texts" (Wacquant, 1992, p. 
36). It is not a new idea and has, for example, long been implicit in social theory, interpretative social sciences and lay contexts such as 'mulling things over' (M. S. Archer, 2007; Holland, 1999). Neither is the concept of reflexivity settled: its etymology is complex, it has various meanings and usages across academic contexts (Ashmore, 1989; M. Lynch, 2000) and is very often used as a portmanteau term, the meaning of which is tacitly assumed (M. S. Archer, 2007). With appreciative humour, R. Smith (2005) declares that the concept "has undoubtedly joined the pantheon of great words with multiple meanings. We may be sure that the word signals a cluster of debates, linked areas of inquiry, rather than a clearly articulated stance” (p. 2). This landscape notwithstanding, I consider in turn four basic and inter-related senses in which 'reflexivity' is employed within the social sciences: (a) the capacity of human beings to consider and act on their social worlds, (b) which may extend into academic critique and disciplinary self-critique, and (c) has implications for the interplay between research and that being researched, including a consideration of how they themselves are constructed as such. Further, (d) reflexivity recognises the emotional and embodied experience of ethical life.

\section{(A) CONSIDERING AND ACTING ON OUR SOCIAL WORLDS}

The capacity that the vast majority of us have to make choices in life rests on the fact that we possess awareness that context shapes us, an ability to take cues from our environment, and endeavour to reshape our contexts in light of this information. This is the kind of reflexivity "that appears (at least since Descartes) to characterize consciousness: thought or feeling is also awareness of there being thought or feeling" (Smith, 2005, p. 3). The idea that we act mindfully and further that our selves are constructed through experience, was famously explored by the social psychologist George Herbert Mead (1934), whose notion of reflexiveness rested on the idea that "the individual is not a self in the reflective sense unless he is an object to himself' (cited in Adams, 2003, p. 232) and this is achieved through shared activity.

In charting reflexivity's biographies in social theory, Margaret Archer (2007) argues that it is a necessary condition of social life, though sociologists may argue about whether "some social formations and ways of life generate more reflexivity than others" and why (p. 29). Her own conception of reflexivity reconceptualises socialisation away from a structure/agency dualism: she sees reflexivity as mediating structure and agency, and socialisation as relational. As a consequence of the latter, her definition does not 
encompass individual actions and pursuits such as mountaineering that also require a type of reflexivity in terms of taking cues from one's context. Drawing on Max Weber, she conceives reflexivity as "the regular exercise of the mental ability, shared by all normal people, to consider themselves in relation to their (social) contexts and vice versa" (p. 4). So central is reflexivity to the human condition, argues Archer, that without it there can be no society. In critiquing the work of early anthropologists such as Evans-Pritchard, who contended that traditional societies were utterly shaped by social norms, she argues that such communities must have been reflexive, for three reasons: (a) "all societies are open systems and hence no normative canon covers all contingencies" (p. 27), (b) that what might be described as routine, practical and 'second nature' actions require reflexivity in order to deal with the unexpected, and (c) that the very concept of tradition "needs the exercise of reflexivity to make it so" (p. 27). Such reflexivity may also extend beyond inter-personal action and bend back on, for example, the environment and the spiritual domain. "Metadiscourses about religion that are found in theology, philosophy and the history of religion have long since established the fact that a reflexive stance is intrinsic to religious belief and faith" (Højbjerg, 2002, p. 3).

Matthew Adams $(2003,2006)$ contends that an 'extended reflexivity thesis' is commonplace in contemporary sociology, even among social theorists whose work otherwise differs. The concept of reflexive modernization (Beck, Giddens, \& Lash, 1994) is a notable nexus for this thinking. The sense in which these and other authors explore reflexivity is in relation to the conditions of late modernity. It denotes a radical questioning and perpetual doubt in a contemporary social world characterised by an increased tendency to remove sources of insecurity by acting on itself. Rather than being rule following, society is conceived as rule altering. Similarly, and particularly in the view of Giddens (1991), one's self-identity in post-traditional societies is also reflexive. In his view, "nothing is more central to, and distinctive of, human life than the reflexive monitoring of behaviour, which is expected by all 'competent' members of society of others" (Giddens, 1976, cited in Adams. 2003, p. 222). But there is something more distinctive about late modernity, he argues. No longer necessarily tied to tradition and culture, we may select from myriad choices of lifestyle and life-politics such that "the individual is no longer painting by numbers, so to speak, she is creating her own work of art" (Adams, 2003, p. 223). It is also notable that at both the societal and individual levels, reflexivity is implicated in our unconscious as much as our conscious choices. The green movement and 'sustainability', for example, may gain expression in mindful 
actions such as recycling or reducing our use of plastic bags, but has also become so suffused in our identities that we may not see these actions as rule-altering.

Just how reflexivity plays itself out in 'second' or 'late' modernity is a matter of open debate among sociologists. Margaret Archer, for example, has taken issue with the idea that reflexivity is a property of the structures and institutions of late modernity; for her it is people that are reflexive (Adams, 2003; Dyke, Johnston, \& Fuller, 2012). By contrast, Beck, Bonss and Lau (2003) argue that more recently "the challenge of theorising reflexive modernization is that the system of co-ordinates is changing" (p. 2). Individualisation, globalisation and trans-nationalisation, for example, trouble previous conceptions of modernity being tied to the nation-state. Another extension of 'reflexive modernisation' engages with the insights of complexity theory. Lash (2003), for example, finds in the work of Beck a register of 'reflexivity as non-linearity' associated with the work of Niklas Luhmann (1995). Luhmann emphasises that communication-based interaction and organisations are inexorably shaped by external forces and influences. Drawing on Maturana and Varela's (1998) use of autopoesis in cognitive biology, Luhmann has argued that, in much the same way cells are shaped within their environment, societies may be 'autopoetic' responding to environmental influences with systemic changes. Ethics, for example, could be thought of as 'laying down a path in walking' (Varela, Thompson, \& Rosch, 1993). Here the concept of autopoesis is strongly linked with reflexivity, recursiveness and adaptation; social systems are seen as re/adapting to, re/modifying and potentially dissolving back into their environments. Thus the persistence of social order is not seen as pre-given: "reflexivity is now at the same time system de-stabilization" (Lash, 2003, p. 50) and reflexive modernization must be understood as a much more emergent, non-normative and nonfoundational process.

The concept of reflexive modernisation is by no means the only way in which reflexivity has been employed in social theory and the human sciences (Ritzer, 2005; Sandywell, 2013; R. Smith, 2005). It is equally important to note that social theory's reflexivities have attracted vigorous critique. Reflexive modernization theorists have, for example, drawn criticism for overlooking the embedded, socialised and culturally-located nature of reflexivity (Adams, 2003; J. Alexander, 1996) and, moreover, for reasserting Western superiority through positioning reflexivity as a “'modern-modern' or 'purely' modern condition, which makes it superior to everyone else, to all traditional conditions and all Other, 'lesser' modernities” (Argyrou, 2003, p. 39). Perhaps, posits Adams (2003), "contemporary notions of reflexivity tell us more about the cultures and traditions of 
Western, late modern society than they do about our liberation from them” (p. 225). Further, Bauman (1993) notes a tacit assumption of a better, safer world contained in 'reflexive' and further points out that the human capacity to learn from experience is not at all guaranteed. Others have argued that the nature and content of reflexive processes warrants greater elucidation (M. S. Archer, 2007; R. Smith, 2005), and have suggested that the notion of 'degrees' of reflexivity "may tell us much more about social division and difference than an individual ability" (Adams, 2003, p. 234). Adams further views the 'project' of reflexivity as overly-rational and individualised because it "implies a centred subject at the helm, overseeing a purposeful trajectory" (pp. 224), thus overestimating the extent to which people may exert control over their conditions.

\section{(B) REFLEXIVITY AS CRITIQUE AND DISCIPLINARY SELF-CRITIQUE}

Let me now turn to the next sense in which reflexivity is used in social sciences literature: as academic critique and disciplinary self-critique. First, and if one accepts that reflexivity is a condition of consciousness, academic thinking is inherently self-reflexive in the way that it involves the systematic re/examination of one's ideas or "persuading colleagues to examine the taken-for granted concepts, values and practices of the field" (R. Smith, 2005, p. 3). Though not all academics would necessarily characterise their thinking as reflexive, particularly given the unsettled nature of the term, each would no doubt see themselves as engaged in critical thinking; fundamental to, and a prized ideal of, education (Bailin \& Siegel, 2003). Yet, intra- and inter-paradigmatic critical thinking involves some kind of recursiveness in thought. In the context of philosophy, for example, Radder (1997) argues that the investigation of the limitations or 'conditions of possibility' of ideas might best be described as 'philosophic reflexivity'. Some authors have argued further that transdisciplinary reflexivity is a requisite element of critical thinking in academia. Holland (1999), for example identifies a radical mode of reflexivity:

Not bound by either paradigms or disciplines. This is transdisciplinary reflexivity ... not so much a fixed location as a method for evaluating systems of knowledge, tied as they are to sectional interests and constellations of power. It invites re-entry into the epistemological and sectional complexities of our human condition to intervene, "knowingly" according to our ethical priorities. (p.476)

This argument points to a more substantive sense in which reflexivity has been applied to disciplinary thinking, one that extends beyond a simple metaphor of cognitive circularity. This is 'epistemological reflexivity', or seeking to understand "the manner in 
which knowledge changes its own subject” (R. Smith, 2005, p. 12). A notable example of this is reflexive sociology, associated with theorists such as Bennett Berger, Alvin Gouldner and Pierre Bourdieu. For Bourdieu, reflexive sociology entails more than simply acknowledging one's position in sociological work - it requires "identifying the key filters that alter sociological perception... limits of knowledge specifically associated with the analyst's membership and position in the intellectual field" (Wacquant, 1992, p. 38). It is through a process of reflexivity, Bourdieu argues, that the epistemic moorings of sociology are both laid bare and strengthened. The ethical content of this stance is particularly notable, especially given the focus of this thesis. Epistemic reflexivity, understood in Bourdieu's terms, is an express commitment to the avoidance of duplicity and complicity in sociological thinking. Though Bourdieu was reluctant to advocate particular moral ends, his sociology "may also be read as an attempt to transform the principles of vision whereby we construct, and therefore rationally and humanely shape, sociology, society and, ultimately, our selves" (Wacquant, 1992, p. 59).

Bourdieu's work moves us closer to a critical orientation to epistemic reflexivity that more overtly 'bends back on' ethical implications. In another context, working in the field of management and organisation theory, Willmott (2008) argues that critical reflexivity involves:

A capacity to recognise the inescapably partial and constructed foundation of all knowledge claims... It involves an awareness of the contingencies of knowledge production, embedded as knowledge inescapably is in particular traditions, disciplines, methodological protocols, temporal contexts, etc. In addition to re-minding us of the particularity of what counts as knowledge - for example, in its dependence upon the privileging of particular epistemological and ontological assumptions - critical reflexivity heightens attentiveness to its (unavoidable) ethical significance with regard to the consequences of taking knowledge claims to be true. (p. 83)

\section{(C) REFLEXIVITY, RESEARCH METHODOLOGIES AND PROFESSIONAL PRACTICE}

A third landscape of usages relates reflexivity to qualitative, interpretative social sciences research fields and methodologies such as ethnomethodology, hermeneutics, critical theory and poststructuralism (Alvesson \& Sköldberg, 2009; Denzin \& Lincoln, 2000). Douglas Macbeth (2001) notes that contemporary social science research reflexivities may turn back on inquiry, theory and/or text. For example, 'textual reflexivity' connotes the researchers' sensitivity to absences and erasures in text, including their own writing. We might think here of literary deconstruction influenced by Derrida, or critical 
discourse analysis (Fairclough, 2003) - methodologies that are alive to textual equivocation, ambiguity and contradiction and historicity, and in which the researcher very often writes "the disruption of realist assurances about representation and textual coherence into the text and, often enough, the disruption of the text itself by various devices and experiments in textual display (Macbeth, 2001, p. 43). 'Positional reflexivity', for Macbeth, involves the researcher critically examining, for example, taken-for-granted assumptions, power relationships and researcher/researched constructions. It begins with an acknowledgement of their location within the research:

Reflexivity demands that inquirers place themselves on the same causal plane as the object of knowledge. They must make explicit the social positions, interests, background assumptions, biases, and other contingent, perspectival features of themselves that shaped the questions, methods, interpretations, and modes of presentation of the claims the knower accepts as knowledge. Reflexivity affirms the partiality of representations without denying their possible claim to truth. (E. Anderson, 2014)

Positional reflexivity sees researchers not as passive scribes but as active participants in knowledge production (Hertz, 1996). While their methodologies may be vastly different, those who deploy the concept of reflexivity in their research inquiries typically share some central intuitions: the partiality of research, the limits of representation, the inseparability of power/knowledge and how this is historically and socially constituted. Sue White (2001) suggests that reflexivity is a process of destabilising research and practice, "looking 'outward, to the social and cultural artefacts and forms of thought which saturate our practices', and inward to challenge the processes by which we make sense of the world" (cited in D'Cruz et al., 2007, p. 78). The analytic rigour sought through surfacing these complicit factors may also incorporate the epistemic reflexivity discussed in the previous section: "decentering not only the sedimentations of the analyst but (reflexively) those of the field itself' (Macbeth, 2001, p. 39).

Another, related use of reflexivity in research methodologies and practice is as a critique of emancipatory and liberal humanism. This links back to the sociological critique made in the last section, that is, of the idea that reflexivity enables one to single-handedly steer the course of life towards something better and freer. For example, Alan Bleakley (1999) argues that, for all that Schön's focus on the artistry of teaching orients us away from technical-rational certainty, it "is still firmly rooted in personalistic humanism and its project of self-development" (p. 322). By contrast, postmodern, poststructuralist and 
deconstructive perspectives attend to the culturally, historically and discursively constituted nature of agency. Critically reflexive practice, "problematises the 'subject', and investigates the conditions of possibility for the constructions of subjectivities" (p. 317). Interestingly, Bleakley wants to stretch a conception of reflexivity further. Drawing on Heidegger, he argues that reflexive teaching practices in higher education should account for being in the world: as ecological, an active world engagement and sensitivity towards context. Further, and in light of his concern that reflection-as-action could simply be an act of faith, his conception of holistic reflexivity incorporates an ethical dimension:

What makes holistic reflexivity different from reflection-as-action is, again, its inclusion of both the aesthetic and the ethical, as a practice of sensitivity to, and a caring for, the world. The ethical dimension in particular constitutes a shift from descriptive reflectivity to critical reflexivity, where the latter theorises (problematises and relativises) action as it happens, reflecting on action against value perspectives. Holistic reflexivity is an inclusive ecological or caring act of reflection as well as an appreciative gesture, with an explicit concern for 'otherness' and 'difference'. (p. 328)

A third sense that reflexivity is used in qualitative inquiries relates to research ethics. Marilys Guillemin and Lynne Gillam (2004) suggest that reflexivity is "a helpful conceptual tool for understanding both the nature of ethics in qualitative research and how ethical practice in research can be achieved" (pp. 262-263). They note three dimensions of ethics in qualitative research: (i) professional codes of ethics that guide research practice, (ii) procedural ethics, involving approval from ethics committees for undertaking research involving people, and (iii) ethics in practice, for instance the unanticipated ethical dilemmas that arise within the course of the research. They focus particularly on ethically important moments, or micro-ethics, "where the approach taken or the decision made has important ethical ramifications, but where the researcher does not necessarily feel himself or herself to be on the horns of a dilemma” (p. 265). For these authors, ethical reflexivity involves subjecting the purpose of the research to ethical scrutiny and attention to the relational substrate of the research. They argue that, for example, it is in ongoing, complex interpersonal interactions "that the process of informed consent really occurs - not on the pieces of paper that an ethics committee peruses” (p. 275). This argument is illustrated by Aaron Kuntz's (2010) and Kim Etherington's (2007) research work. These authors reflect on the importance of being aware of, and sensitive to, the ethically important moments that arose in the (re)negotiation of the research process. Kuntz (2010) experienced an ongoing ethical 
tension between protecting his participants' identities and representing his participants' lives in ways that "recognized the fluid nature of identity, the multiply constituted individual, and the multiple slippages inherent in representation" (p. 426). Etherington (2007) tells of the power and trust relationships that required mindful renegotiation when her work with two ex-clients moved from a therapeutic relationship to her writing a book that included their experiences.

The complexities of both Kuntz's and Etherington's research and writing remind us of the limitations of 'in advance' codified and procedural ethics, both in research and professional practice. Their work instead points to the need for a much greater, ongoing sensitivity and agility in ethical decision-making and action. Tom Strong (2005) argues that, for constructivist psychologists, "practicing reflexively requires some element of social improvisation" (p. 96) but this does not mean that professional codes of ethics are unimportant.

\section{(D) REFLEXIVITY AND EMBODIEMENT}

In her introduction to an article entitled The emotionalization of reflexivity, Mary Holmes (2010) apologises for the way that her writing has subordinated emotion to clarity and muses, "it is perhaps that very effort at clarity which has washed away the flavour of feelings which attend all our thinking (pp. 139-140). Such a statement speaks to a challenge for each of the reflexivity theses outlined above: "how to rescue definitions and explanations of reflexivity from their over-focus on the cognitive and the individual" (p. 140). Holmes's subsequent argument is part of a widening body of sociological research literature that redresses, in varying projects, a lack of attention to the emotional aspects of reflexivity (see also: Brownlie, 2011; Burkitt, 2012; King, 2006). One can see similar concerns cropping out in other fields. In the context of social work, for example, D'Cruz et al. (2007) point out a dominant discourse has been practitioners' control of their emotions, seen as negative and coercive. They argue that emotions may be seen in a more positive and productive light: "the acknowledgment of emotional responses by the practitioner can be used to promote deeper understanding between practitioner and client and ultimately enhance practice" (p. 81). This is not meant to imply uniform success or a simplistic view of the relationship between emotions and one's ability to be reflexive: "emotional reflexivity is not simply a matter of individuals exercising skills. Emotions are done in interaction with others; they involve bodies, thought, talk and action" (Holmes, 2010, p. 149). Thus, for Holmes, reflexivity is: 
An emotional, embodied and cognitive process in which social actors have feelings about and try to understand and alter their lives in relation to their social and natural environment and to others. Emotions are understood not in terms of some that may retard reflection and some that may enhance it; rather reflexivity is thought to be more than reflection and to include bodies, practices and emotions. (p.140)

Holmes' thesis draws our attention to the complex connection between reflexivity, emotion, context and bodies. This brings us to the final trope of reflexivity that I will explore here, and one informed by phenomenological ${ }^{44}$ and post-structural understandings. Broadly speaking, phenomenological theorists may be distinguished from post-structural thinkers in terms of a tendency to focus on the individual rather than the discursive constructions of bodies (Davies, 2010). The notion of embodied reflexivity is underpinned by the idea that the body gives rise to the very possibility of experience (Stoller, 2009; Wilson \& Foglia, 2014) and consequently that "the practice of reflexivity should extend to a consideration of research as embodied experience, both for the participants and the researcher" (Del Busso, 2007, p. 310). A recent return to feminist phenomenology interrupts this apparent binary and has sought to acknowledge both the material reality of bodies and their socially constructed, inscribed nature.

Research in this field highlights the "experiences of bodies in situations, in which it is impossible to disentangle so called 'natural' and 'social' elements" (Lennon, 2014, n.p.). Rather than speaking of bodies as a purely discursive construction 'without flesh' or as a material reality with 'fleshy feelings', we might think of bodies as changing over the life course, in processes that are both biological and social (J. Evans, Davies, \& Rich, 2009). Thus, embodied reflexivity attends to lived experience. Reflexivity's locus is shifted from the head to a whole-bodied account; one that is visceral, spiritual and present in the moment. As Bai and Banack (2006) suggest, "the difference between sensing oneself as having relationships and as being relationships has profound ethical and educational implications" (p. 13).

\section{ETHICAL REFLEXIVITY}

The plethora of meanings canvassed in the previous section perhaps renders reflexivity as a rather figurative and confused concept. This is because at one level it appears

44 Associated with theorists such as Husserl, Heidegger, and Merleau-Ponty. 
axiomatic that reflexivity is a fact of our social world. We all interpret our experience and act on that interpretation; one might call this learning. While it is speculative to suggest that contemporary society has produced more or better reflexivity, it is impossible to deal with the vicissitudes of our ethical world without it. Further, simply being in the world requires a reflexive recourse to the other; having regard to the feelings of those around us or considering what principles should guide interaction, for example, are dependent on the idea that there is a 'something else' one must take account of.

Beyond this self-evident account, reflexivity cannot be expected to do the same extraordinary range of work in social studies education as it does in social theory and the social sciences. This section, therefore, attempts to draw out a conception of ethical reflexivity from the previously described tropes and critiques and considers the usefulness of ethical reflexivity for social studies teaching and learning. For the purposes of social studies education, I argue that ethical reflexivity encapsulates three important dimensions: (a) critical reflection, (b) lived experience, that is, the emotive, embodied, everyday, and emergent dimensions of ethical life, and (c) imagination - a dimension only lightly touched upon in the reflexivity literature. I stress here that these are not separate spheres. For example, the relational and embodied aspects of lived experience that I go on to describe are enfolded with critical reflection and imagination.

\section{CRITICAL REFLECTION}

One persistent meaning of reflexivity in the literature canvassed in this chapter is that of reconsideration - recasting, for example, one's understanding about society, the social sciences as a discipline or role as a researcher. It includes a notion of recursion thought processes that continually fold back on our social world in ways that contribute to the growth of our conceptual schema or radically re-alter it. This extends to selfquestioning accounts of philosophy in matters of scope and representation, that is, an awareness of the field's limits. For Holland and others, transdisciplinary reflexivity also cognises the ways in which the field's modes of thought might move between varying ethical perspectives and into other disciplines. For a number of theorists, such as Bleakley (1999) and Willmott (2008), critical reflexivity takes account of ethical considerations, as assumptions are prised open. In this sense, ethical perspectives serve as a kind of convex mirror, where ideas do not directly arc back on themselves or return to the same point of origin, but are refracted in new lines of thought. 
These varying usages of reflexivity are, following the stipulative definition offered earlier, what I would term critical reflection. Construed as rational 'thinking otherwise' about that which has gone before, this is an important component of my stipulative definition for ethical reflexivity. The previous chapter's argument - a call for a more explicit role for the philosophy of ethics in social studies - draws strongly on critical modes of thought. Thus, my proposal for better supporting learners' ethical decisionmaking and action necessarily involves critical consciousness and reflection through lifting ethical phenomena into the realm of the examined life. The reflexivity literature extends this argument somewhat by suggesting that we should not position learners' reasoning as lab work, that is, as a matter of practising doing ethics with criteria. This point has been made in relation to history education by Kent den Heyer (2012), who argues that critical reflection should "provide opportunities to question the changing epistemological basis of what it means to do history" (p. 190); by extension, to question the truth-processes of their ethics education. Returning to the notion of ethical discourses, introduced in Chapter Two, the reflexivity literature also extends critical reflection to include a discursive interpretation, that is, reflection on the discourses in which we are engaged and in which we are positioned. Here, I am reminded of Elizabeth Heilman's (2006) argument that social studies and global education should include "a deconstructive critical education that continuously explores meaning, power, and positionality and is aware that all teachings, texts, and media, claim, distort, enhance, open, and close perspectives” (p. 207). An important connection to the imaginative aspects of ethical reflexivity lies in the ways in which learners' awareness of their own and others' positionality opens up the consideration of strategies with which to go on.

\section{LIVED EXPERIENCE}

The varying tropes of reflexivity explored in this chapter suggest that the concept has been developed in a more expansive sense than critical reflection. A second dimension seeks to territorialise and re-embody the sense of detachment that I think is conveyed by the term critical reflection - and returns to Schön's swampy, complex and indeterminate aspects of social life. As I intend it, the 'lived experience' aspect of ethical reflexivity pulls in the uncertain messiness of the present and recognises that we are not always in a position to put a great deal of distance on ethical issues at hand or to draw on formal, reasoned knowledge. Very often we muddle through ethical life, sometimes stumbling but other times operating in quite innovative ways. The inclusion of lived experience extends beyond critical reflection in at least three ways. First, 'lived experience' captures 
the emergent nature of ethical action: "contextually appropriate action that is not consciously mediated" (Davis, 2004, p. 214). In Varela's (1999) terms, ethical decisionmaking and action is in many instances 'immediate coping'. It very rarely proceeds along predictable and orderly lines, though much social studies and citizenship literature understandably focuses on the observable means (curricula and pedagogies, for example) by which the overt products of participation may be achieved. Ethical reflexivity does not, however, refer to mindless spontaneity. The concept of emergence "draws attention to the fact that there is required a kind of ethical noticing of what is good...learned after years of listening and practising” (Neyland, 2010, p. 172), such noticing being akin to the improvisational nature of jazz.

Lived experience, secondly, captures the everyday ethical dilemmas and challenges that emerge in social studies learners' daily lives, relationships and experiences. It acknowledges the interpenetration of the distant events and the everyday: the similarities in ethical questions that arise from what they notice in 'private' and 'public' domains, and the ways in which distant controversies become enmeshed in the daily commonplace of cell phones, iPads, and social networks, for example. Understood in this sense, bringing in the 'everyday' facilitates students' contextual thinking (Eilam \& Trop, 2010), that is, their ability to move between circumstance and theory. This reminds us of Dewey's experientialist view that "our principles, values and possibilities for the resolution of morally problematic situations arise within those very situations themselves" (Johnson, 2009, p. 150). Dewey's emphasis on the interplay between firsthand, everyday experience and theory is a theme taken up by Martin Dyke (2013) in his research with dockyard workers who had elected not to participate in higher education. Connecting to M. S. Archer's (2012) conception of relational reflexivity, Dyke interrogates Michael Young's (2008) account of powerful knowledge, outlined in the previous chapter. In the context of the dockyard, Dyke (2013) records:

...a rich seam of informal and lifelong learning. A situated and creative learning culture had developed, one carved from a traditional working-class industrial landscape where people have related reflexively to circumstance in order to shape their lives in ways valued by them and the members of their social network. (p. 14)

To parallel this argument in the formal educational setting of the social studies classroom is to suggest a more complex view of education than the presumption that constructivist/bottom-up learning is necessarily in tension with powerful/top-down approaches. In Dyke’s (2013) view, “we should perhaps seek to have a better 
understanding of the relationships between the elements of learning such as knowledge, practice, reflection and our engagement with others, rather than simply assert the primacy of the aspects over all others" (p. 15).

To understand lived experience as being part of ethical reflexivity is, thirdly, to point to the embodied nature of ethical life: the visceral, spiritual, emotional and fleshy feelings innately connected to ethical decision-making and action. As with research and professional practice, it is to recognise vulnerability and uncertainty. A connection between ethics and emotions is, of course, hardly new. Graham Oddie (2009), for example, points to the history of values empiricists who, in quite different theories, have posited that emotions, feelings and desires are an important source of data about value. Furthermore, not all philosophers regard emotions as morally suspect or something to be overcome. In the book Valuing emotions, Stocker and Hegeman (1996) argue that emotions are central to the good life and are co-constitutive with values. Some ten years on, Ronald de Sousa (2014) argues that there now appears some consensus among philosophers as to the characteristics that an acceptable theory of emotion would need to account for. Among these:

- they typically involve more pervasive bodily manifestations than other conscious states;

- they contribute crucially to defining our ends and priorities;

- they play a crucial role in the regulation of social life;

- they protect us from an excessively slavish devotion to narrow conceptions of rationality;

- they have a central place in moral education and the moral life. (n.p.)

Ethical decision-making and action is, therefore, both cognitive and emotional. And yet, as Marjorie O'Loughlin (2006) argues, "educating the body is not an idea encountered in most programmes of citizenship today. Ideas about democracy and the development of democratic dispositions as a way of being do not at present include the body" (p. 18). As Chapter Three revealed, this critique could be extended to the New Zealand social studies curriculum and, I suspect, if ethical decision-making and action were a stronger curricular feature, this too would read as disembodied and devoid of emotion. Importantly, my sense of ethical reflexivity includes the emergent, embodied and emotive in people's everyday relationships with others, their communities and the environment, without subordinating lived experience to critical thought. It also suggests some caution about placing too much educative weight on the critical. Jim Neyland (2010) argues that while "deliberative knowing plays a kind of watching brief that allows 
us to intervene should the full flow of ethical know-how need to be interrupted" (p. 174), constraining 'full-bodied' know-how through allowing critical reflection to overstep its role reduces people's capacities for fully functioning in the world. But, equally, I do not dismiss the important role of critical reflection. Emotions may inherently raise questions of value and ethics, that is, involving emotions in learning could activate critical ethical thought (Eilam \& Trop, 2010). Further, as Megan Boler (1999), in her book Feeling power: Emotions and education, insists, "a pedagogy that recognizes emotions as central to cognition and morality need not preclude intellectual rigor or critical inquiry (p. 110). Similarly, Varela (1999) argues that formal education has a vital role in developing learners" "understanding of ethics in a non-moralistic framework" (p. ix).

What work does lived experience, together with critical reflection, do in a conception of ethical reflexivity? An ethically reflexive approach that takes account of lived experience invites learners to notice the ethical as it emerges in the particular circumstances of their lives, as they undertake social inquiries, and locate themselves in social issues.

Acknowledging that social issues are very often palpable, sticky, and problematic, ethical reflexivity enables social studies learners to see their lived encounters as "social, logistical, and ideological resources" for ethical action (Peterson, 2009, p. 18, my emphasis) that are equally as useful as top-down ethical theories. Ethical reflexivity also offers learners a more central role in philosophic debates, one in which they can use their "personal experience to critique what passes as accepted knowledge in a field, while also making sense of personal experience through the lens of that accepted knowledge" (Sinacore, Blaisure, Justin, Healy, \& Brawer, 1999, p. 267). Thus, ethical reflexivity locates the learner as wrestling and agonising with the ethical, not as the recipients of pre-figured perspectives. Further, bringing in lived experience draws attention to the relational nature of ethics; social inquiry, for example, becomes that of ongoing, sensitive renegotiation between people in research relationships, rather than a matter of procedural ethical compliance.

\section{ETHICAL IMAGINATION}

What then of bringing about social change? As the previous sections have conveyed, ethical reflexivity is innately concerned with complexity and uncertainty in ethical life. Just as the need for decision-making stems from swampy situations, ethical responses are not a matter of certitude. Notably, much of the social studies and citizenship 
literature carries a kind of instrumental rationality through the use of terms such as: active citizenship, social action, taking action, service learning, and making a difference. By contrast, critical reflection and lived experience imbues ethical reflexivity with a 'participatory sensibility' (Davis, Sumara, \& Luce-Kapler, 2008):

Everything matters, but we can only be aware of only a small part of what goes on around us. We can never know the full consequences of an action and, as such, we must participate mindfully in the unfolding of circumstances around us. (p. 173)

It is this participatory sensibility and its relationship to imagination that I see as being as being a third central aspect of ethical reflexivity. This recognises that the resources of critical thought and daily life provide learners with insufficient response to the complexities of ethical decision-making and action; creativity, innovation, and imagination are also required. It is this, I contend, that propels them beyond the status quo, enables them to create new trajectories and lies in the remaking of their ethical worlds. To me, ethical imagination is generative; it shifts our learners' gaze from absences identified in critical reflection to what could be in their ethical worlds. Using the work of Alain Badiou, den Heyer (2012) argues that social studies education should open and support "an institutional space for truths to emerge from such creative and inventive potential" (p. 205). These spaces may exist in their wonder, for example, at random acts of kindness, or what appears unusual in others' ethical actions, or what moves them. It is, further, what transports them from what they thought they had towards that which is essentially indeterminate, at least in prospect.

Imagination, of course, has been of interest in almost every field of academic thought. C Wright Mills (1959), for example, argued that sociological imagination - a quality of mind that seeks to link history, biography and wider social forces - was vital in terms of developing the capacities of reason and societal critique. And to be sure, imagination has had both a wide variety of applications in philosophy (Gendler, 2014) and something of a chequered history in classical ethics. Thomas Alexander (1993) notes that:

While thinkers in the classical tradition, like Plato and Descartes, saw imagination as a source of error or, like Aristotle, at best as a lower, necessary condition of thought, the romantics and their inheritors made it the source of nonnatural insight into the transcendental infinite or the subconscious, archetypal world inaccessible to mere understanding. (p. 371) 
I will not here attempt to précis all the ways in which imagination and ethics have been linked in moral philosophy, except to point out its prominence amongst contemporary philosophers and social theorists. Richard Rorty, Hilary Putnam, Martha Nussbaum and others have stressed the role of literature and public works such as documentaries in cultivating moral imagination. For Nussbaum, "the novel, more the philosophical text, provides an opportunity to explore the complexities, conflicts, and ambiguities inherent in human life" (Wright, 2003, p. 107). Margaret Somerville (2006) similarly argues that the language of poetry is an important route to many ways of ethical knowing, where "we can gain access to, and explore, numinous realities... What we learn from through them is not inconsistent with reason and logic, just different" (p. 16). For her, imagination is an important building block in creating a shared ethics because it enables consideration of questions that cannot be answered by experiential knowledge and the 'hard sciences' alone. Equally important, she argues, are the stories we tell because they are a vital mechanism for enabling the consideration of difference.

The imaginative consideration of how to go on is thus, firstly, about desire, understood as a will to change. It is also fundamentally relational, whether unfamiliar moral perspectives are accessed through, for example, fictions or face-to-face encounters with the other. The relational importance of ethical imagination is stressed by Henrietta Moore (2011), who views ethical imagination as the primary site for social change, political protest and cultural invention:

... because it engages with and refigures self-stylization and self-other relations in the context of [affect, emotion, the placement of the body, fantasy, and relations with objects, technologies and the material world] ... To grasp it in all its fullness, we have to recognise that it is not just about conformity to the normative or to power, but it is about the strategies that individuals in their freedom' can use in dealing with each other. (p. 21, my emphasis)

When this literature is read together, imagination might be seen as arcing back on myriad surfaces and contributing a constellation of possibilities for social action to my use of ethical reflexivity. The way in which I use ethical imagination, however, is more directly conjunctive with creation and world formation, and resists a sense in which imagination/thought exists a priori to action among these authors' work. Adams' (2003) consideration of life-politics mentioned earlier provides an important link to the way in which I use ethical imagination: the idea that, in reflexive modernity, "the individual is no longer painting by numbers, so to speak, she is creating her own work of art" (p. 223). This is suggestive of what I see as being the enfolded nature of imagination and 
creation, an idea that crops out in a number of authors' work, from a diverse range of theoretical perspectives. Dewey (1922), for example, saw moral reasoning as an imaginative thought experiment, conducted as one temporarily suspends action:

A dramatic rehearsal (in imagination) of various competing possible lines of action... an experiment in making various combinations of selected elements of habits and impulses, to see what the resultant action would be like if it were entered upon. (p. 190)

Understood within Dewey's theory of experience, imagination is not separate from moral life; instead, moral imagination grows in and through experience. Moreover, on Dewey's account we understand what images mean when they show themselves in action. And in his lectures on ethics, it is apparent that "forming and striving to actualize the image constitute a continuous experience: imaging and taking action are not different kinds of experience, but phases in a continuous stream of experience" (Chambliss, 1991, p. 47). More recently, and through Dewey, Mark Johnson (1993, 2009) has developed a metaphor of 'morality as art' to emphasise the role of moral imagination in creativity. Johnson (2009) argues that imagination "is the key to the moral acts by which old conceptions and values are reshaped, our ways of perceiving and responding to situations and people are transformed, and new realities come into existence" (p. 212, my emphases). He posits three types of imagination: imaginative perception, imaginative envisionment, and imaginative action. Although one needs to be cautious about simple taxonomies of imagination, the latter comes close to my use of the imagination within 'ethical reflexivity', in particular because it breaks down a thought/action binary.

Another insight that shapes my use of imagination within ethical reflexivity is that of the social imaginary, most notably from the work of Cornelius Castoriadis. The title of his book, The imaginary institution of society (1987) refers not to fantasy, but to the ways in which imagination brings forth, or institutes social practices and organisations. The social imaginary, for Castoriadis, reflects humanity's profoundly creative dimension, as expressed in its enormous imaginative capacity. Human beings are led continuously to create their social world - one which is in a continuous state of coming-in-to-being. Castoriadis' ontology was particularly sceptical of any view that societal evolution and forms of life are determined by forces or relationships. In his view, society is selfinstituting "emergence of radical otherness, immanent creation, non-trivial novelty" (p. 184). Importantly, drawing Castoriadis' central intuitions about the evolution of society into ethical reflexivity goes beyond autopoesis described earlier in this chapter. 
For Castoriadis a free or autonomous society "is a society that gives itself, effectively and reflexively, its own laws, while knowing that it is doing so" (cited in Asara, Profumi $\&$ Kallis, 2013, p. 227). On his account, people and societies - 'public' and 'private' worlds as co-existent - may knowingly conceive of themselves, and this is strongly linked to what it is to be free and autonomous. Individual political autonomy "is the active and lucid agency that constantly reorganizes its contents, through the help of those same contents...mixtures of what it has already found there before and what it has produced itself' (p. 106). Castoriadis argued that we should be recreating our world, self-consciously and collectively, through 'objective reflexivity ${ }^{45}$. As Gaonkar (2002) explains:

Autonomous societies habitually call into question their own institutions and representations and the social imaginary that underwrites them. Here the people as collective agents recognize the contingency and constructedness of their world and how that world is made possible through the workings of the social imaginary. Hence, one need not think of the social imaginary as a demiurge that sets itself to work behind the backs of the people. It can be reflexively interrogated and hermeneutically reappropriated. (p. 8)

My undertaking in this section has not been to wholly align myself with Dewey, Johnson, Castoriadis or others, or to firmly locate myself within fields such phenomenology or complexity theory. One may derive similar arguments to those I have presented here from a variety of theoretical positions. My concern has been to explore the work that imagination could do in a concept of ethical reflexivity. The argument has been that wonder, desire and generativity, for example, enable social studies learners to move beyond the resources of critical thinking and lived experience (although I re-emphasise that these are not separate spheres). Ethical imagination impels learners' becoming onwards, knowing not where this will lead or whether the strategies they employ in ethical life will amount to satisfactory solutions. Importantly, this expands the places for the possible in learners' counter-socialisation. It suggests that while social issues necessarily involve dilemmas and contentiousness, their ethical action may not always speak to problems. And it reminds us that the insights and modes of thought of the philosophy of ethics, while a much needed insertion into social studies education, is only one contribution to the artistry of learners' ethical lives. Most certainly, the philosophy of ethics offers the means with which to go on but other possibilities are generated and enacted through lived experience and imagination. Thus, ethical reflexivity invites the

45 Which he contrasts with the 'purely reflexive', that is, unconscious reflex. 
philosophy of ethics to the artistry of learners' ethical lives, but is not itself the artwork. This view, I think, would be readily accepted among contemporary academic ethicists, particularly as they have turned away from 'grand theory'.

\section{CONCLUSION: ETHICAL REFLEXIVITY, COUNTER-SOCIALISATION AND REMAKING ETHICAL WORLDS}

There is only one subject and that is life in all its manifestations. (Alfred North Whitehead, 1929)

The work of Chapters Four and Five has been to propose a broad theoretical orientation to supporting social studies learners' ethical decision-making and action. The argument developed in Chapter Four was that the curriculum requirement to bring ethics into social studies education (a) requires a focus on social issues, (b) should be directed towards learners' counter-socialisation and that, (c) both are strengthened by explicitly incorporating the modes of thinking and theoretical perspectives of academic ethics. I argued that mobilising the philosophy of ethics within social studies education is a matter of social justice, in that learners are offered powerful knowledges with which to critically explore ethical decision-making and action, and is vital, furthermore, because it enhances a range of social studies outcomes.

This chapter began from the premise that whether the philosophy of ethics realises its potential in social studies education is dependent on how it is incorporated. The risk, as with any subject, is that it could be taught in an abstracted and distanced manner. In pursuing my research question as to the theoretical spaces that exist for better supporting social studies learners' ethical decision-making and action, the chapter has taken ideas of reflexivity from social theory and social sciences research. On my account, ethical reflexivity is a term capable, stipulatively, of incorporating people's capacities for critical reflection and imaginative action. It recognises also that these capacities are largely borne from lived experience; the surfaces that ethical reflexivity spring back from are manifold and not just those of academic ethics. Of course, other terms may have sufficed as indexical for these features. However, to me the term ethical reflexivity provides continuity for social studies teachers and learners who are familiar with the term critical reflection but at the same time reflection is interrupted, making the familiar unfamiliar.

Having developed this stipulative definition, the final work of this chapter is two-fold:

(i) to draw together the bases upon which reflexive approaches can be defended as an 
important theoretical orientation to better supporting social studies learners' ethical decision-making and action, and (ii) to consider whether, in contrast to the argument developed in the last chapter, an ethically reflexive orientation would require a radical departure from the ways in which social studies in The New Zealand curriculum (Ministry of Education, 2007) currently frames ethical decision-making and action.

\section{ETHICALLY REFLEXIVE APPROACHES AS SUPPORT FOR LEARNERS' ETHICAL DECISION-MAKING AND ACTION}

This chapter has shifted from considering reflexivity's tropes in the social sciences and in social theory to how a concept of ethical reflexivity might be useful in social studies education. In the sense I turn to now, ethical reflexivity describes an educational adaptation to the society within which learners find themselves - a contemporary ethical space that, from a variety of accounts, may be thought of as being marked by reflexivity. We respond reflexively to the demands of societal complexity, pluralism and ambivalence; assembling from myriad reflexive surfaces bespoke, 'good enough for now', responses to the contingencies of ethical life. In this context, strongly aligning ethical decisionmaking and action with critical thinking, as The New Zealand curriculum (Ministry of Education, 2007) does, underserves the needs of learners as they navigate in their ethical worlds. In one important respect, my use of ethical reflexivity highlights aspects of ethical decision-making and action that appear under-acknowledged, and might be arbitrarily distinguished, in social studies teaching and learning. It is notable that recent theorising in North American contexts has revealed the minimal attention to affect (Helmsing, 2014) and imagination (Egan \& Judson, 2009) in social studies education. Even more critically, and to the best of my knowledge, there is no social studies literature that considers the interplay of critical reflection, lived experience, and imagination, let alone the relationship to learners' ethical decision-making and action.

My use of ethical reflexivity resists, as elsewhere in academic thought, representing the social and ethical world as conforming to dualistic conceptions of reason/emotion, formal/informal knowledge and so on. It might be possible, for example, and on one reading of this chapter, to think of ethical reflexivity as the domain of individual thought and action and thus ethical decision-making and action as being a solitary act. As this chapter has pointed out, the individual and society are not separate spheres. Ethical decision-making and action is necessarily a relational activity that arises from a consideration of how we should live our lives with others and the environment. A second binary that I have interrogated is implicit in the phrase ethical decision making and action. I 
submit that conscious ethical decision-making is not separate from, or a priorito, action. Often in the lived world, action is decision. Furthermore, action is a site of ethical imagination. Social studies taught as counter-socialisation ought not, therefore, to simply engage learners in rational decision-making or an ethic of critique (Starratt, 1994) ahead of their active citizenship, but in continuous and evolutionary processes of knowingly recreating their ethical worlds - even if we cannot be certain of how those future worlds will be.

Thus, in another important sense, the literature reviewed in this chapter underscores the need for careful consideration of how ethical decision-making and action might be given expression in New Zealand social studies classrooms. An arid introduction of the philosophy of ethics, minimal opportunities for critical reflection, inattention to learners' lives and ethical imaginations risks closing off the actual and potential contribution that social studies might make to learners' counter-socialisation. Rather than positioning social studies learners as simply recipients of pre-packaged ethical knowledge, reflexive approaches could better support their ethical decision-making and action by encouraging them to assemble the resources of critical reflection, philosophy, lived experience and their imagination in enacting their good life. This resists flat, monotone and distanced approaches, where the aim is to reach once and for all conclusions by the end of the lesson. By contrast, it acknowledges and calls for considerable responsiveness on the part of social studies learners in terms of intellectual agility, sensitivity towards the other, and to context.

A precedent for this approach may be found in Martin Dyke's (2009) framework for reflexive learning, a response to what he sees as the demands of reflexive modernity. Dyke's approach calls on four elements conceived as a non-linear and holistic process: theory (or claims to knowledge), practice (or concrete experience), reflection, and interaction with the other (in a social context). There are significant parallels between Dyke's conception of reflexive learning and an ethically reflexive orientation, not least a connection to the work of Dewey and Schön. The elements of theory and reflection are broadly analogous to my use of critical reflection, practice and interaction with lived experience, and doing with imagination and creativity. There are, of course, some important distinctions; Dyke's concern is not immediately with ethics and the embodied dimensions of reflexivity are not overtly considered, for example. My point here is not to assert that Dyke's argument confirms mine, or is lacking in some respect, but to suggest instead that beyond social studies education others are similarly exploring a concept of reflexivity as it applies to teaching and learning processes. His search, like 
mine, is for pedagogies where the academic disciplines are not seen as directing practice but where the relationship to received wisdom "values the past experience and knowledge claims of others but... does not defer to it" (p. 295).

Dyke's (2009) non-linear and holistic approach suggests how an ethically reflexive orientation could move past a debate/action binary, pedagogically speaking. Much of the previous chapter was indeed concerned with the 'debate side' of this binary and the more explicit insertion of the philosophy of ethics into social studies education. However, I stress that teaching and learning about ethical decision-making and action need not necessarily begin with theoretically informed ethical discussion or debate. It could instead begin and continue with the imaginative - the unusual, absurd or humorous as entry points and stimuli for ethical discussion. An ethically reflexive orientation also leaves room for beginning with action, or the 'concrete' in Dyke's terms. In this way, learners' existing and everyday social participation, their lived experiences, become the site of, and resources for, ethical exploration. This is important because, "now what might be done" (Ministry of Education, 2008, p. 10) about an issue is currently positioned as the outcome of social inquiry, the re-iterative nature of the methodology notwithstanding. I contend that turning the social inquiry model 'on its head' could offer much more fertile ground for learners' consideration of the ethical content of social action.

A pedagogical emphasis on the imaginative and learners' lived experience resists the assumption, implicit in cognitive developmental approaches (Hill, 2014), that reason and debate are the inevitable precursors to acceptable moral behaviour. Moreover, it places critical, ethical reflection in the service of learners' whole lives, rather than being the sole outcome of social studies teaching and learning. What an ethically reflexive approach could look like in social studies classrooms is further developed in Chapter Seven, where I recommend a range of pedagogical approaches that could be assembled, adapted or amplified in strategies for social studies teaching and learning.

\section{BEYOND THE NEW ZEALAND CURRICULUM?}

The previous chapter proposed adjustments to the New Zealand social studies curriculum's extant framing in order to better accommodate learners' ethical decisionmaking and action. There I argued that social studies, as the melded traditions of reflective inquiry and social science, could and should overtly mobilise the philosophy of 
ethics, reconceive social issues as including the 'private', and be more strongly directed towards counter-socialisation. When the argument for an ethically reflexive orientation is also taken into account it would seem, on the surface at least, that all resemblance to social studies as reflective inquiry and social science are lost - an exercise of curricular extrapolation that stretches all bounds of credibility. In this section I demonstrate through the work of Brian Hill (1994) that the connections may not be as strained as they first appear, and that we may expand them further.

The reader will recall two significant features of Hill's work, a first being its strong influence on the development of social inquiry in the New Zealand social studies curriculum. Second, he sees the ultimate aim of social studies as being the empowerment of the social and ethical self. This perspective was cited by the authors of the Waikato position paper (H. Barr et al., 1997) as an important example in the tradition of social studies taught as personal, social and ethical development:

Proponents of this tradition argue that the purpose of social studies is to help students face and deal with problems in today's changing world. They claim that social studies be concerned with the development of the whole person and should help students develop a positive self concept. (p. 3 )

I submit that Hill might recognise much of his thinking in relation to the argument I have built across the previous two chapters. Most certainly, and as I have acknowledged, he is one of the very few Australasian academics to have explored the place of the philosophy of ethics in learners' social studies education. His book, Teaching social studies in a multicultural society (Hill, 1994), devotes an entire chapter to ethical issues and perspectives in social studies. In particular, he argues for an explicit insertion of the philosophy of ethics, as justificatory theories, into social studies. Such is the strength of his conviction, he argues that teachers and learners owe it to themselves to study the field in more depth. I think that Hill would, secondly, concur with the suggestion that a definition of social issues should be expanded to include challenges and dilemmas that are not publicly observable. His suggestions for 'hot topics' at the time of publication could be read as an attempt to bridge a public/private divide in relation to social issues described in Chapter Four. Such topics include 'sex and family', 'my community', 'becoming a person', and 'religion and life'. For all that eyebrows might raise over these topic choices, his motivation appears to lie in ensuring that the nature and purposes of social studies remain close to learners' being in the world. Third, the argument that social studies should be directed towards learners' counter-socialisation appears one that Hill 
would endorse. The aim of social studies, as he sees it, stresses equipping learners with the resources to navigate in and change society: "not merely to achieve the goal of academic understanding and competence, but to build this learning into one's own response to the social environment" (p. 216). He argues for stronger pedagogical attention to social action, that is, a move beyond the skills of reaching and justifying decisions. $\mathrm{He}$ stresses the importance of encouraging learners to interrogate their own cultural conditioning and discursive formation in order to consider strategies for change.

The conception of ethical reflexivity developed in this chapter also appears to resonate with Hill's (1994) work. Notably, what he describes as the initiative domain of social studies is very close to my use of ethical imagination. For him, this domain "is where cognitive and affective elements are inextricably interwoven with the choices and purposes of the integrated self' (pp. 151-152, my emphasis). Further, and in line with my use of critical reflection, he argues that paradigm analysis is central to social studies education, without which "we will not be alerted to the risks of having our understanding limited by inadequate basic assumptions and values" (p. 163). Though he is sceptical of thorough-going relativism, he argues that it "is never too soon, however, to tackle the question of what sorts of evidence and faith underlie particular truth-claims in social explanation" (p. 164). Perhaps we might debate how far this should to be taken. Hill's 'critical affiliation' model allows for an open exploration of democracy's imperfections, in contrast to democracy being an implicit feature of reflective decisionmaking. But he stops short of suggesting that learners could critique values he sees as being "centrally located in democratic ethos" (p. 218).

Arguably, a re-reading of social studies in The New Zealand curriculum (Ministry of Education, 2007) in light of Hill's work could highlight the important intersection of the tradition of social studies taught as personal, social and ethical development $(\mathrm{H}$. Barr et al., 1997) with the curriculum's extant framings. This could address some of the curricular absences noted in Chapter Three - such as its ethical silence, the absence of feeling, and the de-centring of learners - which appear not to be what Hill would have intended for social studies or a model of social inquiry. It perhaps positions ethics education in social studies as responding to what Dewey (1910) called learners' felt difficulties. Further, it could acknowledge the fact that many New Zealand experienced and pre-service social studies teachers see this tradition (in combination with reflective inquiry) as being central to the purposes of social studies (Hawe, Browne, Siteine \& Tuck, 2010), irrespective of the curriculum. 
But I think there are at least two very important reasons for caution about reading my argument for ethically reflexive approaches to social studies education as being wholly aligned with social studies taught as personal, social and ethical development and/or Hill's (1994) variant, the empowerment of the social and ethical self. A first relates to the way in which the whole person is theorised through each orientation. I am wary, for example, of the inherent, humanistic assumptions in concepts such as development and empowerment: of a coherent, bounded self; able to shape its own destiny through inquiry and reason; and conforming to predictable pathways to integrated selfhood. Reflexivity, as I use it, resists these conceptions and instead emphasises an arcing back on the multiplicities of the self and the ground on which its stands. Something of the flavour of this contention is carried in Gilles Deleuze and Felix Guattari's (2013) resistance to conceptions of co-ordinated selfhood. As Mansfield (2000) summarises: Being is to be conceptualised in terms of the endless and multiple involvements that enwrap things in the world in an inevitable, albeit dynamic and transitory interrelationship - in the 'assemblages' that establish 'connections between certain multiplicities'. (p. 140)

These ideas tie in with the idea of counter-socialisation employed in the preceding chapter in the sense that constant, embodied engagement and re-formation in life moves beyond social studies taught as personal, social and ethical development. An ethically reflexive orientation focuses more closely on the complexities and contradictions of social transformation. A second reason why ethical reflexivity moves beyond social studies taught as personal, social and ethical development returns to my point about arcing back on multiplicities. I submit that asserting the primacy of this tradition risks occluding the ways in which ethically reflexive approaches, in life and in pedagogy, may be thought of as assemblages. While it is of course the case that the varying traditions of social studies, however characterised, are inter-related and have been given different emphases over time, my argument here is that ethically reflexive approaches transcend the rather arbitrary nature of such boundaries. One contribution ethical reflexivity makes to social studies is not, therefore, a grand theory of everything, but a provocation in thinking more expansively about how learners' ethical decisionmaking and action might be better supported. 


\section{CHAPTER SIX: PROSPECTS AND CHALLENGES}

Having proposed an ethically reflexive orientation to better supporting social studies learners' ethical decision-making and action, this chapter turns to considering the challenges and prospects abead. It begins by reviewing research about the implementation of the New Zealand Curriculum (Ministry of Education, 2007), especially the V alues statement and the social sciences learning area, in order to establish the extent to which teachers may already be taking an ethically reflexive orientation, despite minimal curricular elucidation. This research suggests that signalling the shifts in meaning (Aitken, 2006) could be a determinant in terms of how ethical decision-making and action is picked up in social studies classrooms. I then explore three further potential influences on how curriculum materials and social studies teaching and learning may give expression to ethical decision-making and action: ethics in an era of the scientific management of education, and knowing what works in evidence-based education, and the ethics of ethics education. While this predominantly reads as a series of constraints, the perspective of a small group of New Zealand social studies teachers and their students, who were asked to consider the role of ethics in social studies education, suggests that a reflexive orientation could transcend the ethically silent space of social studies.

\section{INTRODUCTION: DOING THE 'HARD BITS' OF SOCIAL STUDIES}

I have proposed that learners' ethical decision-making and action would be better supported through an ethically reflexive orientation, one that brings the philosophy of ethics into their critical reflection, and enfolds their lived experiences and ethical imaginations. Across two chapters, the argument for this 'preferable future ${ }^{46}$ has been built primarily along philosophical and sociological lines. In Chapter Four I argued that any approach to ethics education in social studies must focus on social issues and recognise the enmeshed nature of learners' 'private' and 'public' ethical lives. I secondly contended that social studies education should be directed towards counter-socialisation because personal and societal transformation is at least in part dependent on social criticism. In order for social studies education to enlarge learners' critical reflection about ethical decision-making and action, I argued that it needs to (a) be as encompassing of ethical perspectives as possible and (b) make better use of the philosophy of ethics modes of thinking, conceptual language, and categories of thought.

46 'Preferable, possible and probable futures' is a heuristic drawn from Futures Studies, for example the work of Wendell Bell (Kicker, 2009). 
The argument developed in Chapter Five was that ethical decision-making and action involves more than developing the knowledge and skills associated with critical reflection. Thus critical reflection is a necessary but not sufficient condition. This is because ethical decision-making and action is not simply a rational, cognitive and ordered thought experiment. It arises from the multiplicity of learners' selves including bodies, emotions, identities and desires - and in relation to the diverse contexts of their everyday lives. Ethical decision-making is also enacted in learners' lives, through their 'swampy' experiences and imaginations, and within the context of societal uncertainty. These features of learners' ethical lives, together with critical thought, demand considerable agility and sensitivity. For these reasons, I have advocated a reflexive rather than reflective orientation to implementing the curricular expectation that learners' ethical decision-making and action be supported.

This chapter turns to the third of my research sub-questions, an exploration of the difficulties and possibilities for an ethically reflexive orientation that could lie ahead. It considers 'contingent factors' in moral education (Sanger \& Osguthorpe, 2005) introduced in Chapter One. It is important to note that the research evidence about this is at best tenuous. We know from Paul Keown's (1998) research that there has been a longstanding marginalisation of values exploration, social decision-making and social action in New Zealand social studies teaching and learning; these he called the "hard bits' of social studies. But there has been no research that has directly considered the place of ethics, pedagogically speaking, in social studies education. So, considerable extrapolation from research evidence that could intersect with my proposal for an ethically reflexive orientation to social studies appears necessary. With the limitations of the data in mind, this chapter considers a range of influences on how the ethical aspects of the Values statement (Ministry of Education, 2007) could be given expression. This consideration is made through a number of avenues. I take as a starting point for this chapter Paul Keown's (1998) findings, from a range of empirical and theoretical sources, about what was contributing to values and social action being perceived as the hard bits of New Zealand social studies in the 1990s. His findings structure this chapter as illustrative themes, a selection of the kinds of challenges possibly in store for an ethically reflexive orientation. To consider Keown's findings in the present, I explore how they intersect with more recent research about the multiple, and often contradictory, influences on education and, in turn, the prospects and challenges for an ethically reflexive orientation. 
The chapter begins with reviewing research literature to consider whether New Zealand social studies teachers are, in fact, taking an ethically reflexive orientation in spite of minimal curricular guidance as to what ethical decision-making is to mean. I infer from a range of evidence about curriculum delivery that ethical decision-making and action is rarely explicitly attended to in New Zealand social studies teaching and learning. One possible influence on this phenomenon is stressed within this research evidence: the need for curriculum design and professional development to support teachers' interpretation of curricular requirements, or to signal the shifts in meaning. Three further potential influences are then explored in turn, and look to the political, historical, economic and ethical forces that constrain and facilitate educational change: ethics in an era of the scientific management of education, knowing what works in evidence-based education, and the ethics of ethics education. It is important to note that these are examples of what could, in future, contribute to an extended silence in relation to social studies learners' consideration of ethical decision-making and action; the exploration of this lacuna is therefore not exhaustive or conclusive. Instead, the potential influences I outline signal the kinds of prospects and challenges that could be ahead for an ethically reflexive orientation. While the discussion cumulatively suggests that the 'probable future' for an ethically reflexive orientation contains some significant challenges, I consider what 'wriggle room' there might be even within such constraints. To this end, the last section of this chapter reports on a study of the views of a small group of New Zealand social studies teachers and their students, who in the early stages of this thesis were asked to consider the role of ethics in social studies education. Many of the findings might have been safely predicted from the research considered in this chapter; however, some offer perhaps surprising glimpses into the 'possible futures' for an ethically reflexive orientation.

\section{SIGNALLING THE SHIFTS IN MEANING}

In this section I explore whether New Zealand teachers, independently of the curriculum, may already be taking an ethically reflexive orientation to social studies teaching and learning. In addition, I ask what might be influencing this. Given that no research expressly addresses these questions, I draw instead from a range of existing evidence about the delivery of social studies and, more broadly, values education. I consider, firstly, successive Education Review Office (ERO) reports that have provided insight into the quality of social studies teaching and learning prior to the publication of The New Zealand curriculum (Ministry of Education, 2007). There have been no equivalent 
ERO reports since that time. I consider, secondly, the evidence from three recent reports which have examined the progress towards The New Zealand curriculum's implementation. While these do not specifically comment on the social sciences learning area, they provide insight into how the Values statement has been interpreted and imbedded within wider school programmes (Education Review Office, 2010; Sinnema, 2011). My interest is, in particular, how New Zealand social studies teachers might be interpreting the expectation that they encourage learners to "act ethically" and develop their abilities to act ethically and "make ethical decisions and act on them" (Ministry of Education, 2007, p. 10).

Certainly, in the period leading up to the current curriculum's publication teachers were aware of aspects of social studies that strongly align with ethical decision-making and action. The overwhelming majority of 853 primary and secondary teachers who participated in the National school sampling study in 2002 (C. McGee et al., 2003) reported that they were addressing values exploration and social decision-making in their programmes. Nevertheless, considerable disjunction appeared to exist between what teachers reported and the reality of classroom practice. Successive ERO reports (ERO, 2001, 2006) found that values exploration and social decision-making tend to be minimally integrated into planning and assessment practices. Social decision-making was often conflated with rather more generic problem-solving approaches that failed to focus on social issues and taking action. Additionally, values exploration tended to amount to identifying points of view, rather than extending to values analysis. The quality of teaching in years 4 and 8: Social studies report (Education Review Office, 2006) found that planning was rarely linked to what is now called social inquiry, and a reliance on content-driven approaches and recall of knowledge assessment practices ${ }^{47}$ appeared to be limiting opportunities for developing students' social inquiry skills. Fifty-one per cent of the teachers could show little or no evidence of having made links to the social studies curriculum in their planning ${ }^{48}$. Such findings need to be read in light of persistent disquiet over social studies teachers' curriculum understanding, reflected in a lack of alignment between social studies programmes and the curriculum. In sum, therefore, those aspects of social studies curriculum that most closely relate to my understanding of ethical decision-making and action were very unlikely to have been given explicit attention.

47 Of the 40 per cent of teachers who were gathering assessment information.

48 A follow-up report noted some instances of good social studies teaching practice (Education Review Office, 2007), but this sheds little light on how the teachers who were successfully delivering the social studies curriculum were enacting the values exploration and social decision-making processes. 
Did this state of affairs alter after the publication of The New Zealand curriculum (Ministry of Education, 2007)? One report, by ERO (2010) found that by the end of 2009 over three-quarters of 245 primary and secondary schools were 'giving full effect' or 'making good progress' towards giving effect to the new curriculum. The review was particularly complimentary of school-wide approaches to integrating shared school values into teaching and learning, and the way in which schools had heeded the curricular expectation of community dialogue over the values to be encouraged and modelled. A second report, Monitoring and evaluating curriculum implementation (MECI; Sinnema, 2011), suggests that caution should be exercised over the ERO findings. This evaluation sought to examine the progress made in the first two years of the curriculum's implementation, and factors that explain the degree of progress. More than 5000 educators took part in the period between 2008 and 2009. Notably, and in contrast to the ERO (2010) findings, the MECI evaluation found that only limited progress was being made in implementing the curriculum across four elements of the evaluation: support encounters, receptivity, understanding, and practice. Though the revised curriculum was generally well regarded by the respondents, and perceived as being an improvement on the last, the report noted considerable incongruence between curriculum intent and interpretation, in particular a lack of recognition of the complex and interconnected nature of the curriculum.

Two aspects of the MECI findings have particular salience for the question as to how the Values statement (Ministry of Education, 2007), including the requirement to support learners' ethical decision-making, is being interpreted. Its finer-grained analysis (than that undertaken by ERO) found that less attention had been given to the righthand column of the Values statement, crucially, that which encourages greater criticality with regard to ethical decision-making and actions. Notably, there was no change between 2008 and 2009 in the proportion of teachers (15\%) who reported that developing students' skills for exploring values was very strongly evident in their practice and there existed, for example:

.... a superficial view of values in the curriculum (focused on inculcating the national curriculum and school values) rather than the deeper three way values education process signalled in The New Zealand Curriculum (education about values, and in valuing skills alongside encouraging affiliation to key public values). (Sinnema, 2011, p. 4)

And the report later explains: 
While almost one third of respondents said that they consistently or often encourage students to hold The New Zealand Curriculum values, there is still less attention...to the more difficult aspects. Only a small proportion of respondents report integrating values into learning experiences across the curriculum (22\%), learning about the nature of values (17\%), and developing skills for exploring values (15\%). (p.37)

Another aspect of the MECI findings that lends weight to the contention that New Zealand teachers are underplaying the critical aspects of values education is that there was little progress in developing students' competency in thinking. This is one of five cross-curricular competencies of New Zealand's curriculum, and the one that has an express focus on critical thinking. Only $30 \%$ of participants said that this was very strongly evident in their practice by 2009, and less than a quarter reported that all five key competencies had been strongly integrated into learning areas. When findings related to values education and the thinking key competency are read together, it seems unlikely that New Zealand teachers would be interpreting and/or implementing the ethical dimensions of the curriculum through a critical lens.

A third report, which considered the effect of the $V$ alues statement on teaching and learning (Notman, 2012; Notman et al., 2012) drew from a sample of four schools in Otago. This included surveys of 90 intermediate and secondary teachers who were asked about their perceptions of their students' knowledge about values and valuing skills. The teachers perceived their knowledge of the values to be encouraged as uniformly high, as was their perception of their schools' support of those values. On both measures, integrity (which includes acting ethically) rated as extremely high, and it was also the value of most importance to the teachers. However, integrity did not feature highly in the values the teachers had tanght explicitly in the last year. The study also found that teachers perceived their students' skill levels as being low "in relation to critically analysing values; negotiating solutions to differences; and making and acting on ethical decisions" (Notman, 2012, p. 46). Interestingly, when one examines these data (reproduced below), it is an open question as to how teachers interpreted the skill of making ethical decisions and acting on them, as this appears not as strongly aligned with the other, more overtly critical skill areas. My suspicion is that they read this in a normative sense, that is, arriving at 'good' decisions rather than considering a range of possibilities. 


\begin{tabular}{|l|l|l|l|}
\hline & \multicolumn{3}{|l|}{$\begin{array}{l}\text { Percentage of teachers at different levels of } \\
\text { perception of students' value skills }\end{array}$} \\
\hline Values skill area & $1-2$ (low) & 3 & $4-5$ (high) \\
\hline Express their own values & 23.0 & 40.2 & 36.8 \\
\hline $\begin{array}{l}\text { Explore, with empathy, } \\
\text { the values of others }\end{array}$ & 29.9 & 48.3 & 21.8 \\
\hline $\begin{array}{l}\text { Critically analyse values } \\
\text { and actions based on } \\
\text { them }\end{array}$ & 51.8 & 35.3 & 12.9 \\
\hline $\begin{array}{l}\text { Discuss disagreements } \\
\text { that arise from } \\
\text { differences in values } \\
\text { and negotiate solutions }\end{array}$ & 41.2 & 41.2 & 17.6 \\
\hline $\begin{array}{l}\text { Make ethical decisions } \\
\text { and act on them }\end{array}$ & 34.1 & 45.9 & 20.0 \\
\hline
\end{tabular}

Table 2: Teachers' perceptions of level of students' values skills, reproduced from Notman (2012, p. 46)

One further report is important to mention here also: the recent International civic and citizenship education study (ICCS) (Schulz et al., 2010). This is the largest international study on civic and citizenship education ever conducted, and in which over $4000 \mathrm{New}$ Zealand Year 10 students and teachers participated. In this report, New Zealand students' perceptions of openness in classroom discussions were one of the highest rates for any country that participated in the ICCS. On the face of it, this might appear to suggest that, across the curriculum, New Zealand students are being offered opportunities to participate in discussions about social issues that have an ethical content. However, other international research suggests a need to know more about these findings. Diana Hess (2008) points out that "although many teachers and students report social studies classes as being rich with controversial issues discussion, when researchers observe social studies classes they rarely find discussion of any sort and little attention to controversial issues" (p. 127). Students tend to conflate classroom talk with discussion and though they may report their classroom climates as being open, the fact that they feel they have a voice does not equate with an emphasis on controversial issues.

At best, the reports referred to in this section can only be a proxy for evidence about the implementation of the New Zealand curriculum's ethical dimensions in social studies. The ERO, MECI and ICCS findings certainly do not paint a conclusive account of, for example, teachers' engagement with social issues, the philosophy of education or the counter-socialising dimensions of social studies education. However, Paul Keown's (1998) summation of values and social action being the 'hard bits' of social studies education may well be as true today as it was then. That the New Zealand social studies curriculum is an ethically silent space - a matter established in Chapter Three - appears a contention that could well be applied to the subject's programme content and 
pedagogies. Certainly, one may infer that the opportunities for students' critical reflection about ethical decision-making and action are limited. However, I again stress some caution about such inferences, particularly in relation to an ethically reflexive orientation. It is notable, for example, that the studies discussed in this section position ethical decision-making and action as a skill, which means that we can tell very little about how teachers may be drawing in their learners' lived experiences or stimulating their ethical imaginations.

If this is the case that ethically reflexive approaches are rare in New Zealand social studies classrooms, where will the practices that give rise to change evolve from? Curriculum design may be one stimulus for change. At least where ethical decisionmaking and action is concerned, there has been a complete failure to clearly signal the shifts in meaning (Aitken, 2006) in the current curriculum. Another stimulus may be the provision of pedagogical resources. Keown (1998) contends that teachers avoid the hard bits of social studies partly because of a longstanding perception that there "is a lack of solid, creditable and easy to implement methodologies for dealing with values and action issues in the classroom" (p. 140). While Keown's work in this field suggests (see, for example: 1998, 1999, 2003) that this perception is not borne out in reality, it is true to say that there are few New Zealand social studies resources that explicitly draw out the ethical dimensions of values and action. A third stimulus for change could be more professional development in order to support teachers to deliver high quality programmes related to the ethical dimensions of social studies education. The MECI report particularly highlights the inter-dependent nature of curriculum design and professional learning in concluding that progress in curriculum implementation requires greater teacher confidence, which is in turn dependent on developing "deep understandings about the distinctions between the new and the old curriculum elements" (Sinnema, 2011, p. 74). In this view, the prospects for any approach to ethical decision-making and action would be, at least in part, dependent on a careful elucidation of the semantic shift between values and ethics, and the relationship between theoretical underpinnings and pedagogies.

I think some caution is necessary, however, around suggesting that change may solely be brought about through greater curricular and pedagogical clarity. Some may further argue for a culture change, on the basis that curricular attempts to control practice often produce negligible results in relation to teaching and learning. Certainly, my view is that signalling the shifts in meaning is an important component of the ethical dimensions of 
New Zealand's curriculum gaining expression. But a wider view is necessary - looking to the forces that could constrain or support an ethically reflexive orientation to social studies education.

\section{ETHICS IN AN ERA OF SCIENTIFICALLY MANAGING EDUCATION}

The pragmatic issues outlined in the last section do not provide a sufficiently comprehensive account of possible prospects and challenges for an ethically reflexive orientation. In this section I consider another of Keown's (1998) explanations as to why New Zealand teachers tend to avoid values and social action, and instead place greater emphasis on knowledge and skills. He argues that "those in the Western tradition tend to place a very high value on reason, on knowledge, and on the cognitive and tend to undervalue feelings, aesthetics and the affective" (p. 139). This he describes as a dualistic rather than holistic view of education. A related issue identified by Keown is that concepts, facts and skills are rather more straightforward to assess than affective and participatory outcomes. Commenting on developments subsequent to the publication of Social studies in the New Zealand curriculum (Ministry of Education, 1997), Rowena Taylor and Rose Atkins (2005) suggest that this has continued to be the case. While teachers and students have found collaboratively developed templates helpful in terms of clarifying senior social studies assessment requirements (Wood, 2005, as cited in Aitken \& Sinnema, 2008), Taylor and Atkins (2005) observe that even where attempts have been made to assess values exploration, this amounts to generic 'fill in the box' comprehension activities of discrete elements of the process. A risk is that "students can conduct assessments in quite a dispassionate manner as they are not required to reflect on or clarify their own values, or make the transfer to their own values schema, and internalise such values" (p. 134). By extension, the emphasis on critical reflection may marginalise the lived experience and imaginative aspects of ethical reflexivity.

Bronwyn Wood (2007) has argued that social studies teachers' tendency to favour concepts, facts and skills - and thereby avoid societal controversy - has been exacerbated by the scientific management of education. She draws this argument from the work of Jim Neyland $(2004,2010)$ whose account is, of course, only one explanation. Neyland's (2010) view is that “under scientific management, education must, in ever increasing detail, be made readable, recountable in writing, and enumerable so that it can be monitored and managed" (p. 51). This is expressed, for example, in the molecular nature of social studies curriculum and assessment: achievement objectives, 
achievement standards, and assessment programmes at Years 9 and 10 which tend to rely on NCEA-like rubrics (Picken \& Milligan, 2013). It is also detectable in Notman's (2012) recommendation that New Zealand students' learning about values be benchmarked "in the manner of the International Civic and Citizenship Education Study" (p. 48). Neyland traces a marked shift towards scientific management from the 1980s onwards but, like the associated neo-liberal political and educational reforms, it is important to note that this shift was as much a matter of continuity as it was change. Neyland (2005) himself records that a number of social theorists, as early as the 1950s, were arguing that "Western culture is in the grip of a trend towards a largely unquestioned instrumentalism" (p. 110-111). In his view, this preoccupation with the means rather than purposes of education "enfeebles the curriculum's ethical orientation" (p. 109) because teachers and students are not invited to participate in questions as to education's purpose, or asked to explore the good life for themselves. Similarly, Paul Standish (2003) has argued that instrumental reason "has emaciated the ethical language in which we consider our lives and education, distorting the public and private realms of our experience" (p. 230).

One does not have to look too far afield to see how scientific management could manifest itself in relation to the potential expression of ethical decision-making and action in New Zealand's curriculum development. Just across 'the ditch' ${ }^{49}$, ethical understanding is now identified as one of seven general capabilities to be developed across the Australian Curriculum (Australian Curriculum Assessment and Reporting Authority, 2014) $)^{50}$. This represents a significant shift from curriculum development in the mid-2000s which focussed on identifying values to be encouraged in Australian schools (Australian Government Department of Education, 2005) ${ }^{51}{ }^{52}$. By contrast, 'ethical understanding' in the Australian Curriculum now focuses on assisting "students to engage with the more complex issues that they are likely to encounter in the future, and to navigate a world of competing values, rights, interests and norms" (Australian Curriculum Assessment and Reporting Authority, 2014, p. 1). This general capability has

49 The Tasman Sea.

50 These are: Literacy, Numeracy, Information and communication technology (ICT) capability, Critical and creative thinking, Personal and social capability, Ethical understanding, Intercultural understanding.

51 At that time, The National framework for values education in Australian schools (Australian Government Department of Education, 2005) defined values education as: "Any explicit and /or implicit school-based activity which promotes student understanding and knowledge of values, and which develops the skills and dispositions of students so they can enact particular values as individuals and members of the wider community" (p. 8).

52 Interestingly, the association between ethics and value of integrity is akin to the Values statement in New Zealand's curriculum (Ministry of Education, 2007). 
three inter-related organising elements: understanding ethical concepts and issues; reasoning in decision making and actions; and exploring values, rights and responsibilities. Further, the ethical understandings that students can reasonably be expected to have developed across Levels 1 to 6 are identified for each of the organising elements - a broad developmental sequence comprising 48 discrete indicators.

Australia's recent focus on ethical understanding could be considered as something of a model for New Zealand teachers wishing to make sense of the phrase ethical decisionmaking and action. The document represents a significant possible future for materials development, not least because ethics occupies an explicit, central and critical place in the curriculum. I think we would want to exercise some caution about mirroring this path, partly because many incoherent statements are made throughout the document. For example, what constitutes a distinction between "ethical and non-ethical dimensions of ethical issues" (Australian Curriculum Assessment and Reporting Authority, 2014, p. 7) or "the objectivity or subjectivity behind decision-making where there are many possible consequences" (p. 9) is not made clear. My more substantive concerns, however, relate to an impoverished approach to supporting learners' ethical decisionmaking and action. The document does little to elucidate the range of ethical perspectives that inform conflict, complexity and uncertainty; only oblique references are made to character, principles and consequences, for example. Consequently, teachers and learners are offered little in the way of intellectual tools with which to agonise with ethical issues.

But it is the learning continuum in the last pages of the document (Australian Curriculum Assessment and Reporting Authority, 2014) that most keenly suggests that scientific management could present something of a handbrake for ethically reflexive approaches. This is for at least three inter-related reasons. First, not only are the developmental assumptions open to question but the molecular approach of the learning progression misrepresents the complexity of ethical decision-making and action and the interpenetrated nature of social and ethical issues. Second, the teachers and students are not participants in questions about the good life; instead they are participants in mastering the component pieces of ethical understanding. Teachers and students become the deliverers and the recipients of pre-packaged ethical understanding in which students are positioned as the "aggregates of traits in such a way that it is difficult to reassemble the face of the individual" (Neyland, 2004, p. 156). Third, the lived (including emotional and embodied) and imaginative dimensions of an ethically 
reflexive life are entirely subordinated to an emphasis on orderly rational thought, which is reflective of the entire document's tenor. As Neyland (2010) would argue, the spirit of education is marginalised: pleasure, creativity, learning for its own sake, and the use of humour as a response to the 'itch for certainty', for example.

In sum, if the ethical dimensions of New Zealand's curriculum are to be managed scientifically, the prospects for an ethically reflexive approach to better supporting social studies learners' ethical decision-making and action seem enervated. Yet we might take some comfort from the literature that increasingly takes exception with instrumental reason and scientific management, whether within education or elsewhere - this is because much of what goes on in society is concerned with the question of what is the next best decision in a never-ending agonistic struggle. Instrumental reason, scientific management and as I turn to in the next section, scientific evidence (at least) have nothing compelling to say here.

\section{KNOWING WHAT WORKS IN EVIDENCE-BASED EDUCATION}

Another reason that teachers have been reluctant to tackle the 'hard bits' of social studies is "the seeming lack of knowledge about how values learning works and how to influence values through education" (Keown, 1998, p. 140). In this section, I argue that the prospects for an ethically reflexive orientation are at least partly dependent on being able to address the sorts of questions raised by teachers about values education - for example, can one teach ethical decision-making, and if so what actual difference does this make to learners' actions? These kinds of questions also lie at the heart of evidencebased policy and practice which has had a considerable impact on New Zealand educational policy in recent years, including the social sciences learning area (M. Taylor, 2012, 2013). What counts in educational decision-making in this discourse is the systematic use of 'trustworthy' empirical evidence; found, for example, in John Hattie's (2009) synthesis of meta-analyses, and in the Ministry of Education's publications of iterative 'best evidence' syntheses ${ }^{53}$.

Evidence-based education has drawn sharp criticism (see, for example: Biesta, 2007, 2009, 2010), in part via the argument that a focus on evidence is too distant from

53 http://www.educationcounts.govt.nz/topics/BES 
questions of purpose and value in education. Evidence-based policy and practice can tell us little about whether, for example, social studies education should be directed towards counter-socialisation and adopt a reflexive approach to ethical issues. My considerable sympathy for this view notwithstanding, this section suggests a qualified value in evidence-based education. As M. Anderson and Della Sala (2012) point out, choices about educational interventions are moral and political decisions but this does not remove the need for appropriately answering associated empirical questions. Scientific evidence could help us determine whether aspects of the proposal presented in this thesis need refining or whether, practically speaking, it warrants implementation at all. To illustrate, I consider two types of data that inform educational evidence-based policy and practice. The first is classroom-based pedagogy-outcomes evidence, an example of which is the Effective pedagogy in social sciences/Tikanga a iwi best evidence synthesis iteration [Social sciences BES] (Aitken \& Sinnema, 2008; Sinnema \& Aitken, 2012) which has sought to establish "what works, for whom and in what circumstances?” (p. 34) in social sciences education. The authors express their findings as causal yet context-dependent 'mechanisms', or explanations for learning. The second example looks to the kinds of evidential questions "asked, and sometimes answered, by the empirical human sciences" (Doris \& Stich, 2014, n.p.), such as how ethical decision-making is made possible biologically speaking. Given that the literature related to the latter is vast, I focus particularly on neuroscience and neuroethics, examples of fields in which there is growing momentum and which some have argued could make a direct contribution to education's evidence base (M. Anderson \& Della Sala, 2012).

What does the evidence presented in the Social Sciences BES (Aitken \& Sinnema, 2008) suggest about the prospects and challenges ahead for an ethically reflexive orientation to social studies education? It is firstly notable that the strength of the evidence is limited in relation to my topic; what can be established is currently a matter of inference. The synthesis does not include studies about ethics education and relatively few relate to values education. This likely reflects the authors' finding that:

...there are strategies popular in the social sciences for which there is limited or contradictory evidence concerning efficacy. These include project work, processes such as values exploration and social decision-making, and service learning. (p. 48)

One can understand, therefore, why teachers have been somewhat sceptical about the evidence base for teaching the hard bits of social studies. This issue notwithstanding, at 
least three Social Sciences BES (Aitken \& Sinnema, 2008) findings have a bearing on ethically reflexive approaches to social studies education and, most particularly, affirm the need to bring lived experience and imagination into supporting learners' ethical decision-making and action. One mechanism, 'build and sustain a learning community', suggests that if learners are to participate effectively in plural democracies, the content and processes of social studies need to enable them to engage with the societal controversy they encounter. In particular, teaching with and for purposeful discussion promotes forms of civic engagement such as political interest and tolerance. What strikes me as being salient about this mechanism is that the relational experiences of interaction, albeit within the confines of the classroom, are as important to democratic outcomes as the critical aspects of discussion. Thus, if social studies education is to be oriented towards ethically reflexive approaches, it is insufficient to acknowledge learners' lived experiences of the good life as being out there in the world; the classroom is a particular space of emotional, embodied, everyday and emergent experience. In relation to discussion pedagogies, Walter Parker (2006) argues that "seminar and deliberation are not vacuous "processes". They are content intensive; they are about their topics and their participants" (p. 15).

A second mechanism, 'make connections to learners' lives', includes the finding that engagement and achievement are promoted when teaching and learning is "compatible with students' cultural identities and experience" (Aitken \& Sinnema, 2008, p. 60). For example, when studying The Aeneid, Christine McNeight (1998, as cited in Aitken \& Sinnema, 2008) found that her Samoan students' conceptual understandings about Roman religion improved when she asked them to make their own cultural experiences a point of comparison $^{54}$. While there is a need for caution around unwelcome intrusion into learners' life-worlds, and perceptions of cultural compatibility may differ across students and cultural groups, such findings appear to affirm the need to draw on social studies learners' lived experience so that they can see themselves in the content and processes of educative approaches to ethical decision-making and action. A third mechanism, 'interest', includes the finding that stories and narratives with emotional appeal can stimulate learners' imaginations and assist in offering possibilities for personal and social transformation. The reader will recall a similar point made in the previous chapter, albeit without substantiation with the kinds of evidence referred to here.

54 Aitken and Sinnema (2008) caution, however, about the risks of a binary approach and the other-ing that could occur as a result. 
How could evidence generated outside the classroom influence the ways in which an ethically reflexive orientation is taken up, reworked or radically re-altered? Some scientists claim that rapid advances being made in neuroscience may lead us to brainbased explanations for ethical behaviours (Glannon, 2007; Levy, 2007) and at least one view of neuroethics claims that understanding the biological mechanisms underpinning ethical decision-making could carry us to a 'brain-based philosophy of life' (Gazzinga, $2006)^{55}$. The potential influence of this research in education can be seen, for example, in the recent establishment of the Centre for educational neuroscience, a joint research venture across three UK universities ${ }^{56}$ with a focus on the connections between developmental psychology, neuroscience, and evidence-based education. Others are more directly considering the relationship between brain science, the human ethical sense and education (Aoki, Funane, \& Koizumi, 2010) and the ethical issues that 'come along for the ride’ with educational neuroscience (see, for example, Zocchi \& Pollack, 2013). Though the brain science of ethics is in its infancy, there are some findings that appear to support an ethically reflexive orientation. For example, there is now general agreement (a) about the regions of the brain that are implicated in moral judgement, (b) that both emotion and cognition are associated elements (Moll, De Oliveira-Souza, \& Zahn, 2008; Prinz, 2011) and (c) that empathising with the intentions and emotional states of others are key elements of the ethical sense (Aoki et al., 2010). At the very least, this research lends weight to my contention that ethical decision-making and action ought not to be represented to learners as simply a matter of critical reflection.

I stated at this section's outset that such evidence is of qualified value in giving expression to the curricular expectation that learners' ethical decision-making and action be supported. The growing evidence base drawn from neuroscience, moral psychology and other human sciences would no doubt richly inform decisions about whether the proposal for an ethically reflexive orientation to social studies education warrants application in policy and practice. But there is also good reason to be cautious about evidence drawn from these fields. This is firstly because one needs to be wary of assumptions that underpin 'knowing what works'. Illes and Racine (2005) point out, for example, that studies based on concepts such as moral emotions assume "that some emotions are moral and others not. They illustrate the cultural aspect of the interpretation challenge, which is based on the fact that the self is defined in diverse

55 Others have argued that the neurosciences have not produced a complete picture of ethical decision-making, and are unlikely ever to (Kaposy, 2009; Lavazza \& De Caro, 2010; Rasmusson, 2009).

56 University College London, Birkbeck College London, Institute of Education,

http://www.educationalneuroscience.org.uk/ 
ways" (p. 14). Similarly, the way in which affect and emotions are positioned as an outcome in the Social Sciences BES (Aitken \& Sinnema, 2008) is a matter open to critique. Second, the instrumental orientation of evidence-based policy and practice ought not to detract from discussions about the purposes of ethics education in social studies. It is notable, for instance, that questions regarding the purposes of social studies education are effectively buried beneath an over-riding emphasis on pedagogical mechanisms in the Social Sciences BES. Third, a danger is that we may move too readily from 'is' to 'ought'. Take, for example, an article entitled Mechanisms underlying an ability to behave ethically (Pfaff, Kavaliers, \& Choleris, 2008) which suggests that a shared, 'blurring' experience of fear prevents us from harming other and underlies our ability to operate from the 'golden rule'. A response to this article reminds us, "the fact that one is wired for reciprocity does not imply that one ought to act reciprocally" (Da Rocha \& Bergareche, 2008, p. 25). Thus, I submit that despite a movement towards evidencebased policy and practice, social studies educators cannot solely rely on instrumental evidence to determine how learners' ethical decision-making and action could be better supported. It is society that must judge the extent to which such empirical evidence should influence our judgements about morality and, likewise, ethics education.

\section{THE POLITICS AND ETHICS OF ETHICS EDUCATION}

Another reason that Keown (1998) identifies as to why social studies teachers hesitate in relation to values and social action is that they fear both indoctrinating their students and disapprobation from the school community. Diana Hess (2004) adds that "many adults want schools to mirror their ideas, or fear that adding controversy to the curriculum creates controversy" (p. 258). She adds that this general aversion to controversy is supplemented by a range of other barriers:

(1) differing views about the purposes of democracy education,

(2) fears that teachers, other students, or instruments of the "official curriculum" (such as textbooks and films) will indoctrinate students into particular positions on issues, and

(3) sharp conflicts about what should rightly be considered an issue in the first place.

One can see each of the barriers identified above operating in a very public stoush that occurred between a group of Otaki Primary school students, who wrote to Mayor Michael Laws of Wanganui, arguing that Wanganui should be spelt Whanganui, as local 
Māori would wish. In his response, the Mayor accused the teachers of putting their students up to the letter-writing and was reported as saying that he felt they ought not to be "angry about something inanimate" (Newton \& Francis, 2009, n.p.). For Mayor Laws, this was not the kind of participation that the school should be fostering, nor in his view should the matter be of concern to students from another town. The teacher felt, by contrast, that this exercise was entirely within the scope and spirit of the New Zealand curriculum - a piece of persuasive writing in relation to an authentic social issue. He may also have felt that the New Zealand Teachers Council's (2004) code of ethics lent some support to the choice of learning activity in that it is stated that "teachers will strive to...encourage learners to think critically about significant social issues" (n.p.).

That the prospects for an ethically reflexive orientation to social studies education are at least in part a matter of political determination is likely self-evident from the argument built thus far. As Chapter Three indicated, the political machinations in relation to the content and status of values education have been well documented in New Zealand. It is notable that citizenship education in the UK has recently taken, in my mind, a conservative turn and, with that, the curricular focus on ethical controversy has diminished. Citizenship at Key Stages 3 and 4 in the UK was in the past intended to help "young people to develop their critical skills, consider a wide range of political, social, ethical and moral problems, and explore opinions and ideas other than their own" (Department for Education, 2014, n.p.). Following a change of government, the national citizenship curriculum retains a focus on political and social issues, including students' ability to evaluate viewpoints. However, these aspects are considerably subordinated to civic knowledge. The winds of political change could similarly shape the future direction of ethics education in New Zealand's curriculum. Leaving such speculation aside, however, Chapter Seven's recommendations in part suggest that the prospects for an ethically reflexive orientation to social studies (and, indeed, any approach to ethics education in social studies) would be greatly enhanced through a policy environment that accords greater priority to social studies and citizenship education.

While social studies teachers' professional ethics is not the focus of this thesis, it is important to stress that the prospects for an ethically reflexive orientation are intertwined with both teachers' confidence in workable approaches and their own ethical decision-making in relation to the challenges of addressing social issues in the 
classroom. The latter is not just a matter of how teachers choose to operate - such as making decisions about disclosing their own position or about what is legitimately controversial (Hess, 2009) - but also the effects of such choices. Hess (2004) reminds us, for example, that while we all might readily accept that social issues require discussion in social studies classrooms, how students experience those discussions will shape their relationship with democracy. There is not the space here to do justice to the literature that links the teaching of social issues to teachers' ethical decision-making; considerably more insight is likely to be gained from The political classroom: Evidence and ethics in democratic education (Hess \& McAvoy, in press). However, to return to the discussion about reflexivity in relation to wider spheres of professional spheres, social studies teachers' explorations with an ethically reflexive orientation are, themselves, likely to be reflexive - a matter of moment-by-moment negotiation, even with a preferred stance.

TAKING IT TOO FAR? SOCIAL STUDIES TEACHERS' AND LEARNERS' PERCEPTIONS OF ETHICS

This last part of the chapter troubles the discussion thus far, in which I have suggested that the prospects for ethical decision-making and action gaining an explicit toe-hold in New Zealand social studies teaching and learning are bleak, and that ethically reflexive approaches may be fraught with challenges. The discussion returns to the conversation between students, introduced in Chapter Two, and includes findings from focus group discussions with teachers in the school's social studies department, about the place of ethics in social studies education. Given the limited and exploratory nature of this study, one needs to be careful about the promise of these data. Nevertheless, and from many years' work as an adviser in schools, I emphasise that the context and findings of this study are unlikely to be extraordinary. I begin by outlining the research focus and methodology, and then consider how the findings from focus group discussions with the teachers and students speak to the challenges identified in this chapter.

The study ${ }^{57}$ reported here took place in a state, co-educational secondary school in the Wellington region, in which the students are predominantly New Zealand European/Pākehā and drawn from a relatively high socio-economic area. The school

57 Approved by Victoria University of Wellington Faculty of Education Ethics Committee: Approval number RN17078 
was selected largely on the basis of an existing relationship with its social sciences department, developed over some years in my role as an in-service adviser. This was not intended as a case study of teacher excellence; therefore, the sampling procedure did not try to identify schools in which there were social studies teachers who might be considered experts in ethics education. Instead, the potential for the topic to be perceived as both sensitive and extraneous to their teaching programmes led to the selection of a school where a level of collegial trust was already established. Seven teachers within the social sciences department participated, all currently teaching Year 9 and 10 social studies. Six Year 9 social studies students (three boys and three girls) were selected from class members who volunteered to participate. This sample was not intended to be representative; I was interested in talking with a group of students who had shown interest in the subject matter and were willing to articulate their thoughts.

The purpose of this study was to investigate the meanings that teachers attach to ethical decision-making and action, and their responses to the inclusion of this statement in the New Zealand curriculum (Ministry of Education, 2007). This study therefore rests on an interpretative approach (Clark, 1997), where the focus is on the subjective meanings that social studies teachers bring to ethical decision-making and action. In order to permit open discussion, the study was not wedded to any particular ethical framework - such as a 'character' or Kohlbergian view (Kohlberg, 1981). One exception to this openendedness should be noted, however: teachers were introduced to the idea that ethics may be understood in a non-normative, descriptive sense.

Semi-structured focus group interviews were used in order to stimulate naturalistic and open conversation in a social setting (Grudens-Schuck, Allen, \& Larson, 2004). Over two sessions, teachers discussed their understanding of, and enablers and constraints in relation to, supporting students' ethical decision-making and action. The first discussion began by asking the teachers to share their thoughts about the nature and purposes of social studies and ethics education. This was followed by a concept-mapping exercise in which teachers established connections between 13 concepts proximal to ethical decision-making and action, ${ }^{58}$ drawn from the $V$ alues section and social sciences learning area statement (Ministry of Education, 2007). Teachers were free to include other concepts if they wished. The questions and concept-mapping strategy (Novak \& Cañas,

58 Ethical thinking, social inquiry, conceptual understanding, participating in society, social action, citizenship, challenging the basis of assumptions and perceptions, values, perspectives/worldviews, engaging critically with social issues, morals, cultural identities, affective/emotions. 
2014) were designed to draw out the teachers' existing conceptions of ethics and ethical decision-making. In preparation for the next interview, teachers were asked to reflect on the content and relevance of three web pages (BBC, 2014c; University of San Diego, 2014a, 2014b) that provide an overview of the field of ethics and ethical perspectives. In the second interview ${ }^{59}$, teachers were asked to report their responses to these web pages, as I was interested in whether greater exposure to the field of ethics and ethical philosophies would shift their thinking about the relationship between ethics and social studies education. Teachers were also asked about their perceptions of the opportunities and challenges that a greater emphasis on ethical decision-making in social studies might present.

The findings from two focus group interviews with students are also reported here, in which they were asked to reflect on contemporary social issues with an ethical content and strategies for ethical thinking. Importantly, the students explored ethical decisionmaking and action from quite different angles. Whereas the teachers directly considered the concept of ethics, the students were not asked directly about the meanings that they attached to the concept. The students were, however, introduced to the concept of ethics as being about making decisions about what they should do and this definition appeared to make sense for them. Students completed a survey about their moral orientations ${ }^{60}$ and then debated the following scenario about accepting friends on Facebook $^{61}$ :

Tania checks her Facebook site and finds a notification for a friend request and a brief message. It's Mike Boswell, a guy she met at MacDonald's when she was with a group of friends last week. She didn't really talk much to Mike that day, but he seemed OK. She wasn't really sure whether she would see him again. She feels kind of odd accepting him as a friend, but does so anyway, without responding to the message. What should Tania do now and why?

In another session, they explored an ethical issue of their choice, one that had arisen in the previous discussion about media ethics. The questions posed in this session were:

59 Due to unforeseen circumstances, this was conducted in two 'bites'; Josh, Jessie, Alexa and Mia in one group, and Hana and Simon in the other. David was unable to participate in either of the second sessions.

60 Adapted from University of San Diego (2010). On a five point Likert scale, the students were asked how important the following are in their life: religious commands, following my conscience, looking out for myself, doing the right thing/doing my duty, showing respect for everyone, human rights, making the world a better place, justice/fairness, being a good person, caring about others.

61 Adapted from 'When do I friend?' http://www.scu.edu/ethics-center/ethicsblog/atthecenter.cfm?action=viewpost\&c=73483 
What sorts of images should the media be allowed to show on TV or in the newspaper? How should we decide what is $\mathrm{OK} /$ not $\mathrm{OK}$ for the media to show? They examined these through three ethical lenses (deontological/rule-based, consequentialist and virtues/character perspectives), selected so as to represent a range of perspectives and keep the conversation manageable. A written task-sheet with question prompts (see Appendix 5) was designed to support a 'think/pair/share' exploration of these ethical perspectives, but in reality the students preferred to think their way into the issue through conversation.

This study was not devoid of ethical dilemmas. All social studies staff in the department were invited to participate, and all accepted. In one staff member's class, all students were invited to be participants in the focus group discussions. As there were more volunteers than needed, their teacher was asked to select six students on the basis of their ability to articulate their thoughts and likely interest in the project (criteria that were not disclosed to the students); it is possible that some students may have feel left out through this process. While I negotiated discussion times and venues to suit the social studies staff, I was conscious of the demands on their time. Further, and as the student focus group interviews took place in class time, another challenge related to minimising the disruption to the students' learning and ensuring that they were not disadvantaged in any way. The strategy I used was to have, with the teachers' agreement, the remaining students in the Year 9 class participate in the same activities and discussion tasks described above. However, I acknowledge that this lesson was a diversion from the unit of learning at the time. By far the biggest ethical challenge lay in the analysis of the focus group interview discussions and, in particular, representing the teachers' views. I was extremely conscious of not wanting to position the teachers as somehow lacking in relation to giving expression to the ethical content of the Values statement (Ministry of Education, 2007); after all, I was just as mystified as them. However, my initial cut at writing up the results for publication left me concerned about how the teachers felt about the findings and how they had been represented. In retrospect, I wish I had built in more time for discussion with the social studies teachers about my emergent findings. Despite the fact that this would have taken up more of their time, I feel I could have done more to offset the risk of this study appearing as something being done to them, rather than with them.

I initially undertook an inductive thematic analysis of these data, paying attention to both the semantic and latent themes (Braun \& Clarke, 2006). At that point I was particularly interested in the teachers' views about the role of ethical perspectives in 
students' critical reflections, and in retrospect I think I was somewhat disappointed that this did not appear as compelling to them as it did to me. Part of the issue here was the coding process used, in which the coding categories - such as the teachers' 'conceptions of ethics' and 'pedagogical use of ethical perspectives' - lacked a theoretical lens for analysis. The process of developing a stipulative definition for ethical reflexivity led me to return to these data, and this time I used a deductive approach to coding the teacher and student conversations, in which I coded for: (a) the meanings attached to 'ethics' (teachers only), (b) critical thinking, (c) lived experience and (d) imaginative action, and (e) the theoretical and pedagogical tensions implicitly and explicitly identified.

\section{SIGNALLING THE SHIFTS IN MEANING}

A first finding is perhaps entirely predictable given the interpretative challenges noted earlier in this chapter. For this group of teachers at least, the prospects for an ethically reflexive orientation would be likely dependent on greater semantic clarity and elucidation about the work that ethical decision-making and action is intended to do in social studies education. All could see connections between ethics, their existing teaching programmes and current controversies. They identified a wide range of units of work which have an ethical content, although not named as such to the students, including contexts/topics such as 'Earth Rights', 'Human Rights', and 'Values and Beliefs'. Yet, while all saw ethics as being relevant to social studies, they differed in their views about its centrality. Simon, with a university background in ethics, saw the discipline as lying at the heart of social studies: "every topic we teach is about ethics. It's about making choices in society. That's what ethics is." By contrast, Mia asked the group, “Aren't we meant to be thinking about using, bringing in ethics into every unit we teach, or making it an aspect of each unit?" In the main, there was not a strong sense that the teachers saw ethical questions as lying at the heart of controversial issues and therefore being central to social studies. Furthermore, and in line with Keown's (1998) research, it was clear that this was a 'hard bit' of social studies for which they needed greater pedagogical and content knowledge support. Alexa seemed to sum up the feeling of the group, that ethics was seen as a bit of an add-on:

If the term ethical values or whatever they call it in the NZC was clearer and it comes with resources for us to be able to look at and use, then I might be more comfortable, perhaps, doing a unit on ethics. 
How, then, did teachers conceive ethical decision-making and action? Most importantly, they largely wanted to eschew prescriptive interpretations and, in terms of an ethically reflexive orientation, placed considerable weight on critical reflection. Initially, however, six of the seven teachers aligned ethics with prescriptive morality. For example, Josh explained that ethics means "behaving properly towards others. I think of an ethical business person, you know, someone you can trust". But at the same time the teachers wanted to distance themselves from morals and ethics, vastly preferring the term values because it felt less narrow and more usefully ambiguous. For example, Hana felt that values "is seen as a more PC, useable word than moral". Mia added:

Well, it's that word [ethics] isn't it...we don't use that word, we use 'values' which seems to be less value-laden than 'ethics' and 'morals'... [and later said]... We don't use that term. We haven't before in social studies I think. It's always been 'values' which has sat quite comfortably with me because it's looking at different viewpoints isn't it.

What transpired was that what the teachers were wary about was ethics being perceived in a prescriptive sense. Josh and Alexa, for example worried that ethics and morals might “get parents' backs up". They themselves understood ethical decision-making and action as being both contextual and contested - in their terms, "grey" and "value-laden" - and it was this that they wanted their learners to think critically about. The teachers' concept maps emphasised a critical orientation to social inquiry, social action, citizenship and participating in society. Similarly, in the interview discussions, they most strongly aligned ethical decision-making and action with thinking critically about viewpoints and values. Ethics was for them about understanding sides of a debate; of the sort that occur in their social studies classrooms and connected to notions of choice, rational thought and deliberation. David, for example, associated ethics with wisdom, "You know enlightened as opposed to what's normal, what you'd normally expect to happen. And yet you might go against the grain and that's based on rationalization”.

The BBC and San Diego (BBC, 2014c; University of San Diego, 2014a, 2014b) web pages appeared to stimulate the teachers' thinking about opportunities for critical reflection. For five teachers, the website content came as something of a revelation. Mia reflected that "I never knew that there were schools of thought about ethics, I never knew that, and I've never known that anyone had written them down and catalogued them." Similarly, Hana reported an 'a-ha' moment having read about ethics in relation to the global financial crisis: 
But then reading it in the Guardian and it's a big topic, you know, with some really big people [debating the ethical issues]...I thought "gosh, we're talking about a real hot topic here". It was really interesting... discussing it with you and then reading it in the paper. I really felt there was some connection. I thought "oh, this is great".

The majority of teachers could see the immediate pedagogical relevance of the website content as a support for critical reflection. Four teachers reported that one or both was helpful and accessible and, to my surprise, three reported that at least one of the web pages was sufficiently accessible for students. It was suggested that students could use the ethical perspectives outlined in the web pages to reflect their own beliefs. Alexa described this approach as: "just talk to the kids about "which school of thought do you think you fall into?' Does this govern the decisions you make?"' In a variation on this, Simon felt that the students could then evaluate a situation (such as sheltering a Jew from the Nazis) from ethical stand-points. Other strategies for critical ethical reflection suggested by the teachers included the use of dilemmas, creating a court situation where jurors are assigned different perspectives, asking students to put themselves in someone else's shoes, and the use of newspaper photographs as a stimulus for ethical debate. Simon pointed out that strategies such as these are not without their drawbacks and stressed the need to ground ethical dilemmas in context and fact. Citing an image of an Islamic woman being punished, he commented:

...you can't actually discuss that as an ethical issue in isolation without discussing the whole propaganda brought against Muslims at the moment. You know, ethics is not in isolation, the ethical issues and the way they're posed is very much a product of society around us.

Yet, despite seeing a strong link to critical reflection about social issues, the teachers were cautious about the extent to which ethical perspectives might be used as a tool for this. They were reluctant to take this into a deeper exploration of ethical perspectives and were hesitant about employing the conceptual language and categories of thought of the philosophy of ethics. This hesitancy manifested in the language that they drew on. Unless referring to the web pages, the teachers tended not to use the term ethical perspectives to mean the theoretical frameworks that shape decisions about social actions. For the most part, they used ethics interchangeably with points of view, values and perspectives (by which they meant viewpoints) throughout the interviews. The semantic distance between ethics and perspectives was also evident in the concept maps 
where all teachers placed 'ethical thinking' well apart from 'perspectives/worldviews', yet five located it more closely to 'challenging the basis of assumptions and perceptions'.

For the teachers, ethical perspectives were too abstracted, in two senses. A first related to the cognitive demand they perceived ethical perspectives presented for themselves and their students. The teachers queried students' readiness for thinking about ethical perspectives and raised the need to develop students' critical and independent thinking skills in order to be able to tackle ethical dilemmas. One teacher also felt that clarifying 'ethics' may be a pedagogical challenge when the students are most used to the term values. Furthermore, how one might go about teaching theoretical perspectives was a matter of some discussion, in particular whether or not students should be taught a list of these, and where in the learning cycle it would be most appropriate to do so. It was notable that while they discussed the potential of using ethical perspectives in a lesson(s) and possibly units of work, none suggested that they might be a recurring thread in their social studies programmes. Two teachers noted that the vast and contested nature of ethics would make such an endeavour complex:

It makes it very mind-boggling to think about how you would use [ethical perspectives] in your teaching and how you would actually put it to the kids, and do it enough depth that you didn't feel like you've simplified it so much that you were dictating to the kids your morals. [Mia]

I could see maybe teaching this at a higher level, you know linking the theories with real life. But I think just as we are I think that's enough. You know, it's like a taster isn't it of what we could do later on. I was just thinking it's too much... What would you teach, I mean that BBC, that's hard, that's going to be about two or three years' worth of teaching. It's difficult, what bit of the ethics would you teach? Whoa. Would you just teach the history of ethics, would you teach the religious aspect of it, I don't, yeah, and it's all interlinked and that's the difficult part isn't it? [Hana]

A second sense in which ethical perspectives were seen as being abstracted related to the perception that philosophy in general was too distanced from social life. This was expressed most strongly by Simon, who felt that ethics was a very academic and dry discipline "lost in time" and preferred instead to focus on ideologies such as fascism and nationalism. By contrast, Hana felt that ethics was "happening now, it's still a modern issue ... you can use these age-old ... theories can't you?" Nevertheless, and whilst the majority of teachers were not dismissing the philosophy of ethics, it was clearly viewed 
as something quite distinct from what they stressed as being the contextualised nature of social studies:

We teach it [ethics] through a study of society rather than through a study of philosophy ... which does it in an abstract fashion. I think that's progress, I think it's a better way to understand ethics, to understand the world. [Simon]

\section{LINKING THEORIES WITH REAL LIFE: BRINGING IN LIVED EXPERIENCE}

To summarise the discussion so far: while much of the discussion implicitly emphasised the critical reflection aspect of an ethically reflexive orientation, the teachers were on the whole ambivalent about the role of ethical perspectives in social studies education. Thus, there was some distance between their sense of critical reflection and the way in which I have described this in Chapter Four, and whether they would have viewed the philosophy of ethics as powerful knowledge is an open question.

It seemed to me, however, that the teachers were reaching for something more than critical reflection in their thoughts about ethical decision-making and action. In a notable departure from Keown's (1998) findings, the teachers saw ethics as being distant from social studies precisely because they felt the field of ethics places too much emphasis on reason and rational thought. To characterise their views in relation to the argument built in this thesis: bringing in their students' lived experience was as central to better supporting their ethical decision-making and action as critical reflection. This was foreshadowed in their responses to an initial question about what they saw as being the nature and purposes of social studies education. Without naming it as such, and of the four previously described social studies traditions (H. Barr et al., 1997; R. D. Barr et al., 1978), the teachers placed by far the greatest weight on social studies taught as personal, social and ethical development. In their concept map, Hana and Mia expressed this as 'becoming'. All the teachers made much of personal awakening and awareness in the lives of their students, stimulating an interest in "what's going on every day" (Hana), both in New Zealand and overseas. They secondly emphasised relational aspects of social studies learning: their students' connectedness to others and society, cultural identities, empathy, and capacity to appreciate difference. And, thirdly, they were strongly focussed on their students' agency. In their words, this involved helping students to see that "they can make a change" (Simon), be proactive and use their social studies learning to make a difference, "hopefully for good over evil" (David). 
Throughout the rest of the interviews, it was apparent that the teachers wanted to ground ethics in the experiences and decision-making of their learners' lives. They emphasised that their students' critical reflection should be directed towards their lived experience; that is, to come to their own decisions about social issues that affect them and how they will participate in society. For the teachers, 'responsible' decision-making was much more closely connected with their students' consideration of participatory possibilities than it was arriving at a teacher's view about the right thing to do. Jessie, for example, said that in relation to topics such as euthanasia and children in armed conflict, she saw her role as helping the students to make sense of "where people stood on the spectrum of an issue" in order for them to decide where they fit. They did, however, recognise the uncertainty of pedagogical outcomes. Mia began one line of discussion by asking "if it doesn't lead to social action, what's the point?" to which others replied that this might occur in the future and that, at least where public political figures are concerned, one can never be sure about one's influence on students' moral compass.

Two further features signalled that the teachers' views of ethical decision-making and action were directed towards lived experience. First, Hana argued combining "real life scenarios" with ethical theories. Simon repeatedly stressed the contextual nature of ethical decision-making and action, and saw the particularity of lived experience as being central to the work of social studies:

What we teach in social studies is in many ways better than ethics because you've got to start from the situations we find ourselves in and the choices that people make - and then you can ask questions about right and wrong.

Second, the emotional dimensions of ethical life were a strong feature of the discussions. It was notable, for instance, that in all three concept maps 'affective/emotions' was strongly associated with ethical thinking, either directly or via values and morals. The teachers spoke warmly of their students' embodied, "ants in their pants" (Jessie) connection with controversial issues and the lives of others. Jessie felt that "they really care, because they're developing their own values and what they want and who they are". Josh noted the connection students felt to the challenges faced by people in other parts of the world: "some of the things that they come across they can't believe". The teachers wanted to stimulate and affirm what they described as being their students' passion, but were keenly aware about the sensitivities of ethical discussions and that critical reflection had an important role in relation to their students' 
emotional responses. In the words of Mia, "kids get upset and they get on their high horse about stuff and sometimes it can be totally misguided".

\section{KNOWING WHAT TO DO: BRINGING IN IMAGINATION}

This fourth set of findings brings in the students' voices in relation to the discussion above. I share the findings, from the students' point of view, about the relationship between ethics and (a) critical thinking and (b) their lived experience. Their discussion moves beyond that of their teachers in one important respect; they saw the ethical discussions as offering considerable imaginative stimulus.

Like their teachers, the students saw ethical controversies as being appropriate to social studies education. But likely a result of the methodology, they had rather fewer reservations about employing ethical perspectives in their critical reflections. Three students could see a direct connection between the content of the Facebook debate and the moral orientations survey they completed at the beginning of the session. One student, Destiny, reflected that she had initially filled out the survey without thinking too much about it, and that the Facebook conversation had made her realise that using her conscience to make a decision was much more important to her:

I've just realised that I've done - for following your conscience thing I did 'agree' - and after talking about this I think I should have changed it ... I was doing it and then I'm like "oh that's easy, that's easy, that's easy". And then I've talked about it, like I've talked what I do more, then I've realised that I've not done it right.

Another, Bob, could readily see that a religious moral orientation might affect people's decisions and feelings about controversial issues. In the last session, where they elected to discuss the images that the media should be allowed to publish, the students had a minimal introduction to consequentialist, deontological/rules and virtues/character perspectives. I briefly explained what each perspective involved, and there were further prompts on the worksheet they were provided. Yet, despite this minimal elucidation, the students took these up with relative ease and were able to 'inhabit' one or more of the ethical perspectives, albeit with varying degrees of confidence. Michael, for example, explained that considering the consequences is important in determining the images the media should be allowed to show:

I was just going to say like I think like the rule should be like if it's going to harm, like affect us, then we should know. So that like if it's like got all these people are dying blah 
blah blah blah then that's like fair enough. But if it's like 'this person was killed but we caught the killer' then what's the point in telling us?

The importance of bringing in learners' everyday lives was palpable in the students' conversations. Most reflected that they were more engaged in the Facebook activity than the discussion about the images the media should be allowed to portray, and all said that they related to the Facebook dilemma better. The students felt that the noticeable decline in engagement in the 'media' discussion stemmed from the context being distant from their everyday lives, and lacked sufficient detail to support them to make sense of the debate. However, this did not dent their enthusiasm for debates of this nature. In particular, they stressed the relational nature of ethical decision-making and action. In their final reflections the students reported that they got more of a chance to: offer their thoughts without embarrassment; listen to other people's views; get to know people with whom they had not previously worked; and become more aware about what is going on in the world. Echoing the views of the group, Money said "we should just stay like this forever". Though there was clearly more room for developing the students' understanding of ethical perspectives, the sole reservation the students had about the activities was that: "you should only do this in class if you're in a small group like this because a whole class group there would be hardly be any say, you know it would be only the teacher's favourites like..." (Michael). It is interesting to note, here, that the students strongly equated critical reflection with the relational, lived experience of such discussions.

What was particularly striking about the students' conversations was their emphasis on the imaginative aspects of ethical reflexivity. This manifested in at least three related ways. First, the extent to which the respondents felt able to adjust their positions (at times, somewhat microscopically) as the discussion progressed was impressive. They each began with a 'working model' of what it is to behave decently, at many points drawing on influences in their lives which they had either followed, rejected, or both. At times they found difficulties in making that model work to their own satisfaction when applied to situations that they had not thought through or when considering another student's argument. Rather than feeling stuck, the conversations generated multiple ways forward. Second, and in contrast to their teachers' tendency to construe ethical decision-making and action in either/or terms, the students resisted coming to an easy consensus. Third, and although the students did not radically alter their positions about whether they would accept a Facebook friend they barely knew, all said that this activity gave them increased 
confidence about the actions they would take, typically reporting that "if it happens I know what to do" (Isaac). Even the least engaged student, Money, emphasised that the real-life nature of the Facebook scenario could "teach you what to do and stuff." There was not the sense here that the students were seeing these 'solutions' in once and for all terms; rather that the conversations had opened a realm of possibility and offered ways to go on.

The students' experiences of these focus group discussions appear to resonate with the findings from similar studies conducted by Susan Pass and Wendy Willingham (Pass, 2007; Pass \& Willingham, 2009), who have explored the power of ethical perspectives in social studies education. The participants' responses to their research, which involved making ethical philosophies transparent to teachers and students, has encouraged the authors in their view that open discussion about these perspectives is not only desirable in social studies education but that there exists a "real hunger" (p. 29) because it helps students to make sense of complex societal debates. However, what struck me most about the students with which I worked was the reflexive nature of their conversations - the movement between the critical, lived and imaginative dimensions of ethical decision-making and action. In the discussion below, for example, the 'Facebook' ethical dilemma prompted the students' thinking about police professional ethics. It might have been easy to regard this portion of the discussion as a digression. The students were, in fact imaginatively bringing the ethical content of the fictitious Facebook dilemma into the context of their own lives. And, in doing so, they were exploring consequentialist and deontological perspectives.

Destiny: $\quad$ On I think Facebook or something the police did this search thing where they sign up as a 16-year-old or 17-year-old or, whatever, 14-year-old, and then they like emailed everyone and whoever replies like "Oh I really like this school" and like "blah blah blah" and then they go round to their house and they get their parents and they all talk about how that could affect everyone if had been someone else other than the police.

Michael: It's like on Bebo a couple of years ago there was these two English girls and they started talking to this guy and they decided to meet him one day and one of the girls got sick and she couldn't go and the other girl got murdered. And they'd never met him.

Isaac: Well, what the police did that was fraud, so they could get in trouble for that...So they're not telling the truth. 
Destiny: It's not protecting them, because what if it happened to be like someone else that actually meant harm.

\section{COMPLEXITY AND UNCERTAINTY: THEORETICAL AND PEDAGOGICAL}

\section{TENSIONS}

One last set of findings returns to the ethics of ethics education. The teachers primarily sought to provide balance in their approach, yet they also clearly articulated concerns about indoctrination and a tension between privileging a position and avoiding it altogether (responses outlined by Hess, 2004). Though they were particularly anxious to avoid strongly normative ends in ethics education, all could identify aspirations for their students that could be construed in these terms. The teachers mentioned that they directed social studies teaching and learning towards: social justice, fair play, antiexploitation, right and wrong, fairness, the way to treat others, social conscience, appreciating difference, empathy, and a balanced view of society. Yet they viewed the socialising aspects of social studies education as being in tension with a countersocialising approach to ethical decision-making and action. The teachers themselves noted that one can never entirely eradicate prescriptive expectations from social studies curricula no matter how much one might prefer to maintain a neutral stance. Further, numerous interchanges highlighted the multiple, often competing, ethical frameworks that infuse societal decision-making. For example, the problem of moral relativity was discussed in relation to the Holocaust and Mia picked up on ethical universalism, pondering "is there a set of rules that is intergenerational, universal? I guess there is". Simon most clearly expressed the group's central conundrum by questioning what was expected by the curriculum: "exactly what's the line between indoctrination and teaching people to think for themselves?" While some stressed that social studies teachers tried hard not to impose their views or sway students' thinking, and that neutrality was important, the same teachers readily acknowledged that their own moral stand-points inevitably infused their social studies teaching:

I do think that on a day-to-day basis there's a subtle undertone of morality in social studies lessons, but I've never wanted to explicitly say that to the kids. I've wanted to put stuff before them and then they become passionate about it, upset and all that sort of stuff. [Mia]

I think it's very hard as a teacher to be unbiased because even though you say 'these are all the viewpoints'...you still some come over and, like the Holocaust, you know, you still go 'this was awful, we never want this to happen again'. [Hana] 


\section{CONCLUSION: WHAT WIGGLE ROOM FOR AN ETHICALLY REFLEXIVE ORIENTATION?}

Where do the insights of these teachers and students leave us, the large part of this chapter having painted a somewhat sombre future for ethically reflexive approaches to social studies education? It is important to restate that the findings are only a limited test of the barriers to, and prospects for, an ethically reflexive orientation identified in this chapter. The data are limited, and clearly there is a long way to go in terms of understanding New Zealand social studies teachers' conceptions of, and pedagogical approaches to, supporting their learners' ethical decision-making and action.

Nevertheless, and especially given the lack of professional development in relation to this aspect of The New Zealand curriculum (Ministry of Education, 2007), I doubt that the findings would be significantly different if the study were to be expanded to include more Year 9 and 10 social studies teachers in different schools.

It was not possible to determine from this study what the impact of scientifically managed or evidence-based education might be on the teachers' approaches to enacting the ethical aspects of the Values statement (Ministry of Education, 2007). This is unsurprising given that the focus group discussions represented, for the majority of teachers, their first foray into thinking about the relationship between ethics and social studies. I suspect that the potential influences of instrumentalism and evidence-based policy would be more likely detectable if the teachers had been at the point of considering the relationship between the Values statement, social inquiry, and the content of assessment tasks. In the main, the teachers' concerns related to the need for (a) greater clarity about what ethics is to mean and the work it is to do in social studies, (b) appropriate pedagogical tools, and (c) the inherent ethical challenges in any 'valuesladen' approach to social studies.

Moving beyond these concerns, there was some evidence to suggest that an ethically reflexive orientation to social studies would sit comfortably with the teachers and students in this study. Their responses strongly emphasised the need for ethics education in social studies to amount to something more than critical reflection, most particularly that which appears an exercise in abstraction. Indeed, the teachers' somewhat subdued responses to the role of ethical perspectives in social studies challenged me to take my thinking further in this regard. The need for a more expansive sense of ethical decision-making and action notwithstanding, one wonders how greater 
support for exploring the philosophy of ethics and its relationship to social studies education, as Brian Hill (1994) has urged, might shift teachers' perceptions of the discipline. It is entirely possible that the novelty of 'ethics' and/or the way it was presented to the teachers in this study hampered a deeper consideration about its fertility. Arguably, this reinforces the need for both research methodologies and curriculum support materials that more carefully bridge pedagogical and content knowledge. In particular, it would appear that teachers may need greatest support in terms of teaching ethics as societal perspectives, if classroom discourse is to move beyond the language of values.

Chapter Three noted the ways in which the current curriculum decontextualises, disembodies and decentres learners. These appear matters that the teachers and students would want to strongly resist. It is notable that lived experience, in the sense I have previously outlined, was an important dimension of social studies education from their perspective. For them, giving expression to the ethical dimensions of the New Zealand curriculum's $V$ alues statement (Ministry of Education, 2007) would require considerable attention to grounding ethical dilemmas and challenges in contemporary societal contexts; moving between the abstract and concrete, the everyday and what is 'out there in the world', the personal and the socio-political. Furthermore, the emotional dimensions of ethical decision-making and action would need greater acknowledgement. For the teachers and students, the challenges of ethical issues, and pedagogical approaches to exploring these, were 'felt difficulties' for the teachers and students; not simply a matter of intellectual engagement but emotional and relational work also.

It would appear that, for the students in particular, bringing in the imaginative dimension of ethical decision-making is vitally important. It was in their generative discussions, focussed on exploration rather than conclusion, that they felt a sense of agency; they could see a constellation of possibilities for social action. Most likely this dimension of ethical reflexivity was compelling because they could draw their experiences of discussing ethical dilemmas; the teachers, by contrast, were discussing the pedagogical implications in the abstract. One wonders, therefore, how the teachers would have responded if they had trialled a similar activity, and whether their emphasis on sides of a debate and making choices might have opened out to a language of multiplicities. The latter question is particularly interesting, given the tension that they felt between the socialising and counter-socialising aspects of social studies. While I have argued that better supporting social studies learners' ethical decision-making and 
action requires robust ethical pluralism (Hinman, 2013) and agonism (Mouffe, 2000, 2013), one cannot say for certain what the teachers' views about this might be. It is also an open question as to whether they would concur with 'social studies as countersocialisation' in the terms described in Chapter Four.

Such questions aside, and to address the third of my research sub-questions, the focus group discussions suggest that the prospects for an ethically reflexive orientation to social studies might not be as bleak as it would appear from the bulk of this chapter. Between the teachers' desire for a pedagogy that placed their learners' lived experience at the centre, and their students' capacity to imaginatively engage with ethical perspectives, one sees the potential for an ethically reflexive orientation to more successfully respond to what each group was reaching for in doing ethics. Greater support for such approaches might just conceivably transcend the ethically silent space of social studies. Possibilities for this are explored in the next, concluding chapter. 


\section{CHAPTER 7: TRANSCENDING THE ETHICALLY SILENT SPACE OF NEW ZEALAND SOCIAL STUDIES EDUCATION}

This chapter comprises five sections. It opens with a summary of the thesis' theoretical and empirical findings in relation to my research questions, and is followed by a section that explores the limitations to the thesis. The third and fourth sections consider where practices that give rise to change could evolve from, in light of the possibilities and constraints explored in the previous chapter. Two sets of recommendations are made: (i) policy related, centring on an appeal for agonistic spaces in which the New Zealand social studies community could engage with this thesis' argument and, (ii) implementation related, suggesting a variety of existing pedagogical strategies that intersect with an ethically reflexive orientation and could usefully be explored in social studies teaching and learning. The latter rounds off a consideration of my third research sub-question by exploring pedagogical possibilities for an ethically reflexive orientation. The thesis closes by returning to the wero/challenge with which it began: a question of placing stakes in the ground.

\section{SUMMARY OF FINDINGS}

This thesis has considered how social studies learners' ethical decision-making and action could be better supported. This concern arose in part from The New Zealand curriculum's expectation that students will "be encouraged to value... acting ethically" and "develop their ability to... make ethical decisions and act on them" (Ministry of Education, 2007, p. 10). However, the research rationale extends beyond a matter of policy directive; it stems from ongoing debates about the proper relationship between ethics and education. Chapter Two established that ethics matters in life and in education because it is central to the human condition - each of us must make moral choices, whether or not we bring the philosophy of ethics to bear on them. Were the choices simple and unemotional, there would perhaps be no need for discussion about the relationship between education and ethical life. But contemporary ethical space is marked by pluralism, ambivalence and multiplicities; the choices are far more complex than either/or or once-and-for-all decisions. It is, therefore, hardly surprising that educational debates, especially in democracies charged with supporting learners to respond to such complexity, are unlikely to arrive at an incontrovertible blueprint.

Against the backdrop of an ongoing conversation, the work of this thesis has been to propose a broad theoretical orientation to better supporting social studies learners' ethical decision-making and action. The argument has distinguished ethics from values 
and morals, taking ethics to mean an activity - that of coming to an understanding of, and reflecting upon, a range of perspectives about social action. Successive chapters have considered the 'is' and the 'ought', for example, how ethics has gained expression in social studies curricula and the place that it could occupy in future. In this section I summarise this thesis' findings, responding to each of my research sub-questions in turn:

1. What opportunities for ethical decision-making and action are offered through New Zealand social studies curriculum documentation?

2. What theoretical spaces exist for better supporting social studies learners' ethical decision-making and action?

3. What could be possibilities and challenges within these spaces?

In relation to the first of these questions, this thesis has found rich veins of opportunity for learners' exploration of ethical decision-making within the purposes of social studies, at least as they are ostensibly construed in The New Zealand curriculum (Ministry of Education, 2007). Social studies could be considered a natural home for ethics because the subject focuses on learners' open and critical exploration of their societies and participation within them. It is notable that the social studies curriculum (i) recognises the societally contentious, (ii) prompts learners' consideration of diverse values, perspectives, and, implicitly, conceptions of the good life, and (iii) provokes questions about how to go on. Further, and as Chapter Three's content analysis revealed, the phrases "acting ethically" and "make ethical decisions and act on them" (p. 10) are closely connected to supporting learners to think otherwise about what constitutes a worthwhile life or how we might live together. Such considerations are arguably central to social studies education because the subject focuses on social issues and responses to them.

For all these opportunities, in a semantic and theoretical fog, ethics looms as a silent and ghostly presence in New Zealand's social studies curriculum. This is because ethics has appeared over the curricular horizon, without a clear sense of the work it is meant to do in social studies. This is not to say that social studies is devoid of ethical content; over 80 years of curriculum documents examined in this thesis have highlighted ethical tensions inherent in the subject. It is to say that (a) the usages of ethics in the Values statement (Ministry of Education, 2007) are not clarified, (b) the concept does not reappear in the social sciences learning area statement, and (c) ethics' linkages to other proximal social studies terms are not made clear to the reader. Furthermore, there is a lifelessness to the social sciences learning area statement that works against the purposes 
of social studies and learners' exploration of ethical decision-making and action. As has been argued, the statement is somewhat disconnected from learners' identities, emotions and everyday lives and enervates both the participatory dimensions of social studies and the sense that there are pressing, complex societal issues at hand.

If ethics' centrality to social studies education was to be made more explicit, what theoretical spaces exist for better supporting learners' ethical decision-making and action? This thesis has found that the usages of ethics in The New Zealand curriculum (Ministry of Education, 2007) float on an open and permissive sea of curricular theory. One appears able to cast the net wide in considering a theoretical re-orientation; a great deal appears possible. This matter notwithstanding, the social studies curriculum is pulled by an undertow of two melded theoretical traditions: social studies taught as reflective inquiry, and as social science. The reflective inquiry tradition frames the social inquiry methodology as a re-iterative analysis of social issues, ideas, and themes related to decision-making and participation in society. The social sciences tradition provides, in a sense, the raw material for such inquiry and analysis - conceptual understandings drawn from disciplinary modes of thinking. These traditions have in common an emphasis on critical reflection, understood as the rational capacity to think otherwise and thinking that 'arcs back' on theory and concepts, that is, inherited understandings and existing bodies of thought.

Three findings point to a need to adjust the melded traditions of social studies taught as reflective inquiry and social sciences, in order to (a) offer ethics a more explicit place within these extant theoretical framings, and (b) to better accommodate learners' consideration of ethical life. The first relates to the way in which the phrase "engage critically with societal issues" (Ministry of Education, 2007, p. 30) is subordinated in the social sciences learning area statement. In order to meet the present curriculum's $V$ alues statement expectations, social studies requires a stronger focus on social issues, as the very notion of ethical decision-making and action presupposes dilemmas and challenges of some kind. Further, and because ethical questions do not map easily onto a public/private divide, attention to learners' everyday experiences of ethical decisionmaking and action could provide them with a great deal of insight into the ethical content of 'public' issues, and vice versa.

A second necessary adjustment to the New Zealand social studies curriculum pertains to its participatory aims; currently a curriculum aspect open to considerable interpretation 
(Abbiss, 2011). I have argued that social studies education needs to be primarily directed towards counter-socialisation (Engle \& Ochoa, 1988; Ochoa-Becker, 2007) if learners' exploration of ethical decision-making and action is (a) to have any meaningful scope, and (b) amount to more than a replication of the status quo. My use of countersocialisation emphasises the enacted dimensions of social criticism, and that critical reflection takes places in an ethical world marked by inconsistency, disagreement and uncertainty. Further, I have argued that the complexities of learners' countersocialisation could be better supported through (a) learners having access to as an encompassing range of ethical perspectives as possible and, (b) representing ethics as an ongoing conversation about the best decision that can be made in the moment and circumstances, rather than an exercise in arriving at final decisions. In light of this, social studies education could usefully employ robust ethical pluralism (Hinman, 2013) and agonism (Mouffe, 2000, 2013) as approaches to better supporting learners' ethical decision-making and action, in part because both position differences in worldview as productive counter-points in considering how we shall live together.

A third curricular adjustment builds from the previous two. I have made a case for strengthening New Zealand social studies education through a more overt mobilisation of the philosophy of ethics. As Chapter Three has described, the centrality of this discipline to social studies education has been under-acknowledged in the history of New Zealand curriculum development. And yet, the philosophy of ethics' discourses and modes of thought - among many resources that learners may draw on in navigating the vicissitudes of ethical life - offer social studies learners significant tools with which to explore the ethical content of social issues in depth. The formal study of ethics does so through (i) access to powerful knowledge that holds considerable explanatory power, and (ii) supporting a wide range of social studies outcomes.

However, the extent to which the proposed adjustments better support social studies learners' ethical decision-making and action depends on (a) bow they are mobilised in educational approaches, and (b) how they articulate with the society within which learners find themselves. Here, the thesis arrived at a fourth, and arguably the most important, finding in relation to the second of my research questions. It charts a course through the curriculum's extant theoretical framings and on to more open waters, finding that theoretical spaces exist for understanding what it is to be in our ethical world as ethically reflexive acts. The stipulative definition built for ethical reflexivity enfolds three important dimensions: (a) critical reflection, (b) lived experience, that is, 
the emotive, embodied, everyday, and emergent dimensions of ethical life, and (c) imagination - a dimension only lightly touched upon in the reflexivity literature. An ethically reflexive orientation to social studies education thus brings in bodies, feelings, relationships, desires, creativity and wonder. Attention to such dimensions moves social studies taught as social issues, as counter-socialisation and as engaging with the philosophy of ethics beyond being purely matters of critical reflection. Enfolding learners' lived experiences and imaginations recognises that ethical decision-making and action does not solely arc back on inherited understandings in a rational and orderly manner. Ethical life is not a simple matter of reflection or even refraction; the multiple, fluid and contradictory nature of its surfaces make such linear moves impossible. Thus, a conception of ethical reflexivity in social studies education resists the sense that learners' ethical decision-making and action is to converge at permanence; the cogency of this lies in a more honest representation of the uncertain and emergent nature of ethical life.

What challenges and possibilities lie within ethically reflexive spaces? Building from Paul Keown's (1998) research, this thesis has explored four forces that may shape the barriers and prospects ahead: (a) a continued lack of curricular explication as to what ethics is to mean and look like in social studies education, (b) scientific, or instrumental, approaches that render ethics as a cognitive exercise of molecular mastery, (c) evidence-based approaches that occlude a consideration of the aims of ethics education, and (d) teachers' legitimate concerns as to ethics of an ethically reflexive orientation. This was not meant as an exhaustive consideration, and most certainly the contentions made here warrant stronger empirical evidence, but it is notable that these forces have already imprinted social studies education in New Zealand, albeit not directly in relation to learners' ethical decision-making and action. While these read primarily as a set of possible constraints, the views of a small group of social studies teachers and several of their students offered some cause for optimism. The first and last of the previously described factors appeared central to the teachers' immediate concerns about the place of ethics in social studies education. These reservations notwithstanding, the teachers and students arguably saw the role of ethics in social studies education as encompassing of, but being more than, critical reflection. The teachers particularly emphasised abstractedness as being a risk of employing the philosophy of ethics in social studies teaching and learning, and instead wanted to attend to their learners' lived experiences. The students were less reticent about ethical perspectives, having engaged with a selection of these in conversations about ethical dilemmas. They saw such ethical discussions as connected to their own lives and as 
offering considerable imaginative stimulus. Thus, whilst not directly endorsing an ethically reflexive approach (partly because they were not directly asked about this), there appeared some 'wiggle room' for such an orientation to gain expression in social studies teaching and learning.

\section{LIMITATIONS OF THE RESEARCH}

This thesis is a largely conceptual piece that has, at various points, drawn on empirical evidence. I acknowledge at least three limitations to the strength of this evidence. First, and given international variations in social studies and citizenship education, one may question the extent to which the international evidence to which I have referred to speaks to the New Zealand context. Second, the justification for mobilising the philosophy of ethics in social studies education, made in relation to powerful knowledge and social studies outcomes, could be strengthened with empirical evidence. There is no research, for example, about the link between the formal study of ethics in schools and social mobility. Further, while there is more general evidence about philosophy education in schools, none relates ethical thinking to the full range of social studies education outcomes. Third, there are few large-scale studies of New Zealand social studies classroom practice; much of what does exist is anecdotal or based on the perceptions of teachers. For example, while principals, teachers and students report an emphasis on open-ended discussion in their classrooms (Schulz et al., 2010), the actual extent to which social studies learning is counter-socialising is not known. So, in relation to the focus of this thesis it would be helpful to have a better picture of (a) where ethics is explicitly addressed in New Zealand schools as, for example, part of social studies, religious or philosophy education, and (b) how the curricular requirement to better support learners' ethical decision-making and action is given expression in these sites. The curricular content analysis presented in Chapter Two offers only a partial insight into the place of ethics in social studies education and the ways in which ethics and its cognates have been understood by social studies curriculum writers, teachers and learners. Further, and though focus group interviews reported in Chapter Six offer a window into teachers' and learners' conceptions of, and explorations with, ethics, the small-scale nature of the study is limited in its generalisability.

One further limitation of this research has to do with the argument for an ethically reflexive orientation. While this has been defended on theoretical grounds, the idea is yet to be tested in practice. Such empirical research could take place in classrooms that 
already make ethics an explicit part of teaching and learning or with teachers who have an interest in exploring ethically reflexive approaches.

\section{POLICY RECOMMENDATIONS: A NEED FOR AGONISTIC SPACES}

Such limitations acknowledged, this section considers policy recommendations that could be drawn from the thesis. Given the challenging, complex issues that face all of us on this earth and form a perhaps less visible part of learners' lives, this thesis has argued that ethics requires a far more explicit role in social studies education. A way forward has been proffered in theoretical terms, the argument being that an ethically reflexive orientation could be a means to transcend the ethical silence New Zealand's social studies curriculum. But clearly, and especially given the constraints outlined in the previous chapter, some consideration of where, practically speaking, future change could evolve from is necessary. I suggest that this is not simply to be achieved by way of social studies support materials that might, for example, provide a glossary or links between terms familiar to social studies teachers (such as values exploration and social decision-making) and usages of ethics in the Values statement.

If the history of moral education and over 70 years of social studies policy development in this country are any indication, the place of ethics in social studies is necessarily a matter of ongoing reconsideration. However, I urge that greater policy attention be given to the nature of that conversation: where and how the voices of the New Zealand social studies community are brought in, who the conversation includes, what is discussed, and how it takes place. The central recommendation made here is for a more inclusive approach to social studies policy development - one that permits the whole community to agonise, or wrestle with, diverse aspirations for social studies education in New Zealand. This includes a consideration of the work that ethics is to do, that is, its cogency, in social studies education. There is not necessarily a shared understanding of the aims of social studies education in this country. New Zealand social studies academics have tended towards counter-socialisation as being the subject's primary goal, variously expressed through emphases on social studies' critical, participatory citizenship and/or transformative dimensions. Transcending the ethically silent space of the social studies curriculum, in the terms outlined in this thesis, is tied to a counter-socialising orientation but, in view of limited data, it is an open question as to the extent to which teachers share this orientation and/or feel able to translate it into practice. 
I make three points about the agonistic spaces that are needed. The first relates to the small size of the social studies community. My experience of the social studies curriculum, support material and NCEA assessment development process over at least 10 years has been that of a piecemeal and fracturing approach. Subsets of an already small community have been called upon to contribute to developments and initiatives without the opportunity to co-ordinate their efforts with others, or discuss the challenges and considerations that arise from that work. Much of the ensuing confusion and distrust could, I venture, be offset through closer attention, on the part of the Ministry of Education's part, to (a) building and maintaining relationships across the social studies community, and (b) wherever possible, ensuring that there is collaboration and continuity across projects.

The second point is that any consideration of the work ethics is to do in social studies education requires the input of philosophers of education and ethics - a marginalised voice in recent curriculum revisions, at least since the 1990s. To be sure, the extent of sector engagement with the most recent curricular revision, and extent of political accord in relation to the final document, is commendable. But, like many aspects of The New Zealand curriculum (Ministry of Education, 2007), the detail is bedevilled where the relationship between ethics and social studies education is concerned. One important contribution that philosophers could make is in sketching out the contentiousness that forms the backdrop to perhaps attractive and too readily taken-for-granted curriculum terminology. Granted, policy documents inescapably must be stakes in the ground and represent choices made among possibilities. But, if the social studies community is to be genuinely invited to future policy debates, then the insights of philosophic critique should be available to all as one means of considering what the possibilities could be and an understanding of where disagreement lies. I think we need to be wary of the politics of consensus that contributed to the marginalisation of theoretical considerations in the last curriculum revision round, and alert always to the voices that are silenced or excluded in the name of consensus.

A third point returns to the marginalisation of citizenship and social studies education described in this thesis' introduction. Perhaps there is little to be done about a crowded curriculum and timetabling decisions at the school level. However, I suggest that, with effort, we could better co-ordinate the independent industry, within and beyond the education sector, related to social studies resourcing. For example, social studies is viewed by many governmental and non-governmental organisations as being a key 
anchor for their educational aims. We have seen see a plethora of resources produced for social studies education, about, for example: tax education, voting, blood donation, World War I commemorations, naturalization, and child poverty. In addition, there are numerous programmes that relate to social studies education: Human Rights in Education, Amnesty International, Enviroschools and the Outlook for Someday sustainability film challenge, for example. All of these compete for social studies teachers' and learners' time and attention. But, in a strongly marketised approach to education resourcing, there is not a consistent, collective, or prioritised approach to such learning materials and experiences. I stress that there is an urgent need to consider how the varying projects articulate with (a) each other, and (b) the transformative potential of social studies and citizenship education. This would greatly support a discussion about the place of ethics in social studies education.

There is, in sum, a very great need for the social studies community to have the opportunities to agonise with ideas about the future direction of social studies in a way that seeks to include marginalised and isolated voices. However, while I venture that an ethically reflexive orientation to social studies education is most likely to evolve from the recommendation above, I do not suggest that one must wait for policy leadership. Here, I think we could recognise the power of school-based curriculum decision-making and, in particular, the role of social studies teachers as reflexive practitioners. This contention returns the swampy-ness (Schön, 1992) and full-bodied knowing (Neyland, 2010) of teachers' professional experience, and particularly their felt difficulties. It suggests that future change in relation to an ethically reflexive orientation could well evolve from individual or small groups of teachers who have an interest in re/considering the nature and purposes of social studies education and exploring the role that ethics could play - if that matters to them. In this context, teacher professional learning becomes much less about deciphering or over-assimilating policy intent, and more about a reflexive exploration of how multiple visions for the good life might be accommodated in, and enacted through, social studies education. My second recommendation is, therefore, that consideration be given to a more organic approach to policy development which develops out of such reflexive explorations, and the challenges and contradictions that are revealed in the process. In this way, social studies policy development becomes a genuinely agonistic undertaking, with teachers. 
IMPLEMENTATION RECOMMENDATIONS: PEDAGOGICAL MODELS AS REFLEXIVE SURFACES

Recommending an organic approach may be all very well, but how might social studies teachers come to a point of noticing or rethinking the relationship between ethical decision-making and action and social studies, much less a desire to reconsider professional practice? Of the many possible impetuses, my central recommendation in this section relates to the need for second-tier materials that support the $V$ alues statement (Ministry of Education, 2007). I urge that such support materials should stimulate a reflexive consideration of possibilities for giving expression to the curriculum requirement that learners' ethical decision-making and action be supported. That is, they should resist representing ethics education as a matter of pedagogical bullets - of the sort that might be marketed to schools as 'ticking off' the Values statement.

This section suggests practical ways in which such an ethically reflexive orientation could be given expression in New Zealand social studies classrooms. It picks up on teachers' concerns, reported in the previous chapter, about a lack of pedagogical models for mobilising ethics in social studies education. What follows is in no way an attempt to quell the reservations of those teachers. It is written in the spirit of keeping the conversation going and offers, instead, an array of reflexive surfaces - potentially fruitful avenues of inquiry for the social studies community's ongoing re/ consideration of the place of ethics in social studies education. The discussion demonstrates that exploring an ethically reflexive orientation to social studies education need not be an exercise in pedagogical novelty; there are valuable insights in the existing literature that could be assembled, altered, or amplified. It is, admittedly, a highly partial selection of strategies that might be considered. While each aspect of ethical reflexivity is treated separately, the reader is invited to think of the following discussion as inter-connected and cumulative, hence the use of 'enfolding' in the section headings.

ENFOLDING CRITICAL REFLECTION: There exists a plethora of literature and teaching materials dedicated to enabling learners to thinking critically about ethical concepts, questions and issues and, in many cases, to explore named ethical perspectives. There is not the space here to do justice to it all. Instead, I recommend several productive seams of inspiration, drawn primarily from the literature on values and philosophy education (Keown, 2003), and focussed, in particular, on approaches to ethical reasoning. 
Keown outlines several alternatives to Kohlbergian moral reasoning that make thinking about a range of ethical perspectives a more explicit feature of critical reflection. A first, 'the moral principles test' (Quality Public Education Coalition, 2000; Snook, 2000; Snook \& McGeorge, 1978) asks students to apply five ethical principles to a proposed action, such as whether the action minimises harm or preserves the right for people to pursue their own ends. A second, from the work of Kidder (1995) and the Institute for global ethics (2014), broadens the ethical landscape by including, for example, consequentialist and care-based thinking. To Keown's examples, I would add the Markkula center for applied ethics' (Santa Clara University, 2014) framework for ethical thinking, which encourages the use of utilitarian, rights, fairness/justice, common good, and virtue approaches as resources for ethical decision-making. Closer to home, and drawing on work of Reiss $(1999,2010)$, approaches to ethical inquiry in science focus learners' ethical reasoning on both established ethical frameworks (consequentialism, rights and duties, autonomy, and virtues ethics) and multiple perspectives/axes of identity (B. Ryan \& Buntting, 2012; Saunders \& Rennie, 2013). Notably, the New Zealand biotechnology learning $h u b^{62}$, which provides resources for primary and secondary teachers, supplies a digital thinking tool that uses this framework for considering socio-scientific issues. Another approach, exemplified in The if machine (Worley, 2011), centres on philosophical questions and topics such as The Ring of Gyges as the basis for classroom discussion. What makes this kind of approach distinctive from those previously discussed is that primary school "children discuss, in an obviously simplified form, ideas that might figure in a standard philosophy syllabus" (J. White, 2012, p. 453).

Another approach, Philosophy for children, was mentioned in Chapter Four. Arguably, it has less to do with 'teaching children Aristotle' or how to apply ethical theories. It nonetheless has a strong orientation towards critical reflection and a central commitment to collaborative procedures of inquiry, including ethical inquiry. Drawing on a social constructivist approach (Gregory, 2011; Keown, 2003), learners are encouraged, in communities of inquiry, to determine, and think together about, philosophical questions and ethical issues (Burgh et al., 2006; Sprod, 2002). The teacher's role is primarily to open up thinking and provide an environment in which the habits of good questioning and good reasoning are cultivated (Golding, 2005).

62 http://www.biotechlearn.org.nz/ 
How could such approaches to critical reflection be enfolded with lived experience and imagination? One example lies in the array of opportunities for social action that already exist in learners' schools and communities - through, for example, the requirements of senior social studies and education for sustainability assessment, service projects and activities, and the day-to-day organisation of school life. In many cases, learners' social action stems from personal connections to, and concerns about, social issues that they have identified as being important. Their actions may represent a careful consideration of possibilities, and enacting their responses may well provide a considerable sense of agency - a community garden is created, money is raised, students have contributed to a political decision-making process, and so on. This thesis has made an argument for extending such experiences to include a critical exploration of ethical questions and perspectives. At the very least, the students' engagement with ethical dilemmas (reported in the previous chapter) suggest that it is possible to do so without eroding positive affect.

ENFOLDING LIVED EXPERIENCE: As the argument built in this thesis has stressed, an ethically reflexive orientation to social studies education moves pedagogy beyond critical reflection. In this section, I recommend several approaches to narrative ethics, suggested because in varying ways they draw in learners' lived experiences, that is, the everyday, embodied and emergent dimensions of their ethical decision-making action. I emphasise that what is suggested here is highly selective, given that the field of narrative ethics is both wide (Adams, 2008; Montello, 2014) and informed by a variety of theoretical positions.

As could all the approaches noted in the previous section, Philosophy for children has been subjected to extensive criticism "as just one normative model of human subjectivity among many" (Gregory, 2011, p. 208) and, in particular, for privileging analytic reasoning (J. White, 2012). While I share these reservations, Pbilosophy for children draws in lived experience in three ways. First, advocates of the approach argue that the deliberative nature of ethical inquiry not only allows learners to "examine precisely what is normally taken for granted in moral discourse" (Lipman, 2003, p. 113) but makes caring, empathy, and morally serious thinking possible. Thus, while it is possible for the methods described in the previous section to be applied in a purely cognitive manner, Philosophy for Children is fundamentally a relational approach. Second, its narrative approach (Knight \& Collins, 2010b) begins from learners identifying and discussing the ethical issues that matter in their lived experience. A notable extension of this is the growing use of 'cafe philosophy' in New Zealand schools, where young people organise lunchtime and afterschool discussion 
sessions. Third, a number of theorists are considering how Philosophy for Children could break away from its humanist and pragmatic foundations (J. White, 2012). One author, for example, has considered how emotions, play and creativity could be embraced in the approach (Weber, 2011) - important dimensions of an ethically reflexive orientation.

Philosophy for Children is not the only approach to deliberative democracy with a narrative orientation. Ralph Levinson (2006), for example, has argued that use of personal narratives may help bridge "the gap between the local/personal and the emergent science" (p. 855) in learners' consideration of controversial socio-scientific issues. Another example draws from the work of Iris Young $(1990,1997,2000)$ and, in particular, her concern about the ways in which the processes of reason may exclude some voices. Her proposal for communicative democracy hoped "to make way for a deliberative conception that was open to means of expression beyond the rational expression of mainstream deliberative democratic theory" (McAfee, 2014, n.p.). Enslin, Pendlebury, and Tjiattas (2001) suggest that citizenship education could be productively informed by Iris Young's emphasis on story-telling in deliberation because it "exhibits the situated knowledge of the collective from each perspective, and the combination of narratives from different perspectives produces the collective social wisdom not available from any one position" (p. 126).

However, this thesis has expressed caution about the consensus politics of deliberation and has, instead, argued for agonistic approaches. How could this be enacted in social studies classrooms? One possibility is suggested by Keown (2003) and drawn from poststructural and social constructionist theories. The process he outlines engages learners in identifying stories/discourses about an ethical issue, describing the dominant features of the story (deconstruction), selecting a preferred story (using ethical criteria), and considering and implementing a plan to give the story more power. The productive potential of this approach is that it (a) highlights the effects of overlapping and contradictory discourses on learners' choices, values and actions, (b) leaves open the possibility that ethical perspectives could be positioned as interlocutors in relation to learners' everyday lives, (c) prompts attention to voices, and experiences of ethical life, that are missing, and (d) enables a consideration of how stories could offer different ways to go on.

There is arguably some way to go in considering how collective passions, as Mouffe (2000) puts it, could be pedagogically mobilised in this process, that is, how the visceral, 
spiritual, emotional and fleshy feelings innately connected to ethical decision-making and action could be brought in. In light of the literature regarding embodiment discussed in this thesis I make two recommendations. This is an extension of approaches to bringing in feelings that were a focus of New Zealand social studies education in the 1970s. One local example of this is a group of Year 10 social studies students who were asked to write about their embodied experiences of extreme natural events in the lead-up to considering how different theoretical perspectives have a bearing on responses to natural disasters (Harcourt, 2009). The second recommendation relates to the marginalisation of religion and spirituality in successive New Zealand social studies curricula. Here, I suggest that the literature on learners' everyday spirituality in education (see, for example, Bone, Cullen, \& Loveridge, 2007; Sewell, 2009; K. Simon, 2001; Tolliver \& Tisdell, 2006) offers useful pedagogical examples in terms of bringing in this aspect of learners' lives. In addition, I strongly recommend work that is occurring in independent schools that engages with the idea that the demands of contemporary society necessitate learning about and from - that is, not a sole focus on instruction into - religion (Syms, 2011). While there exists considerable variation in approach across independent schools, the work of the Dialogue Australasia Network ${ }^{63}$ and, in particular, Peter Vardy (2002) is salient to this discussion in the way that it connects the affective to learners' critical consideration of ethical decision-making and action. A 'five strand' model includes a theory-based approach to (i) ethics, (ii) the philosophy of religion, (iii) biblical studies, (iv) world religions (understanding and tolerance), and an affective strand that (v) brings in stillness and silence. Notably, Dialogue Australasia Network's membership is not limited to independent and Catholic schools; it has been taken up in secular state schools.

ENFOLDING IMAGINATION: How could imaginative perception, envisionment, and action (Johnson, 1993) be enfolded, pedagogically speaking, with critical reflection about, and learners' lived experiences of, ethical decision-making and action? Perhaps we might conceive bringing in lived experience in less formalised terms than recommended in the previous section. Noddings (1994), for example, makes a case for ordinary conversation between adults (including teachers) and children as the basis of moral education. One of the key characteristics of this kind of conversation is that "for both parties, in the conversation under consideration, the partner is more important than the topic, the conclusion or the argument" (n.p.). Such ordinary conversation is an important site of

63 http://www.dialogueaustralasia.org/ 
imaginative responses to ethical issues. Conversely, Egan and Judson (2009) have argued for an insertion of the extraordinary into social studies teaching and learning, and have identifed a range of 'cognitive tools' through which learners of different ages could imaginatively engage with the social studies curriculum. For example, they suggest that topics could be associated with (i) an "emotionally charged image" (p. 130) that captures learners' imaginations, (ii) powerful abstract opposite concepts (such as good and evil) used as a structuring device, (iii) jokes and humour as a method for noticing incongruity and, (iv) exposure to mysteries, the surprising and the seemingly absurd. What interests me about these suggestions is the potential for the imaginative consideration of ethical issues to enfold lived experience and critical reflection. Consider the following cartoon as an example: "Does my butt look big in this?" asks a woman. "Yes", replies a man. A tag line reads, "Surprisingly, Immanuel Kant did not get many dates" ${ }^{64}$.

Another seam of imaginative possibility stems from the use of fiction to explore ethical themes and questions ${ }^{65}$. This might seem paradoxical in a subject concerned with real world social issues. However, I've observed many primary and secondary social studies teachers use books such as The Lorax (Dr. Seuss) and Belonging (Baker, 2004) to explore environmental ethics. Social studies teaching and learning could provide more opportunities for students to traverse and imaginatively transform both fiction and nonfiction texts and, in doing so, develop their critical literacy:

Knowledge that texts are not ideologically natural or neutral -- that they represent particular points of views while silencing others and influence people's ideas -- and that their designs and discourses can be critiqued and redesigned in novel and hybrid ways. (Luke \& Freebody, 2014, n.p.).

To return to the importance of enfolding the relational and embodied dimension of lived experience in learners' consideration of ethical decision-making and action, LuceKapler, Sumara, and Ifody (2010) note that in an online, media-saturated world, people's real lives often become "presented in fictional structures" (p. 538). They argue that teaching ethical know-how is central to learners' ability to enter imaginatively into everyday lives of the other.

These suggestions draw social studies more closely to what might be considered the preserve of English teaching and learning. However, I suggest that the opportunities for

64 http://www.deviantart.com/?offset=48\&view_mode=2\&order=9\&q=immanuel + kant

65 For a discussion of narrative ethics used in this literary sense, see Lothe and Hawthorn (2013). 
enfolding imagination do not end there. New Zealand Anglican Life's 2014 Big picture competition $^{66}$, for example, involves both social studies and the visual arts learning in learners imagining and creatively communicating responses to child poverty in their local communities. While recently attending the Wellington regional round of the New Zealand stage challenge ${ }^{67}$, a purely student-run dance and drama competition, I was struck by the opportunities for follow-up in social studies classrooms that the student entries afforded. The students had imaginatively explored themes of, for example, government suveillance, nuclear disarmament, family violence, and the impact of technology as social issues that are pressing in their lives. Similarly, a UK programme, Theatre of debate, enables young people to explore social and moral issues through performance, digital technology, and live debate. ${ }^{68}$

SUMMARY: This section perhaps reads as an eclectic mix of pedagogical suggestions. My undertaking here has not been to exclusively advocate for one approach over another, but to point to some opportunities that are (a) extant in the literature and school life and, (b) intersect with an ethically reflexive orientation. The real and actual potential of many of these suggestions are journeys yet to be made. However, just as democratic societies depend on plural visions of the good life, I urge that social studies teachers' reflexive consideration of the V alues statement is at least in part dependent on access to a repertoire of pedagogical approaches to better supporting learners' ethical decisionmaking and action - approaches that assist learners to assemble responses to ethical issues in their lives.

\section{PLACING STAKES IN THE GROUND}

Ehara i te mea, he kotahi tangata nāna I whakaaro te pō. It is not as if there's only one person watching the night.

To return to the wero introduced at the beginning of this thesis: what of placing stakes in the ground? To the extent that a thesis is a book of oneself, this research has called into question my previous professional preoccupation with critical thinking in social studies education. It has simultaneously expanded my sense of the ground on which social studies education could lie and provoked an ongoing reconsideration of where, for the moment, I place my stakes in that ground. I have found within the literature an enlivening dimension of social studies education - and an enlivened sense of ethics that

66 http://thebigpicture.org.nz/

67 http://www.stagechallenge.co.nz/

68 http:/ /www.theatreofdebate.com/ 
is a world away from childhood experiences of philosophic debate as combative, disembodied and abstract. This thesis has argued that ethically reflexive orientation to social studies education is an important means of transcending a curricular lacuna and a response to the immediate, everyday challenges of social studies education. The cogency and ethics of this argument is, however, to reprise Hill (1994), a matter for each and every social studies educator's consideration. This thesis offers $a$ way to go on, in the hope that others may join in the conversation. 


\section{REFERENCES}

Abbiss, J. (2011). Social sciences in the New Zealand curriculum: Mixed messages. Curriculum Matters, 7(2011), 118-137.

Abowitz, K. K., \& Harmish, J. (2006). Contemporary discourses of citizenship. Review of Educational Research, 76(4), 653-690. doi.org/10.3102/00346543076004653

Adams, M. (2003). The reflexive self and culture: A critique. The British Journal of Sociology, 54(2), 221-238. doi:10.1080/0007131032000080212

Adams, M. (2006). Hybridizing habitus and reflexivity: Towards an understanding of contemporary identity? Sociology, 40(3), 511-528. doi.org/10.1177/003803850663672

Adkins, A. (1989). Plato. In R. J. Cavalier, J. Gouinlock \& J. P. Sterba (Eds.), Ethics in the bistory of western philosophy (pp. 1-31). New York: St Martins Press.

Aitken, G. (2004, May). Social studies traditions. Paper presented at the Ministry of Education New Zealand Curriculum Project Social Sciences Hui., Town Hall, Wellington Convention Centre.

Aitken, G. (2005a). The purpose and substance of social studies: Citizenship education possibilities. In P. Benson \& R. Openshaw (Eds.), Towards effective social studies (pp. 85-112). Palmerston North: Kanuka Grove Press.

Aitken, G. (2005b). Curriculum design in New Zealand social studies: Learning from the past (Doctor of Education thesis). University of Auckland, Auckland.

Aitken, G. (2006). Signalling shifts in meaning: The experience of social studies curriculum design. Curriculum Matters, 2, 6-25.

Aitken, G., \& Sinnema, C. (2008). Effective pedagogy in social sciences/tikanga-a-iwi: Best evidence synthesis iteration [BES]. Wellington, New Zealand: Ministry of Education.

Alcorn, N. (1999). To the fullest extent of his powers: C.E. Beeby's life in education. Wellington, NZ: Victoria University Press.

Alexander, J. C. (1996). Critical reflections on `reflexive modernization'. Theory, Culture \& Society, 13(4), 133-138. doi: 10.1177/0263276496013004009

Alexander, L., \& Moore, M. (2014). Deontological ethics. The Stanford Encyclopedia of Philosophy. Winter 2012. Retrieved from http://plato.stanford.edu/archives/win2012/entries/ethics-deontological/

Alexander, T. M. (1993). John Dewey and the moral imagination: Beyond Putnam and Rorty toward a postmodern ethics. Transactions of the Charles S. Peirce Society, 29(3) 369-400.

Almond, B. (1993). Rights. In P. Singer (Ed.), A companion to ethics: Blackwell companions to philosophy (pp. 259-269). USA: Blackwell Publishing.

Alvesson, M., \& Sköldberg, K. (2009). Reflexive methodology: New vistas for qualitative research. ( $2^{\text {nd }}$ ed.) London: Sage.

Anderson, E. (2014). Feminist epistemology and philosophy of science. The Stanford encyclopedia of philosophy. Fall 2012. Retrieved from http://plato.stanford.edu/archives/fall2012/entries/feminism-epistemology/

Anderson, M., \& Della Sala, S. (Eds.). (2012). Neurosceince in education: The good, the bad and the ugly. UK: Oxford University Press.

Annette, J. (2006). Education for community involvement and as service learning. In T. Breslin \& B. Dufour (Eds.), Developing citizens: A comprehensive introduction to effective citizenship education in the secondary school (pp. 257-264). UK: Hodder Murray.

Aoki, R., Funane, T., \& Koizumi, H. (2010). Brain science of ethics: Present status and the future. Mind, Brain, and Education, 4(4), 188-195. doi:10.1111/j.1751228X.2010.01098.x

Appiah, K. A. (2006). Cosmopolitanism: Ethics in a world of strangers (1st ed.). New York: W. W. Norton. 
Archer, E., \& Openshaw, R. (1992). Citizenship and identity as "official goals" in social studies. In R. Openshaw (Ed.), New Zealand social studies: Past, present and future (pp. 19-33). Palmerston North: Dunmore Press.

Archer, M. S. (2007). Making our way through the world: Human reflexivity and social mobility. Cambridge: Cambridge University Press.

Archer, M. S. (2012). The reflexive imperative in late modernity. Cambridge: Cambridge Univeristy Press.

Argyrou, V. (2003). Reflexive modernization and other mythical realities. Anthropological theory, 3(1), 27-41. doi.org/10.1177/1463499603003001750

Arthur, J., \& Cremin, H. (Eds.). (2012). Debates in citizenship education. Abingdon, UK: Routledge.

Arthur, J., \& Davies, I. (Eds.). (2008). Citizenship education (Vol. 1-4). London: Sage.

Arthur, J., Davies, I., \& Hahn, C. (Eds.). (2008). The Sage handbook of education for citizenship and democracy. London: Sage.

Asara, V., Profumi, E., \& Kallis, G. (2013). Degrowth, democracy and autonomy. Environmental Values, 22(2), 217-239. doi: 10.3197/096327113X13581561725239

Ashmore, M. (1989). The reflexive thesis: Wrighting sociology of scientific knowledge: Chicago: University of Chicago Press.

Australian Curriculum Assessment and Reporting Authority. (2014). Ethical understanding. Retrieved from http://www.australiancurriculum.edu.au/GeneralCapabilities/ethicalunderstanding/introduction/introduction

Australian Government Department of Education, Science and Training. (2005). National framework for values education in Australian schools. Canberra: Author. Retrieved from http://www.curriculum.edu.au/verve/_resources/framework_pdf_version_for _the_web.pdf.

Bagnall, R. G. (1998). Moral education in a postmodern world: Continuing professional education. Journal of Moral Education, 27(3), 313-331. doi: 10.1080/0305724980270304

Bai, H., \& Banack, H. (2006). To see a world in a grain of sand: Complexity ethics and moral education. Complicity: An International Journal of Complexity \& Education, 3(1), $5-20$.

Baier, K. (1993). Egoism. In P. Singer (Ed.), A companion to ethics: Blackwell companions to philosophy (pp. 197-204). USA: Blackwell Publishing.

Bailey, D. (2005). Who we are: Learning about our identity in social studies. In P. Benson \& R. Openshaw (Eds.), Towards effective social studies (pp. 163-188). Palmerston North: Kanuka Grove Press.

Bailin, S., \& Siegel, H. (2003). Critical thinking. In N. Blake, P. Smeyers, R. Smith \& P. Standish (Eds.). The Blackwell guide to the philosophy of education (pp. 181-193). Oxford: Blackwell.

Baker, J. (2004). Belonging. UK: Walker Books.

Banks, J. A., McGee Banks, C. A., Cortes, C. E., Hahn, C. L., Merryfield, M. M., Moodley, K. A., ... Parker, W. C. (2005). Democracy and diversity: Principles and concepts for educating citizens in a global age. Seattle: Center for Multicultural Education, University of Washington.

Barr, H. (1998). The nature of social studies. In P. Benson \& R. Openshaw (Eds.), New borizons for New Zealand social studies (pp. 103-120). Palmerston North: ERDC Press, Massey University.

Barr, H., Graham, J., Hunter, P., Keown, P., \& McGee, J. (1997). A position paper: Social studies in the New Zealand curriculum. New Zealand: School of Education, The University of Waikato. 
Barr, R. D., Barth, J. L., \& Shermis, S. S. (1978). The nature of the social studies. Palm Springs, CA: ETC.

Barrow, R. (1978). Plato and education. London: Routledge \& Kegan Paul.

Bauman, Z. (1993). Postmodern ethics. USA: Blackwell.

Bauman, Z. (1997). Postmodernity and its discontents. Cambridge: Polity Press.

BBC. (2014a). Moral maze. Retrieved from http://www.bbc.co.uk/programmes/b006qk11

BBC. (2014b). Everyday ethics. Retrieved from http://www.bbc.co.uk/podcasts/series/ethics

BBC. (2014c). Introduction to ethics. Retrieved from http://www.bbc.co.uk/ethics/ introduction/

Beals, F. (2001). Let's dig down deep: A philosophical look at the social studies education in New Zealand using a post-structural geneological analysis. New Zealand Annual Review of Education, 11, 199-213.

Beauchamp, T. (1984). On eliminating the distinction between applied ethics and ethical theory. Monist, 67, 514-531. doi.org/10.5840/monist198467430

Beauchamp, T. (2003). The nature of applied ethics. In R. Frey \& C. Wellman (Eds.), Blackwell companion to applied ethics (pp. 1-16). Oxford: Blackwell.

Beck, U., Bonss, W., \& Lau, C. (2003). The theory of reflexive modernization problematic, hypotheses and research programme. Theory, Culture \& Society, 20(2), 1-33. doi.org/10.1177/0263276403020002001

Beck, U., Giddens, A., \& Lash, S. (1994). Reflexive modernization: Politics, tradition and aesthetics in the modern social order: Cambridge, England: Polity.

Berlin, I. (1999). Concepts and catgories: Philosophical essays. London: Pimlico. Retrieved from http://berlin.wolf.ox.ac.uk/published_works/cc/index.html

Bernstein, R. J. (1987). The varieties of pluralism. American Journal of Education, 95(4), 509-525. doi.org/10.1086/444323

Biesta, G. (2007). Why "what works" won't work: Evidence-based practice and the democratic deficit in educational research. Educational Theory, 57(1), 1-22. doi.org/10.1111/j.1741-5446.2006.00241.x

Biesta, G. (2009). Good education in an age of measurement: On the need to reconnect with the question of purpose in education. Educational Assessment, Evaluation and Accountability (formerly: Journal of Personnel Evaluation in Education), 21(1), 33-46. doi.org/10.1007/s11092-008-9064-9

Biesta, G. (2010). Why 'what works' still won't work: From evidence-based education to value-based education. Studies in Philosophy and Education, 29(5), 491-503. doi.org/10.1007/s11217-010-9191-x

Blattner, W. (2008). What Heidegger and Dewey could learn from each other. Philosophical Topics, 36(1), 57-77. doi.org/10.5840/philtopics20083614

Bleakley, A. (1999). From reflective practice to holistic reflexivity. Studies in Higher Education, 24(3), 315-330. doi.org/10.1080/03075079912331379925

Boethius. (d. 524). The consolation of philosophy of Boethius. (Trans. H.R. James, 1897). Retrieved from http://www.gutenberg.org/files/14328/14328-h/14328-h.htm

Boler, M. (1999). Feeling power: Emotions and education. New York: Routledge.

Bone, J., Cullen, J., \& Loveridge, J. (2007). Everyday spirituality: An aspect of the holistic curriculum in action. Contemporary Issues in Childhood Education, 8(4), pp. 344-354.

Brannelly, T., Boulton, A., \& te Hiini, A. (2013). A relationship between the ethics of care and Māori worldview: The place of relationality and care in Maori mental health service provision. Ethics and Social Welfare, 7(4), 410-422.

Braun, V., \& Clarke, V. (2006). Using thematic analysis in psychology. Qualitative Research in Psychology, 3(2), 77-101. doi: 10.1191/1478088706qp063oa

Brennan, A., \& Lo, Y.-S. (2014). Environmental ethics. The Stanford encyclopedia of philosophy. Fall 2011. Retrieved from http://plato.stanford.edu/archives/fall2011/entries/ethics-environmental/ 
Brooks, C. (2013). How do we understand conceptual development in school geography? In D. Lambert \& M. Jones (Eds), Debates in geography education. (pp. 75-88) UK: Routledge.

Brownlie, J. (2011). 'Being there': Multidimensionality, reflexivity and the study of emotional lives. The British Journal of Sociology, 62(3), 462-481.

Bruner, J. (1960). The process of education. Cambridge: Harvard University Press.

Burbules, N. C. (2000). Philosophy of education. In B. Moon, M. Ben-Peretz, \& S. Brown (Eds.), Routledge international companion to education (pp. 3-18). London: Routledge.

Burgh, G. (2004). Seeking justice as a strategy for teaching and learning in SOSE: The ring of Gyges, the veil of ignorance and the prisoner's dilemma. The Social Educator, 22(3), 25-33.

Burgh, G., Field, T., \& Freakley, M. (2006). Ethics and the community of inquiry: Education for deliberative democracy. Melbourne, Australia: Thomson Social Science Press.

Burkitt, I. (2012). Emotional reflexivity: Feeling, emotion and imagination in reflexive dialogues. Sociology, 46(3), 458-472. doi.org/10.1177/0038038511422587

Butler, J. (2011). For and against precarity. Tidal: occupy theory, occupy strategy, December 2011(1), 12-13. Retrieved from http://tidalmag.org/pdf/tidal1_the-beginningis-near.pdf

Butler, J. (2012, February). Occupy as form: Judith Butler. Retrieved from http://arcdirector.blogspot.co.nz/2012/02/occupy-as-form-judith-butler.html

Camillus, J. C. (2008). Strategy as a wicked problem. Havard Business Review, 86(5), 98106.

Caplan, A. L. (1979). Ethics and values in education: Are the concepts distinct and does it make a difference? Educational theory, 29(3), 245-253. doi: 10.1111/j.17415446.1979.tb00857.x

Caputo, J. D. (2000). The end of ethics. In H. LaFollette (Ed.), The Blackwell guide to ethical theory (pp. 111-128). USA: Blackwell.

Carpenter, J. J. (2006). The development of a more intelligent citizenship: John Dewey and the social studies. Education and Culture, 22(2), 31-42. doi:10.1353/eac.2007.0001

Carr, D. (1999). Cross questions and crooked answers: Contemporary problems of moral education. In J. M. Halstead \& T. H. McLauchlin (Eds.), Education in morality (pp. 23-42). Hoboken: Routledge.

Carr, D. (2000). Exploring theory and practice in moral education. In B. Moon, M. BenPeretz \& S. Brown (Eds.), Routlege International Companion to Education (pp. 19-27). London: Routledge.

Carrington, B., \& Troyna, B. (1988). Children and controversial issues: Strategies for the early and middle years of schooling. London: Falmer.

Case, R. (1993). Key elements of a global perspective. Social Education, 57(6), 318-325.

Castells, M. (2012). Networks of outrage and hope: Social movements in the internet age. UK: Polity Press.

Castoriadis, C. (1987). The imaginary institution of society. Cambridge: Polity Press.

Catling, S., \& Martin, F. (2011). Contesting powerful knowledge: The primary geography curriculum as an articulation between academic and children's (ethno) geographies. Curriculum Journal, 22(3), 317-335.

Catton, P. (2012, September). Philosophy, maturanga Māori and the meaning of biculturalism. Notes accompanying Keynote address to New Zealand Association for Philosophy Teaching conference, Christchurch.

Caws, P. (1996). Ethics from experience. Massachusetts, USA: Jones \& Bartlett.

Centre for the Study of Historical Consciousness. (2014). The historical thinking project: Historical thinking concepts. Retrieved from http://historicalthinking.ca/historicalthinking-concepts 
Chamberlain, M. (2004). Commentary: New Zealand/Te anga matauranga o Aotearoa project: A response. Teachers and Curriculum, 7, 79-80.

Chambliss, J. (1991). John Dewey's idea of imagination in philosophy and education. Journal of Aesthetic Education, 25(4), 43-49. doi.org/10.2307/3332902

Chazan, B. I. (1985). Contemporary approaches to moral education: Analyzing alternative theories. New York: Teachers College Press.

Claire, H. (2001). Not aliens: Primary school children and the citizenship/PSHE curriculum. London: Trentham Books.

Claire, H. (2003). Dealing with controversial issues with primary teacher trainees as part of citizenship education. citizED Commisioned Research Projects. Retrieved from http://www.citized.info/?strand=0\&r_menu=res

Claire, H., \& Holden, C. (Eds.). (2007). The challenge of teaching controversial issues. Staffordshire, England.: Trentham Books.

Clark, John (1997). Educational Research: philosophy, politics, ethics. Palmerston North, NZ: ERDC Press.

Clark, J. (2000). Values education in New Zealand: Past, present and future. DELTA, 52(1), 69-74.

Clark, J. (2004a). Rigorous eclecticism: The Ministry of Education's bizarre philosophy of the curriculum. In A. O'Neill, J. Clark, \& R. Openshaw (Eds.), Reshaping culture, knowledge and learning: Policy and content in the New Zealand curriculum framework (pp. 127-140). Palmerston North, NZ: Dunmore Press.

Clark, J. (2004b). The curriculum stocktake report: A philosophical critique. Teachers and Curriculum, 7, 73-78.

Codd, J., Clark, J., O'Neill, A., \& O'Neill, J. (Eds.). (1996/7). Delta: Policy and practice in education. Palmerston North, NZ: Massey University.

Collins, C. (2004). Education for a just democracy: the role of ethical inquiry. (PhD thesis). Adelaide: University of South Australia. Retrieved from http://arrow.unisa.edu.au:8081/1959.8/51285

Collins, C., \& Knight, S. (2006). Ethical inquiry as central to the society and environment learning area. Paper presented at the The Australian Association for Research in Education National Conference, Adelaide. Retrieved from http://www.aare.edu.au/publications-database.php/4997/ethical-inquiry-ascentral-to-the-society-environment-learning-area

Cook, H. (2013, September 7, 2013). Secular ethics alternative to religion in state schools, The Age. Retrieved from http://www.theage.com.au/victoria/secularethics-alternative-to-religion-in-state-schools-20130906-2tau0.html

Cortina, A. (2008). The public task of applied ethics: Transnational civic ethics. In A. Cortina, D. García-Marzá \& J. Conill (Eds.), Public reason and applied etbics: The ways of practical reason in a pluralist society (pp. 9-30). England: Ashgate.

Cortina, A., García-Marzá, D., \& Conill, J. (Eds.). (2008). Public reason and applied etbics: The ways of practical reason in a pluralist society. England: Ashgate.

Counsell, C. (2011). What do we want students to do with historical change and continuity? In I. Davies (Ed.), Debates in history teaching, (pp. 109-123) UK: Routledge.

Critchley, S. (2002). Did you hear the one about the philosopher writing a book on humour? Think, 1(02), 103-112. doi:10.1017/S147717560000035X

Crown. (2001). National certificate in education, Geography/Mātauranga Matawhenua: Statement on perspectives. Retrieved October 6, 2008 from http://www.nzqa.govt.nz/

Cubitt, S. (2005). Understanding social studies: Addressing the challenges posed by recent reviews of the curriculum statement. In P. Benson \& R. Openshaw (Eds.), Towards effective social studies (pp. 5-18). Palmerston North, NZ: Kanuka Grove Press.

Cubitt, S. (2006). The draft New Zealand curriculum. Curriculum Matters, 2, 195+. 
Da Rocha, A. C., \& Bergareche, A. M. (2008). Wired for autonomy. The American Journal of Bioethics, 8(5), 23-25. doi.org/10.1080/15265160802180042

Dall'Alba, G., \& Barnacle, R. (2007). An ontological turn for higher education. Studies in Higher Education, 32(6), 679-691. doi.org/10.1080/03075070701685130

Davies, B., \& Harré, R. (1990). Positioning: The discursive production of selves. Journal for the Theory of Social Behaviour, 20(1), 43-63. doi: 10.1111/j.1468-

5914.1990.tb00174.x Retrieved from http://www.massey.ac.nz/ alock/position/position.htm

Davies, B. (2010). The implications for qualitative research methodology of the struggle between the individualised subject of phenomenology and the emergent multiplicities of the poststructuralist subject: The problem of agency. Reconceptualizing Educational Research Methodology, 1(1), 54-68. Retrieved from https://journals.hioa.no/index.php/rerm/article/view/171

Davis, B. (2004). Inventions of teaching: A genealogy. New York: Lawrence Erlbaum.

Davis, B., Sumara, D., \& Luce-Kapler, R. (2008). Engaging minds: Changing teaching in conplex times (2nd ed.). New York: Routledge.

D’Cruz, H., Gillingham, P., \& Melendez, S. (2007). Reflexivity, its meanings and relevance for social work: A critical review of the literature. British Journal of Social Work, 37(1), 73-90. doi.org/10.1093/bjsw/bcl001

de Botton, A. (2007). The consolations of philosophy. London: Penguin Books.

de Sousa, R. (2014). Emotion. The Stanford encyclopedia of philosophy. Spring 2014. Retrieved from http://plato.stanford.edu/archives/spr2014/entries/emotion/

Dearden, R. F. (1981). Controversial issues and the curriculum. Journal of Curriculum Studies, 13(1), 37-44. doi:10.1080/0022027810130105

Del Busso, L. (2007). III. Embodying feminist politics in the research interview: Material bodies and reflexivity. Feminism \& Psychology, 17(3), 309-315. doi.org/10.1177/0959353507079084

Deleuze, G., \& Guattari, F. (2013). A thousand plateaus. London: Bloomsbury Academic. den Heyer, K. (2012). History education as a disciplined 'ethic of truths'. In P. Clark (Ed.), New possibilities for the past: Shaping history education in Canada. Vancouver: UBC Press. Retrieved from http://www.secondaryed.ualberta.ca/en/People/AcademicStaff/ /media/seco ndaryed/Documents/People/KentDenHayer/historyethicsoftruthsdenHeyer.pdf

Denzin, N. K., \& Lincoln, Y. S. (2000). The Sage handbook of qualitative research (3rd ed.). Thousand Oaks: Sage.

Department for Education. (2013). Secondary national curriculum until 2014: Citizenship. Retrieved from http://webarchive.nationalarchives.gov.uk/20130904095100/https://www.edu cation.gov.uk/schools/teachingandlearning/curriculum/secondary/b00199157/ citizenship

Department for Education. (2014). Statutory guidance: National curriculum in England: citizenship programmes of study. Retrieved from

https://www.gov.uk/government/publications/national-curriculum-in-englandcitizenship-programmes-of-study

Department of Education. (1928). Syllabus of instruction for public schools. Wellington: Government Printer.

Department of Education. (1944). The post-primary school curriculum: Report of the committee appointed by the Minister of Education in November, 1942 (The Thomas Report). Wellington: Government Printer.

Department of Education. (1948). The primary school revised syllabus: Social studies in history and geography. New Zealand: Author. 
Department of Education. (1971). Suggestions for teaching social studies in the primary school: Parts I, II, III, IV. Wellington: Government Printer.

Department of Education. (1973). Human development and relationships across the curriculum (The Ross Report). Wellington: Government Printer.

Department of Education. (1977a). Social studies syllabus guidelines: Forms 1-4. Wellington, New Zealand: Author.

Department of Education. (1977b). The report of the committee on health and social education: Growing, sharing, learning (The Johnson Report). Wellington: Government Printer.

Department of Education. (1978). Faces primary social studies newsletter 4. Wellington, New Zealand: Author.

Department of Education. (1981). Faces 5 primary social studies newsletter: Thinking, feeling, valuing. Wellington, New Zealand: Author.

Department of Education. (1983). Faces 6 primary social studies newsletter: Social studies in the primary school. Wellington, New Zealand: Author.

Dewey, J. (1910). How we think. Boston: D.C Heath.

Dewey, J. (1916). Essays in experimental logic. Chicago: University of Chicago Press.

Dewey, J. (1922). Human nature and conduct: An introduction to social psychology. New York: Henry Holt.

Dewey, J. (1939). Logic: The theory of inquiry. London: Allen \& Unwin.

Diosecan School For Girls. (2014). Centre for ethics. Retrieved from https://www.diocesan.school.nz/centre-for-ethics

Dogan, M., \& Pahre, R. (1990). Creative marginality: Innovation at the intersections of social science. Boulder, USA: Westview Press.

Doris, J., \& Stich, S. (2014). Moral psychology: Empirical approaches. The Stanford encyclopedia of philosophy. Spring 2014. Retrieved from http://plato.stanford.edu/archives/spr2014/entries/moral-psych-emp/

Dowden, T. (2011). Locating curriculum integration within the historical context. History of Education Review, 40(1), 47-61. doi:10.1108/08198691111140802

Dr Seuss. (1971). The Lorax. London: Collins.

Duncan, C., Cloutier, J. D., \& Bailey, P. H. (2007). Concept analysis: The importance of differentiating the ontological focus. Journal of Advanced Nursing, 58(3), 293-300. doi:10.1111/j.1365-2648.2007.04277.x

Dyke, M. (2009). An enabling framework for reflexive learning: Experiential learning and reflexivity in contemporary modernity. International Journal of Lifelong Education, 28(3), 289-310. doi.org/10.1080/02601370902798913

Dyke, M. (2013). Reconceptualising learning as a form of relational reflexivity. British Journal of Sociology of Education, iFirst article. doi:10.1080/01425692.2013.843445

Dyke, M., Johnston, B., \& Fuller, A. (2012). Approaches to reflexivity: Navigating educational and career pathways. British Journal of Sociology of Education, 33(6), 831848. doi.org/10.1080/01425692.2012.686895

Eagleton, T. (2009). Trouble with strangers: $A$ study of ethics. UK: Wiley-Blackwell.

Education Forum. (1996). Social studies in the New Zealand curriculum: A submission on the revised draft. Auckland, NZ: Author.

Education Review Office. (2001). The New Zealand curriculum: An ERO perspective. Wellington, NZ: Author.

Education Review Office. (2006). The quality of teaching and learning in years 4 and 8: Social studies. Wellington, NZ: Author.

Education Review Office. (2007). The teaching of social studies: Good practice. Wellington, NZ: Author.

Education Review Office. (2010). Preparing to give effect to the New Zealand curriculum. Wellington, NZ: Author.

Egan, K. (1997). The educated mind: How cognitive tools shape our understanding. Chicago: Chicago University Press. 
Egan, K., \& Judson, G. (2009). Values and imagination in teaching: With a special focus on social studies. Educational Philosophy and Theory, 41(2), 126-140. doi: 10.1111/j.1469-5812.2008.00455.x

Eilam, E., \& Trop, T. (2010). ESD pedagogy: A guide for the perplexed. The Journal of Environmental Education, 42(1), 43-64. doi.org/10.1080/00958961003674665

Engle, S. H., \& Ochoa, A. S. (1988). Education for democratic citizenship: Decision-making in the social studies. New York: Teachers College Press.

Ennis, R. (2011). Critical thinking. Inquiry: Critical Thinking Across the Disciplines, 26(2), 519. doi.org/10.5840/inquiryctnews201126215

Enslin, P., Pendlebury, S., \& Tjiattas, M. (2001). Deliberative democracy, diversity and the challenges of citizenship education. Journal of Philosophy of Education, 35(1), 115-130. doi: $10.1111 / 1467-9752.00213$

Ermine, W. (2007). The ethical space of engagement. Indigenous Law Journal, 6(1), 193203.

Ermine, W., Sinclair, R., \& Jeffrey, B. (2004). The ethics of research involving indigenous peoples: Report of the Indigenous People's Research Centre to the Interagency Advisory Panel on Research Ethics. Retrieved from http://ahrnets.ca/files/2010/05/ethics_review_iphrc.pdf

Etherington, K. (2007). Ethical research in reflexive relationships. Qualitative Inquiry, 13(5), 599-616. doi.org/10.1177/1077800407301175

Evans, J., Davies, B., \& Rich, E. (2009). The body made flesh: Embodied learning and the corporeal device. British Journal of Sociology of Education, 30(4), 391-406. doi.org/10.1080/01425690902954588

Evans, R. W. (2004). The social studies wars: What should we teach our children? New York: Teachers' College Press.

Evans, R. W. (2010). The social studies wars, now and then. In W. C. Parker (Ed.), Social studies today: Research and practice (pp. 25-34). Hoboken: Taylor \& Francis.

Evans, R. W., Newmann, F. M., \& Saxe, D. W. (1996). Defining issues-centred education. In R. W. Evans (Ed.), Handbook on teaching social issues: NCSS bulletin 93 (pp. 2-5). Washington, DC: National Council for the Social Studies.

Evans, R. W., \& Saxe, D. W. (Eds.). (1996). Handbook on teaching social issues: NCSS bulletin 93. Washington, DC: National Council for the Social Studies

Fairclough, N. (2003). Analyzing discourse: Textual analysis for social research. New York: Routledge.

Fenton, E. (1991). Reflections on the 'new social studies'. Social Studies, 82(3), 84-90. doi.org/10.1080/00377996.1991.9958313

Ferguson, S. (2007). Commentary on the New Zealand curriculum draft for consultation 2006: Paper prepared for the Ministry of Education's New Zealand Curriculum Marautanga Project. Australia: Australian Council for Educational Research (ACER).

Fischer, D. H. (2012). Fairness and freedom: A bistory of two open societies: New Zealand and the United States. New York: Oxford University Press.

Foucault, M. (1983). On the genealogy of ethics: An overview of a work in progress. In H. L. Dreyfus \& P. Rabinow (Eds.), Michel Foucault: Beyond structuralism and hermeneutics (pp. 231-232). Chicago: University of Chicago Press.

Francis, G. S. (2007). Simple ethical skills for use in social inquiry and ethical decision-making. New Zealand: Author. Retrieved from www.valueseducation.co.nz

Francis, G. S. (2009a). Forty lessons on citizenship for years 7-13. New Zealand: Author. Retrieved from www.valueseducation.co.nz

Francis, G. S. (2009b). Key competencies, values and citizenship: A programme for primary schools relating to the 2007 curriculum. Wellngton, NZ: First Edition.

Francis, G. S. (2009c). Dealing with values: How schools and their communities can achieve the outcomes required by the values statement in the $2007 \mathrm{NZ}$ curriculum. Wellington, New Zealand: First Edition. 
Frazer, E. (2008). Key perspectives, traditions and disciplines: Overview. In J. Arthur, I. Davies \& C. Hahn (Eds.), The Sage Handbook of education for citizenship and democracy (pp. 281-291). London: Sage.

Freire, P. (1986). Pedagogy of the oppressed. England: Pelican Books.

Gallie, W. B. (1956). Eseentially contwested concepts. London: Williams \& Northgate.

Gaonkar, D. P. (2002). Toward new imaginaries: An introduction. Public Culture, 14(1), 1-19. doi.org/10.1215/08992363-14-1-1

Gavison, R. (1992). Feminism and the Public/private distinction. Stanford Law Review, 45(1), 1-45. doi:10.2307/1228984

Gazzinga, M. S. (2006). The ethical brain: The science of our moral dilemmas. New York: Harper Collins.

Gendler, T. (2014). Imagination. The Stanford encyclopedia of philosophy. Fall 2013. Retrieved from http://plato.stanford.edu/archives/fall2013/entries/imagination/

Gert, B. (2014). The definition of morality. The Stanford encyclopedia of philosophy. Fall 2012. Retrieved from http://plato.stanford.edu/archives/fall2012/entries/moralitydefinition/

Gibson, S. E. (2009). Teaching social studies in elementary schools: A social constructivist approach. Toronto: Nelson Education.

Gibson, S., \& McKay, R. (2005). Reexamining competing views of citizenship education and their influence on social studies. In C. White \& R. Openshaw (Eds.), Democracy at the crossroads: International perspectives on critical global citizenship education (pp. 167-186). USA: Lexington Books.

Giddens, A. (1976). Central problems in social theory: Action, structure, and contradiction in social analysis. London: Macmillan.

Giddens, A. (1991). Modernity and self-identity: Self and identity in the late modern age. Cambridge: Polity.

Gifford, R. (2011). The dragons of inaction: Psychological barriers that limit climate change mitigation and adaptation. Am Psychol, 66(4), 290-302. doi:10.1037/a0023566

Gilbert, R., \& Hoepper, B. (Eds.). (2004). Teaching society and the environment (4th ed.). Australia: Cengage Learning.

Glannon, W. (Ed.). (2007). Defining right and wrong in brain science: Essential readings in neuroethics. New York: Dana Press.

Glass, R. D. (2009). Education and the ethics of democratic citizenship. In M. S. Katz, S. Verducci, \& G. Biesta (Eds.), Education, democracy and the moral life (pp. 9-30). USA: Springer.

Goldberg, I. Y. (2011). Reasoning and religion: The relevance of the academic study of religion to critical thinking pedagogy. (PhD thesis). Hamilton, New Zealand: University of Waikato.

Golding, C. (2002). Connecting concepts: Thinking actvities for students. Australia: ACER Press.

Golding, C. (2005). A 'philosophy for children' approach to social studies. In P. Benson \& R. Openshaw (Eds.), Towards effective social studies (pp. 113-130). Palmerston North, NZ: Kanuka Grove Press, Massey University.

Gorrie, A. M. (1963). Jam for breakfast, dinner and tea. Educational Research, 10(12), 1723.

Gray, J. (2000). Pluralism and toleration in contemporary political philosophy. Political Studies, 48(2), 323-333. doi:10.1111/1467-9248.00262

Gregory, M. (2009). Ethics education and the practice of wisdom. Teaching Ethics, 9(2), 105-130.

Gregory, M. (2011). Philosophy for children and its critics: A Mendham dialogue. Journal of Philosophy of Education, 45(2), 199-219. doi: 10.1111/j.1467-9752.2011.00795.x

Grudens-Schuck, N., Allen, B. L., \& Larson, K. (2004). Focus group fundamentals. Retrieved from http://www.extenison.iastate.edu/Publications/PM1969B.pdf 
Guillemin, M., \& Gillam, L. (2004). Ethics, reflexivity, and "ethically important moments" in research. Qualitative Inquiry, 10(2), 261-280.

Gyekye, K. (2014). African ethics. The Stanford Encyclopedia of Philosophy. Fall 2011. Retrieved from http://plato.stanford.edu/archives/fall2011/entries/africanethics/

Hanvey, R. (2004). An attainable global perspective. Retrieved from http://www.globaled.org/an_att_glob_persp_04_11_29.pdf

Harcourt, M. (2009). Teaching perspectives as part of social inquiry. Presentation to Victoria University of Wellington, Faculty of Education, EPOL347 class.

Harrison, K. (1998). Social studies in the New Zealand curriculum: Dosing for amnesia or enemy of ethnocentrism? In P. Benson \& R. Openshaw (Eds.), New horizons for New Zealand social studies (pp. 63-82). Palmerston North: ERDC Press, Massey University.

Hartoonian, H. M., \& Laughlin, M. A. (1989). Designing a social studies scope and sequence for the 21st century. Social Education, 53(6), 388-398.

Hattie, J. (2009). Visible learning: A synthesis of over 800 meta-analyses relating to achievement. Abingdon, Oxford: Routledge.

Hawe, E. M., Browne, I., Siteine, A., \& Tuck, B. (2010). Beliefs of experienced and student teachers about the nature and purpose of social studies education in New Zealand elementary schools. Asia Pacific Journal of Education, 30(3), 289-304. doi: 10.1080/02188791.2010.495842

Haydon, G. (2003). Moral education. In R. Curren (Ed.), A companion to the philosophy of education (pp. 320-331). USA: Blackwell.

Heilman, E. (2006). Critical, liberal, and poststructural challenges for global education. In A. Segall, E. Heilman, \& C. Cherryholmes, (Eds.). (2006). Social studies - the next generation: Re-searching in the postmodern, (pp. 189-208). New York: Peter Lang.

Helm, B. (2014). Friendship. The Stanford Encyclopedia of Philosophy. Fall 2013. Retrieved from http://plato.stanford.edu/archives/fall2013/entries/friendship/

Helmsing, M. (2014). Virtuous subjects: A critical analysis of the affective substance of social Studies Education. Theory \& Research in Social Education, 42(1), 127-140. doi: 10.1080/00933104.2013.842530

Hertz, R. (1996). Introduction: Ethics, reflexivity and voice. Qualitative Sociology, 19(1), 39. doi.org/10.1007/BF02393245

Hess, D. E. (2002). Discussing controversial public issues in secondary social studies classrooms: Learning from skilled teachers. Theory \& Research in Social Education, 30(1), 10-41. doi: 10.1080/00933104.2002.10473177

Hess, D. (2004). Controversies about controversial issues in democratic education. Political Science and Politics, 37(2), 257-261. doi.org/10.1017/S1049096504004196

Hess, D. (2008). Controversial issues and democratic discourse. In L. L. Levstik \& C. A. Tyson (Eds.), Handbook of research in social studies education. Hoboken: Routledge.

Hess, D. (2009). Controversy in the classroom: The democratic power of discussion. New York: Routledge.

Hess, D., \& McAvoy, P. (in press). The political classroom: Evidence and ethics in democratic education. Routledge.

Hill, B. V. (1994). Teaching secondary social studies in a multicultural society. Australia: Longman Cheshire.

Hill, B. V. (2014). The schooling of ethics. Educationl Philosophy and Theory, 46(3), 296310. doi: 10.1111/j.1469-5812.2011.00832.x

Hinman, L. M. (2008). Ethics: A pluralistic approach to moral theory (4th ed.). USA: Thomson Wadsworth.

Hinman, L. M. (2013). Ethics: A pluralistic approach to moral theory (5th ed.). USA: Wadsworth Cengage Learning.

Hirst, P. H., \& Peters, R. S. (1970). The logic of education. London: Routledge \& K. Paul. 
Højbjerg, C. K. (2002). Religious reflexivity: Essays on attitudes to religious ideas and practice. Social Anthropology, 10(1), 1-10. doi.org/10.1111/j.14698676.2002.tb00042.x

Holland, R. (1999). Reflexivity. Human Relations, 52(4), 463-484. doi.org/10.1177/001872679905200403

Holmes, M. (2010). The emotionalization of reflexivity. Sociology, 44(1), 139-154. doi.org/10.1177/0038038509351616

Hsieh, H. F., \& Shannon, S. E. (2005). Three approaches to qualitative content analysis. Qualitative Health Research, 15(9), 1277-1288. doi:10.1177/1049732305276687

Hugman, R. (2003). Professional values and ethics in social work: Reconsidering postmodernism? British Journal of Social Work, 33(8), 1025-1041. doi: 10.1093/bjsw/33.8.1025

Hugman, R. (2005). New approaches in ethics for the caring professions. UK: Palgrave Macmillan.

Hunter, P. (2006). Framing a social sciences learning area in the New Zealand curriculum: Draft for consultation 2006. Teachers and Curriculum, 9, 19-26.

Hunter, P. (2007). Comment: Social sciences in the New Zealand curriculum: A case of arrested developemnt? Mediating challenges ahead. Teachers and Curriculum, 10, 47-50.

Hunter, P., \& Keown, P. (2001). The New Zealand social studies curriculum struggle 1993-1997: An 'insider' analysis. Waikato Journal of Education, 7, 55-72.

Hupcey, J. E., Penrod, J., Morse, J. M., \& Mitcham, C. (2001). An exploration and advancement of the concept of trust. Journal of Advanced Nursing, 36(2), 282-293. doi:10.1046/j.1365-2648.2001.01970.x

Illes, J., \& Racine, E. (2005). Imaging or imagining? A neuroethics challenge informed by genetics. The American Journal of Bioethics, 5(2), 5-18. doi:10.1080/15265160590923358

Institutue for Global Ethics. (2014). Global ethics. Retrieved from http://www.globalethics.org/

Irwin, M. (1999). A decade of curricular reform. New Zealand Journal of Education Studies, 34(1), 156-166.

Jackson, P., \& Massey, D. (2005). Thinking geographically. Retrieved from http://www.geography.org.uk/aboutus/papersandresponses

Janman, P. (Director). (2012). Tongan Ark [Documentary film]. New Zealand: Public Films.

Jasanoff, S. (2002). New modernities: Reimaging science, technology and development. Environmental V alues, 11, 253-276.

Jensen, E. (2009, September). Almighty row over ethics class in schools, Sydney Morning Herald. Retrieved from http://www.smh.com.au/national/almighty-row-overethics-class-in-schools-20090925-g6a0.html

Johnson, M. (1993). Moral imagination: Implications of cognitive science for ethics. London: University of Chicago Press.

Johnson, M. (2009). What cognitive science brings to ethics. In D. Ambrose \& T. Cross (Eds.), Morality, ethics and gifted minds (pp. 147-150). Dordrecht: Springer.

Joll, N. (2010). Contemporary metaphilosophy. Internet encyclopedia of philosophy. Retrieved from http://www.iep.utm.edu/con-meta/

Jones, P. (2006). Toleration, value-pluralism, and the fact of pluralism. Critial Review of International Social and Political Philosophy, 9(2), 189-210. doi.org/10.1080/13698230600655016

Kallio, K. P., \& Häkli, J. (2011). Tracing children's politics. Political Geography, 30(2), 99109. doi:org/10.1016/j.polgeo.2011.01.006

Kant, I. (1952). General introduction to the metaphysic of morals. In R. M. Hutchins (ed.) Great books of the western world: Kant (pp. 385-394). Chicago: William Benton. 
Katz, M. S., Noddings, N., \& Strike, K. A. (Eds.). (1999). Justice and caring: The search for common ground in education. New York: Teachers College Press.

Kaposy, C. (2009). Will neuroscientific discoveries about free will and selfhood change our ethical practices? Neuroethics, 2(1), 51-59. doi.org/10.1007/s12152-008-9020$\mathrm{x}$

Keller, D. R. (2010). An introduction to ethics for teaching. Teaching Ethics, 11(1), 1-54. DOI: $10.5840 /$ tej20101111

Kennedy, K. (Ed.). (1997). Citizenship education and the modern state. London: Falmer Press.

Keown, P. (1998). Values and social action: Doing the hard bits. In P. Benson \& R. Openshaw (Eds.), New horizons for New Zealand social studies (pp. 137-159). Palmerston North: ERDC Press.

Keown, P. (1999). Some strategies for the development of the values exploration and social decision making processes. In Social Studies on Broadway: Proceedings of the 1999 FSS A Conference, Palmerston North. Wellington: Federation of Social Studies Associations of New Zealand.

Keown, P. (2001). Weak, indecisive and ineffectual? Towards a national dialogue in values education through social studies. DELTA, 53(1\&2), 43-60.

Keown, P. (2003). Values education and the curriculum. Hamilton, NZ: School of Education. University of Waikato. Unpublished Manuscript.

Keown, P., McGee, C., \& Sands, F. (1993). Values education and social studies: Research and development: $V$ alues in social studies project research monograph 1. Hamilton, New Zealand: University of Waikato.

Keown, P., Parker, L., \& Tiakiwai, S. (2005). Values in the New Zealand curriculum: A literature review on values in the curriculum. (Report for the Ministry of Education by the Wilf Malcom Institute of Educational Research). New Zealand: University of Waikato.

Kicker, D. (2009). Wendell Bell and Oliver W. Markley: Two futurists' views of the preferable, the possible and the probable. Journal of Futures Studies, 13(3), 161178.

Kidder, R. (1995). How good people make tough choices. New York: Simon and Schuster.

King, D. S. (2006). Activists and emotional reflexivity: Toward Touraine's subject as social movement. Sociology, 40(5), 873-891.

Knight, S. (2010). NSW ethics course trial: Final report. Australia: University of South Australia.

Knight, S., \& Collins, C. (2010a). ETHIC: A procedure for ethical decision making within society and environment. Paper presented at the SEAA Biennial Conference with SASOSE Annual Conference: Learning for Life, Sustainability, Global Citizenship and Social Justice, Adelaide, Australia.

Knight, S., \& Collins, C. (2010b). Enlivening the curriculum: The power of philosophical inquiry. Theory and Research in Education, 8(3), 305-318. doi: 10.1177/1477878510381630

Kohlberg, L. (1981). Essays on moral development (Vol. 1\&2). San Fransisco: Harper \& Row.

Kuntz, A. M. (2010). Representing representation. International Journal of Qualitative Studies in Education, 23(4), 423-433. doi.org/10.1080/09518398.2010.492769

LaFollette, H. (2000). Introduction The Blackwell guide to ethical theory (pp. 1-12). USA: Blackwell.

Lambek, M. (Ed.). (2010). Ordinary ethics: Anthropology, language and action. USA: Fordham Univerity Press.

Lambert, D., \& Morgan, J. (2010). Teaching Geography 11-18: a conceptual approach. England: Open University Press .

Lash, S. (2003). Reflexivity as non-linearity. Theory, Culture \& Society, 20(2), 49-57. doi.org/10.1177/0263276403020002003 
Lather, P. (2006). Paradigm proliferation as a good thing to think with: Teaching research in education as a wild profusion. International Journal of Qualitative Studies in Education, 19(1), 35-57. doi:10.1080/09518390500450144

Lavazza, A., \& De Caro, M. (2010). Not so fast. On some bold neuroscientific claims concerning human agency. Neuroethics, 3(1), 23-41. doi.org/10.1007/s12152-0099053-9

Le Métais, J. (2002). New Zealand stocktake: An international critique: Contract research for the New Zealand Ministry of Education. UK: National Foundation for Educational Research.

Lee, G., \& Hill, D. (1996). Curriculum reform: Outlining the new or restating the familiar? DELTA, 48(1), 19-32.

Lee, G., \& Lee, H. (2007). Some reflections on the New Zealand curriculum. Teachers and Curriculum, 10(2007), 35-38.

Lennon, K. (2014). Feminist perspectives on the body. The Stanford Encyclopedia of Philosophy. Fall, 2010. Retrieved from http://plato.stanford.edu/archives/fall2010/entries/feminist-body/

Levin, K., Cashore, B., Bernstein, S., \& Auld, G. (2012). Overcoming the tragedy of super wicked problems: Constraining our future selves to ameliorate global climate change. Policy Sciences, 45(2), 123-152. doi:10.1007/s11077-012-9151-0

Levinson, R. (2006). Towards a theoretical framework for teaching controversial socioscientific Issues. International Journal of Science Education, 28(10), 1201-1224. doi:10.1080/09500690600560753

Levy, N. (2007). Neuroethics: Challenges for the 21st century. UK: Cambridge University Press.

Lipman, M. (2003). Thinking in education (2nd ed.). Cambridge: Cambridge University Press.

Lister, R. (2003). Citizenship: feminist perspectives (2nd ed.). New York: New York University Press.

Lister, R. (2007). Inclusive citizenship: Realizing the potential. Citizenship Studies, 11(1), 49-61. doi:10.1080/13621020601099856

Lockstone, R. H. (1963). The neglect of mind: Social studies in the primary school. Landfall, 17(1), 49-55.

Lockstone, R. H. (1996). The end of history at the end of the world. New Zealand Education Review, 18(1), 8-15.

Lockwood, A. L., \& Harris, D. E. (1985). Reasoning with democratic values: Ethical problems in United States history (Vol. 1, pp. 1607-1876). New York: Teachers College Press.

Longboat, C. (2010). Ethical space as an engagement strategy. In J. S. Te Rito, \& S. M. Healy (Eds.) Proceedings of the 4th International Traditional Knowledge Conference: Kei Muri $i$ te Kapara He Tangata Ke: Recognising, Engaging, Understanding Difference. Auckland, New Zealand: Ngā Pae o te Māramatanga.

Longstaff, S. (2010). Almighty row over ethics in schools: Democracy and the welfare of children.

Retrieved from http://stephenlaw.blogspot.co.nz/2010/04/almighty-row-overethics-in-schools.html

Luce-Kapler, R., Sumara, D., \& Iftody, T. (2010). Teaching ethical know-how in new literary spaces. Journal of Adolescent \& Adult Literacy, 53(7), 536-541. doi: 10.1598/JAAL.53.7.1

Luhmann, N. (1995). Social systems. USA: Stanford University Press.

Luke, A. (2005). Nothing objectionable or controversial: The image of Maori ethnicity and 'difference' in New Zealand social studies. In Y. Nozaki, R. Openshaw, \& A. Luke, Struggles over difference: Curriculum, texts, and pedagogy in the Asia-Pacific. (Eds.) (pp, 25-40) Albany: State University of New York Press. 
Lynch, M. (2000). Against reflexivity as an academic virtue and source of privileged knowledge. Theory, Culture \& Society, 17(3), 26-54. doi.org/10.1177/02632760022051202

Lynch, S. (2009). The fact of diversity and reasonable pluralism. Journal of Moral Philosophy, 6(1), 70-93. doi:doi:10.1163/174552409X365937

Macbeth, D. (2001). On "reflexivity" in qualitative research: Two readings, and a third. Qualitative Inquiry, 7(1), 35-68. doi.org/10.1177/107780040100700103

MacDonald, M. N., \& O'Regan, J. P. (2013). The ethics of intercultural communication. Educational Philosophy and Theory, 45(10), 1005-1017. doi:10.1111/j.14695812.2011.00833.x

MacIntyre, A. (1996). A short history of ethics: A historical moral philosophy from the Homeeric age to the twentieth century. New York: Touchstone.

Mackie, J. L. (1979). Ethics: Inventing write and wrong. UK: Penguin Books.

Mansfield, N. (2000). Subjectivity: Theories of the selffrom Freud to Haraway. Australia: Allen \& Unwin.

Margolis, E., \& Laurence, S. (2014). Concepts. The Stanford encyclopedia of philosophy Spring 2014. Retrieved from http://plato.stanford.edu/archives/spr2014/entries/concepts/

Mason, E. (2014). Value pluralism. The Stanford encyclopedia of philosophy. Retrieved from http://plato.stanford.edu/archives/fall2011/entries/value-pluralism/

Maturana, H., \& Varela, F. (1998). The tree of knowledge: The bological roots of human understanding. (Rev. ed.). Boston, USA: Shambala.

May, S. (1992). Taha what? Social studies and multicultural education: An holistic alternative. In R. Openshaw \& E. Archer (Eds.), New Zealand Social Studies: Past, present, and future (pp. 122-136). Palmerston North: Dunmore Press.

McAfee, N. (2014). Feminist political philosophy. The Stanford Encyclopedia of Philosophy. Spring 2014. Retrieved from http://plato.stanford.edu/archives/sum2014/entries/feminism-political/

McGee, C. (1995). Ideological influences on curriculum and teachers. Waikato Journal of Education, 1, 29-44.

McGee, C. (2004). Commentary: Curriculum revision critique: A response to Clark. Teachers and Curriculum, 7, 81-83.

McGee, C., Jones, A., Cowie, B., Hill, M., Miller, T., Harlow, A., \& MacKenzie, K. (2003). Teachers' experiences in curriculum implementation: English, languages, science and social studies: National School Sampling Study. Hamilton, NZ: University of Waikato.

McGee, J. (1998). Curriculum in conflict: Historical development of citizenship education in social studies. In P. Benson \& R. Openshaw (Eds.), New horizons for New Zealand social studies (pp. 43-62). Palmerston North: ERDC Press, Massey University.

McGee, J. (2001). Changing attitudes towards curriculum development: 1900-1940. DELTA, 53(1\&2), 7-24.

McGeorge, C. (1992). The moral curriculum: Forming the Kiwi character. In G. McCulloch (Ed.), The school currculum in New Zealand: History, theory, policy and practice (pp. 40-56). Palmerston North, NZ: Dunmore Press.

McGeorge, C. (2000). More than talk this time? Values education in a new millennium. DELTA, 52(1), 57-68.

McLaughlin, T. H. (1992). Citizenship, diversity and education: A philosophical perspective. Journal of Moral Education, 21(3). Retrieved fromhttp://www.tandfonline.com/doi/abs/10.1080/0305724920210307?journa lCode $=$ cjme 20

Meyer, J., \& Land, R. (2003). Threshold concepts and troublesome knowledge: Linkages to ways of thinking and practising within the disciplines: UK: University of Edinburgh. 
Meyer, J., \& Land, R. (2005). Threshold concepts and troublesome knowledge (2): Epistemological considerations and a conceptual framework for teaching and learning. Higher Education, 49(3), 373-388. doi.org/10.1007/s10734-004-6779-5

Meyer, J., \& Land, R. (2006). Overcoming barriers to student understanding: Threshold concepts and troublesome knowledge. UK: Routledge.

Milligan, A. (2006). Representing the social world: New Zealand's social studies curriculum (Masters of Education). Victoria University of Wellington, New Zealand.

Milligan, A., \& Beals, F. (2004). Inserting the question marks: The impact of postmodernism on teaching and learning in social studies. The New Zealand Journal of Social Studies, 12(1), 16-23.

Milligan, A., Taylor, M., \& Wood, B. E. (2011). Teachers' conceptions of citizenship in New Zealand social studies education. Citizenship Teaching and Learning, 6(3), 287301. doi:10.1386/ctl.6.3.287_1

Milligan, A., \& Wood, B. (2010). Conceptual understandings as transition points: making sense of a complex social world. Journal of Curriculum Studies, 42(4), 487501. doi:10.1080/00220270903494287

Mills, C. W. (1959). The sociological imagination. New York: Oxford University Press.

Minister of Education. (1988). Tomorrow's schools: The reform of education administration in New Zealand. Wellington: Government Printer.

Ministry of Education. (1961). Syllabuses for schools: Social studies in the primary school. Wellington, NZ: Author.

Ministry of Education. (1991). Social studies forms 3 and 4: A handbook for teachers. Wellington, NZ: Learning Media.

Ministry of Education. (1993). The New Zealand curriculum framework. Wellington, NZ: Learning Media.

Ministry of Education. (1994). Social studies in the New Zealand curriculum: Draft. Wellington, NZ: Learning Media.

Ministry of Education. (1996). Social studies in the New Zealand curriculum: Revised draft. Wellington, NZ: Learning Media.

Ministry of Education. (1997). Social studies in the New Zealand curriculum. Wellington, NZ: Learning Media.

Ministry of Education. (1998). Social studies in the New Zealand curriculum: Getting started. Wellington, NZ: Learning Media.

Ministry of Education. (2004). The New Zealand curriculum exemplars: Social studies. Wellington, NZ: Learning Media.

Ministry of Education. (2005a). Setting the direction for learning: The New Zealand curriculum marautanga project. Wellington, NZ: Learning Media.

Ministry of Education. (2005b). V alues in the New Zealand curriculum: Background, rationale and recommendations. Retrieved from

http://nzcurriculum.tki.org.nz/Archives/Curriculum-project-archives

Ministry of Education. (2006a). Draft Social Sciences Essence Statement. Retrieved from

http://www.tki.org.nz/r/nzcurriculum/whats_happening/social_science_e.php

Ministry of Education. (2006b). The New Zealand curriculum: Draft for consultation 2006.

Wellington, NZ: Learning Media.

Ministry of Education. (2007). The New Zealand curriculum. Wellington, NZ: Learning Media.

Ministry of Education. (2008a). Building conceptual understandings in the social sciences: Approaches to social inquiry. Wellington, NZ: Learning Media.

Ministry of Education. (2008b). Building conceptual understandings in the social sciences: Belonging and participating in society. Wellington, NZ: Learning Media. 
Ministry of Education. (2009a). Building conceptual understandings in the social sciences: Approaches to building conceptual understandings. Wellington, NZ: Learning Media. Retrieved from http://ssol.tki.org.nz/

Ministry of Education. (2009b). Building conceptual understandings in the social sciences: Being part of global communities. Wellington, NZ: Learning Media.

Ministry of Education. (2012). Building conceptual understandings in the social sciences: Taking part in economic communities. Wellington, NZ: Learning Media.

Ministry of Education. (2014a). The Mãori education strategy: Ka bikitia - accelerating success 2013-2017. Retrieved from http://www.minedu.govt.nz/theMinistry/PolicyandStrategy/KaHikitia.aspx

Ministry of Education. (2014b). New Zealand curriculum guides senior secondary: Philosophy. Retrieved from http://seniorsecondary.tki.org.nz/Social-sciences/Philosophy

Ministry of Education. (2014c). New Zealand curriculum guides senior secondary: Social sciences. Retrieved from http://seniorsecondary.tki.org.nz/Social-sciences

Ministry of Education. (2014d). New Zealand curriculum guides senior secondary: Senior social studies. Retrieved from http://seniorsecondary.tki.org.nz/Socialsciences/Senior-social-studies

Ministry of Education. (2014e). Points of view, values, and perspectives in senior social studies. New Zealand curriculum guides: Senior secondary. Retrieved from http://seniorsecondary.tki.org.nz/Social-sciences/Senior-socialstudies/Pedagogy/Social-inquiry/Points-of-view

Ministry of Education. (2014f). Using a social inquiry approach in geography. New Zealand curriculum guides: Senior secondary. Retrieved from http://seniorsecondary.tki.org.nz/Socialsciences/Geography/Pedagogy/Social-inquiry\#exploring

Mitchell, K., \& Parker, W. C. (2008). I pledge allegiance to...Flexible citizenship and shifting scales of belonging. Teachers College Record, 110(4), 775-804.

Moll, J., De Oliveira-Souza, R., \& Zahn, R. (2008). The neural basis of moral cognition. Annals of the New York Academy of Sciences, 1124(1), 161-180. doi:10.1196/annals.1440.005

Moore, H. L. (2011). Still life: Hopes, desires and satisfactions. Cambridge: Polity Press.

Moore, T. (2011). Critical thinking: Seven definitions in search of a concept. Studies in Higher Education, 38(4), 506-522. doi:10.1080/03075079.2011.586995

Mouffe, C. (2000). Deliberative democracy or agonistic pluralism. Political Science Series. Institute for Advanced Studies, Vienna. Retrieved from http://www.ihs.ac.at/publications/pol/pw_72.pdf

Mouffe, C. (2009). Democracy in a multipolar world. Millennium: Journal of International Studies, 37(3), 549-561. doi:10.1177/0305829809103232

Mouffe, C. (2013). Agonistics: Thinking the world politically. London: Verso.

Mullen, A. (2004). "Some sort of revolution": Reforming the social studies curriculum, 1957-1972. In C. Woyshner, J. Wattras \& M. S. Crocco (Eds.). Social education in the twentieth century: Curriculum and context for citizenship (pp. 110-126). New York: Peter Lang.

Mulnix, J. W. (2012). Thinking critically about critical thinking. Educational Philosophy and Theory, 44(5), 464-479. doi.org/10.1111/j.1469-5812.2010.00673.x

Munby, H. (1989). Reflection-in-action and reflection-on-action. Education and Culture, 9(1), 31-41.

Munshi, D., Broadfoot, K. J., \& Smith, L. T. (2011). Decolonizing communication ethics: A framework for communicating. In G. Cheney, S. May \& D. Munshi (Eds.), The Handbook of communication ethics (pp. 119-133). New York; UK: Routledge. 
Mutch, C. (1998). The long and winding road: The development of the new social studies curriculum in New Zealand. Paper presented at the New Zealand Educational Administration Society Biennial Conference Wellington, New Zealand.

Mutch, C. (2000). Values education in New Zealand: Old ideas in new garb. Children's Social and Economics Education, 4(1), 1-10. doi.org/10.2304/csee.2000.4.1.1

Mutch, C. (2005a). Confident, informed and responsible citizens: By what means? In P. Benson \& R. Openshaw (Eds.), Towards effective social studies (pp. 69-84). Palmerston North, NZ: Kanuka Grove Press.

Mutch, C. (2005b). Developing global citizens: The rhetoric and the reality in the New Zealand curriculum. In C. White \& R. Openshaw (Eds.), Democracy at the crossroads: International perspectives on critical global citizenship education (pp. 187-209). Lanham: Lexington Books.

Mutch, C. (2011). Citizenship education in New Zealand: We know 'what works' but to what extent is it working? Citizenship, Social and Economics Education, $10(2$ \& 3), 182-198. doi.org/10.2304/csee.2011.10.2.182

Mutch, C., Hunter, P., Milligan, A., Openshaw, R., \& Siteine, A. (2009). Understanding the social sciences as a learning area: A position paper. Prepared for the Ministry of Education. Retrieved September 9, 2010 from: http://nzcurriculum.tki.org.nz/Media/Files/UV-files/Understanding-thesocial-sciences-as-a-learning-area-A-position-paper-February-2008

Neiman, S. (2004). Evil in modern thought: An alternative history of philosophy. New Jersey, USA: Princeton University Press.

Nelson, J. (1996). The historical imperative for issues-centred education. In R. W. Evans \& D. W. Saxe (Eds.), Handbook on teaching social issues: NCSS bulletin 93 (pp. 1424). Washington, DC: National Council for the Social Studies.

New Zealand Teachers Council. (2004). Code of ethics for registered teachers. Retrieved from http://www.teacherscouncil.govt.nz/content/code-ethics-registered-teachers-1

Newseum. (2014). The Bancroft family ethics center. Retrieved from http://www.newseum.org/exhibits-and-theaters/permanent-exhibits/ethicscenter/index.html

Newton, K., \& Francis, C. (2009). School letter stoush: Michael Laws invited to Otaki. Retrieved from http://www.stuff.co.nz/national/politics/2828828/Schoolletter-stoush-Michael-Laws-invited-to-Otaki

Neyland, J. (2004). An ethical critique of the paradigm case: The mathematics curriculum. In A. O'Neill, J. Clark \& R. Openshaw (Eds.), Reshaping culture, knowledge and learning? Policy and content in The New Zealand Curriulum Framework (pp. 143-160). Palmerston North, NZ: Dunmore Press.

Neyland, J. (2005). Towards an ethically oriented curriculum: Resisting the growth of instrumentalism. Curriculum Matters, 1, 109-129.

Neyland, J. (2010). Rediscovering the spirit of education after scientific managament. Rotterdam: Sense.

Noddings, N. (1994). Conversation as moral education. Journal of Moral Education, 23(2), 107-118. doi: 10.1080/0305724940230201

Noddings, N. (2007). Philosophy of education (2nd ed.). USA: Westview Press.

Notman, R. (2012). Integrating values in the New Zealand curriculum (2007): Four years on. Set, 3, 41-49.

Notman, R., Latham, D., Angus, H., Connor, P., McGregor, K., \& Scott, J. (2012). Integrating values in the New Zealand curriculum: Caught or tanght? New Zealand: Teaching and Learning Research Initiative. 
Novak, J. D., \& Cañas, A. J. (2014). The theory underlying concept maps and how to construct and use them: Technical report, 2008. Institute for Human and Machine Cognition. Retrieved from http://cmap.ihmc.us/publications/researchpapers/theorycmaps/theoryunderlyi ngconceptmaps.htm

O'Loughlin, M. (2006). Embodiment and education: Exploring creatural existence (Vol. 15). The Netherlands: Springer.

O'Neill, A., Clark, J., \& Openshaw, R. (2004). Reshaping culture, knowledge and learning? Policy and content in the New Zealand curriculum framework. Palmerston North, NZ: Dunmore Press.

O'Neill, O. (1993). Kantian ethics. In P. Singer (Ed.), A companion to ethics: Blackwell companions to philosophy (pp. 175-185). USA: Blackwell Publishing.

Ochoa-Becker, A. S. (2007). Democratic education for social studies: An issues-centred decision making curriculum. USA: Information Age.

Oddie, G. (2009). Values educaton. In H. Siegel (Ed.), The Oxford handbook of philosophy of education. (pp. 260-277) Oxford: Oxford University Press.

Oliver, D., \& Shaver, J. P. (1986). Teaching public issues in the high school. Boston: Houghton Mifflin.

Openshaw, R. (1995). Unresolved struggle: Consensus and conflict in New Zealand state postprimary education. Palmerston North, NZ: Dunmore Press.

Openshaw, R. (1998). Citizen who? The debate over economic and political correctness in the social studies curriculum. In P. Benson \& R. Openshaw (Eds.), New borizons for New Zealand social studies (pp. 19-42). Palmerston North: ERDC Press, Massey University.

Openshaw, R. (2000). Culture wars in the Antipodes: The social studies curriculum controversy in New Zealand. Theory and Research in Social Education, 28(1), 65-84. doi.org/10.1080/00933104.2000.10505897

Openshaw, R. (2004). Able to take their part? Social studies and the curriculum framework. In A. O'Neill, J. Clark \& R. Openshaw (Eds.), Reshaping culture, knowledge and learning: Policy and content in the New Zealand curriculum framework (pp. 245-264). Palmerston North: Dunmore Press.

Openshaw, R., Adams, P., \& Hamer, J. (2005). Education and society in Aotearoa New Zealand. Southbank, Vic: Thomson.

Openshaw, R., \& Archer, E. (1992). The battle for social studies in the New Zealand secondary school: 1942-1964. In R. Openshaw (Ed.), New Zealand social studies: Past, present and future (pp. 49-64). Palmerston North: Dunmore Press.

Openshaw, R., \& White, C. (2005). Democracy at the crossroads? In C. White \& R. Openshaw (Eds.), Democracy at the crossroads: International perspectives on critical global citizenship education (pp. 3-12). USA: Lexington Books.

Osler, A., \& Starkey, H. (2005). Changing citizenship: Democracy and inclusion in education. Maidenhead: Open University Press.

Oulton, C., Day, V., Dillon, J., \& Grace, M. (2004). Controversial issues: Teachers' attitudes and practices in the context of citizenship education. Oxford Review of Education, 30(4), 489-507. doi:10.1080/0305498042000303973

Paley, J. (1996). How not to clarify concepts in nursing. Journal of Advanced Nursing, 24(3), 572-576. doi:10.1046/j.1365-2648.1996.22618.x

Palmer, P. J. (1998). The courage to teach: Exploring the inner landscape of a teachers' life. USA: Jossey-Bass.

Parker, W. C. (2006). Public discourses in schools: Purposes, problems, possibilities. Educational Researcher, 35(8), 11-18. doi: 10.3102/0013189x035008011

Partington, G. (1998). Social studies in the New Zealand curriculum. In P. Benson \& R. Openshaw (Eds.), New horizons for New Zealand social studies (pp. 83-102).

Palmerston North, NZ: ERDC Press, Massey University. 
Patrick, J. J., Vontz, T. S., \& Nixon, W. A. (2002). Issues-centred education for democracy through Project Citizen. In W. C. Parker (Ed.), Education for democracy: Contexts, curricula and assessments (pp. 93-112). USA: Information Age.

Patterson, J. (1992). Exploring Maori values. Palmerston North, NZ: Dunmore Press

Patterson, J. (1994). Maori environmental virtues. Environmental Ethics, 16(4), 397-409.

Rabinow, P. (Ed.). (1984). The Foucault reader. New York: Pantheon Books.

Pass, S. (2007). Exploring teaching ethics in social studies. International Journal of Social Education, 21(2), 62-78.

Pass, S., \& Willingham, W. (2009). Teaching ethics to high school students. The Social Studies, 100(1), 23-30. doi: 10.3200/TSSS.100.1.23-30

Paul, R. (2012). Teaching critical thinking in the strong sense: A focus on self-deception, world views, and a dialectical mode of analysis. Critical thinking: What every person needs to survive in a rapidly changing world (pp. 465-474). California, USA:

Foundation for Critical Thinking.

Paul, R. (2014). Critical thinking movement: 3 waves. Retrieved from https://www.criticalthinking.org/pages/critical-thinking-movement-3waves $/ 856$

Payne, P. G. (2010). Moral spaces, the struggle for an intergenerational environmental ethics and the social ecology of families: An 'other' form of environmental education. Environmental Education Research, 16(2), 209-231. doi:10.1080/13504620903580545

Peterson, A. L. (2009). Everyday ethics and social change: The education of desire. New York: Columbia University Press.

Pfaff, D. W., Kavaliers, M., \& Choleris, E. (2008). Mechanisms underlying an ability to behave ethically. The American Journal of Bioethics, 8(5), 10-19. doi.org/10.1080/15265160802179994

Pence, G. (1993). Virtue theory. In P. Singer (Ed.), A companion to ethics: Blackwell companions to philosophy (pp. 249-258). USA: Blackwell Publishing.

Picken, A., \& Milligan, A. (2013). The challenges of assessment in secondary social studies: Exploring the potential of learning stories. New Zealand Journal of Education Studies, 48(2), 112-129.

Pike, G., \& Selby, D. (1988). Global teacher, global learner: London: Hodder \& Stoughton.

Pinar, W. F., Reynolds, W. M., Slattery, P., \& Taubman, P. M. (Eds.). (1995). Understanding curriculum: An introduction to the study of historical and contemporary curriculum discourses. New York: Peter Lang.

Poole, R. (1972). Towards deep subjectivity. USA: Harper Torchbooks.

Popke, E. J. (2003). Poststructuralist ethics: Subjectivity, responsibility and the space of community. Progress in Human Geography, 27(3), 298-316. doi: $10.1191 / 0309132503 \mathrm{ph} 429 \mathrm{oa}$

Popke, J. (2010). The spaces of being in common: Ethics and social geography. In S. Smith, R. Pain, S. Marston \& J. P. Jones (Eds.), The SAGE handbook of social geographies (pp. 435-454). London: Sage.

Porter, E. (1999). Feminist perspectives on ethics. New York: Pearson Education.

Preston, N. (2007). Understanding ethics (3rd ed.). Australia: The Federation Press.

Pring, R. (2007). John Dewey: A philsopher of education for our time? London: Continuum.

Pring, R. (2008). Philosophy in schools. London: Continuum Books.

Prinz, J. J. (2011). The emotional construction of morals. Oxford: Oxford University Press Oxford.

Pritchard, M. (2014). Philosophy for children. The Stanford encyclopedia of philosophy. Spring 2014. Retrieved from http://plato.stanford.edu/archives/spr2014/entries/children/ 
Qualifications and Curriculum Authority. (1998). Education for citizenship and the teaching of democracy in schools: Final report of the Advisory Group on Citizenship (the Crick Report). London: Author.

Quality Public Education Coalition. (2000). V alues in schools. Palmerston North, NZ: Kanuka Grove Press.

Radder, H. (1997). Philosophy and history of science: Beyond the Kuhnian paradigm. Studies in History and Philosophy of Science Part A, 28(4), 633-655. doi: http://dx.doi.org/10.1016/S0039-3681(97)00015-0

Rasmusson, A. (2009). Neuroethics as a brain-based philosophy of life: The case of Michael S. Gazzaniga. Neuroethics, 2(1), 3-11. doi.org/10.1007/s12152-008-90246

Raths, L., Harmin, M., \& Simon, S. (1978). Values and teaching: Working with values in the classroom (2nd ed.). Columbus, Ohio: Merrill.

Rawls, J. (1999). A theory of justice. Oxford: Oxford University Press.

Reiss, M. J. (1999). Teaching ethics in science. Studies in Science Education, 34(1), 115-140. doi: $10.1080 / 03057269908560151$

Reiss, M. J. (2010). Ethical thinking. In A. Jones, A. McKim \& M. Reiss (Eds.), Ethics in the science and technology classroom: A new approach to teaching and learning (pp. 7-17). The Netherlands: Sense.

Reynolds, R. (2009). Teaching studies of society and the environment. Australia: Oxford University Press.

Risjord, M. (2009). Rethinking concept analysis. Journal of Advanced Nursing, 65(3), 684691. doi:10.1111/j.1365-2648.2008.04903.x

Ritzer, G. (2005). The Sage encyclopedia of social theory. Thousand Oaks, CA: Sage.

Rohloff, A. (2011). Shifting the focus? Moral panics as civilizing and decivilizing processes. In S. P. Hier (Ed.), Moral panic and the politics of anxiety (pp. 71-85). London: Routledge.

Rohloff, A., \& Wright, S. (2010). Moral panic and social theory: Beyond the heuristic. Current Sociology, 58(3), 403-419. doi:10.1177/0011392110364039

Rorty, A. (2005). Morality as an educational institution. In J. M. Halstead \& T. H. McLauchlin (Eds.), Education in morality (pp. 7-22). Hoboken: Taylor \& Francis. Retrieved from http://VUW.eblib.com/patron/FullRecord.aspx?p=235163.

Rorty, A. (2012). The use and abuse of morality. Journal of Ethics, 16, 1-13. doi.org/10.1007/s10892-011-9116-0

Rorty, R. (1976). Overcoming the tradition: Heidegger and Dewey. The Review of Metaphysics, 30(2), 280-305. doi: 10.2307/20126921

Ross, E. W. (1985). The evolution of the relationship between reflective inquiry and social studies education: Implications for the future. Paper presented at the Annual Meeting of the National Council for the Social Studies, Chicago, Illinois.

Ross, E. W. (2006). The social studies curriculum: Purposes, problems, and possibilities (3rd ed.). USA: State University of New York.

Ryan, B., \& Buntting, C. (2012). Integrating ethics into primary science programmes. Set: Research Information for Teachers, 1, 17-25.

Ryan, G. W., \& Bernard, H. R. (2000). Data management and analysis methods. In N. K. Denzin \& Y. S. Lincoln (Eds.), The Sage handbook of qualitative research (3rd ed., pp. 769-802). Thousand Oaks: Sage.

Sandywell, B. (2013). Reflexivity and the crisis of western reason: Logological investigations (Vol. 1). London: Routledge.

Sanger, M., \& Osguthorpe, R. (2005). Making sense of approaches to moral education. Journal of Moral Education, 34(1), 57-71. doi:10.1080/03057240500049323

Santa Clara University. (2014). Markkula Center for Applied Etbics. Retrieved from http://www.scu.edu/ethics/ 
Saunders, K., \& Rennie, L. (2013). A pedagogical model for ethical inquiry into socioscientific issues in science. Research in Science Education, 43(1), 253-274. doi:10.1007/s11165-011-9248-z

Saxe, D. W. (1992). Framing a theory for social studies foundations. Review of Educational Research, 62(3), 259-277. doi: 10.2307/1170739

Samu, T. W. (2009). The location and dislocation of Pacific knowledge and experience in New Zealand social studies (1997-2007). Curriculum Matters 5: 2009.

Schön, D. A. (1983). The reflective practitioner: How professionals think in action. USA: Basic Books.

Schön, D. A. (1987). Educating the reflective practitioner: San Francisco: Jossey-Bass.

Schön, D. A. (1992). The theory of inquiry: Dewey's legacy to education. Curriculum Inquiry, 22(2), 119-139. doi.org/10.2307/1180029

Schroeder, M. (2014). Value theory. The Stanford encyclopedia of philosophy. Spring 2012. Retrieved from http://plato.stanford.edu/archives/sum2012/entries/valuetheory/

Schulz, W., Ainley, J., Fraillon, J., Kerr, D., Losito, B., \& (2010). ICCS 2009: Civic knowledge, attitudes, and engagement among lower secondary school students in 38 countries. Amsterdam: IEA.

Schutt, R. (2001). Inciting democracy: A practical proposal for creating a good society. USA: SpringForward Press. Retrieved from http://www.vernalproject.org/IcD/contents/IcDDownload.html

Scott, D., \& Lawson, H. (Eds.). (2002). Citizenship education and the curriculum. USA: Alex.

Segall, A. (2004). Social studies and the discourses of postmodernity. In C. Woyshner, J. Wattras \& M. S. Crocco (Eds.). Social education in the twentieth century: Curriculum and context for citizenship (pp. 160-175). New York: Peter Lang.

Segall, A. (2013). Revitalizing critical discourses in social education: Opportunities for a more complexified (un)knowing. Theory \& Research in Social Education, 41(4), 476493. doi:10.1080/00933104.2013.836382

Segall, A., Heilman, E. E., \& Cherryholmes, C. H. (Eds.). (2006). Social studies - the next generation: Re-searching in the postmodern. New York: Peter Lang.

Sewell, A. (2009). Evoking children's spirituality in the reciprocal relationships of a learning community. International Journal of Children's Spirituality, 14(1), 5-16.

Siegel, H. (2003). Cultivating reason. In R. Curren (Ed.), A companion to the philosophy of education (pp. 305-319). USA: Blackwell.

Seixas, P. C., Morton, T., Colyer, J., \& Fornazzari, S. (2013). The big six: Historical thinking concepts. Toronto: Nelson Education.

Shaver, J. P. (1992). Rationales for issues-centred social studies education. Social Studies, 83(3), 95-100.

Shuker, R. (1992). Social studies as curriculum history. In R. Openshaw (Ed.), New Zealand social studies: Past, present and future (pp. 34-48). Palmerston North: Dunmore Press.

Simon, J. (1992). Social studies: The cultivation of amnesia? In G. McCulloch (Ed.), The school currculum in New Zealand: History, theory, policy and practice (pp. 253-271). Palmerston North, NZ: Dunmore Press.

Simon, K. (2001). Moral questions in the classroom: How to get kids thinking deeply about real life and their schoolwork. New Haven, USA: Yale University Press.

Sinacore, A. L., Blaisure, K. R., Justin, M., Healy, P., \& Brawer, S. (1999). Promoting reflexivity in the classroom. Teaching of Psychology, 26(4), 267-270. doi.org/10.1207/S15328023TOP260405

Singer, P. (1993). A companion to ethics: Blackwell companions to philosophy. USA: Blackwell Publishing.

Singer, P. (1994). Ethics. UK: Oxford University Press. 
Singer, P. (2014). Ethics. Encyclopaedia Britannica online. Retrieved from http://www.britannica.com/EBchecked/topic/194023/ethics

Sinnema, C. (2011). Monitoring and evaluating curriculum implementation: Final evaluation report to the Ministry of Education on the implementation of the New Zealand curriculum 20082009. New Zealand: University of Auckland.

Sinnema, C., \& Aitken, G. (2012). Effective pedagogy in social sciences. Belley International Academy of Education, International Bureau of Education. Retrieved from http://www.ibe.unesco.org/fileadmin/user_upload/Publications/Educational_ Practices/EdPractices_23.pdf

Siteine, A. (2013). 'Positive in their own identities?': Social studies and identity affirmation. New Zealand Journal of Education Studies, 48(2), 99-111.

Skelton, T. (2010). Taking young people as political actors seriously: Opening the borders of political geography. Area, 42(2), 145-151. doi:10.1111/j.14754762.2009.00891.x

Slattery, P., \& Rapp, D. (2003). Ethics and the foundations of education: Teaching convictions in a postmodern world. USA: Pearson Education.

Smith, D. M. (2001). Progress reports, geography and ethics: Progress, or more of the same? Progress in Human Geography, 25(2), 261-268. doi.org/10.1191/030913201678580511

Smith, R. (2005). Does reflexivity separate the human sciences from the natural sciences? History of the Human Sciences, 18(4), 1-25. doi.org/10.1177/0952695105058468

Snook, I., \& McGeorge, C. (1978). More than talk: Moral education in New Zealand. Wellington, New Zealand: Department of Education.

Snook, I. (2000). The ethics and politics of values education. Delta, 52(1), 45-56.

Snook, I. (2007). The timid curriculum. Teachers and Curriculum, 10(2007), 39-42.

Somerville, M. (2006). The ethical imagination: Journeys of the buman spirit. Toronto, Canada: Anansi Press.

Splitter, L. J., \& Sharp, A. M. (1995). Teaching better thinking: The classroom community of inquiry. Melbourne, Australia: The Australian Council for Educational Research.

Sprod, T. (2002). Philosophical discussion in moral education: The community of ethical inquiry. London: Routledge.

St James Ethics Centre. (2014). Our work. Retrieved from http://www.ethics.org.au/our-work/ethi-call

Standish, P. (2003). The nature and purposes of education. In R. Curren (Ed.), $A$ companion to the philosophy of education (pp. 221-231). USA: Blackwell.

Standish, P. (2009). Global perspectives in the geography curriculum: Reviewing the moral case for geography. UK: Routledge.

Starratt, R. J. (1994). Building an ethical school: A practical response to the moral crisis in schools. London: Falmer Press.

Stemler, S. (2001). An overview of content analysis. Practical Assessment, Research and Evaluation, 7(17). Retrieved from http://pareonline.net/getvn.asp?v=7\&n=17

Stenhouse, L. (1968). The humanities curriculum project. Journal of Curriculum Studies, 1(1), 26-33. doi:10.1080/0022027680010103

Stenhouse, L. (1971). The humanities curriculum project: The rationale. Theory Into Practice, 10(3), 154-162. doi.org/10.1080/00405847109542322

Sterba, J. P. (2001). Three challenges to ethics: Environmentalism, feminsim, and multiculturalism. New York: Oxford University Press.

Stern, B. S. (2010). The new social studies: People, projects and perspectives. USA: Information Age.

Stocker, M., \& Hegeman, E. (1996). Valuing emotions. Cambridge: Cambridge University Press. 
Stoller, S. (2009). Phenomenology and the poststructural critique of experience. International Journal of Philosophical Studies, 17(5), 707-737. doi:10.1080/09672550903301762

Stone, R. C. J. (1963). Human solutions are not enough. NZPPTA Journal, X(6), 27-29.

Stradling, R. (1984). The teaching of controversial issues: An evaluation. Educational Review, 36(2), 121-129. doi: 10.1080/0013191840360202

Strong, T. (2005). Constructivist ethics? Let's talk about them: An introduction to the special issue on ethics and constructivist psychology. Journal of Constructivist Psychology, 18(2), 89-102. doi:10.1080/10720530590914752

Sullivan, K. (2002). Unreal tournament: The battle over the New Zealand social studies curriculum. New Zealand Annual Review of Education, 2001(11), 179-198.

Swoyer, C. (2014). Relativism. The Stanford encyclopedia of philosophy. Spring 2014. Retrieved from http://plato.stanford.edu/archives/spr2014/entries/relativism/

Syms, C. (2011). Enhancing the effectiveness of religion and values education within ISNZ schools: Rationale, purpose and practice. Heads of Independent Schools Scholarship Trust Research Project. Retrieved from 2010/201http://www.isnz.org.nz/sites/default/files/SymsCatherineReport.pdf

Taba, H., Durkin, M. C., Fraenkel, J. R., \& McNaughton, A. H. (1971). A teacher's bandbook to elementary social studies: An inductive approach (2nd ed.). Reading, MA: Addison-Wesley.

Taylor, M. (2012). Social science teachers' critical engagement with best evidence synthesis research (Master's thesis). Victoria University of Wellington, New Zealand.

Taylor, M. (2013). Social sciences teachers' utilisation of best evidence synthesis research. New Zealand Journal of Education Studies, 48(2), 34-50.

Taylor, R. M., \& Atkins, R. A. (2005). Putting the 'values' back into the values exploration process. In P. Benson \& R. Openshaw (Eds.), Towards effective social studies (pp. 131-146). Palmerston North, NZ: Kanuka Grove Press, Massey University.

Television New Zealand. (2009). Cadbury bows to pressure over palm oil. Retrieved from http://tvnz.co.nz/national-news/cadbury-bows-pressure-over-palm-oil2921239

Thiroux, J. P., \& Krasemann, K. W. (2009). Ethics: Theory and practice (10th ed.). New Jersey, USA: Prentice Hall.

Thomas, S. (1994). Artifactual study in the analysis of culture: A defense of content analysis in a postmodern age. Communication Research, 21(6), 683-697. doi:10.1177/009365094021006002

Thrupp, M. \& White, M. (2013). Research, analysis and insight into national standards (RAINS) project final report: National standards and the damage done. Report commissioned by the New Zealand Educational Institute Te Rui Roa (NZEI). Hamilton, New Zealand: Wilf Malcom Institute of Educational Research. http://www.waikato.ac.nz/_data/assets/pdf_file/0010/179407/RAINS-Finalreport_2013-11-22.pdf

Todd, S. (2003). Learning from the other: Levinas, psychoanalysis, and ethical possibilities in education. Albany: State University of New York Press.

Tolliver, D., \& Tisdell, E. (2006). Engaging spirituality in the transformative higher education classroom. New Directions for Adult and Continuing Education, 109, 37-47. DOI: $10.1002 /$ ace. 206

Tong, R., \& Williams, N. (2014). Feminist ethics. The Stanford encyclopedia of philosophy. Spring 2014. Retrieved from http://plato.stanford.edu/archives/spr2014/entries/feminism-ethics

Tweedie, R. (2013). Philosophy manifesto. Retrieved from http://nzapt.net/?page_id=246 
UNESCO. (2009). Teaching philosophy in Asia and the Pacific. Retrieved from http://www.unescobkk.org/resources/e-library/publications/article/teachingphilosophy-in-asia-and-the-pacific/

University of San Diego. (2010). Moral orientations survey. Retrieved February 5, 2010 from

http://ethics.sandiego.edu/ActiveWebSurvey/General/MoralOrientations.asp

University of San Diego. (2014a). Basic moral orientations. Retrieved from http://ethics.sandiego.edu/presentations/Theory/BasicOrientations/index.asp

University of San Diego. (2014b). Brief overview. Retrieved fromhttp://ethics.sandiego.edu/presentations/Theory/Brief_Overview/

Vanderbeeken, R. (2011). A plea for agonism between analytic and continental philosophy. Open Journal of Philosophy, 1, 16-21. doi:10.4236/ojpp.2011.11003.

Vardy, P. (2002). Becoming fully buman: A five strand approach to religious and values education. Paper presented at 2002 DAN conference. Retrieved from http://www.dialogueaustralasia.org/?page_id=23

Vardy, P., \& Vardy, C. (2012). Ethics matters. London: SCM Press.

Varela, F. J. (1999). Ethical know-how: Action, wisdom and cognition. USA: Stanford University Press.

Varela, F. J., Thompson, E., \& Rosch, E. (1993). The embodied mind: Cognitive science and buman experience. Cambridge, MA: MIT Press.

Verducci, S. (2009). Education, democarcy and the moral life: Where opposites collide. In M. S. Katz, S. Verducci \& G. Biesta (Eds.), Education, deocracy and the moral life (pp. 1-8). USA: Springer.

Vosniadou, S. (2010). International handbook of research on conceptual change: New York: Routledge.

Wacquant, L. J. D. (1992). Epistemic reflexivity. In P. Bourdieu \& L. J. D. Wacquant (Eds.), An invitation to reflexive sociology (pp. 36-46). Chicago: University of Chicago Press.

Warner, K. D., \& De Cosse, D. (2014). A short course in environmental ethics lesson one: An autobiography of your relationship with the earth. May 2009. Retrieved from http://www.scu.edu/ethics/practicing/focusareas/environmental_ethics/lesson 1.html

Weber, B. (2011). Childhood, philosophy and play: Friedrich Schiller and the interface between reason, passion and sensation. Journal of Philosophy of Education, 45(2), 235250. doi: 10.1111/j.1467-9752.2011.00804.x

Weiskrantz, L. (2009). Blindsight: A case study spanning 35 years and new developments. UK: Oxford University Press.

Wellington, J. J. (Ed.). (1986). Controversial issues in the classroom. Oxford, England: Basil Blackwell.

White, J. (2012). Philosophy in primary schools? Journal of Philosophy of Education, 46(3), 449-460. doi: 10.1111/j.1467-9752.2012.00860.x

White, M. D., \& Marsh, E. E. (2006). Content analysis: A flexible methodology. Library Trends, 55(1), 22-45. doi:10.1353/lib.2006.0053

Whitehead, A. N. (1929). The aims of education and other essays. New York: The Macmillan company.

Williams, B. (2011). Ethics and the limits of philosophy. Abingdon, UK: Routledge.

Willmott, H. (2008). For informed pluralism, broad relevance and critical reflexivity. In D. Barry \& H. Hansen, (Eds.). The Sage handbook of new approaches in management and organization, (pp. 82-83). London: Sage.

Wilson, R. A., \& Foglia, L. (2014). Embodied cognition. Fall 2011. Retrieved from http://plato.stanford.edu/archives/fall2011/entries/embodied-cognition/

Wood, B. E. (2005). Beacon schools for senior programmes in social studies: Final report (unpublished). Wellington: Minsitry of Education. 
Wood, B. E. (2007). Conflict, controversy, and complexity: Avoiding the 'slippery stuff in social studies. Critical Literacy: Theories and Practices, 1(2), 42-49.

Wood, B. E. (2012). Crafted within liminal spaces: Young people's everyday politics. Political Geography, 31(6), 337-346. doi:http://dx.doi.org/10.1016/j.polgeo.2012.05.003

Wood, B. E., Taylor, R. M., \& Atkins, R. A. (2013). Fostering active citizenship through the New Zealand social studies curriculum: Teachers' perceptions and practices of social action. New Zealand Journal of Educational Studies, 48(2), 84-98.

Worley, P. (2011). The if machine: Philosophical enquiry in the classroom. London: Continuum.

Wright, T. (2003). Phenomenology and the moral imagination. Logos: A Journal of Catholic Thought and Culture, 6(4), 104-121. doi.org/10.1353/log.2003.0049

Wringe, C. (2006). Moral education: Beyond the teaching of right and wrong. The Netherlands: Springer.

Young, I. M. (1990. Justice and the politics of difference. Princeton: Princeton University Press.

Young, I. M. (1997). Intersecting voices: Dilemmas of gender, political philosophy, and policy. Princeton: Princeton University Press.

Young, I. M. (2000). Inclusion and democracy. Oxford political theory. Oxford: Oxford University Press.

Young, M. (2008). Bringing knowledge back in: From social constructivism to social realsim in the sociology of education. London: Routledge.

Young, M. (2013). Overcoming the crisis in curriculum theory: A knowledge-based approach. Journal of Curriculum Studies, 45(2), 101-118. doi:10.1080/00220272.2013.764505

Young, M., \& Muller, J. (2010). Three educational scenarios for the future: Lessons from the sociology of knowledge. European Journal of Education, 45(1), 11-27. doi.org/10.1111/j.1465-3435.2009.01413.x

Young, M., \& Muller, J. (2013). On the powers of powerful knowledge. Review of Education, 1(3), 229-250. doi:10.1002/rev3.3017

Zevin, J. (2000). Social studies for teh twenty-first century (2nd ed.). New Jersey: Lawrence Erlbaum.

Zevin, J. (2007). Social studies for the twenty-first century: Methods and materials for teaching middle and secondary schools (3rd ed.). New Jersey, USA: Lawrence Erlbaum.

Zocchi, M., \& Pollack, C. (2013). Educational neuroethics: A contribution from empirical research. Mind, Brain, and Education, 7(1), 56-62.

doi:10.1111/mbe.12008 
APPENDICES

Appendix 1: Values in The New Zealand Curriculum

Appendix 2: Concept frequencies

Appendix 3: Ethics in NCEA achievement standards

Appendix 4: Social inquiry model

Appendix 5: Student focus group discussion task 


\section{APPENDIX 1: VALUES IN THE NEW ZEALAND CURRICULUM}

\section{Values \\ To be encouraged, modelled, and explored}

Values are deeply held bellets about what is important or desirable. They are expressed through the ways in which people think and act.

Every decision relating to curriculum and every interaction that takes place in a school reflects the values of the individuals inwotred and the collectwe values of the institution.

The values on the ust below enjoy widespread support because it is by hoiding these values and acting on them that we are able to twe together and thrive. The list is neither exhaustive nor exclusive.

Students will be encouraged to value.

- excellence, by aiming high and by persevering in the face of difficulties;

- Innovation, Inquiry, and curlosity, by thinking critically, creatively, and reflectively;

- diversity, as found in our different cultures. languages, and heritages;

- equity, through faimess and social justice;

- community and participation for the cornmon good:

- ecological sustainabillty, which includes care for the erwironment

- Integrity, which imwolves being honest, responsible, and accountable and acting ethically:

and to respect themsetves, ochers, and human rights.

The specific ways in which these values find expression in an indwidual school will be guided by dlalogue between the school and its community. They should be evident in the school's philosophy, structures, curriculum, classrooms, and relationships. When the school cornmunity has developed strongly held and clearly articulated values, those values are tikely to be expressed in everyday actions and interactions within the school.
Through their learning experiences, students will learn about:

- their own values and those of others:

- different kinds of values, such as moral, social, cultural, aesthetic, and economic values;

- the values on which New Zealand's cultural and institutional traditions are based:

- the values of other groups and cultures.

Through their learning experiences, students will develop their ability to:

- express their own values.

- explore, with empathy, the values of others;

- critically analyse values and actions based on thern;

- discuss disagreements that arise from differences in values and negotiate solutions;

- make ethical decisions and act on thern.

All the values listed above can be expanded into clusters of related values that collectwely suggest their fuller meanings. For example, cornmunity and pardopaton for the cormmon good is associated with values and notions such as peace, citizenship, and manaakitanga.

Ministry of Education, 2007, p.10 


\section{APPENDIX 2: CONCEPT FREQUENCIES}

\begin{tabular}{|c|c|c|c|c|}
\hline $\begin{array}{l}\text { Curriculum statement } \\
\text { and content analysed }\end{array}$ & $\begin{array}{l}\text { Ethics, cognates and proximal terms } \\
\text { Note: Italicised terms mentioned in the } \\
\text { pejorative }\end{array}$ & $\begin{array}{l}\text { Societal controversy, complexity, } \\
\text { diversity } \\
\text { Ideal societies } \\
\text { Criticality/creativity } \\
\text { Affect }\end{array}$ & Examples of virtues/character & $\begin{array}{l}\text { Emphases noted but not } \\
\text { coded }\end{array}$ \\
\hline $\begin{array}{l}\text { 1928: Syllabus of } \\
\text { instruction for public } \\
\text { schools } \\
\text { General introduction } \\
\text { and character training } \\
\text { sections (pp. 5-6, 63-65) } \\
\text { History (pp. 31-34, 144- } \\
\text { 146) } \\
\text { Geography (pp. 35-41, } \\
\text { 147-164) }\end{array}$ & $\begin{array}{l}\text { Ethics and cognates: } 0 \\
\text { Ethics as a contributing discipline: } 0 \\
\text { Utilitarianism: } 1 \\
\text { Evil results of behaviour: } 1 \\
\text { Character and character training: } 16 \\
\text { Virtues and moral habits: } 5 \\
\text { Examples of virtues: } 65 \\
\text { Moral ideas: } 1 \\
\text { Moral lessons: } 2 \\
\text { Morality: } 2 \\
\text { Right conduct and moral ideals: } 9 \\
\text { Duties and responsibilities of students: } 6 \\
\text { Rules and laws: } 10 \\
\text { Service and playing part in society: } 5 \\
\text { Rights: } 2\end{array}$ & $\begin{array}{l}\text { Conflict: } 5 \\
\text { Citizen/Citizenship: } 8 \\
\text { Peace: } 3 \\
\text { Reason intelligently: } 1 \\
\text { Justify conclusions: } 1 \\
\text { Spiritual development: } 1 \\
\text { Personal happiness: } 2 \\
\text { Love of social life: } 1 \\
\text { Self-expression/individuality: } 2\end{array}$ & $\begin{array}{l}\text { Confident, giving: } 2 \text {, initiative: } 2 \text {, } \\
\text { endurance, concentration, self- } \\
\text { controlled: } 4 \text {, leadership, seeks the } \\
\text { general good, honest and truthful: } 6 \text {, } \\
\text { modest: } 3 \text {, perseveres, self-reliant, } \\
\text { honourable, fair, patient, pride in } \\
\text { effort, considerate, non-interfering, } \\
\text { sense of obligation, polite, kind: } 3 \text {, } \\
\text { helpful, obedient, cheerful, cares for } \\
\text { others' property: } 4 \text {, responsible: } 3 \text {, } \\
\text { co-operative: } 3 \text {, accepts defeat, well } \\
\text { behaved, courageous: } 2 \text {, industrious: } \\
3 \text {, dignified, self-sacrificing: } 3 \text {, } \\
\text { patriotic: } 3 \text {, pride, respectful of law, } \\
\text { noble, sense of community }\end{array}$ & $\begin{array}{l}\text { Opportunities for } \\
\text { experiencing } \\
\text { responsibilities e.g. prefect } \\
\text { system, keeping the school } \\
\text { grounds tidy }\end{array}$ \\
\hline $\begin{array}{l}\text { 1944: The post- } \\
\text { primary school } \\
\text { curriculum: Report of } \\
\text { the committee } \\
\text { appointed by the } \\
\text { Minister of Education }\end{array}$ & $\begin{array}{l}\text { Ethics and cognates: } 0 \\
\text { Ethics as a contributing discipline: } 0 \\
\text { Morality: } 1 \\
\text { Character: } 3 \\
\text { Examples of character: } 18 \\
\text { Law: } 1\end{array}$ & $\begin{array}{l}\text { Conflict/Current problems of } \\
\text { national/world importance: } 6 \\
\text { Citizens/Citizenship: } 10 \\
\text { Democratic society, community, } \\
\text { institutions, school system: } 4 \\
\text { Values of democracy : } 3 \\
\text { Democratic virtues: } 1 \\
\end{array}$ & $\begin{array}{l}\text { Self-disciplined, free in spirit, gifted } \\
\text { in work and enjoyment, worthy, } \\
\text { desirable, responsible: } 2 \text {, generous, } \\
\text { give and take, willing to serve social } \\
\text { ends, intellectually curious, } \\
\text { tenacious, clear thinking, flexibly }\end{array}$ & $\begin{array}{l}\text { History, Geography, Civics, } \\
\text { Psychology, Anthropology, } \\
\text { descriptive Economics } \\
\text { mentioned as contributing } \\
\text { disciplines for social } \\
\text { studies. }\end{array}$ \\
\hline
\end{tabular}




\begin{tabular}{|c|c|c|c|c|}
\hline $\begin{array}{l}\text { in November } 1942 \\
\text { (The Thomas Report) } \\
\text { Introduction and } \\
\text { General aims (pp. 1-9) } \\
\text { The common core: } \\
\text { social studies (pp. 14-15, } \\
\text { 22-29) } \\
\text { Options for the school } \\
\text { certificate: social studies } \\
\text { (pp. } 48-50 \text { ) }\end{array}$ & $\begin{array}{l}\text { Justice: } 1 \\
\text { Economic ideologies: } 1 \\
\text { Service and taking an active place in society: } \\
5 \\
\text { Solving problems on democratic lines: } 1 \\
\text { Acts intelligently: } 3 \\
\text { Acts in the common good: } 1 \\
\text { Duties and responsibilities of students: } 3 \\
\text { Choices of adult life: } 1 \\
\text { Pakeha and Maori viewpoints: } 1\end{array}$ & $\begin{array}{l}\text { Civilized values: } 1 \\
\text { Civil liberties: } 1 \\
\text { Co-operation: } 1 \\
\text { Clear civic thinking: } 2 \\
\text { Firm social judgement: } 1 \\
\text { Creative powers youth: } 1 \\
\text { Spiritual values and religion: } 2 \\
\text { Emotional health: } 1\end{array}$ & $\begin{array}{l}\text { minded, capacity to adjust, sense of } \\
\text { dignity and power, uses initiative. }\end{array}$ & $\begin{array}{l}\text { Reference to 'sexual ethic' } \\
\text { as part of 'general ethics' in } \\
\text { recommendations for } \\
\text { physical education }\end{array}$ \\
\hline $\begin{array}{l}1948 \text { Social studies in } \\
\text { history and geography } \\
\text { Introduction } \\
\text { Prescription (including } \\
\text { general suggestions, } \\
\text { objectives, content, and } \\
\text { suggestions for } \\
\text { treatment) pp. } 78-99\end{array}$ & $\begin{array}{l}\text { Ethics and cognates: } 0 \\
\text { Ethics as a contributing discipline: } 0 \\
\text { Examples of character: } 5 \\
\text { Ideals: } 1 \\
\text { Examples of ideals: } 7 \\
\text { Service/improving society: } 3 \\
\text { Duties and responsibilities of students: } 5\end{array}$ & $\begin{array}{l}\text { Democratic system: } 1 \\
\text { Interdependence: } 7 \\
\text { Co-operation/relationships: } 5 \\
\text { Weigh evidence: } 1 \\
\text { Think independently: } 1 \\
\text { Emotional life: } 1\end{array}$ & $\begin{array}{l}\text { Patriotic, willing to serve country, } \\
\text { loyal member of groups, unselfish, } \\
\text { ready to accept responsibility }\end{array}$ & \\
\hline $\begin{array}{l}1961 \text { Syllabuses for } \\
\text { schools: Social studies } \\
\text { in the primary school } \\
\text { All }\end{array}$ & $\begin{array}{l}\text { Ethics and cognates: } 0 \\
\text { Ethics as a contributing discipline: } 0 \\
\text { Examples of character: } 17 \\
\text { Responsibilities: } 6 \\
\text { Viewpoints of others: } 3 \\
\text { Standards and ideals*: } 4 \\
\text { Values: } 2 \\
\text { Laws: } 2 \\
\text { Fairness: } 1 \\
\text { Justice: } 2 \\
\text { Protection^: } 2 \\
\text { Rights : } 3 \\
\text { Playing their part in society: } 1 \\
\text { Act intelligently: } 3\end{array}$ & $\begin{array}{l}\text { Social problems": } 32 \\
\text { Current events: } 6 \\
\text { Differences in background: } 1 \\
\text { Citizenship: } 2 \\
\text { Democracy: } 2 \\
\text { Cooperation/interdependence: } 12 \\
\text { Critical/clear thinking: } 7 \\
\text { Creativity: } 1 \\
\text { Feelings: } 3 \\
\text { Sympathetic interest in others: } 4 \\
\text { Beliefs: } 1 \\
\text { Going to church: } 1 \\
\text { Attitudes: } 2 \\
\text { Aspirations: } 6 \\
\text { Pleasures: } 8\end{array}$ & $\begin{array}{l}\text { Habits of thought, open-minded, } \\
\text { sympathetic, generous: 2, loyal to } \\
\text { truth, tolerant, kindly, honest, } \\
\text { courageous, just, independent, } \\
\text { modest, respectful, accepts } \\
\text { responsibility, energetic, } \\
\text { adventurous. }\end{array}$ & $\begin{array}{l}\text { Anthropology, History, } \\
\text { Geography, Literature, } \\
\text { Music, Art and Languages } \\
\text { mentioned as contributing } \\
\text { disciplines } \\
\text { *Includes respect for law } \\
\text { ^ of environment and } \\
\text { working conditions } \\
\sim \text { Civil, commercial, human } \\
\text { " Includes threats to peace } \\
\text { and well-being }\end{array}$ \\
\hline
\end{tabular}




\begin{tabular}{|c|c|c|c|c|}
\hline & Learning how to carry out the good life: 1 & & & \\
\hline $\begin{array}{l}1962 \text { Suggestions for } \\
\text { teaching social studies } \\
\text { in the primary school } \\
\text { Aims and principles } \\
\text { School schemes } \\
\text { Necessary conditions } \\
\text { Methods } \\
\text { Evaluation } \\
\text { The study of the Maori } \\
\text { people } \\
\text { pp. 7-33, NB: pagination } \\
\text { refers to the 1971 } \\
\text { edition }\end{array}$ & $\begin{array}{l}\text { Ethics and cognates: } 0 \\
\text { Ethics as a contributing discipline: } 0 \\
\text { Suitable kinds of people: } 4 \\
\text { Examples of character: } 19 \\
\text { Standards^ and ultimate loyalties: } 12 \\
\text { Societal values: } 1 \\
\text { Rights: } 4 \\
\text { Act/responsibly: } 7 \\
\text { Act intelligently: } 9 \\
\text { What others believe the good life to be: } 1\end{array}$ & $\begin{array}{l}\text { Social problems: } 16 \\
\text { Current events: } 4 \\
\text { Similarities/differences in cultures: } 2 \\
\text { Citizenship: } 4 \\
\text { Democratic society, aims, values, } \\
\text { methods, behaviour, virtues: } 14 \\
\text { Civilisation: } 1 \\
\text { Interdependence: } 2 \\
\text { Critical/clear thinking: } 10 \\
\text { Creative thinking: } 1 \\
\text { Sympathetic interest/sensitivity: } 3 \\
\text { Attitudes: } 10 \\
\text { Aspirations: } 1\end{array}$ & $\begin{array}{l}\text { Wisdom: } 2 \text {, tolerance: } 3 \text {, } \\
\text { independence: } 2 \text {, generosity: } 2 \text {, } \\
\text { loyalty: } 6 \text {, honesty, just: } 2 \text {, respect for } \\
\text { independence of mind. }\end{array}$ & ${ }^{\wedge}$ Equated with values: 3 \\
\hline $\begin{array}{l}\text { 1977 Social studies } \\
\text { syllabus guidelines: } \\
\text { Forms 1-4 } \\
\text { All }\end{array}$ & $\begin{array}{l}\text { Ethics and cognates: } 0 \\
\text { Ethics as a contributing discipline: } 0 \\
\text { Important ideas about human behaviour: } \\
11 \# \\
\text { Examples of character: } 6 \\
\text { Commitments: } 1 \\
\text { Examples of commitments*: } 5 \\
\text { Values positions: } 1 \\
\text { Values: } 28 \\
\text { Value systems: } 3 \\
\text { Scale of values: } 1 \\
\text { Ways of looking at the world: } 1 \\
\text { Problem-solving/Decision making: } 6 \\
\text { Social action/participation: } 13 \\
\text { Individual and human rights: } 2 \\
\text { Consequences: } 2 \\
\text { Laws and rules: } 2 \\
\text { Freedom: } 1\end{array}$ & $\begin{array}{l}\text { Societal complexity: } 3 \\
\text { Conflict: } 11 \\
\text { Individual/cultural difference: } 9 \\
\text { Co-operation/interdependence: } 7 \\
\text { Clear/critical thinking : } 8 \\
\text { Rational examination (of values): } 1 \\
\text { Clarification (of values): } 1 \\
\text { Beliefs: } 4 \\
\text { Attitudes: } 5 \\
\text { Aspirations: } 1 \\
\text { Feelings: } 2 \\
\text { Think with sensitivity: } 1 \\
\text { Display sensitivity towards others: } 1\end{array}$ & $\begin{array}{l}\text { Independent, objective, open- } \\
\text { minded, willing to be involved in } \\
\text { community, sense of personal } \\
\text { identity: } 2 \text {. }\end{array}$ & $\begin{array}{l}\text { "Draws on the knowledge, } \\
\text { ideas and methods of } \\
\text { inquiry of the social } \\
\text { sciences and humanities" } \\
\text { (p. 4). } \\
\text { \#Based around the themes } \\
\text { of cultural difference, } \\
\text { interaction, social control, } \\
\text { social change. } \\
\text { *Respect for human } \\
\text { dignity, concern for others, } \\
\text { respect for difference, } \\
\text { uphold social justice, } \\
\text { acceptance of } \\
\text { responsibility. } \\
\sim \text { Includes objective, } \\
\text { realistic, reasoned and } \\
\text { rational thought }\end{array}$ \\
\hline
\end{tabular}




\begin{tabular}{|c|c|c|c|c|}
\hline $\begin{array}{l}\text { 1978 Faces Primary } \\
\text { Social Studies } \\
\text { Newsletter } 4 \\
\text { pp. } 2-10\end{array}$ & $\begin{array}{l}\text { Ethics and cognates: } 0 \\
\text { Ethics as a contributing discipline: } 0 \\
\text { Examples of character: } 5 \\
\text { Ideas about human behaviour: } 1 \\
\text { Values: } 4 \\
\text { Decision-making: } 1 \\
\text { Social participation/action: } 12 \\
\text { Rules/law: } 2 \\
\text { Justice: } 3 \\
\text { Responsibilities: } 3 \\
\text { Keeping order: } 1 \\
\text { Respect: } 1 \\
\text { Caring for others: } 1\end{array}$ & $\begin{array}{l}\text { Problems/disagreements/conflict and } \\
\text { challenges: } 7 \\
\text { Personal identities: } 1 \\
\text { Interdependence/co-operation: } 4 \\
\text { Valuing skills: } 2 \\
\text { Feelings: } 12 \\
\text { Hopes and fears: } 2 \\
\text { Beliefs: } 2 \\
\text { Aspirations: } 1 \\
\text { Attitudes: } 2 \\
\text { Religion: } 3 \\
\text { Pleasures }=2 \\
\text { Sense of belonging: } 1\end{array}$ & $\begin{array}{l}\text { Open-minded, concern for truth and } \\
\text { justice, feelings of empathy and } \\
\text { humanity }\end{array}$ & \\
\hline $\begin{array}{l}1981 \text { Faces } 5 \text { Primary } \\
\text { Social Studies } \\
\text { Newsletter } \\
\text { pp. 2-13, not including: } \\
\text { Reiteration of previous } \\
\text { curricula - p. } 4 \text {; Bank of } \\
\text { concepts - p. } 6 \text { and } 7 \text {; } \\
\text { explanation of moral } \\
\text { reasoning - p. } 10 .\end{array}$ & $\begin{array}{l}\text { Ethics and cognates: } 0 \\
\text { Ethics as a contributing discipline: } 0 \\
\text { Moral instruction: } 2 \\
\text { Character training: } 1 \\
\text { Differences of opinion: } 1 \\
\text { Moral viewpoints: } 1 \\
\text { Values/valuing: } 27 \\
\text { Values education: } 1 \\
\text { Value system: } 1 \\
\text { Social participation/responses: } 14 \\
\text { Act responsibly: } 1 \\
\text { Act intelligently: } 1 \\
\text { Decision making/choices: } 11 \\
\text { Rules of conduct: } 1 \\
\text { Commitments/ideals: } 5 \\
\text { Principles: } 2 \\
\text { Obligation: } 1 \\
\text { Consequences: } 3\end{array}$ & $\begin{array}{l}\text { Issues/challenges/conflict/problems: } \\
8 \\
\text { Moral dilemmas: } 7 \\
\text { Cultural diversity (including } \\
\text { multicultural awareness)*: } 2 \\
\text { Citizenship: } 1 \\
\text { Think clearly: } 1 \\
\text { (Value) judgements: } 2 \\
\text { (Values) clarification: } 3 \\
\text { Moral decisions/reasoning: } 14 \\
\text { Feelings: } 42 \\
\text { Enter sympathetically (into the } \\
\text { feelings of others): } 1 \\
\text { Beliefs and religion: } 3 \\
\text { Aspirations: } 1 \\
\text { Pleasures: } 1\end{array}$ & $\begin{array}{l}\text { Re-iteration of virtues from 1904, } \\
1928,1961 \text { and } 1978 \text { included as a } \\
\text { stimulus for teacher discussion about } \\
\text { the place of values in education. }\end{array}$ & $\begin{array}{l}\text { *Emphasis on similarities } \\
\text { and differences between } \\
\text { own and others cultures } \\
\text { extends the comparative } \\
\text { approach of Faces } 4 . \\
\\
\text { Note concepts listed on pp. } \\
6 \text { and } 7 \text { that have a distinct } \\
\text { moral content: e.g. rules, } \\
\text { faith, loyalty, obedience, } \\
\text { fair play, justice, right and } \\
\text { wrong, disagreement. } \\
\text { ^ NB: "no simple right or } \\
\text { wrong" (p. 12) }\end{array}$ \\
\hline
\end{tabular}




\begin{tabular}{|c|c|c|c|c|}
\hline & $\begin{array}{l}\text { Rules: } 6 \\
\text { Respecting elders: } 1 \\
\text { Fairness: } 1 \\
\text { Right and wrong: } 2^{\wedge} \\
\text { Social contract: } 1 \\
\text { Concern for others: } 1\end{array}$ & & & \\
\hline $\begin{array}{l}1983 \text { Faces } 6 \text { Primary } \\
\text { Social Studies } \\
\text { Newsletter } \\
\text { pp. 2-15, not including } \\
\text { bank of contexts for } \\
\text { study - p. 6; examples of } \\
\text { skills - p. } 7\end{array}$ & $\begin{array}{l}\text { Ethics and cognates: } 0 \\
\text { Ethics as a contributing discipline: } 0 \\
\text { Ideas about human behaviour: } 4 \\
\text { Points of view: } 1 \\
\text { Values: } 6 \\
\text { Act intelligently: } 2 \\
\text { Responsible/social participation: } 22 \\
\text { Rules: } 2 \\
\text { Problem solving: } 2 \\
\text { Commitment: } 1 \\
\text { Courage: } 1 \\
\text { Ideals: } 1 \\
\text { Consider consequences of moral decisions: } \\
1 \\
\text { Tolerance: } 1 \\
\text { Justice: } 1 \\
\text { Responsibilities: } 1\end{array}$ & $\begin{array}{l}\text { Social problems/challenges: } 7 \\
\text { Current events: } 3 \\
\text { Cultural diversity: } 5 \\
\text { Reason about moral issues/dilemmas: } \\
\text { Valuing skills: } 3 \\
\text { Critical/clear thinking: } 3 \\
\text { Sympathetic interest in others: } \\
\text { Feelings: } 16 \\
\text { Beliefs: } 5 \\
\text { Aspirations: } 5 \\
\text { Pleasures: } 2 \\
\text { Attitudes: } 1\end{array}$ & $\begin{array}{l}\text { Virtues from } 1961 \text { syllabus reiterated } \\
\text { in a quote: open-minded, } \\
\text { sympathetic, generous, loyalty to } \\
\text { truth, strong feelings of humanity } \\
\text { and kindness. }\end{array}$ & $\begin{array}{l}\text { Note contexts listed on } \\
\text { p. } 6 \text { that have a distinct } \\
\text { moral content: e.g. seeking } \\
\text { justice, taking } \\
\text { responsibility, practising } \\
\text { religion. } \\
\text { Note bank of valuing and } \\
\text { social participation skills p. } \\
7\end{array}$ \\
\hline $\begin{array}{l}\text { 1991 Social Studies } \\
\text { Forms } 3 \text { and 4: A } \\
\text { Handbook for } \\
\text { teachers } \\
\text { pp. 1-51, note that not } \\
\text { all grade related criteria } \\
\text { for exploring values and } \\
\text { social participation (pp. }\end{array}$ & $\begin{array}{l}\text { Ethics and cognates: } 0 \\
\text { Ethics as a contributing discipline: } 0 \\
\\
\text { Important ideas: } 6 \# \\
\text { Commitments^: } 4 \\
\text { Points of view: } 11 \\
\text { Ways of looking at the world: } 1 \\
\text { Values: } 53 \\
\text { Value systems: } 16\end{array}$ & $\begin{array}{l}\text { Controversial issues/societal } \\
\text { complexity: } 15 \\
\text { Current events: } 3 \\
\text { Conflict/resolution: } 12 \\
\text { Cultural diversity/perspectives: } 7 \\
\text { Co-operation/interdependence: } 8 \\
\text { Think clearly/critically/objectively: } 5 \\
\text { Valuing: } 8 \\
\quad \text { Objectively examine: } 1\end{array}$ & $\begin{array}{l}\text { Objectivity, open-mindedness, } \\
\text { willingness to be involved in } \\
\text { community. }\end{array}$ & $\begin{array}{l}\text { Reiterates emphasis on } \\
\text { comparative and inquiry } \\
\text { approach of } 1997 \text { syllabus } \\
\text { \#Based around the themes } \\
\text { of social control, and social } \\
\text { change, and an emphasis of } \\
\text { the handbook. }\end{array}$ \\
\hline
\end{tabular}




\begin{tabular}{|c|c|c|c|c|}
\hline $\begin{array}{l}\text { 47-48) are reflected in } \\
\text { the coding. }\end{array}$ & $\begin{array}{l}\text { Values conflict: } 2 \\
\text { Decision-making/reasoned choices: } 7 \\
\text { Social participation/action: } 24 \\
\quad \text { Initiate/respond to change: } 1 \\
\quad \text { Contribute constructively to group: } \\
\quad 8 \\
\quad \text { Apply to welfare of people: } 1 \\
\text { Laws/rules: } 6 \\
\text { Human rights: } 8 \\
\text { Social justice: } 3 \\
\text { Conformity: } 7 \\
\text { Accepting/responsibility: } 12 \\
\text { Treaty principles: } 1\end{array}$ & $\begin{array}{l}\text { Consequences: } 3 \\
\text { Values judgement: } 1 \\
\text { Open-mindedness: } 2 \\
\text { Values exploration: } 3 \\
\text { Identify relationships between } \\
\text { values: } 1 \\
\text { Identify points of } \\
\text { agreement/disagreement: } 1 \\
\text { Resolving conflict: } 2 \\
\text { Feelings/sensitivity: } 6 \\
\text { Feelings } \\
\text { Beliefs: } 11 \\
\text { Attitudes: } 6 \\
\text { Aspirations: } 2 \\
\end{array}$ & & 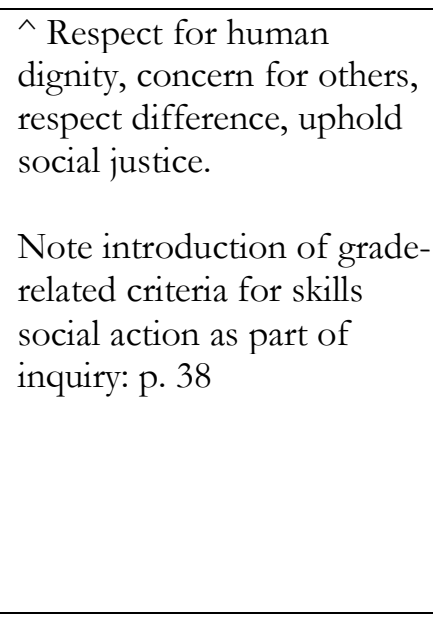 \\
\hline $\begin{array}{l}1993 \text { The New } \\
\text { Zealand Curriculum } \\
\text { Framework } \\
\text { pp. 1-9, 14, 17-28 }\end{array}$ & $\begin{array}{l}\text { Ethics and cognates: } 0 \\
\text { Ethics as a contributing discipline: } 0 \\
\text { Valued attributes: } 1 \\
\text { Examples of valued attributes: } 27 \\
\text { Viewpoints: } 2 \\
\text { Values: } 21 \\
\text { Commonly held values: } 2 \\
\text { Examples of commonly held values*: } 13 \\
\text { Perspectives: } 2 \\
\text { Rights: } 3 \\
\text { Responsibilities: } 2 \\
\text { Decision-making/problem-solving: } 6 \\
\text { Social participation/action: } 8\end{array}$ & $\begin{array}{l}\text { Issues/problems/challenges: } 6 \\
\text { Conflict: } 1 \\
\text { Diversity (including bicultural and } \\
\text { multicultural): } 8 \\
\text { Context nature (of values): } 1 \\
\text { Democratic society: } 3 \\
\text { Democratic citizenship: } 2 \\
\text { Consensus: } 1 \\
\text { Co-operative skills: } 4 \\
\text { Valuing skills: } 1 \\
\text { Explore values: } 1 \\
\text { Clarify own values : } 2 \\
\text { Informed judgements: } 1 \\
\text { Think clearly/critically: } 3 \\
\text { Thinking creatively: } 1 \\
\text { Reflective thinking: } 1 \\
\text { Feelings/emotions: } 3 \\
\text { Attitudes: } 13 \\
\text { Beliefs: } 2 \\
\text { Religion/spirituality: } 2\end{array}$ & $\begin{array}{l}\text { Confident, informed, responsible: } 7 \text {, } \\
\text { initiative, effort, self-esteem, } \\
\text { commitment, perseverance, courage, } \\
\text { enterprise, self-discipline, integrity: } 2 \text {, } \\
\text { reliable, trustworthy, caring, fair, } \\
\text { diligence, tolerance, hospitable, life- } \\
\text { long learner }\end{array}$ & $\begin{array}{l}\begin{array}{l}\text { Schools will provide in } \\
\text { particular for social studies, } \\
\text { history, geography and } \\
\text { economics. }\end{array} \\
\text { Note references to ethics in } \\
\text { Health/PE and science } \\
\text { descriptors. } \\
\text { *Concern for social justice, } \\
\text { Acceptance of diversity, } \\
\text { Respect for environment, } \\
\text { Individual and collective } \\
\text { responsibility, Honesty, } \\
\text { Reliability, Respect for } \\
\text { others, Respect for law, } \\
\text { Tolerance, fairness, Caring, } \\
\text { Non-sexism, Non-racism. }\end{array}$ \\
\hline
\end{tabular}




\begin{tabular}{|c|c|c|c|c|}
\hline $\begin{array}{l}\text { 1997 Social studies in } \\
\text { the New Zealand } \\
\text { Curriculum } \\
\text { pp. } 5-58\end{array}$ & $\begin{array}{l}\text { Ethics and cognates: } 0 \\
\text { Ethics as a contributing discipline: } 0 \\
\text { Human behaviour: } 9 \\
\text { Examples of character: } 8 \\
\text { Consequences: } 35 \\
\text { Principles: } 2 \\
\text { Standards: } 2 \\
\text { Points of view/values positions: } 36 \\
\text { Values: } 12 \\
\text { Perspectives: } 24 \\
\text { Social decision-making/choices: } 44 \\
\text { Resolving conflict: } 3 \\
\text { Participation/social action: } 60 \\
\text { Problem-solving skills: } 1 \\
\text { Responsibilities: } 22 \\
\text { Rights: } 37 \\
\text { Social justice: } 7 \\
\text { Rules/laws: } 15\end{array}$ & $\begin{array}{l}\text { Current/social issues/problems: } 44 \\
\text { Global issues: } 2 \\
\text { Conflict: } 5 \\
\text { Diversity (including bicultural and } \\
\text { multicultural): } 32 \\
\text { Identities (personal, cultural, national): } \\
26 \\
\text { Citizens (citizenship): } 4 \\
\text { Democracy: } 3 \\
\text { Co-operation/co-operative skills: } 8 \\
\text { Interdependence: } 2 \\
\text { Think clearly and critically: } 3 \\
\text { (Skills of) reflection: } 7 \\
\text { Informed judgements: } 3 \\
\text { Values exploration: } 10 \\
\text { Values clarification: } 2 \\
\text { Evaluate: } 14 \\
\text { Establish/use evaluation criteria: } 7 \\
\text { Feelings: } 1 \\
\text { Attitudes: } 9 \\
\text { Beliefs/belief systems/religion: } 21 \\
\text { Aspirations: } 4\end{array}$ & $\begin{array}{l}\text { Informed: } 3 \text {, confident: } 3 \text {, } \\
\text { responsible: } 2 \text {, effective }\end{array}$ & $\begin{array}{l}\text { Pull-out flaps not included } \\
\text { in coding } \\
\text { Social studies is the } \\
\text { systematic study of an } \\
\text { integrated body of content } \\
\text { drawn from the social } \\
\text { sciences and the } \\
\text { humanities p. } 7 \text {... see } \\
\text { definition on p. } 57 \\
\text { 'Perspectives' section } \\
\text { contains examples of } \\
\text { principles to be adhered to } \\
\text { in social studies teaching } \\
\text { e.g. non-racist, non-sexist. } \\
\text { Arguably many of these } \\
\text { extend to learners'. }\end{array}$ \\
\hline $\begin{array}{l}2007 \text { The New } \\
\text { Zealand Curriculum } \\
\text { pp. } 4-17,30,34-44 \text {, fold } \\
\text { out flaps of AOs }\end{array}$ & $\begin{array}{l}\text { Ethics and cognates: } 2 \\
\quad \text { Acting ethically: } 1 \\
\quad \text { Make ethical decisions and act on } \\
\quad \text { them: } 1 \\
\text { Ethics as a contributing discipline: } 0 \\
\text { Moral values: } 1 \\
\text { Examples of character: } 29 \\
\text { Encouraged to value*: } 11 \\
\text { Viewpoints: } 3 \\
\text { Values: } 51\end{array}$ & $\begin{array}{l}\text { Issues/community challenges: } 9 \\
\text { Disagreements: } 1 \\
\text { Diversity (including bicultural and } \\
\text { multicultural): } 15 \\
\text { Identities (personal, cultural, national): } \\
10 \\
\text { Citizens/Citizenship: } 7 \\
\text { Common good: } 1 \\
\text { Peace: } 1 \\
\text { Critical thinking : } 9 \\
\text { Creative thinking: } 2\end{array}$ & $\begin{array}{l}\text { Informed, responsible, critical, } \\
\text { creative, energetic, enterprising } \\
\text { seize opportunities, work to } \\
\text { recognise all cultures, confident ( } 5 \\
\text { examples), connected ( } 5 \text { examples), } \\
\text { actively involved ( } 2 \text { examples), } \\
\text { lifelong learner ( } 4 \text { examples) }\end{array}$ & $\begin{array}{l}* \text { Note that these are } \\
\text { clusters of values which } \\
\text { could be read both as } \\
\text { virtues and principles: } \\
\text { excellence, innovation, } \\
\text { inquiry, curiosity, diversity, } \\
\text { equity, community and } \\
\text { participation, ecological } \\
\text { sustainability, integrity, } \\
\text { respect. }\end{array}$ \\
\hline
\end{tabular}




\begin{tabular}{|c|c|c|c|c|}
\hline & $\begin{array}{l}\text { Perspectives: } 4 \\
\text { Ideologies: } 1 \\
\text { Decision-making/problem-solving: } 12 \\
\text { Participation/social action: } 64 \\
\text { Consequences: } 8 \\
\text { Care for the environment: } 1 \\
\text { Social justice/fairness: } 3 \\
\text { Rights: } 8 \\
\text { Responsibilities: } 7 \\
\text { Rules/laws: } 2\end{array}$ & $\begin{array}{l}\text { Explore values: } 2 \\
\text { Critically analyse values/actions: } 1 \\
\text { Reflective thought: } 9 \\
\text { Challenge basis of assumptions: } 1 \\
\text { Evaluate (sustainability): } 1 \\
\text { Beliefs: } 4 \\
\text { (Explore values) with empathy: } 1 \\
\text { Attitudes: } 1\end{array}$ & & $\begin{array}{l}\sim \text { Includes critical analysis } \\
\text { of values and actions } \\
\\
\text { 'Purpose and scope' and } \\
\text { 'Principles' sections include } \\
\text { principles for curriculum } \\
\text { design and decision- } \\
\text { making. Arguably many of } \\
\text { these extend to learners'. }\end{array}$ \\
\hline $\begin{array}{l}2008 \text { Approaches to } \\
\text { social inquiry } \\
\text { pp. } 2-16\end{array}$ & $\begin{array}{l}\text { Ethics and cognates: } 1 \\
\quad \text { Make ethical decisions and act on } \\
\quad \text { them: } 1\end{array}$ & $\begin{array}{l}\text { Social issues: } 19 \\
\text { Disagreements: } 1 \\
\text { Citizens: } 1 \\
\text { Democracy: } 1 \\
\text { Critical thinking: } 20 \\
\text { Reflective thinking: } 26 \\
\text { Critically analyse values/actions: } 1 \\
\\
\text { Beliefs: } 7 \\
\text { (Explore values) with empathy: } 1 \\
\text { Attitudes: } 1 \\
\text { Aspirations: } 1\end{array}$ & Informed, responsible. & $\begin{array}{l}\text { Note that the more critical } \\
\text { aspects of the Values } \\
\text { statement are emphasised } \\
\text { in this document. }\end{array}$ \\
\hline
\end{tabular}




\section{APPENDIX 3: ETHICS IN NCEA ACHIEVEMENT STANDARDS}

\begin{tabular}{|c|c|c|}
\hline Subject & Level & Achievement standard \\
\hline Accounting & 2 & AS91481 - Demonstrate understanding of a topical accounting issue for decision-making \\
\hline Biology & 3 & US6315 - Complete an investigation into the ecological niche of an animal species, with guidance \\
\hline Biology & 3 & AS91602 - Integrate biological knowledge to develop an informed response to a socio-scientific issue \\
\hline Biology & 3 & AS91607 - Demonstrate understanding of human manipulations of genetic transfer and its biological implications \\
\hline Business Studies & 1 & AS22847 - Demonstrate knowledge of enterprising behaviour, innovation, and entrepreneurship in business contexts \\
\hline Business Studies & 2 & AS90848 - Carry out, review and refine a business activity within a community context with guidance \\
\hline Business Studies & 3 & AS90848 - Carry out, with consultation, an innovative and sustainable business activity \\
\hline Classical Studies & 2 & AS91204 - Demonstrate understanding of the relationship between aspects of the classical world and aspects of other cultures \\
\hline Classical Studies & 3 & AS91398 - Demonstrate understanding of the lasting influences of the classical world on other cultures across time \\
\hline Digital Technologies & 1 & AS91071 - Implement basic procedures to produce a specified digital information outcome \\
\hline Digital Technologies & 2 & AS 91367 - Demonstrate understanding of advanced concepts relating to managing shared information within information systems \\
\hline Health & 3 & US23392 - Describe ethical behaviour in a health, disability, or community setting \\
\hline Health & 3 & AS91464 - Analyse a contemporary ethical issue in relation to well-being \\
\hline Home Economics & 3 & AS91468 - Analyse a food related ethical dilemma for New Zealand society \\
\hline Media Studies & 2 & AS91254 - Demonstrate understanding of an ethical issue in the media \\
\hline
\end{tabular}




\begin{tabular}{|c|c|c|}
\hline Media Studies & 3 & AS91494 - Produce a design for a media product that meets the requirements of a brief \\
\hline Physical Education & 3 & AS91500 - Evaluate the effectiveness of a performance improvement programme \\
\hline Physical Education & 3 & AS91504 - Analyse issues in safety management for outdoor activity to devise safety management strategies \\
\hline Physics & 3 & AS91527 - Use physics knowledge to develop an informed response to a socio-scientific issue \\
\hline Psychology & 2 & US27692 - Analyse ethical standards in psychological practice \\
\hline Religious Studies & 1 & AS90818 - Describe the application of the key ethical principle(s) of a religious tradition to an issue \\
\hline Religious Studies & 3 & AS90826 - Analyse the response of a religious tradition to a contemporary ethical issue \\
\hline Social Studies & 1 & AS91040 - Conduct a social inquiry \\
\hline Social Studies & 3 & AS91599 - Examine personal involvement in a social action(s) that aims to influence policy change(s). \\
\hline Sociology & 1 & US9001 Conduct a quantitative sociological enquiry with direction \\
\hline Sociology & 1 & US9005 - Conduct a qualitative sociological enquiry with direction \\
\hline Technology & 1 & AS91051 - Demonstrate understanding of how different disciplines influence a technological development \\
\hline Technology & 3 & AS91612 - Demonstrate understanding of how technological modelling supports technological development and implementation \\
\hline Technology & 3 & AS91616 - Demonstrate understanding of how the fitness for purpose of technological outcomes may be broadly interpreted \\
\hline
\end{tabular}


APPENDIX 4: SOCIAL INQUIRY OVERVIEW (MINISTRY OF EDUCATION, 2008A, P. 3)

Figure 1: A sodal tnquity overview

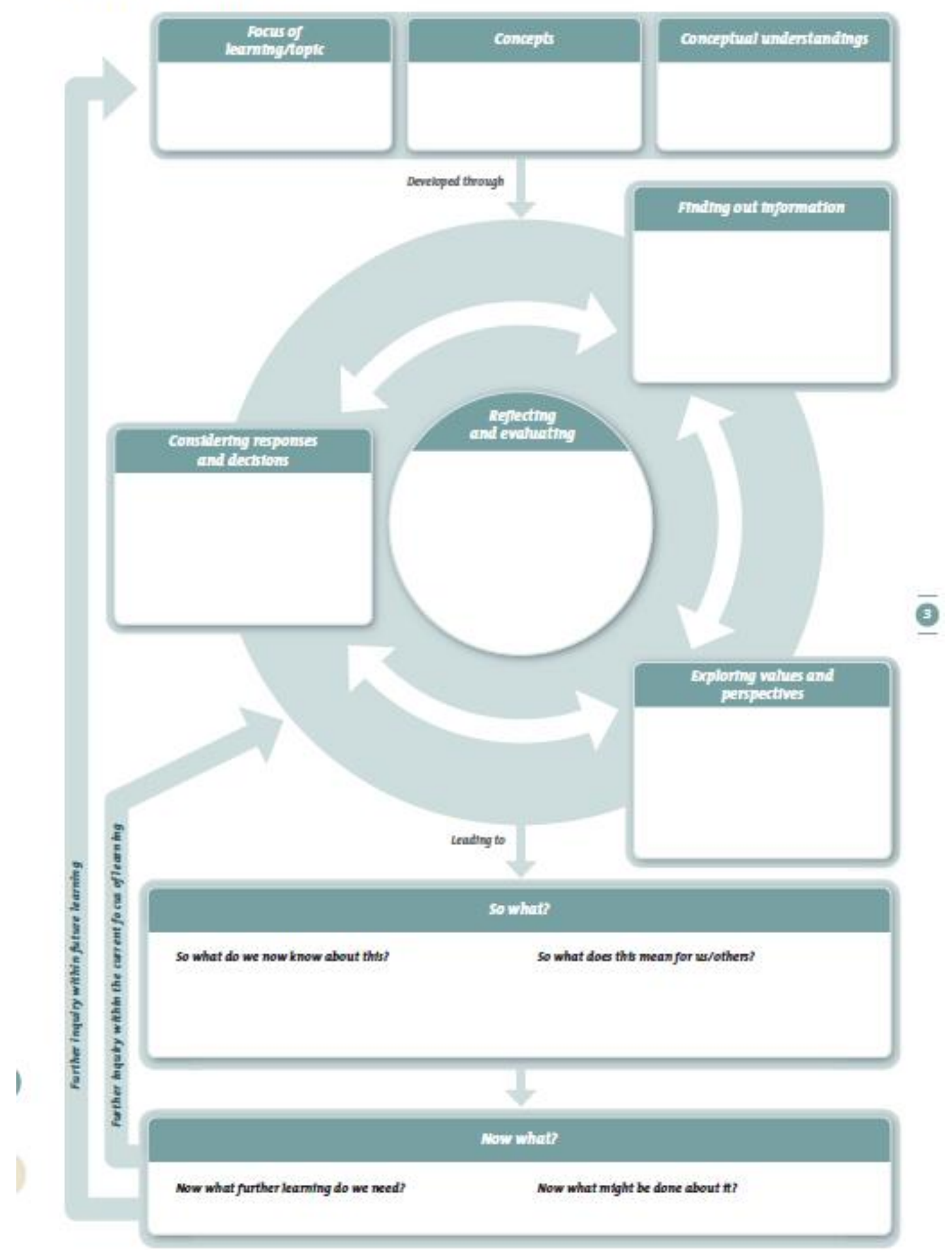




\section{What should we do?}

\section{Consequentialist perspectives}

What actions could be taken?

What might be the consequences: for you, your group, others, and everyone?

Choose the action that has the best consequences.

\section{Deontological perspectives}

What are some of the rules that people might follow (e.g. doing our duty, religious rules)?

Choose the rule that seems the best:

What would happen if this rule was followed?

\section{Character perspectives}

What kind of person do I want to be? E.g. courageous, truthful, respectful

What action(s) should I take, being this kind of person?

4. Taking these perspectives into account, what should we do and why? What would you actually do and why? 